COLLABORATIVE CURRICULUM DEVELOPMENT IN TEACHER DESIGN TEAMS Adam Handelzalts 


\title{
COLLABORATIVE CURRICULUM DEVELOPMENT IN TEACHER DESIGN TEAMS
}

\author{
Adam Handelzalts
}


DOCTORAL COMMITTEE

Chairman: $\quad$ Prof. dr. H. W. A. M. Coonen - University of Twente

Promoter: $\quad$ Prof. dr. J. J. H. van den Akker - University of Twente

Assistant promoter: Dr. N. M. Nieveen - Stichting Leerplan Ontwikkeling

Members: $\quad$ Prof. dr. J. M. Pieters - University of Twente

Prof. dr. J. F.M. Letschert - University of Twente

Prof. dr. U. Hameyer - University of Kiel, Germany

Prof. dr. T. C. M. Bergen - Eindhoven University of Technology

Prof. dr. P. J. C. Sleegers - University of Twente

\section{ico}

This research was carried out in the context of the Interuniversity Centre for Educational Research.

Handelzalts, Adam

Collaborative curriculum development in teacher design teams.

Thesis University of Twente, Enschede.

ISBN 978-90-365-2863-4

DOI $10.3990 / 1.9789036528634$

Cover: Pieter Frank de Jong

Layout: Sandra Schele

Press: PrintPartners Ipskamp - Enschede

(C) Copyright, 2009, Adam Handelzalts 


\title{
COLLABORATIVE CURRICULUM DEVELOPMENT
}

IN TEACHER DESIGN TEAMS

\section{DISSERTATION}

\author{
to obtain
}

the degree of doctor at the University of Twente, on the authority of the rector magnificus, prof. dr. H. Brinksma,

on account of the decision of the graduation committee to be publicly defended on Thursday the 17th of September 2009 at 13.15

by

Adam Handelzalts

born on the $6^{\text {th }}$ of October 1976

in Tel Aviv, Israel 
Promoters:

Assistant promoter
Prof. dr. ir. J. J. H. van den Akker

Dr. N. M. Nieveen

This dissertation has been approved by the promoter and assistant promoter. 


\section{PREFACE}

After all is said and done, and the dissertation is as good as ready (although the work is never done), many doctoral candidates, feeling that they are no longer bound by the strict rules of academic writing, try on the literary shoe, striving to write a "creative" forward. Unfortunately, many of them, me included, were not blessed with the literary talents they would have liked to possess. Therefore I will try to keep my Thank-You's short and to the point:

- First and foremost, I wish to thank all the teachers and school-leaders who allowed me to observe their practice. They also took the extra time to explain to an outsider how they think and work in the context of curriculum reform.

- Jan van den Akker and Nienke Nieveen have created an atmosphere of critical academic discussion, which allowed me much space to spread my academic wings. Jan always had a welcome new insight to offer when I was at loss about various issues. Both in the professional and personal conversations Nienke and I have had during the process, she has proven to be a true reflective practitioner and a real friend.

- The colleagues in the department of Curriculum Design and Educational Innovation at the University of Twente offered me stimulating professional and social support.

- Sandra Schele, in her effortless ways, made sure that the collection of words, sentences and paragraphs I delivered has been made into a presentable book.

- Friends, both in Israel and in the Netherlands, have indulged me when I was complaining and offered a sometimes more than welcome distraction from the trials and tribulations of the research process.

- Rosemarie Frijda-Bouman and her family have made my landing in the Netherlands very soft indeed. They have been a surrogate family away from home, with all its implications. 
- My family in Israel, despite the physical distance, was always there for me. My parents, Judith and Michael, have always provided me all the intellectual chances and stimulation, together with unconditional emotional support. If I prove to be half the parent they both are, I will die a happy man.

- My partner in life, Anne, your patience seems unlimited. I can be pretty unbearable sometimes and you always know how to handle it. Thank you for giving me the time and space in the past few months of hard work. In you I have found a life mate to explore the world and hope to grow very very old with.

- Noa and Tamar, you have enriched my life in so many ways. You offered welcome distraction after a long day at the computer. But more than all, you have put things in perspective for me when I was in danger of forgetting the right priorities. I look forward to our Mondays together.

I probably forgot many others that have in one way or another contributed to the whole process. Please forgive me.

At the close of this five year process I look back with much satisfaction, but also with a measure of critical reflection. I hope to apply the lessons I have learnt in the years to come, both in the academy and in the educational practice.

Adam Handelzalts 


\section{TABLE OF CONTENTS}

LIST OF FIGURES AND TABLES vii

Prologue ix

1. ORIGINS AND OVERVIEW OF THE STUDY 1

$\begin{array}{ll}1.1 \text { Origins of the study } & 1\end{array}$

1.1.1 Developments in the Dutch educational policy context 1

1.1.2 School-based and school-wide curriculum reform 3

1.1.3 Teacher teams in curriculum reform 5

1.1.4 Introduction to the concept of Teacher design teams $\quad 7$

1.2 Overview of the study 9

1.2.1 Research questions and relevance 9

1.2.2 Overall design of the study 11

$\begin{array}{ll}1.3 \text { Overview of the dissertation } & 12\end{array}$

2. COLLABORATIVE CURRICULUM DESIGN BY TEACHER TEAMS 13

$\begin{array}{ll}2.1 & \text { Curriculum design and the school perspective } 13\end{array}$

2.1.1 Curriculum and curriculum development 13

2.1.2 Teachers as 'curriculum makers' 19

2.1.3 A school-based and school-wide perspective of curriculum development 22

2.2 Collaboration between teachers - nature and impediments 26

2.2.1 Teacher collaboration in schools 26

2.2.2 Collaboration for coherent curriculum development 29

2.2.3 Collaboration for professional development of teachers 30

2.2.4 Collaboration for school development 32

2.2.5 Learning communities vs. task communities 34 
2.3 Teacher collaboration in curriculum development in schools

2.3.1 Conditions for collaborative curriculum development at the team level

2.3.2 Guidelines for collaborative curriculum development process

2.3.3 Organizational conditions for collaborative curriculum development

2.4 Framework for describing collaborative curriculum development

2.4.1 Description of team characteristics

2.4.2 Description of the curriculum development process in teacher design teams

2.4.3 Description of the organizational conditions of the teams

2.4.4 Description of the curricular results of the teams

3. DESIGN OF THE STUDY

3.1 Research Questions

3.2 Case study setup

3.3 Research methods

3.3.1 Baseline study

63

3.3.2 Process documentation

3.3.3 Process reconstruction

$\begin{array}{lll}3.3 .4 & \text { Variations research methods } & 70\end{array}$

$\begin{array}{lll}3.4 \text { Analysis } & 71\end{array}$

$\begin{array}{lll}\text { 3.4.1 First analysis stage - within case analysis } & 71\end{array}$

3.4.2 Second analysis stage-cross-case analysis within the school sites

$\begin{array}{lll}\text { 3.4.3 Third analysis stage-cross-study analysis } & 73\end{array}$

3.5 Measures taken to support research quality

4. TDTS IN COPERNICUS HIGH SCHOOL 77

4.1 Methodology of the study in Copernicus High School 77

4.2 Introduction to Copernicus High School 78

$\begin{array}{lll}\text { 4.2.1 The school } & 78\end{array}$

$\begin{array}{ll}\text { 4.2.2 The reform background } & 79\end{array}$

$\begin{array}{ll}\text { 4.2.3 School-wide reform process } & 79\end{array}$ 
4.3 How the TDTs addressed and carried out their development work 82

4.3.1 Recurring curriculum development activities 84

4.3.2 Curriculum development stages 86

4.3.3 Curriculum components in discussion/work 87

$\begin{array}{ll}\text { 4.3.4 Substantive consideration } & 89\end{array}$

$\begin{array}{ll}\text { 4.3.5 Main quality considerations } & 89\end{array}$

$\begin{array}{ll}\text { 4.3.6 Sequence of activities } & 90\end{array}$

$\begin{array}{lll}4.3 .7 & \text { Place of activities } & 91\end{array}$

$\begin{array}{ll}\text { 4.3.8 Participants and their role } & 91\end{array}$

4.3.9 Work orientation 93

4.3.10 Organization of work 94

4.4 Conducive or hindering activities and approaches 95

4.5 Conducive or hindering school conditions 97

$\begin{array}{ll}\text { 4.5.1 Infrastructure } & 97\end{array}$

4.5.2 External support and role of researcher in work of team 99

4.5.3 Coordination - contact with rest of school/teams 101

4.5.4 Role of school leaders and school-wide framework 103

4.6 Summary of the collaborative curriculum development in

$\begin{array}{ll}\text { Copernicus High School } & 105\end{array}$

5. TDTS IN KEPLER HIGH SCHOOL 109

5.1 Methodology of the study in Kepler High School 109

5.2 Introduction to Kepler High School 111

$\begin{array}{ll}\text { 5.2.1 The school } & 111\end{array}$

5.2.2 The reform background 112

5.2.3 School-wide reform process 112

5.3 How the TDTs addressed and carried out their development work 114

5.3.1 Recurring curriculum development activities 117

5.3.2 Curriculum development stages 118

5.3.3 Curriculum components in discussion/work 121

$\begin{array}{ll}\text { 5.3.4 Substantive consideration } & 123\end{array}$

$\begin{array}{ll}\text { 5.3.5 Main quality considerations } & 123\end{array}$

$\begin{array}{ll}\text { 5.3.6 Sequence of activities } & 124\end{array}$

$\begin{array}{lll}\text { 5.3.7 Place of activities } & 125\end{array}$

$\begin{array}{lll}\text { 5.3.8 Participants and their role } & 126\end{array}$

$\begin{array}{ll}\text { 5.3.9 Work orientation } & 128\end{array}$

$\begin{array}{ll}\text { 5.3.10 Organization of work } & 129\end{array}$ 
5.4 Conducive or hindering activities and approaches 130

5.5 Conducive or hindering school conditions 133

$\begin{array}{lll}\text { 5.5.1 Infrastructure } & 133\end{array}$

5.5.2 External support and role of researcher in work of team 135

5.5.3 Coordination - contact with rest of school/teams 136

5.5.4 Role of school leaders and school-wide framework 137

5.6 Summary of the collaborative curriculum development in

$\begin{array}{ll}\text { Kepler High School } & 140\end{array}$

6. CROSS-STUDY ANALYSIS

6.1 The reforms in Copernicus High School and Kepler High School 143

6.2 How the TDTs addressed and carried out their development work 144

6.2.1 Recurring curriculum development activities 144

6.2.2 Curriculum development stages 144

6.2.3 Curriculum components in discussion/work 147

6.2.4 Substantive consideration and main quality considerations 148

$\begin{array}{ll}\text { 6.2.5 Sequence of activities } & 148\end{array}$

$\begin{array}{lll}\text { 6.2.6 Place of activities } & 150\end{array}$

6.2.7 Participants and their role 150

6.2.8 Work orientation 152

6.2.9 Organization of work 153

6.3 Conducive or hindering activities and approaches 153

6.4 Conducive or hindering school conditions 156

$\begin{array}{lll}6.4 .1 & \text { Infrastructure } & 156\end{array}$

6.4.2 External support and role of researcher in work of team

6.4.3 Coordination - contact with rest of school/teams 158

6.4.4 Role of school leader and school-wide framework 160

$\begin{array}{ll}\text { 7. DISCUSSION } & 163\end{array}$

$\begin{array}{lll}7.1 & \text { Recapitulation } & 163\end{array}$

$\begin{array}{ll}\text { 7.1.1 Origins of the study } & 163\end{array}$

$\begin{array}{lll}7.1 .2 & \text { Reseacher design } & 165\end{array}$

$\begin{array}{ll}\text { 7.1.3 Main findings } & 165\end{array}$ 
7.2 Relation to insights on TDTs from other studies 168

7.2.1 Related studies into collaborative curriculum development in the Netherlands 168

7.2.2 Related findings on how TDTs address and carry out

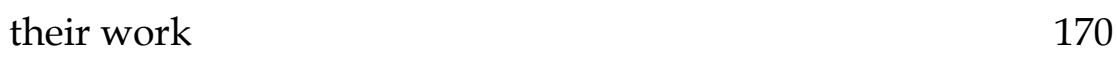

7.2.3 Related findings on conducive or hindering activities $\begin{array}{ll}\text { and approaches } & 173\end{array}$

7.2.4 Related findings on conducive or hindering school $\begin{array}{ll}\text { conditions } & 175\end{array}$

$\begin{array}{lll}7.3 & \text { Overall conclusions } & 180\end{array}$

$\begin{array}{lll}7.4 & \text { Recommendations } & 188\end{array}$

7.4.1 Recommendations for TDTs and school leaders $\quad 188$

7.4.2 Recommendations for pilocy and support 190

$\begin{array}{ll}\text { 7.4.3 Recommendations for research } & 191\end{array}$

$\begin{array}{ll}\text { REFERENCES } & 193\end{array}$

$\begin{array}{lr}\text { ENGLISH SUMMARY } & 201\end{array}$

$\begin{array}{ll}\text { NEDERLANDSE SAMENVATTING } & 215\end{array}$

$\begin{array}{lr}\text { APPENDIX } & 229\end{array}$

$\begin{array}{ll}\text { ICO DISSERTATION SERIES } & 233\end{array}$ 


\section{LIST OF FIGURES AND TABLES}

\section{FIGURES}

2.1 Typology of curriculum representations 14

2.2 Curricular spider web 15

2.3 Generic model of educational development 18

2.4 A matrix of SBCD variations 23

3.1 Storyline form used with practitioners 69

4.1 Levels of joint work in the TDTs in Copernicus High School 92

5.1 Initial ambition for common work in the TDTs in Kepler High

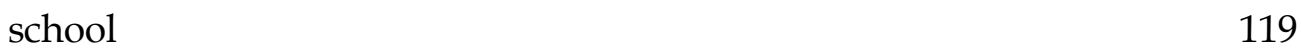

5.2 Levels of joint work in the TDTs in Kepler High School 127

\section{TABLES}

4.1 TDTs and their composition in Copernicus High School 81

5.1 TDTs and their composition in Kepler High School 114

6.1 Results of the analysis of the curriculum development process 145

6.2 Results of the analysis of the curriculum development process patterns 149

6.3 Results of the analysis of the curriculum development process characteristics 151

6.4 Results of the analysis of the conducive and hindering activities and approaches 154

6.5 Results of the analysis of the infrastructure conditions 156

6.6 Results of the analysis of the external support and cross-over structures

6.7 Results of the analysis of the role of school leaders and the schoolwide framework 


\section{Prologue}

When reading popular sources on educational change, different approaches can be observed. On the one hand there is a call for educational improvement at the system level. This line of reasoning asserts that the educational system faces challenges that require steering and coordinating at the national level. In that case, reform comes from outside the school, through the leadership of the school to the work floor. The problem of reform is seen as an issue of implementation of the initiatives. The other line of thought on educational reform expects the changes to come from within the school and to be initiated by the teachers. They are seen as professionals who should have professional discretion and are capable of realizing improvement. From this perspective, the teachers should be the main motor for educational change.

Although these approaches are not necessarily mutually exclusive, the existing discussion seems to present an 'either/or' option. Each one of these approaches has its potentials and drawbacks. In reform literature there is somewhat of a consensus that the pure 'top-down' approach is eventually ineffective in realizing substantial and sustainable change in practice. Teachers, more often than not, tend to operate quite independently in their classrooms, doing what they think as right behind closed doors, and therefore school leaders can't 'force' teachers to adopt change directed form outside the classroom. Teachers tend to be suspicious of external agents like 'the management', 'the ministry' or 'university experts', coming up with complicated plans that are in the teachers view impractical, and not beneficial to the students. At the same time, leaving educational reform to the discretion of individual teachers appears to lead to reforms which are not sustainable in the long run. Moreover, the need for more coherence in school curricula means that some form of cooperation or coordination between individual teachers and outside initiatives is called for. How can one combine these seemingly contradicting forces - the pressure to realize system and schoolwide (top-down) reforms and the (bottom-up) perspective of individual teachers? 
One promising way of combining the two processes is to make curriculum reform a collaborative endeavor, in which teachers participate in redesigning the curriculum, incorporating their own reform wishes and needs into nationwide and school-wide frameworks, aimed at securing common quality and coherence. This dissertation is aimed directly at the heart of such a possible move forward. How can one create curricular space that teacher teams can use to realize their wishes and stimulate these teams to take advantage of this autonomy? What challenges and promises are to be expected of such an approach? And what possible solutions can be offered to support these teams in their efforts? 


\section{CHAPTER 1}

\section{Origins and overview of the study}

This first chapter sketches the origins of this study. It starts (in section 1.1.1) with a short description of the shifts within the Dutch educational policy context that provides the backdrop of the developments in schools and therefore of this study. Following this (in sections $1.1 .2 \mathcal{E}$ 1.1.3), two central themes in this study are discussed briefly: (1) school-based and school-wide curriculum reform and (2) teacher collaboration in curriculum development. Each theme is considered in light of developments in educational policy and practice in The Netherlands and insights from reform literature, and is then followed by a discussion of existing tensions. A more extensive discussion of theses issues is provided in chapter 2. Next, the concept of teacher design teams, which is central in this study, is explained and discussed. In section 1.2, a general overview of the study is given, including a short outline of the research design and research methods. Finally, in section 1.3, a brief preview of the dissertation is presented.

\subsection{ORIGINS OF THE STUDY}

\subsubsection{Developments in the Dutch educational policy context}

Compared to other European countries, Dutch schools enjoy a great deal of autonomy in shaping the kind of education they provide for their students (Kuiper, van den Akker, Hooghoff \& Letschert, 2006). This is especially the case for lower secondary education (12-14 years) that forms the context of this study. The number and detail of prescribed attainment targets for lower secondary education was strongly reduced (cf. Taakgroep Vernieuwing Basisvorming, 2004). Schools are guided in their decisions about curriculum by 58 general attainment goals (instead of the previous 320) and seven general characteristics of the education at this level. The general characteristics are as follows: 
1. The students are actively and increasingly engaged in learning independently.

2. The students learn with others.

3. The students learn in coherence.

4. The students familiarize themselves with their future.

5. The students learn in a stimulating learning environment.

6. The students learn in a safe and healthy learning environment.

7. The students learn in a continuous line from primary to secondary education.

Although the characteristics are mandatory, schools have great lenience in the way they accomplish them. The schools are held accountable for the realization of these characteristics. The third characteristic, coherence across the subject matters, has gained a central role in the work of many schools. Much of the (informal) steering of the Ministry of Education has been aimed at this coherence. It has been the first and one of the primary themes in the yearly report of the coordination agency of the ministry (Onderbouw-VO, 2006; 2007; 2008). And it was also reflected in the schools that were involved in this study. All of them stated that integration of school subjects was central in their reform efforts. The general attainment goals and general characteristics were intended as a guideline for schools and teachers in redesigning their curriculum as well as a frame of reference for public accountability. Because there is no national examination at the end of lower secondary education, it is left to the discretion of the schools to interpret and shape the national attainment goals.

The reasoning behind the increase of the autonomy in lower secondary education can be found in the education evaluation in this sector. The inspectorate concluded in their report that the centralized curriculum policy in this sector has led to an overloaded and fragmented curriculum (Inspectie van het onderwijs, 1999). In addition, this centralized approach did not yield the expected pedagogical change towards active learning and a more studentcentered approach. The assumption implied in the policy change was that if strong schools would make use of a more decentralized curriculum policy, more variety would arise. This will give students more options to chose from and enable them to find schools that fit their wishes and needs. Schools would also have the opportunity to tailor their curriculum to the specific needs and characteristics of their environment and student population. 


\subsubsection{School-based and school-wide curriculum reform}

Changes in Dutch schools

A central element of the changes in lower secondary education in the Netherlands is that reforms are school-based; schools are central in deciding on the substantive elements of their reform. Influenced by the expanded autonomy, by 2007 93\% of all schools for lower secondary education were reported to be engaged in or about to start renewing their school-wide curriculum and schoolwide organization, led by their own curriculum preferences and possibilities (Onderbouw-VO, 2008). Within this innovation trend, a great variety is apparent, with some schools choosing modest pedagogical changes in the existing subjects, others introducing interdisciplinary learning-projects, and some (newly opened) schools going as far as to radically give up the division of learning in subject areas by offering an alternative organization of the curriculum (Hendriks, 2004; Onderbouw-VO, 2007; 2008).

Many schools also approach their reform efforts from a school-wide perspective. In order to realize curricular coherence, they initiate reforms that concern the whole breadth of the curriculum in the school. This means a departure from the traditional and somewhat fragmented structure and work process of secondary education in The Netherlands. Secondary schools have been mainly organized in vertical subject departments covering all grades (lower and higher secondary) and to a large extent function autonomously when setting their educational courses with little substantive coordination with other departments.

Although the developments are evident in the Dutch context, schools encounter difficulties in engaging in these processes (Onderbouw-VO, 2008). Most noted difficulties are a lack of time and resources for work on the reforms (57\% in 2007); negative attitude of teachers towards the reform (42\% in 2007); and teachers' lack of knowledge and therefore difficulties in participation (27\% in 2007). Another notable result is the reported experienced differences between what teachers aim for and the more ambitious and far-reaching goals expressed by the school management (26\% in 2007). All these hindering factors are keeping schools busy as they try to realize the reforms in the lower secondary education.

Insights from educational reform literature

Reform literature provides many motives for planning reform in a school-based and school-wide manner. The school-based line of reasoning calls for a central 
role and commitment of teachers and other practitioners in the forming of teaching practice (Clandinin \& Connelly, 1992; Skilbeck, 1998). As curriculum reform is highly dependent on the teachers who will eventually realize it, they have to be engaged in the reform process. The teachers are also the ones that have the intimate knowledge of everyday practice and the needs of their students. This knowledge is crucial for the realization and success of any reform.

The school-wide line of reasoning is more concentrated on strengthening reform by making it a shared practice across the school (Grossman, Wineburg \& Woolworth, 2001; Hord, 2004) and in doing so, realizing sustainable, significant, and coherent educational reform in schools and between the teachers. The schoolwide approach is essential for transforming reform from an incidental and isolated process in a part of the school, towards a sustainable and coherent change for the whole school. The proponents of the school-wide approach state that many innovation plans fail at an early stage, and when an attempt does succeed, it is often an isolated effort of a few teachers embracing a reform. In the long run, most curriculum innovations and projects that rely on individual teachers' voluntary commitments do not last (Hargreaves, 2003). Therefore, there is a need to organize reform in a school-wide manner in which all teachers are somehow involved.

An implication of the change in orientation (aiming at coherent and schoolwide sustainable reform) is that there is a need for synergy and productive relationships between curriculum development at various levels (system, school, and classroom), professional development of teachers, and school development. This synergy of processes is the key for sustainable reform (cf. Fullan, 2001; Hopkins, 2001). Curriculum and curriculum reform can be seen as the central element of this trio as they touch directly on the learning of students, the daily work of teachers and their interaction with the students, and the way learning is organized in the school as a whole. The policy reform in the Dutch lower secondary education is specifically aimed at changes in schools' curriculum. However, as curriculum reform, teacher development, and school development interact, all of them have to be addressed. This puts the teachers at the forefront of this curriculum improvement as they are central agents in all of theses developments. As it is, teachers have a central role as curriculum makers of their school-based curriculum (Clandinin \& Connelly, 1992, Skilbeck, 1998). Additionally, focusing on improving the curriculum is also intrinsically motivating to teachers. Contrary to broader organizational issues that are not 
always perceived as relevant to their direct practice, planning the actual learning processes of their students in their own subject matter domain is appealing to them (cf. Black \& Atkin, 1996; Grossman \& Stodolsky, 1995). Moreover, Skilbeck (1998) argues that teacher participation in curriculum development potentially helps to improve the quality and relevance of what is taught and will strengthen teacher professionalism.

\section{Dilemmas}

Educational reform processes focused on curriculum as a main driver of change in a school-wide context in which a large group of teachers is actively involved seems to be the advisable move forward. But realizing this kind of work is far from easy (as schools have reported) as it involves both curriculum development activities in collaboration between teachers, a learning process of the participants, and changes at the school level. Although these kinds of integral activities already take place in some schools on various levels, it is far from being a common phenomenon and only a few schools have experience with it. Moreover, schools that try this kind of work report many tensions concerning the work at the school level, and the relationship between the school level and the various teams of teachers within it. In view of its promise and growing popularity, the school-wide and school-based approach in Dutch school-reform practice forms the context in which this study has been conducted.

\subsubsection{Teacher teams in curriculum reform}

\section{Changes in Dutch schools}

A common strategy lower secondary schools apply to realize curriculum reform in their education is organizing teams of teachers that are responsible for specific curricular domains (for example, 'The Humanities' or 'Foreign languages') . In $2007,59 \%$ of the schools reported that they had organized at least some of the reform efforts in the form of these teacher teams from adjacent subjects who are responsible for redesigning their common subjects or interdisciplinary learningprojects. By the year 2012, 87\% of schools are expecting to work in this manner (Onderbouw-VO, 2008). This phenomenon is mainly driven by practical reasoning. First, these teams bridge the gap between the aspirations at the schoollevel on the one hand, and the aspirations and practice of individual teachers on the other. Working in teams can help teachers translate the school-level ambitions to concrete materials, lessons plans, and eventually teaching. Having an active 
role in creating the reform also enables the teachers to enact their own wishes and plans in the school curriculum. Second, the inclination for teacher cooperation is part of the drive for achieving coherence, which is central to the lower secondary reform. Schools and teachers are searching for ways to integrate parts of their curriculum and create fruitful connections between subject domains. This manner of realizing school-wide curriculum reform is a relatively new phenomenon in the Dutch educational policy field and calls for further exploration.

\section{Insights from educational reform literature}

Insights from reform literature also support teacher collaboration in teams as a fruitful means for educational reform. Recent literature maintains that teacher collaboration in the form of, for example, 'professional learning communities' is a central element in achieving sustainable school reform (e.g. Hord, 2004; Lieberman \& Miller, 2004; McLaughlin \& Talbert, 2001; McLaughlin \& Talbert, 2006). In fact, one of the problems of school reform is that most teachers teach alone in isolated classes without having (or taking) the opportunity to reflect together on their teaching practices, to introduce new perspectives, to discuss new ideas, to give each other feedback on improvement efforts, and to jointly develop new initiatives. Schools that aim at innovation need thus to organize teacher collaboration centered on the teaching practice (Little 1990). Collaboration between teachers is expected to have an impact on practice. There is considerable research showing that collaborative teacher teams are beneficial for student learning, which is the bottom line of educational quality (Louis \& Marks, 1998; McLaughlin \& Talbert, 2006). Collaborative teams have the most impact on student achievement when the focus of the work shows a persistent link to student learning and the initiatives taken are directly related to curriculum and instruction (Sackney, Mitchell \& Walker, 2005; Vescio, Ross \& Adams, 2008). Grossman et al. (2001) go even further and suggest that teachers need common curriculum experience in their collaboration (either by teaching together or observing each other teaching) in order to achieve effective collaboration that influences students achievements.

Teachers' participation in development processes and in implementing the curricular products in practice can also be beneficial for teacher learning. When designing their future practice, teachers build on their current practice and adapt it in relation to their needs and wishes. By piloting the design product and by reflecting on the experiences and results, teachers can become aware of the specific 
potentials and problems of the reform. Based on such systematic reflections, they will gain new insights for the design. This can lead to yet another cycle of design, evaluation, and reflection. This learning process is an important part of the curriculum reform and development process, because in many curriculum changes a shift in teacher beliefs, roles, and methods is essential (Fullan, 2001). Adding these arguments to the strength of the curriculum perspective in the school reform discussed in the previous section, leads to a strong argument to concentrate teacher collaboration in schools on curriculum planning.

\section{Dilemmas}

Considering the potential and appearance of teacher teams that concentrate on curriculum (design), there are only a few clear guidelines as to how these teams should pursue their curriculum development task. Although there is much research on teacher communities and teacher collaboration in the context of the school (cf. Henze, 2006; Meirink, 2007; Zwart, 2007), the focus is mostly on the forming of communities and the learning process of the teachers. Little research is available on curriculum design processes of teacher teams within schools and the kind of activities and conditions that contribute to the success of such processes. Moreover, most research deals with the input and output of these kinds of collaborative teams and there is still little known about how these teams get off to a good start and are sustained in their design work (McLaughlin \& Talbert, 2006).

The developments in the Dutch educational practice as well as the insights and open questions concerning school-based and school-wide curriculum reforms and teacher collaboration gave rise to this study. The decentralized Dutch educational policy climate enables schools and teacher teams to take an active part in curriculum development and therefore made extensive study of the work of the teams possible. This study aims at describing the development of such teacher teams, the kind of curriculum design activities they undertake in this context, and ways to support their efforts.

\subsubsection{Introduction to the concept of Teacher Design Teams}

The main focus of this study is a specific form of teacher collaboration in curriculum design, the Teacher Design Teams (TDTs). A TDT is defined as 'a group of at least two teachers, from the same or related subjects, working together on a regular basis, with the goal to (re)design and enact (a part of) their common curriculum'. 
The defining characteristic of a TDT is its specific and central design task; the main goal of TDTs is to (re)design their common curriculum. Teachers' teams usually described in literature (i.e. professional learning communities, communities of practice) mostly focus on improving the teaching process through the professional development of the teachers. In the case of the TDT the goals of professional development or building of cohesion in the staff are seen as secondary to the main design goal. These secondary goals play a role in the work of the TDT, but are seen as contributing factors to realizing a better curricular product. In some instances a TDT can also be seen as a professional learning community, but that is not necessarily the case.

Another central element of the TDT is collaboration of several teachers concerned with (re)designing their curriculum. Such collaboration effort is seen as a crucial factor for sustainable change that is effective on the student level (McLaughlin \& Talbert, 2006). The characteristic of related subjects, in this respect, emphasizes the fact that teachers need to have some common ground on which they collaborate. The extent of the relationship can vary according to the perception of the teachers in the specific context. They are the ones making this consideration and if they can see a relationship with another subject (for example between geography and history), then these are considered 'related subjects'. This characteristic is related to the research context, the reform in the Dutch lower secondary education. A large part of the reform is aimed at creating more connections between different subjects in order to create more coherence in the curriculum. Finally, TDTs develop their common future practice and enact it. This emphasis separates TDTs from teachers' teams that develop curricula not for their own use (such as, for example, teachers participating in the development of learning materials with publishers). Collaboration in design of materials that the teachers themselves will use, and will therefore affect their practice directly, raises their stakes in the process and the ownership of the product. This is also in line with a central tenet of this study: reform efforts have greater effect when they are school-based.

A TDT is an ad hoc functional unit, meaning that it is not an organizational entity on its own but rather a description of how a team of teachers functions within a time frame. For example, a subject department in a school can, during a certain period, function as a TDT when they consciously redesign their common curriculum. As soon as this task is no longer central in their work, they will not be considered as a TDT anymore. 
The focus in this study is specifically on teams in their first year of cooperation

as it seems that patterns of collaboration in design and design-decisions tend to be formed in the initial stages of the work. These patterns are then perpetuated during the rest of the design process. According to Romme and Endenburg (2006) early choices and notions create boundaries around subsequent stages in the development. The design process can be divided into 'liquid' and 'crystallized' states. During the liquid state the problem and its solution strategy are still open to many directions. Once it is crystallized, the ability to revise key elements of the design without incurring extra costs (monetary or otherwise) is greatly reduced. As the way teams negotiate their design task and react to different activities and conditions is at the heart of the study, this criterion was applied in all the studies. Additionally, the teams that were chosen for this study did not represent extreme or deviant examples. The choice was made for teams that are neither very early nor very late adapters of new practice. Teams were not experiencing very extreme circumstances (such as very bad collegial relationships) as such teams will present other challenges.

The choice for this specific definition and focus came from the developments in Dutch reform practice. In addition to this, insights from reform literature about how sustainable reform is realized call for teachers' collaboration centered on practice (Little 1990). TDTs seem to have much potential in the context of school reform as they concentrate on the teachers' work on curriculum matters, making them change agents in curriculum design. Additionally, this collaboration may lead to an exchange between teachers which can contribute to their professional development and the development of the school organization on the whole.

\subsection{OVERVIEW OF THE STUDY}

\subsubsection{Research questions and relevance}

Developments in educational policy context, current educational practice, and insights from reform literature have led to the following research question:

What are conducive (or hindering) approaches and conditions for collaborative curriculum development by teacher design teams in view of school-wide reform? 
Two elements play a role in the context of this study: the school-wide and schoolbase perspectives and lower secondary education. Shifts in the Dutch educational policy drove the choice for the lower secondary education. The policy in this sector has been highly decentralized, enabling schools to make many site specific curricular choices. This gave rise to more local curriculum development activities, often in line with the TDT concept. The choice for a school-wide perspective arose as it seemed the most conducive context for the work of TDTs in educational reform and was observed in many school reform practices.

This main research question was divided into three sub-questions considering the three aspects to be explored:

\section{A. How do teacher design teams address and carry out collaborative curriculum development activities?}

The first sub-question focuses on the description of the activities and overall rationale that teams apply in their efforts to redesign their curriculum. Description of the activities also included their sequence and the kind of curriculum considerations that occur in the discussions in these teams.

B. What are conducive (or hindering) approaches and activities for teacher teams engaged in this collaborative curriculum development process?

Based on the description of the activities and approaches (first sub-question), an effort has been made to identify those activities that were conducive or hindering for teachers and teacher design teams in their efforts to design their curriculum. The main criterion for effect in this study was the extent to which the teachers themselves perceived the activities they undertook as conducive or as hindering for their efforts to redevelop their common curriculum.

C. What school conditions contribute to (or hinder) the work of teacher design teams involved in a collaborative curriculum development process?

Finally, several school conditions that facilitated or hindered the work of the teams in the context of the school-wide and school-based reform process have been studied. The exploration of the school conditions added to our understanding of the work of the TDTs as the cases (the teams) in this study are embedded in their context (the school and the reform). 
Relevance of the study

Describing the design processes in TDTs is seen as a contribution to understanding reform processes of schools and specifically school-based and school-wide reform initiatives. This perspective has not yet been widely explored. Additionally, different dilemmas are involved as schools struggle to realize this process. They need to balance between the expected advantages and encountered difficulties. Gaining insight specifically into critical events and conditions in the collaborative curriculum design process and learning why these are critical would contribute to our understanding of the process and illuminate what teachers see as important to this kind of work. This, therefore, will increase our knowledge on the role of teachers in schools.

From the policy perspective, the results are assumed to be helpful in two ways. On the one hand, the conclusions of this study can be used to shape further policy and reform initiatives at the school and team level, improving the work of teacher teams. On the other hand, the examples of schools and reform processes described in this study may be inspiring examples for schools contemplating similar reform projects.

\subsubsection{Overall design of the study}

Collaborative curriculum design takes place within the context of schools. Therefore this study was conducted as a 'multiple case study research'. According to Yin (1994) case study research is suitable specifically when the borders between a phenomenon and its context cannot clearly be drawn. The focus of the research was on the teacher teams, forming the cases, and redesigning their common curriculum. Each case was built around one of the teams followed in the study. The cases included the activities and development in the team during this redesign, the organizational conditions which they were confronted with, and their interaction with their professional environment during the course of the reform (more details on the methodology can be found in chapter 3). During the study, 12 TDTs were followed in two school sites. These sites were involved in a school-wide reform in which all teachers in teams were in some way involved and in which there was a general or emerging organizational framework that teams needed to take into consideration in their work. The results were analyzed initially on case level, later on cross-case level within each site, and finally on cross study level comparing the findings from both sites 


\subsection{OVERVIEW OF THE DISSERTATION}

The research activities and findings of this study are presented in the subsequent chapters. In Chapter 2, the theoretical basis of this study is described. Both curriculum development and teacher cooperation are discussed extensively. This chapter ends with a framework for the analysis of the work of TDTs. Chapter 3 provides a description of the design of this study, including the research and analysis methods. Chapters 4 and 5 present the findings of the study in two school-sites in which the 12 TDTs have worked. Each of these chapters is divided into three parts, corresponding with the three research questions. The findings from the two results chapters come together in Chapter 6 , where the results of the cross-study analysis of the findings are presented. In Chapter 7, after a short summary of the study, the results are reflected upon in light of other research findings. Following that, final conclusions are drawn and, recommendations for practitioners and research are made. 


\section{CHAPTER 2}

\section{Collaborative curriculum design by teacher teams}

Literature concerning the focus of this study, curriculum development by teacher teams, is reviewed and discussed in this chapter. As this subject has not yet received a proper integral conceptualization, key aspects of this topic are explored separately with the aim to form an overall conceptual framework for describing curriculum development by teacher teams in the school context. This chapter will start with a general introduction of the curriculum and curriculum development fields in order to define the kind of elements that are observed and described in the study. Special attention is paid to the school-based and schoolwide perspectives of curriculum development which form the starting point and context of this study (section 2.1). Following that, teacher collaboration in general is discussed. More specifically, the distinction is made between learningrelated teacher collaboration and task-related teacher collaboration, the latter being the focus of this study and less illuminated in research thus far (section 2.2). In section 2.3, the subject of teacher collaboration in curriculum development is elaborated in order to identify guidelines for activities and conditions for this work. In section 2.4 the findings of the review are summarized into a conceptual framework which will be used to describe and compare the collaborative curriculum development by the teacher design teams in this study.

\subsection{CURRICULUM DEVELOPMENT AND THE SCHOOL-WIDE PERSPECTIVE}

\subsubsection{Curriculum and curriculum development}

Before considering how teams of teachers can approach curriculum development and what factors play a role in that process, it is important to understand the concepts of curriculum and curriculum development. 


\section{Curriculum}

The term curriculum has been conceptualized in many different ways. Each definition stresses a different element of it or elaborates on certain aspects of it. Probably the most basic and straight forward definition is Taba's (1962, in Van den Akker, 2003) 'plan for learning'. The strength of this definition is in its limitation to the core elements, enabling different elaborations in different contexts. It limits itself to two core elements: (1) it is planned, thus intentional, and (2) it is aimed at the learning of the target group. This plan for learning can be found on different levels of the educational system ranging from the supra (international) through the macro (national/regional), meso (school), micro (classroom) to the nano (personal/individual) level. In these different levels there are different representations of curriculum - from the abstract ideas to the very concrete learning results of the learners. Van den Akker (1990, 2003) elaborated on a typology suggested by Goodlad, Klein and Tye (1979), making a clear distinction between intended, implemented, and attained curricula (Figure 2.1). This differentiation in representations makes clear the different manifestations curricula can have, and how many transformations it undertakes while developing from one representation to the next, as each transformation is prone to interpretations and actions of different actors and circumstances. This is even amplified when different representations are created at different levels of the system. For example, when written curricula (textbooks) are produced outside of the school, they will need to be interpreted by teachers at the school level (in one of the school departments) and will be enacted and experienced by individual teachers and students.

\begin{tabular}{|c|c|c|}
\hline \multirow[t]{2}{*}{ INTENDED } & Ideal & $\begin{array}{l}\text { Vision (rationale or basic philosophy } \\
\text { underlying a curriculum) }\end{array}$ \\
\hline & Formal/Written & $\begin{array}{l}\text { Intentions as specified in curriculum } \\
\text { documents and/or materials }\end{array}$ \\
\hline \multirow[t]{2}{*}{ IMPLEMENTED } & Perceived & $\begin{array}{l}\text { Curriculum as interpreted by its users } \\
\text { (especially teachers) }\end{array}$ \\
\hline & Operational & $\begin{array}{l}\text { Actual process of teaching and learning } \\
\text { (also: curriculum-in-action) }\end{array}$ \\
\hline \multirow[t]{2}{*}{ ATTAINED } & Experiential & $\begin{array}{l}\text { Learning experiences as perceived by } \\
\text { learners }\end{array}$ \\
\hline & Learned & Resulting learning outcomes of learners \\
\hline
\end{tabular}

Figure 2.1 Typology of curriculum representations (Van den Akker, 2003) 
Another useful typology when conceptualizing curriculum as a plan for learning is that of curriculum components. According to Van den Akker (2003), elaborating on Eash (1991) and Klein (1991), curricula can be divided into ten components that address specific elements of the learning process:

- Rationale: Why are they learning?

- Aims and objectives: Toward which goals are they learning?

- Content: What are they learning?

- Learning activities: How are they learning?

- Teachers' role: How is the teacher facilitating the learning?

- Materials and resources: With what are they learning?

- Grouping: With whom are they learning?

- Location: Where are they learning?

- Time: When are they learning?

- Assessment: How far has learning progressed?

The rationale is the major guiding component, while the other nine components are ideally linked to the rationale and are also consistent with each other. Van den Akker (2003) stresses the importance of the consistency of the curriculum components by drawing a curricular spider web (Figure 2.2). The metaphor stresses the many interconnections possible but also the vulnerability of the whole; when one component is considered and changed, other components will have to be adjusted as a result, in order to maintain coherence.

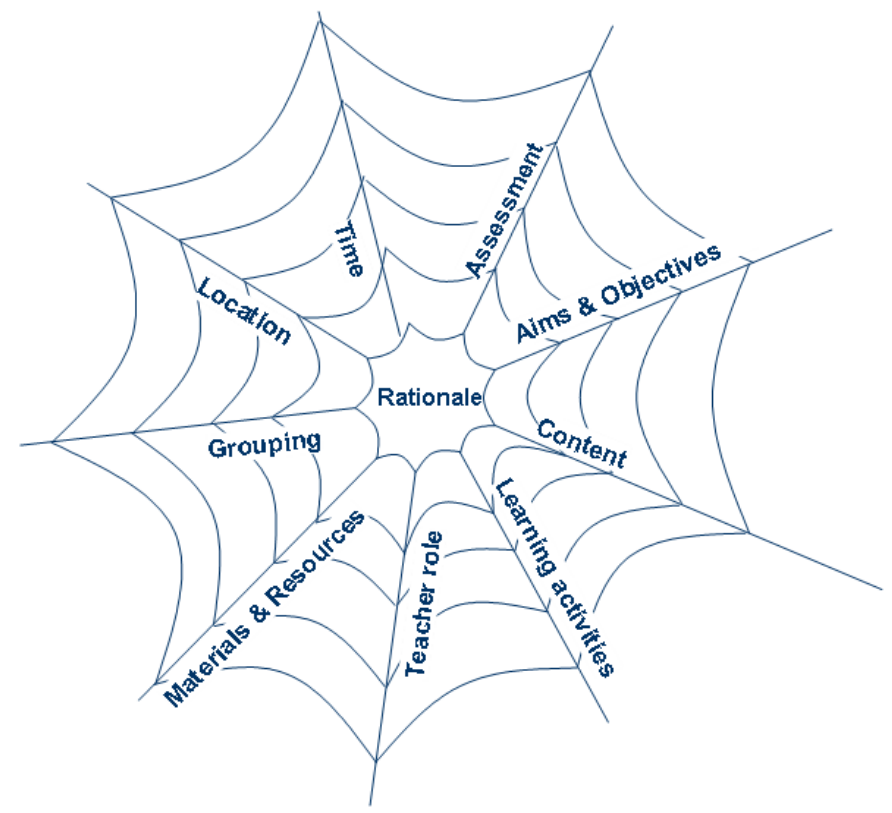

Figure 2.2 Curricular spider web ( Van den Akker, 2003) 


\section{Curriculum development}

Whereas the subject of curriculum definitions and typologies often seems complex, the subject of curriculum and instructional design or development seems outright confusing. There is a multitude of different models and definitions aimed at different goals and practitioners (cf. Gustafson \& Branch, 2002; Van den Akker, 2003). Even the distinction between curriculum and instructional design is somewhat ambiguous. Whereas instructional design (models) often refer to a systematic procedure for the production of instruction (Gustafson \& Branch, 2002), the use of the broader term 'curriculum design' often refers to a more comprehensive process of considering design of broader units on meso level. Limiting himself to instructional design, Gustafson (1981, in Gustafson \& Branch, 2002) developed a taxonomy of models, trying to bring order to the variety of models available. This taxonomy consists of three categories indicating if the model is best applied to developing (1) individual classroom instruction (mainly to be used by teachers), (2) products that are developed for use of other users other than the developers, and (3) large (meso level) instructional systems aimed at an organization's problems or goals that are more in line with the curriculum design models. These three groups of models differ in many aspects concerning both their input (the level of resources and expertise that is needed to apply them) and their results (level of output, specificity, and implementation factors). Considering the body of literature on design models containing hundreds of models, Gustafson and Branch (2002) conclude that there is a great overlap in the models, many of them actually being adaptations and minor adjustments of earlier models. Additionally, many of the models are of a prescriptive nature, depicting the ideal situation as the researchers see it, and are not based on an analysis of design processes or testing of the models. Many of them also imply some linearity, depicting a set order of activities, while most developers approach the task as a problem solving process which is more iterative (Visscher-Voerman, 1999). This is even more so in collaborative design processes. The collaboration makes the process even messier because of the involvement of more participants. Coordination and communication in the process itself come into play. Therefore, it seems impossible to reduce it to a 'neat' model (McCutcheon, 1996; Odenthal, 2003).

Even though, Nieveen (1997) states that these models have an important advantage in that they make often long and complex processes transparent for participants. She names specifically three important functions for the use of curriculum design models: 
1. Facilitating project planning and management by allowing prediction of time-lines and intermediate products.

2. Reducing complexity of decision making by providing heuristics for work.

3. Enabling communication between different stakeholders by providing a clear overview of stages and products.

Concentrating on curriculum development in the broader sense and not only on instructional design, Verhagen, Kuiper and Plomp (1999), after considering different models and approaches to educational development, come up with a more generic model of educational development that depicts a conceptual representation of development processes (Figure 2.3). This model consists of five stages: analysis, design, development, implementation, and evaluation that are in one way or another part of the curriculum development process and are depicted in many other models. By its generic character, the model does not relate to a specific development model, and is not instrumental in the sense that it does not give direct guidelines for the curriculum development. This makes the depicted stages appropriate in describing curriculum development as it might take place in practice. On the one hand it supplies an orderly framework for looking at development processes without limiting oneself to a specific perspective on the process. Using a more specific prescriptive model runs the danger that when practice deviates from theory, the analysis labels will be rendered unusable. The generic model allows for non-linear processes as different stages can be repeated and revisited. This seems more in line with curriculum development as encountered in practice (cf. Visscher-Voerman, 1999).

Models of curriculum development represent the 'technical-professional' perspective of curriculum development (Goodlad, 1994). This perspective refers to the 'mechanics' of the curriculum development process, i.e. what activities are undertaken and in what order with the goal of designing a curriculum (on different levels). This aspect is central in this study of how teacher teams approach and execute curriculum development. Nevertheless, one may also look at curriculum development from 'socio-political' and 'substantive' perspectives (Goodlad, 1994). The 'socio-political' perspective refers to the process in which different stake-holders interact concerning their views and interests. In this process, the different views brought into the discussion could be weighted and compared in order to come to an actual curriculum, while the different actors try to realize the points that are of interest to them. 


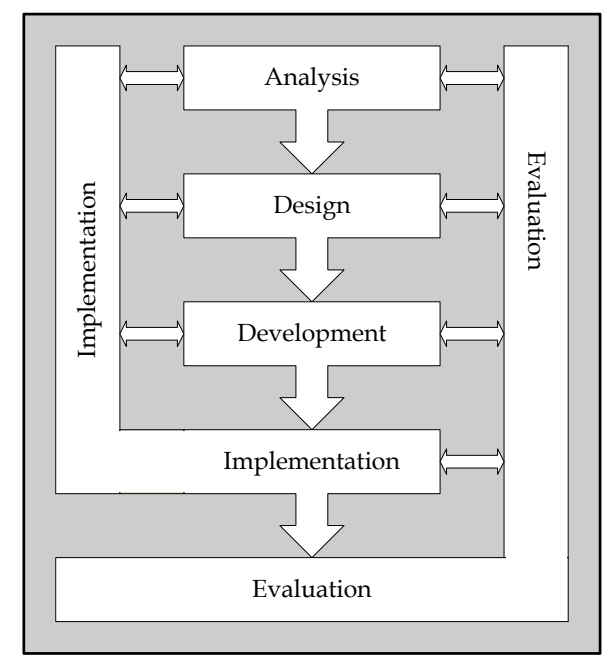

Figure 2.3 Generic model of educational development

The 'substantive' perspective focuses on the questions of what is worthwhile to include in the curriculum. This includes the main rationale of learning, its content, and the manner in which it should taught or learned. In considering this substantive perspective, Marsh and Willis (1999) suggest three considerations which might guide decision making. The first consideration is the nature of the subject itself and the content that should be chosen - which one is the most important? What represents the nature of the subject? The second possible consideration is society. Here the guiding element in the content of curriculum is based on the needs of society at large and how to prepare students for taking part in it. The leading question here is if the student is being prepared to contribute to the society. Finally, the consideration of the nature and development of the individual student can be addressed. How can the curriculum contribute to the personal development of the students and account for their own interests and talents? Although all of these considerations are important and are, on one level or another, always taken into play, in different processes one of them tends to get the upper hand, leading many or all of the substantive decisions (Marsh \& Willis, 1999).

Curriculum development processes lead to varied products. The curriculum representations discussed earlier can be used to describe these products. At a certain point in time, a process can be seen to have resulted in an intended curriculum in the form of guidelines or written materials, or as an implemented curriculum that has been used in a learning situation where the effects on the learners are not (yet) central or measured, or else as an attained curriculum 
which is implemented and its effect in practice is examined. While, logically, all curriculum design processes strive eventually towards the latter, when examining one during a certain period, it is possible that the main tangible result of a design process will be in effect 'only' a written document.

Considering the quality of a curriculum, different quality criteria come into play. Nieveen (1997) offers validity, practicality, and effectiveness as markers of quality of the curriculum. Validity refers to the fact that the product is based on state of the art knowledge and is internally consistent. When assessed as valid, the product is, at least theoretically, sound. Practicality means that the product meets the needs of the target group and can be used in their context. Finally, effectiveness refers to the impact of the curriculum product on the target group. An effective product realizes the goals for which it was developed. While validity can be assessed before curricula are implemented (thus when they are still in their written form) and practicality can partly be assessed before curriculum products are used (in the written form and at the initial implementation or piloting), effectiveness can be assessed only when curriculum products are implemented.

\subsubsection{Teachers as 'curriculum makers'}

Johnson (1993) describes two extreme types of curriculum development with an implication for the teachers' role. In the administrative model decisions are made 'top-down'. Curriculum is essentially designed and constructed away from the school. Teachers have little or no involvement in the curriculum development process. This model relies on the assumptions that curriculum documents are clear to the teacher and that they implement the curriculum faithfully. Johnson lists several strengths and several deficiencies of such an approach. This central initiative enables broad and uniform education and the engagement of experts in the curriculum development process. It also takes work out of the hands of the teachers and gives them concrete materials they can use. The major impediment of this approach is the implementation problem, as most centrally initiated curricula are not implemented in the manner in which the designers envisioned (Clandinin \& Connelly, 1992). Moreover, this approach can alienate teachers, inhibit their enthusiasm for reform, and create teachers who are dependent on these materials and unused to approaching their curriculum critically. As teachers are the source of stability and change in schools, their role must be more closely considered in the process of reform (Clandinin \& Connelly, 1992). 
The bottom-up approach, alternatively, relies on local initiatives of individuals or groups. In this approach curricula are used within the setting in which they were designed and the work of the teachers is focused on the pedagogical aspect, concentrating on curriculum and instruction. This presents several advantages:

- Creating a better fit between the planned curriculum and the context of work - teachers are aware of the context, the needs and problems of their students, and assess the potential of curricular ideas and materials for their classrooms (Johnson, 1993; Kimpston \& Rogers, 1988; Skilbeck, 1998).

- Promoting learning and understanding by the teachers themselves in the process of curriculum design (Johnson, 1993; Skilbeck, 1998).

- Increasing the sense of ownership of curricula by the teachers and therefore increasing the quality of implementation (Johnson, 1993).

- Increasing the motivation and satisfaction of teachers by focusing on actual learning processes of the students in their subject matter domain (Black \& Atkin, 1996; Grossman \& Stodolsky, 1995; Kruse \& Louis, 1997).

- Contributing to the collegial work at school and therefore to the work of the organization as a whole (Johnson, 1993).

- Increasing the effectiveness of the curriculum in meeting the learning needs of the students (Sackney et al., 2005).

Teachers' willingness to take part in school decision-making depends on the kind of decision they are asked to make, the amount of expertise they perceive as asked of them, and the degree to which they actually influence the final decision (Kimpston \& Rogers, 1988). But according to Young (1985), writing at the heyday of the school-based curriculum development wave (see section 2.1.3), teachers prefer the translation of curriculum into instruction-giving form to the concrete class activities and not discussing curriculum at the school level. Young adds that even then, many teachers are also ambivalent towards participation in curriculum development activities because it often means more responsibilities and more work. Additionally, the bottom-up approach implies an explicit designer's role for the teachers for which they are often ill-prepared. Even schools that apply a bottom-up approach tend to combine it with some form of coordination which could be seen as a form of a top-down approach. This is done in the form of central guidelines at the school level as they try to maintain some coherence.

Clandinin and Connelly (1992) come to the conclusion that at the time they were writing on the 'teacher as curriculum maker' the dominant view of teachers in the process of curriculum implementation and curriculum reform 
was that of a conduit-merely transforming the curriculum made outside of the classroom. Teachers were often described as an impediment to curriculum implementation or as an instrument to be used during that 'correct' implementation of curriculum materials. According to Clandinin and Connelly, this image has changed somewhat over time but that main premise has not. Within that, much of the discourse on curriculum and school reform depicts teachers as unwilling to change and their professional knowledge as insufficient or lacking (Carlgren, 1999). Moreover, the nature of many educational reforms implies a loss of competence from the teachers' perspective as they are required to do things that they are unused to and that implies that their current practice is considered as lacking. Teachers' previous practical knowledge becomes useless and sometimes even counterproductive. Reforms therefore often form a rupture in their professional knowledge base. Carlgren (1999) considers the design aspect of teachers' work as an unrecognized aspect. According to her, most writing and thought is centered on their work in the classroom. What they do before and after working in the classroom is considered intermediate for that main interest. There is thus too little conceptualization of their role as curriculum designers, considering the possible advantages of this. Additionally, development of materials (and professional development) should not be seen as something teachers do in addition to teaching but as an integral part of the teacher's role (Carlgren, 1999; Friedman, 1997). At the same time, in contexts where years of central educational policy have "de-professionalized" teachers, it is not even clear if teachers can do what is expected of them in an extended professional image - their knowledge base does not match the tasks demanded of them as designers of curriculum. They are asked to do something they have not done before and have little experience with (Carlgren, 1999). This means that teachers should be assisted in developing this aspect of their professionalism. Moreover, there is a need to develop a tradition of language for design work of teachers as most of the current terminology on teacher's knowledge and work is concentrated on their classroom practice rather than their role as potential designers of curriculum.

Teachers are sometimes seen as partners in curriculum development in the context of combined efforts with curriculum or pedagogical experts to rewrite schoolbooks or parts of the national curriculum (cf. Deketelaere \& Kelchtermans, 1996). This is a form of participatory design in which the clients are asked to participate in the design process, both to provide input on the 
quality of the product being developed and to contribute their expertise in order to improve the product itself. In this form of participatory design, however, the teachers involved do not necessarily or directly redesign their own practice but merely participate in the redesign of a general practice. This is in contrast with the study presented in this dissertation in which teachers redesign their own practice.

\subsubsection{A school-based and school-wide perspective of curriculum development}

Although giving the teacher a (central) role in curriculum design and enactment thus seems beneficial from a bottom-up point of view, this should happen in the context of a broader process in the school. Innovations that give teachers a designer's role often rely on individual teachers or incidental work. These initiatives do not last long and have little effect in the long run (Hargreaves, 2003). Therefore, in order to reach sustainable change, there is a need to organize reform in a school-based and school-wide manner in which all teachers are involved.

\section{School-based perspective}

Approaching curriculum reform from a school-based perspective relies on the same kind of argumentation as the one used to support the active role of teachers in curriculum design. It has the potential to bring about a curriculum with a better fit for students, to contribute to the professionalism of those actively involved, and it enables making the curriculum design process beneficial for the organizational development (see discussion in section 2.2 on the potentials of collaborative curriculum design).

In the past, this issue was extensively developed by a strand of writing that considered school-based curriculum development (SBCD) as a way of bringing the 'curriculum making' into the school. In light of possible variations of SBCD and many different definitions Marsh, Day, Hannay and McCutcheon (1990) describe a typology suggested by Brady (1987) along two dimensions:

- type of curriculum development activity (creation, adaptation, selection, or exploration of materials);

- persons involved (individual teachers, small groups of teachers, whole staff or teachers with parents and students). 
These dimensions help order the different kinds of SBCD initiatives and imply 16 different variations. Marsh et al. (1990) suggest adding a third dimension: time commitment. This refers to the time frame of the SBCD activity ranging from a one off activity (a single meeting or discussion), through medium-term plans (a five-month long cycle of activities with coherent goals), up to long- term plans including several years of action. According to them the time commitment factor is crucial in SBCD because one-off initiatives, no matter how successful they are, have little chance of significantly influencing the curriculum unless they are a part of a long term process. This third dimension makes it possible to construct a three dimensional model for the typology of SBCD as depicted in Figure 2.4.

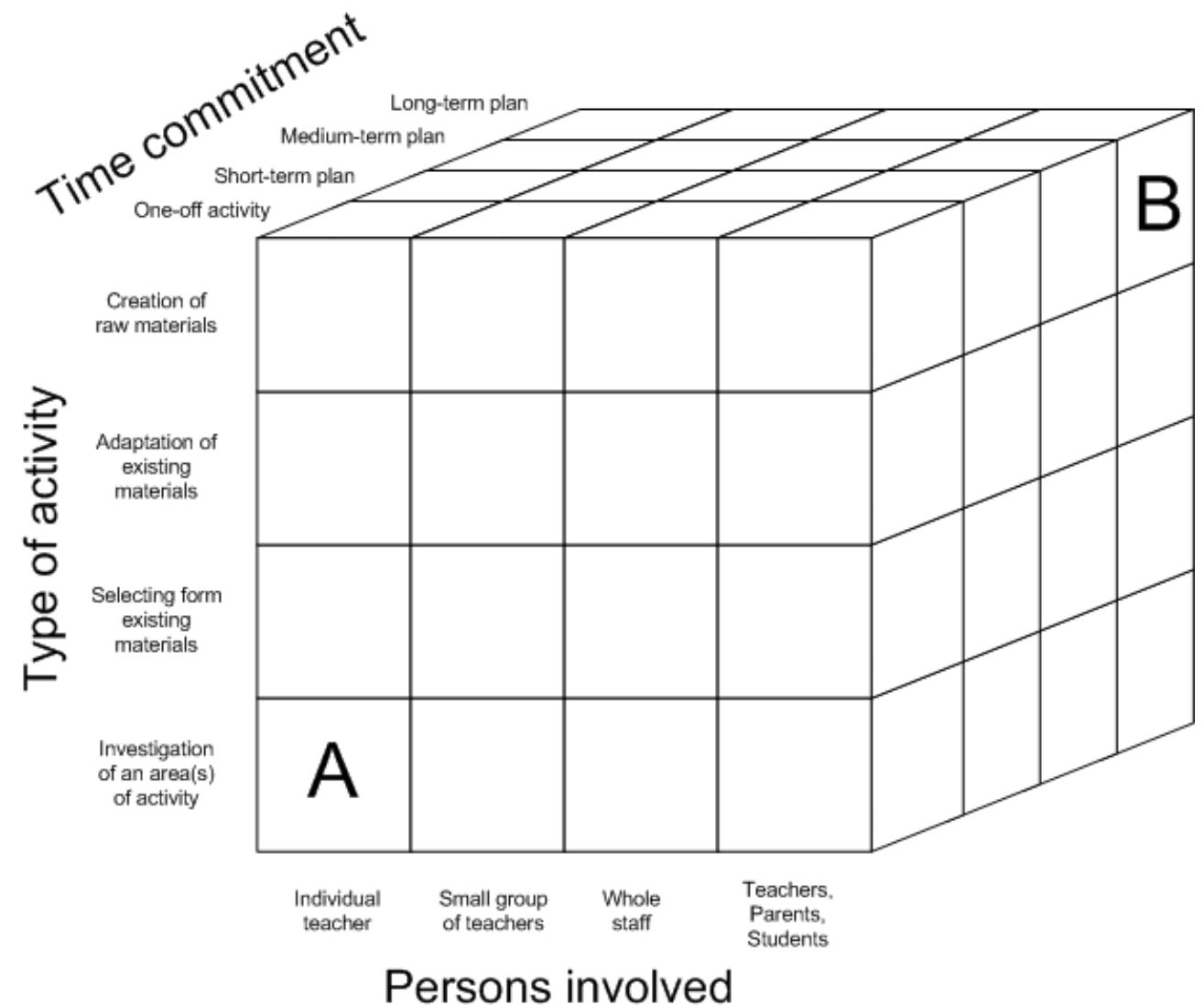

Figure 2.4 A matrix of SBCD variations (adapted from Marsh et al., 1990, p. 49)

Figure 2.4 illustrates that SBCD can be one of a range of activities. The range of activities describes the difference in the jurisdiction of the teachers - from very limited to deep with a long-term initiation of change. It could constitute an individual, one-off investigation of an activity by one teacher (square $\mathrm{A}$ in Figure 2.4). It can also be a long-term cooperation between teachers and 
students in order to write new teaching materials about a specific subject (square B in the figure 2.4). It might even be so that some activities identified in this matrix are not even seen as SBCD by some. For instance, a general inspection of a part of the curriculum by one teacher as a one-off activity (square A in the figure 2.4) can hardly be considered as SBCD as it is not 'school based' but 'teachers based' and is too limited and superficial to have any sustainable impact on the school. This study limits itself in the array of SBCD activities it examines. Cooperation of staff members is considered in this study as an important theme for SBCD. As this study aims to investigate the cooperation of staff members, it limits itself to examining activities by 'small groups of teachers' and 'whole staff' (see also the discussion on the school-wide perspective). Additionally, because of the limited potential effect of one-off activities on the school's curriculum, they too are not considered powerful enough to elicit sustainable change in the school. Therefore, 'one-off activities' and 'short-term plans' are also excluded from this study. Finally, as curriculum design processes are at the heart of this study, 'general investigation of area of activity' is not considered in this study unless those investigations are a part of a more extensive curriculum development process. The focus of the study is therefore on the center part of the back of Figure 4.

Bolstad (2004) concludes as a part of her literature review that most of the writing and research on SBCD took place between the mid 70's and the beginning of the 90's. She offers two explanations for the apparent disappearance of this policy and research area. First, SBCD faded from the educational landscape at the onset of widespread centralized reforms in many Anglo-Saxon countries with a shift towards more short-term, single teacher interventions to realize change in the classroom. Another explanation is that there was a shift in the terminology used to describe essentially the same processes but using different accents. An apt example is the prolific use of the term 'Curriculum innovation' to describe reforms at many different levels. Many of these kinds of reform could easily fit in the SCBD definition and framework.

\section{School-wide perspective}

Organizing reform in a school-wide manner is aimed at coherence across the curriculum both between school-subjects and different year-groups. This is supposed to improve the consistency of the students' learning experience in the school. Broader participation also helps make innovations more robust and not 
dependent on the incidental and voluntary involvement of individual teachers. Additionally, this school-wide approach allows schools to connect different developments that support and enable one another. The connection of developments at the school level (both in the organizational as well as pedagogical aspects) with changes in the classroom level is crucial for the success of school reforms (Ainscow, 1995; Harris, 2005). The connection, though, is "slippery and unreliable" (Harris, 2003) and in the end sustainable change should be reflected in what individual teachers actually do in the classroom (Harris, 2005).

Comparing two reform approaches-a school-wide approach and a department-centered reform approach - Little (2002) warns that both have their pitfalls. The school-wide approach can be too general and offers the teachers little guidance in specific learning problems and specific reforms in the classrooms. The role of the teacher turns into that of a generalist, lacking the subject-related activities and development which are some of the strongest motivations for teachers' work. Using the subject department as the main source and focus of reform relies, on the other hand, on the initiatives and efforts of a small group of teachers and lacks organizational support, possibly creating an innovation bubble which stays isolated. Little (2002), weighing both options on their advantages and disadvantages, eventually concludes that combining whole school reform with specific support for teachers' work in subject-related groups (or subject departments) is a viable option worth pursuing as it potentially yields the best results. This, she concludes, still needs to be tested. Clandinin (1998) also advocates centering the developments on groups of teachers within schools, as according to her any development focused solely on the work of individual teachers (even if it is done in a school-wide manner) offers limited possibilities for change. But Kruse and Louis (1997) draw our attention to the inherent tension between the team-centered approach and the whole school-community approach. Teams, by virtue of their existence and focus can undermine the whole school community to effectively attend to reform. This tension revolves around five themes: time distribution between the two, the focus of the program development, the focus of the reflection of the teachers, the autonomy distribution, and the tension between small team cohesiveness and critical challenges from other teams. Therefore, a balance should be struck between the team and the school. Even when the concentration is on the team level, school organization factors should be considered. This will be further elaborated when the organizational factors influencing the work of the teams are discussed (section 2.3.3). 


\subsection{COLLABORATION BETWEEN TEACHERS - NATURE AND IMPEDIMENTS}

\subsubsection{Teacher collaboration in schools}

In the past few years much has been written on teacher collaboration in schools. Often the term 'communities', in many different combinations, is used to describe a form of collaboration between teachers. According to Supovits (2002) much of the attention and widespread use and research of teams in order to improve practice and instruction comes from the organization theories on group practice and communities in the workplace. Collaboration in teams or communities is presented as an effective response to increasing change and a knowledge based workforce. By collaborating, professionals pool their knowledge and can together create new knowledge. It is also often implied that this is a way to produce a more effective organization. According to Wenger (1998) who coined the term of 'communities of practice', this kind of grouping has three elements to it:

1. mutual engagement on the task at hand;

2. common negotiation of the focus of work;

3. development of a shared repertoire to effectively address the work.

These teams develop a shared history of learning by exchanging experiences and working together.

In the educational research literature communities are seen mainly as settings for ongoing teacher learning (Grossman et al., 2001; Hord, 2004; Little, 1990). This learning and the actions that follow are expected to improve instruction and this in turn is expected to improve students' results.

A central line in the writing on collaborations in school is that of the professional learning communities (Hord, 2004) or teacher learning communities (McLaughlin \& Talbert, 2006). These refer to a team of teachers in schools that together share a common goal, actively negotiate this goal, and try to come to a solution. According to Stoll, Bolam, McMahon, Wallace and Thomas (2006) there is no one definition of (professional/teacher) learning communities but most definitions come to the consensus that this is "a group of people sharing and critically interrogating their practice in an ongoing, reflective, collaborative, inclusive, learning oriented, growth-promoting way".

Research on teachers' communities in schools vary from studies concentrating on a small group of teachers in the context of subject departments (cf. Witziers, 
Sleegers \& Imants, 1999) through studies of groups of teachers cooperating in schools across subject borders (cf. Grossman et al., 2001; McLaughlin \& Talbert, 2006), to studies of whole school communities (cf. Hord, 2004; Louis \& Marks, 1998). Considering this variety of definitions and forms, Grossman et al. (2001) warn that the term 'community' has lost most of its meaning. There are no criteria as to what constitutes a community. Additionally, most research addresses already formed communities, giving little information on how these groups were formed and developed thus missing an important link in describing how these communities came to be (McLaughlin \& Talbert, 2006).

Nevertheless, insights from research into these varied communities can be applied when looking into teacher cooperation at the small group level with specific design goals such as is the case in this study.

Expected benefits of teacher collaboration in school

After reviewing the difficulties of the realization of communities, Grossman et al. (2001) posed the question: "if we are right in saying that even with substantial resources a community is difficult to attain and even harder to sustain, we may reasonably ask: Why bother? Why bother with a costly process that has shallow roots in the culture of school and is destined to fail more often than it succeeds?" (p. 993). They, as propagators of the concept, of course have an answer for their own question. They see the benefits in the intellectual renewal and venue for learning that lies potentially in these teams. Additionally, a community is a venue for cultivating leadership at different levels of the school, allowing teachers to take their practice into their own hands. And eventually they describe communities as allowing for the opportunity to reculture the school, changing the nature of work and discussion, and leading to learning benefits for the students.

Different authors, considering the subject of teacher collaboration in school present different arguments as to why this should be enacted in school:

- increasing the motivation and commitment of teachers (Day, Elliot \& Kington, 2005);

- contributing to building culture of collaboration and deliberation (Marsh, 1994);

- enabling the application of broader reform to specific locations within the school and filling the policy void in school (Wohlstetter \& Mohrman, 1996);

- allowing for a positive correlation between the presence of teacher collaboration and the innovative level of schools (Geijsel, Sleegers, van den Berg \& Kelchtermans, 2001). 
Kruse and Louis (1997), synthesizing literature, come up with six main benefits for schools and teachers as a result of creating teacher teams and/or a schoolwide community:

1. Redistribution of authority-there is an increase in decision making in different levels of the school. This gives access to new ideas and encourages a greater sense of ownership.

2. Broader participation in decision making process - teachers have more time to think and discuss, and have an opportunity for more informal participation because they get more information and data.

3. Personal rewards - the team structure gives teachers more emotional and moral support, and by extending their role stimulates them intellectually.

4. Increased communication and interaction between teachers.

5. Increased sense of efficacy - through interaction about teaching, teachers can improve their practice and gain a better sense of efficacy, a crucial element in improving their teaching.

6. Greater collective responsibility for teachers learning-through the interaction and collaborative work the common goals are strengthened. This has a powerful effect on school performance.

These advantages relate to several elements: the curriculum of the school itself (through boarder participation in decision making process), how teachers feel and learn within these teams (increased sense of efficacy and personal rewards), and the school-wide reculturing and change (redistribution of authority, increased communication, greater collective responsibility). Considering the core business of school - the learning of students - research has compelling evidence that schools with collaborative communities among teachers enable more coherence across teaching practice as well as a teaching practice that is better suited for the student population (McLaughlin \& Talbert, 2006; Shank, 2006).

Based on the discussion above and the work of other authors, the expected effects of the teacher teams' work in school reform can be divided into three domains (cf. Grossman et al., 2001; Little, 2002; Sackney et al., 2005; Supovitz, 2002). First, they are expected to lead to development and use of new curriculum materials and have an influence on teacher practice and thus lead to change in the curriculum taught in the school. Second, the interaction of the teachers in the team is supposed to contribute to the professional development of the teachers. Third, the work in the team is supposed to change the way teachers work and interact, 
contributing to organizational change at both the school-cultural level as well as the school-structural level. These three domains are also often approached in combination because the developments in the different domains interact and influence one another (cf. Fullan, 2001; Hopkins, 2001). This is not without difficulty as these domains do not always mix well. There is a possible contrast between the promise of direct applicability of materials and the distant goal of intellectual renewal and professional development of teachers. The one calls for short term and direct application and the other for time for reflection and consideration. These domains need to be in balance for the successful work of communities in the school (Grossman et al., 2001). Little (2003), although supporting the theoretical grounds of this argument, comments that there is still little research on communities that support this broad claim of improving all three domains. These three domains are shortly discussed in the following pages.

\subsubsection{Collaboration for coherent curriculum development}

In this study the main goal of the teacher's collaboration is the improvement of their common curriculum and renewing it in line with school-wide reform goals. Teacher teams are in this context a good instrument in making the connection between structural changes and reform intentions and the practice of teachers in their classroom (Harris, 2003). Additionally, teacher cooperation brings teachers together to discuss their curriculum and therefore can bring about more curricular coherence across the school as teachers from the same or related subject can at least coordinate or in some cases integrate their subject matter. As curricular coherence (in the specific subjects and across subjects) increases the quality of the curriculum (Van den Akker, 2003), this seems a worthwhile goal to pursue.

By collaborating on curriculum issues the 'egg-crate' organization (e.g. the classic description of Lortie, 1975) is changed. There is a drive to shift situations in which teachers keep their teaching to themselves and their classroom to situations in which teachers share their thoughts and possibly their practice either by coordinating their practice or collaboratively planning it to maybe even team teaching. Louis and Marks (1998) found that organizing the work of teachers in teams concentrating on the work of students and improvement of the curriculum led to improved academic performance of the students. They attributed that to the increase in authentic pedagogy in the classroom, across the classroom of the teachers involved. The specific pedagogy aside, learning was found to improve across the teams meaning that by collaborating and exchanging ideas some form of coherence in the teaching was created, which lead to similar teaching and 
results by the teachers. Assuming that teachers, assisted or unassisted, can develop strong pedagogical interventions to aid their students, collaboration increases the chance for the spread of this practice across classrooms.

As collaboration of teachers in curriculum development efforts is the main subject of this study, this is more extensively discussed in section 2.3 of this chapter.

\subsubsection{Collaboration for professional development of teachers}

As argued, teacher teams have the potential to contribute to teacher learning. However, Little (1990) found that collaboration or interaction on its own is not enough to lead to a learning process. The content of that interaction is highly important in considering the contribution of collaboration to professional development. The more teachers are dependent on each other, the more potential the interaction has for learning. Little describes four levels of collaboration:

1. Storytelling-occasional and sporadic content-related interaction between teachers in which they exchange 'war stories' or fragments of ideas. These are neither organized nor intentional.

2. Help-individual teachers seek specific help from a colleague. They also only offer help to a colleague when asked to, and limit it to the subject of the help request.

3. Sharing documents - a routine of sharing materials and methods and the open exchange of ideas and opinions between colleagues.

4. Joint work - encounters among teachers that share a responsibility for teaching (interdependence). This form of collaboration includes a collective conception of autonomy and a group affiliation grounded in professional work.

Little (1990) found that although the latter forms (sharing documents and joint work) have more learning potential for teachers, they are much less frequent in most schools (cf. Kwakman, 2003; Little, 2003). Even in organized interaction in formal professional development activities that are designed and led by professionals, it seems difficult to achieve and sustain a deep conversation that constitutes joint work (Little, 2003).

Collaboration in curriculum design can create the learning affordance of 'sharing documents' and 'joint work'. Kolodner et al. (2003) demonstrate that collaborative design as an activity in general has a great learning potential. 
Their approach, called Learning by design, refers specifically to the learning of science concepts, but their ideas on the learning potential of design as a whole can also be applied to adults and teachers in a working environment. Learning here is a result of solving coherent and life-like problems. By doing this, the problem and the knowledge needed to solve it become relevant to the learners. This will certainly be the case when teachers solve 'problems' that concern their daily work. The power of design as a learning instrument lies according to Kolodner et al. (2003) in its affordances for learning as it:

- focuses the learning;

- turns seeming failures into opportunities for learning as part of the process;

- naturally involves iterations as part of the process - similar to the process of learning;

- combines doing with reflecting and therefore helps learners to apply knowledge and order their experience into accessible reusable cases.

An important part of the learning takes place in the interaction and exchange of ideas between the participants. Four points in time during the design process seem to be of critical importance for learning: (1) after the initial investigation of the problem; (2) while planning the design solution; (3) during implementation; and (4) at the completion and evaluation of the design.

Although collaborative design is not often explicitly discussed as a strategy for professional development of teachers, collaboration in (curriculum) design can potentially lead to several possible learning gains for teachers:

- content knowledge in a target domain (Kolodner et al., 2003; Louck-Horsley, Hewson, Love \& Stiles, 1998);

- pedagogical-didactical knowledge and skills (Guskey, 2000; Louck-Horsley et al., 1998);

- general process and collaboration skills (Guskey 2000; Kolodner et al., 2003);

- heightened self efficacy and inclination to adopt new classroom behaviors (Rosenholtz, 1989);

- better understanding of school organization and ways in which individuals can influence and operate within the school organization (Guskey, 2000).

As the learning from curriculum design processes has not yet been studied extensively, it is not surprising that the issue of learning curriculum design skills is not mentioned as an explicit learning gain. 
When examining the process of collaborative curriculum development it can be asserted that professional development of teachers is important for its success. For example, teachers need to have alternative perspectives and ideas available to them in order to critically examine their practice. And as they (need to) redevelop their curriculum, they should have some basic (curriculum) design skills.

\subsubsection{Collaboration for school development}

The third domain of change expected by collaborative work of teachers is often labeled as 'school development'. School development refers to a collection of approaches and techniques in which educational reform is aimed both at the improvement of the student learning and the increase of the school's capacity to engage with a changing environment and handle change (Hopkins, 1998). This development refers to changes in both the culture and structure of the school as an organization.

As a result of more rigorous and frequent meaningful cooperation between teachers (for example in TDTs) the expectation is that the schools' culture or organizational climate will change (Bryk, Camburn \& Louis, 1999; Fullan, 2001; Maehr \& Midgley, 1996; McLaughlin \& Talbert, 2001). It is also precisely the element of enabling and supporting collaboration and mutual learning which is decisive for school development. Without this collaboration, organizational change will do little to promote culture development and meaningful pedagogical change which will impact the students. In that sense, teacher teams are ideally positioned for making the connection between structural changes in school and change in the school practice (Harris, 2003). There is thus a relationship between changes in school culture and changes in school teaching. This points to the deep relationship between structure and culture in schools (Hargreaves, 1994). Structures are not neutral as they create affordances and limitations for certain behaviors. On the other hand structures are also created by people and are therefore a concrete image of certain cultural norms.

This relationship between structure and culture of work is demonstrated in the findings of Little (1990) and Kwakman (2003), which are in line with Lortie (1975). They assert that teachers are still very much driven by the structure of the school, which in most cases leads to isolation and not to a collaborative attitude. Frequency of collaborations in schools that demand more than mere discussion is often low (Kwakman, 2003). But even when teachers are placed in 
an organizational context in which they are required to cooperate with others, even in their daily practice, teachers are often not convinced this has an added value for their work (Pomson, 2005). This ambivalence comes partly from simply not having learned to cooperate and a lack of guidance in it. Additionally, teachers seem to resist entering relationships imposed on them by third parties. They object to prescribed collegiality which is often the case in these schools. This is similar to what Hargreaves (1994) describes as contrived collegiality. While it can work for a specific goal for a short time, it is highly unlikely to develop to a productive cooperation. Imants (2002) reminds us that not only are structural changes not synonymous to changing teachers' beliefs and actions, they can also hamper improvement. People participating in reform can become preoccupied with the structural aspects and their attention will be drawn away from the content of the reform itself. Additionally, the manner in which adaptations of the organization interacts with the change in the classroom is complicated and not clearly understood (Peterson et al., 1996).

At the same time, in order to enable structural changes as in the forming of TDTs, some basic collaborative culture must be in place. In schools where the culture is strongly individual and the teachers resist cooperation, the chances of initiating successful teams are greatly reduced. Schools need to have some basic vision and capacity to create and lead change efforts. However, schools cannot postpone change efforts until most participants are committed or no change will take place. In fact, it is the paradoxical reality that those schools that need to improve the most, are those that often have the least conducive cultures for improvement (Peterson et al., 1996).

Although both elements (structure and culture) are important, often change strategies address the change in structures as an instrument to change school culture and classroom practice. This is due to the fact that structures are more accessible for manipulation from the outside whereas culture (by nature) is inaccessible for direct manipulation. Although school development is not the focus of this study, some elements of the school level are important insofar that they impact how the TDTs operate-both in the team and in interaction with the school-wide reform framework. These conditions and their implications are addressed in section 2.3.5. 


\subsubsection{Learning communities vs. task communities}

According to Supovits (2002) two concepts that are often associated with the rational for teacher teams are the concepts of team teaching and devolved decision making. Team teaching relates to a situation in which teachers band together to teach collaboratively. This is seen as a way to improve collegiality and foster a community. Early failures of this form of work were attributed to lack of organizational support. This kind of work implies both structural change in the school (for example other time-tables) and supporting the teachers in learning to work together. Devolved decision making concentrates on bringing decision making closest to those who are most knowledgeable and to those who have the most influence on the students, i.e. the teachers. This autonomy is also supposed to have a relationship with eliciting professional development of the teachers. These two concepts relate to two aspects of cooperation: common practice and common decision making. Supovits (2002) found that schools and teachers were more likely to engage in academic preparation and student grouping strategies (thus common decision making) than to collectively teach or engage in common action.

This is also reflected in much of the research literature on teacher teams or professional learning communities (PLC). There the focus is often set on the learning perspective of the teachers. The main subjects of research are describing the learning process in the teams and in assessing their success. This is, for example reflected in a book on the subject of PLCs (Stoll \& Seashore Louis, 2007). Different authors discuss here perspectives of the subject, often referring to joint actions that the PLCs undertake or plan. At the same time these actions and the process of work are hardly discussed, while the learning of teachers is discussed extensively. Even when it is mentioned that teacher teams have a common curriculum task (McLaughlin \& Talbert, 2007) there is little discussion of what the task is and how they handle it. In many cases, even if the teams have the task of (re)designing a part of the curriculum (often referred to as collaborative curriculum planning), the curriculum (design) perspective is often mentioned as a by-product or is described only shortly and in broad terms. There is more attention paid to the learning function and less to the (curriculum) task that the team fulfils. At the same time, collaboration on subject specific content and pedagogies is the element that is supposed to have a significant impact on the learning of the students (Little, 2002; Supovitz, 2002; Visscher \& Witziers, 2004). In this study, therefore, the focus lies in teams which have a common curriculum 
development task. These TDTs are defined as 'a group of at least two teachers, from the same or related subjects, working together on a regular basis, with the goal to (re)design and enact a (part of) their common curriculum'. The characteristic that defines a TDT is, in the first place, the specific and central design task. While other teacher collaboration goals such as professional development or building of cohesion in the staff are seen as part of the main design goal and contributing to it, they are not the main focus of the teams' work.

\subsection{TEACHER COLLABORATION IN CURRICULUM DEVELOPMENT IN SCHOOLS}

While the literature on curriculum development and design is quite prolific (see discussion earlier in this chapter), there is little consideration of collaborative processes (of teachers) in relation to curriculum design endeavors. In Gustafson and Branch's' discussion of a variety of models (2002) this is not discussed. The subject of cooperation is limited to the assertion that in some forms of curriculum development, depending on the expected product, the process might be undertaken by a single developer or a team. This is not elaborated on in the models discussed and is not developed further.

Walkers' deliberative approach (1990) to curriculum development is probably the most explicit in its discussion of cooperation between different stakeholders in the design process. Walker studied how design processes occur in practice in order to give a depiction of how and what works. He asserts that the process of curriculum development is rooted in formulating a 'platform of ideas' which are then the basis for development of curricular solutions. This platform, whether initially present or in development, forms the basis of deliberation between the participants. The deliberation is concerned with generating and weighing different options. When that has been done, design is initiated in which the plans are translated into concrete materials. The design phase in itself is therefore not necessarily a collaborative action-it is concerned with executing that which had been 'deliberated' before it. It does not provide guidelines for collaborative curriculum development. While this might make the model less fitting to use as a concrete guideline to collaborative curriculum development in schools, it stresses the importance of coming to a "platform of ideas' which is common to the participating teachers in the collaboration process and not only the 'tinkering' with teaching materials. 
McCutcheon (1996) concludes that because of the multitude of layers and factors playing a role, collaborative curriculum design is difficult to capture in models. Specifically the cyclic nature of curriculum design and deliberation in a team make models practically useless in her opinion. This assertion, together with the lack of existing models aimed at this collaborative process, leads to the conclusion that procedural models might not suffice in this case. Collaborative curriculum design might better be captured in several guiding (design) principles that teams need to follow and not in detailed models of action.

The discussion of guidelines for the work of TDTs is structured on the basis of the dimensions of SBCD of Marsh et al. (1990) described in section 2.1.3. The dimension 'Persons involved' from the model corresponds with the discussion on the conditions that are needed at the team level when approaching collaborative curriculum development (section 2.3.1). Both the teams' characteristics and the initial manner in which they should organize their work are discussed. The dimension 'Type of activity' corresponds with the exploration of the guidelines for the (design) approaches and activities, which are conducive for the work of the team (section 2.3.2). As the timeframe for the work of the teams in a school-based reform is highly dependent on the school organizational context and the possibility it offers, the dimension 'Time commitment' is part of a complex of conditions, namely the organizational conditions (section 2.3.3).

\subsubsection{Conditions for collaborative curriculum development at the team level}

Characteristics of teams

The first level of looking at teams is their structural characteristics: their composition and background. There are few clear conclusions and advice about these elements for TDTs. This might be due to the fact that research on communities (with or without relationships to curriculum development) is spread over a large variety of different forms of teams ranging from two teachers to whole school teams and having diverse goals. Nevertheless there are some usable insights from research on professional learning communities that might be applicable to the case of TDTs.

The first issue is that of participation. Should the teachers in the team all be volunteers or should there be an element of obligated teacher participation in 
teams? On the one hand, Fullan (1993) asserts that all persons involved in school should be agents of change in the process. On the other hand, Skilbeck (1998) points out that as talents and interests vary, and as there are different kinds of development tasks to perform, matching procedures are inevitable, meaning that not all teachers need to be actively involved in all curriculum development tasks. Erickson, Branders, Mitchell and Mitchell (2005) go even further and suggest that although participation should be broad and stable, it should be voluntary because of the demands of the work. These suggestions are not contradictory per se. Variation in participation remains supportive as long as all teachers are involved in one way or another in some (parts) of the development process of the new curriculum, create a consistent environment for the learners, and feel responsible for it. Hargreaves (2003) also recommends a combination of broad participation based on collaborative culture and agreements on the goals (professional learning communities) and some 'forced' collaboration-depending on the context and situation. He does warn against trying to force collaboration in a situation where there is very little agreement on the goals of the work. This leads to 'contrived collegiality' which is counter-productive. Findings from studies suggest that voluntary participation is recommended. However, this might lead to only partial participation of teachers in the reform process. As school-wide reforms demand broad participation, this might mean that they will then be doomed from the start if relying on volunteers only (Cordingley, Bell, Evans \& Firth, 2005; Grossman et al., 2001). For this reason, it is recommended starting the process with some mandatory change and participation and supplementing this with support for the teams so that a sense of ownership will develop.

The second issue to be dealt with is that of subject composition of the team. Should teachers in the team teach the same or diverging subjects? This would to some extent be dictated by the specific circumstances of the school and its reform goals. A school striving for more integrated curricula would more naturally choose teams composed of teachers from different subjects in order to achieve integration. However, other considerations may play a role here as well. Teachers, who collaborate on the renewal of their curriculum, may initially feel a loss of individual freedom that enables then to act on personal preferences unexamined by colleagues. On top of that, group settings more readily reveal possible uncertainties of the classroom. Therefore, to collaborate effectively in a TDT, teachers need to feel the following (cf. Hargreaves, 2003; Little, 1990): 
- that they require each other's contributions in order to succeed in their own work;

- that they are inspired by new perspectives that their colleagues from (especially) other subjects bring to the design floor;

- that there is a fit to some degree between naturally occurring teacher relationships, and the artificially constructed links that are introduced (or imposed) in the service of improvement initiatives.

For these reasons, it also seems preferable to compose teams of teachers from possibly different but related subject domains.

Considering the issue of team composition, Thomas et al. (1998) also reminds us of the difference between how experienced and beginning teachers work in such teams. Experienced teachers who have long-standing norms of privacy and isolation have the most at stake in these teams - both to gain and lose. They have often more difficulty with giving up their autonomy in favor of collaboration. However, when they buy into the idea of community and reform, they are often most able to capitalize on that and enact it and therefore have the most impact on practice. New teachers are less socialized in the tradition of isolation and privacy and therefore exhibit fewer problems with collaboration. On the other hand, being new to the profession, they still deal with other concerns, mainly those of coming to terms with class management (Fuller, 1969). (Beginning) teachers start on a new venture with concerns about self, then about the teaching task, and finally about the student learning. This will impact the focus of teachers in the context of collaborative curriculum design. Since they are still more concerned with issues of their position as teachers and classroom management issues, pedagogical issues and student learning will not be the focus of their work. Additionally, new teachers often lack experience with different learning arrangements and groups of students. This might hinder then from considering other curricular matters on a more general level. Participation in communities might help new teachers to be introduced into the profession by being exposed to considerations and work of other, more experienced teachers.

Related to the composition of the team is the issue of team background. Should teams with a common history and past cooperation be preferred? Or should newly formed teams with little common past experiences be favored? This will partly be dictated by the content and form of the school reform efforts. When schools strive for integrated curricula by making a transition from the traditional subject-oriented curriculum, at least some new teams of teachers who have rarely cooperated in the past will be formed. Common sense can lead 
to the conclusion that, considering the trust levels and cooperation skills needed in the design process, it might be advisable to have a team whose members know each other and has already had some experience in cooperation. At the same time, teams who had already cooperated in the past might have some negative experiences which will obstruct further cooperation rather then help it (Grossman et al., 2001). It might, therefore, be advisable to consider the former work relationships of teachers in the team. When there are some strong negative experiences, further cooperation can be difficult if not impossible. However, there seem to be few clear guidelines on this issue.

Another issue of team characteristics is the size of the team. This issue remains rather arbitrary, as it (to a certain extent) depends on the existing patterns within a school. An extensive review of collaborative initiatives in schools done in Britain concluded that smaller teams are more effective in achieving impact on curriculum (Cordingley, Bell, Evans et al., 2005). Hord (2004) also concludes that smaller size and physical proximity of the team is advisable. But Hord, dealing with school-wide communities, refers to the school as a whole and considers groups of about 20 to 40 teachers as small. Thousand and Villa (1993) recommend teams of four to six teachers. According to them the team is then large enough to have a variety of viewpoints and knowledge that can lead to fruitful discussion and work. At the same time it is small enough to allow for everybody in the team to participate in the work. They conclude that considering the number of members, the more cohesive and unified the team is to begin with and the more they share a common vision, the bigger the team can be and still be effective in their work. Eventually, there is some common sense in the message that the team needs to have at least two teachers (preferably more, to stimulate diversity in experiences and perspectives), but no more than about six to maintain a workable organization of collaborative, content-related activities.

\section{General organization of the collaboration process}

In considering the initial organization of the work of the team there are few direct resources that deal with teams that attempt collaborative curriculum design. Some of these organization conditions are dependant on the school context (such as availability of time and resources). These are discussed further in section 2.3.3. In this section the focus is how the collaboration work of the team should be organized in general. 
Considering the work of teacher teams that have specific reform tasks Thousand and Villa (1993) stress the importance of keeping track of the work of the team through minutes taking and task lists. In addition to helping to structure the work of the team and make it efficient it also makes individual work of teachers visible and therefore allows for accountability within the team. According to them, the monitoring and assessing of the functioning of team members should happen on a regular basis. Mohrman and Wohlstetter (1994) add to this that the team as a whole should have clear performance-related criteria for their work (see also Hargreaves, 2002). This helps the team to concentrate on their common goals instead of teachers concentrating on their private concerns. These criteria should be used periodically to assess the teams' work.

These conditional factors of the characteristics of the team and the organization of its work are necessary and might be conditional for their work but they are insufficient (Grossman et. al., 2001). Eventually it will be up to the kind of activities the team undertakes and how they interact that will determine the result of their work. This is discussed in the following section.

\subsubsection{Guidelines for collaborative curriculum development process}

Searching the literature for concrete guidelines for the work of teachers' teams with or without a clear design task yields a varied result. Most of the guidelines refer to teams or communities in general and are often discussed in broad terms. Many authors describe general guidelines for the work of communities. In most cases they are similar to the community components the authors describe (e.g. Hord, 2004, in which the community's components are the development guidelines for the community). Grossman et al. (2001) try to come to more concrete guidelines that should develop as communities mature in their work:

- Formation of group identity - the teachers have to form a group identity in which they develop from a collection of individuals and subgroups to one group. In this process individuals are initially interchangeable, but as their individual contribution grows they become a part of the teams' fabric. The team members need to assume communal responsibility for the work of the team in contrast with individual responsibility to the personal actions.

- Navigation of default lines and conflicts-learning to use conflict and differences as being productive. While these are initially hidden and often even denied, these need to be brought into the open and be used to encourage 
discussion and production. Rousseau (2004) adds the distinction between conflicting views of teachers in the team and conflicts between the values of the innovation and those of the current (team) practice. She asserts that avoiding the discussion and reflection on these conflicts leads to a partial implementation of an innovation and the retreat of the teachers to their old routine.

- Negotiation of essential tension of development-learning to balance the focus of the development between the students and the teachers. The team has to come to a common perspective in which both are addressed.

- Communal responsibility to individual growth - the team needs to develop a common responsibility of the members to the work of other participants. Whereas in the beginning each teacher contributes on an individual basis in a community, here the teachers not only contribute themselves but are also sharing responsibility for each others work.

These principles concentrate mainly on the interaction and learning in the community itself and are not concentrating on the (design) task the community in and of itself has in relation to the school. These principles are also still at a high aggregation level referring to abstract concepts and giving little direction to the work of teams in practice.

One clear consensus seems to be the need for a clear instructional focus of the work in the team. This can be subject matter (Little, 2002), the issue of how students learn (Ericson, 2005; Hord, 2004; Stoll et al., 2006), and the students' achievement (Vescio et al., 2008). Little (2002) refers to elements that are discussed among teachers as 'collaboration points' that create a focus in the team and can create discussion and interdependence. According to her "conversations that do not regularly deal with the complex relationship of teaching, learning and content will fall short of the pursuit of high school reform" (p. 710). This will seriously constrain efforts in transforming education. At the same time, the findings of De Kock, Sleegers and Voeten (2005) show that teachers often concentrate on the organizational issues of their practice. Looking at choices teachers concentrate on while arranging their curricula in both traditional and reform environments, they found three elements teachers focus on:

1. Division of teachers' and learners' role during the interaction.

2. Learning goals of the learning arrangement, mostly being content acquisition.

3. Learning materials to be used - the schoolbook is and stays a prominent tool in the eyes of the teachers. 
This is foremost in their thinking about their 'new' practice. Applying Van den Akkers' (2003) curricular spider web (see section 2.1.1 of this chapter) to these findings it seems that teachers concentrate less on the central part of the web (the rationale) and more on the concrete manifestation of the work in the form of teaching materials (Materials and Resources) and their role in the interaction (Teachers' role). When teachers redesign their practice in line with a wider reform vision, De Kock et al. (2005) also noticed that teachers have difficulties in addressing these reform goals that divert form their current practice. Apparently they do not have clear images of these learning goals in practice and therefore have difficulty in envisioning them. This could also be due the changing structures that are often introduced alongside educational reforms. Teachers participating in educational reform can then become preoccupied with the structural aspects and their attention is then drawn away from the teaching and learning conditions needed to make these structures actually effective (Imants, 2002).

Visscher and Witziers (2004) find that an instructional focus is not sufficient in this context. They found that communities which concentrate their work on evaluation aspects have the most potential to impact the learning results of students. These teams ideally make an explicit connection between learning goals and the teaching process, make the prioritization of the goals explicit, have a clear policy as to how they will evaluate their work and act upon that evaluation both in the team as with the students. They see this as a departure from the 'softer' approach to team work that stresses reflective dialogue and sharing of materials and visions as the main instrument for change as discussed above. At the same time, the approach they offer is aimed at evaluating and adapting existing practices and not at setting up new goals and projects. Additionally, even if you apply this 'harder' approach to the process, the curriculum development process still needs to take place, and there are few solid guidelines for this. Finally, the evaluative approach to curriculum reform might be threatening to practitioners and therefore it presents its own difficulties and limitations.

But even in the 'softer' approaches the instructional focus of the team is not enough on it own. The specific focus (the problem to be solved, the reform to be realized) needs to have a relevance to the members of the team and meet a real and existing need of the individual participants and the team as a whole (Ericson, 2005; Thousand \& Villa, 1993). This is not a constant element and needs to be guarded during the process by repeatedly examining and negotiating the goals of the team (Thousands \& Villa, 1993). 
Within this instructional and relevant focus, common experiences seem to play an important role in inspiring the teachers and creating a common ground on which teachers can work. On the one hand, teams need many external inspiration sources in the form of experts, visits, and training sessions (Friedman, 1997). A necessary component in relation to these external inspiration sources is the need to be combined with reflection on these common new experiences. This develops the relationships in the team and also brings in new information and inspiration for the team which can be used in their new design. On the other hand, teachers need to also have common experiences in their own context (Cordingley, Bell, Thomas \& Firth,, 2005; Grossman et al., 2001). This can be in the form of observing one another (Cordingley, Bell, Thomas et al., 2005) or in teaching together (Friedman, 1997; Grossman et al., 2001). Common experiences support the creation of a common history, cohesion and relationships in the team, and create a basis on which the team can build. This relationship dimension is seen as associated with effective community work (Louis \& Marks, 1998). At the same time, teachers seem to prefer to cooperate in preparation and discussion rather then in teaching (Supovits, 2002; see section 2.2.5). Therefore, these common experiences need to be created and encouraged during the reform process itself. An approach that brings the creation of common experiences with new inspirational input together is collaborative piloting or experimenting with new approaches and teaching methods. This kind of work is associated with having a high impact on teacher and student change within collaborative reform initiatives (Cordingley, Bell, Thomas et al., 2005).

Although it is important to define the focus of the team and create common experiences, it seems that the initial predispositions teachers have towards curriculum work directly affects the perception of the process and product to be created (Kimpston \& Rogers, 1988). Accordingly, much should be invested in the introduction and preliminary stages of such initiatives to make the goals of the team clear and to explore how they relate to the predisposition of teachers. Then some match can be made, either in the goals of the team or in the expectations and role of the teachers. Next to the match between the goals of the reform process, the team as a whole, and the predisposition of the teachers, the 'unit of change' which teams handle at any given moment should be of a 'human scale' (Leat \& Higgens, 2002). Leat and Higgins refer to the fact that sometimes teams are asked to realize far-reaching reforms across the whole of their curriculum. Trying to change all at once seems to be a task beyond the 
capacities of most teams. They suggest breaking reform into units that are more easily accessible to manipulation, experimentation, and observation. By doing this, the teachers can deal with change units step-by-step, which is more manageable. The size of these units will probably differ between teams, depending on their capacity to handle change. This finding of Leat and Higgins (2002) can be interpreted in two ways. On the one hand this can mean that the process of change itself should be broken down into smaller units, thus proceeding through the reform in a systematic manner. On the other hand, this can be taken as to refer to the reform work itself. This will mean that the reform itself should be limited in its scope. Either way, they imply that reforms need to be dependent on the teams themselves and should be modest in their demands for changes that teams can realize.

Finally, the sort of interaction and cooperation that takes place in the team needs to be substantial and meaningful. Little (1990) proposed a taxonomy of teachers' cooperation (see section 2.2.3). According to her, cooperation can vary from superficial (storytelling) to deep (joint work). The latter implies some kind of team work of teachers. Although Little's taxonomy refers to interaction between individual teachers in school, it can also be used when looking into the work of the team itself. While Little describes naturally occurring patterns, in many schools (such as the schools described in this dissertation) groups are organized with the goal to work together on a school-wide reform. But this organization in and of itself does not guarantee 'joint work'. It might be possible that a team that is organized and expected to cooperate limits its interaction to a form of storytelling or helping one another and do not go as far as actually working jointly. This could limit both their learning and work process. In line with Little's' finding it thus seems advisable that cooperation in teams would move further than only this superficial level of interaction.

There are few guidelines concerning the specific way in which teachers' (design) teams ought to operate. Aside from the discussed elements of the kind of cooperation and the general guidelines for work discussed in this section, it is difficult to find concrete guidelines to follow the day-to-day working of the teams. It is, therefore, also the intention of this study to describe the reality of the teams' work on a day-to-day basis: who participates in the daily meetings and in what capacity? What do they discuss? Why do they meet and what is their general orientation? When and where do they meet? This last element is 
directly dependent on the organizational conditions in the school. These organizational conditions will be discussed in the following section.

\subsubsection{Organizational conditions for collaborative curriculum development}

The teacher design teams that are designing their curriculum interact with their environment. The way that environment (the school) is organized and the way in which it tries to influence the work of the team directly and indirectly has an impact on the process of the team and, therefore, their result. Recommendations about organizational environments found in literature on teachers' communities can be organized into four categories. First is the kind of infrastructure that the team is provided with. These concern the material conditions given to the team in order to facilitate their work. Second is the kind of professional support that the teams get. This can be in the form of a coach, expert, or any other access to information that supports their work. Third is the coordination mechanism that schools have/provide in order to align developments in the team with other developments in the school. In the context of a school-wide development this can consist of coordinating the developments between different teams and between the teams and the school concept. In schools where the reform is not a school-wide process but is limited to one or two teams, this can mean aligning the developments and wishes in the teams with those outside it. The fourth category consists of the role of the school/track leader in relation to the team. This can be in their interaction with the team as well as in the way that they provide a framework for the work of the team.

In this study the cultural conditions in the organization are not discussed. This is not due to a lack of importance. Culture in the organization can inhibit or enable actions of teachers (Hargreaves, 1995). At the same time it is difficult to manipulate it in the short term (Fink, 2000). Therefore, when one considers using TDTs it is not a matter of 'supplying' a kind of culture for its work, but more a matter of trying to asses the culture in school to see if work in teams has potential in this particular culture. In the following section the four categories that have been introduced are discussed more extensively.

\section{What infrastructure is needed?}

Discussion on the infrastructure needed for the work of teacher teams often comes down to the time element (Hord, 2004; Kruse \& Louis, 1997; Louis, Marks \& Kruse, 1996). All authors agree that teams need to be facilitated in time to meet and work together. As school systems and schools differ there are no concrete 
guidelines on what this exactly entails. As the work of the teams described by the different authors and encountered in practice also differs it is questionable if there is a point to describing it in more specific terms. It seems reasonable that the time they get needs to be proportional to the design task of the team and their experience with collaborative design. The greater the design task and the less experienced the teachers in the team, the more time for work is needed. Thousand and Villa (1993) make two additions to the time element. First, they contend that the time available to the team needs to be scheduled at regular meeting times in which the teams come together. This schedule needs to be held almost sacredthe schedule should not be changed regularly and meetings should not be canceled to accommodate for regular school activities or meetings. Additionally, all the teams' members need to attend most of the meetings. Attendance should be recorded in order to create, at least initially, an obligation to participate. At the same time Thousand and Villa (1993) state that the meetings themselves should be limited in time. They should not be too long as teachers have other duties they need to attend to and the kinds of activities required of the teachers in these meeting are very demanding (critically considering and redesigning your practice). Therefore, there is a limit to what teachers can do in one meeting. Unfortunately Thousand and Villa do not specify what that limit is.

\section{What roles and forms of external support are needed?}

In some cases schools provide teams with external coaches to assist them in their task. An extensive review of research on the collaborative and individual continuous professional development projects in schools conclude that in both the role of external expertise is crucial in providing important information to the teachers and therefore assisting their development and their work on school reform (Cordingley, Bell, Evans et al., 2005; Cordingley, Bell, Thomas et al., 2005). The kind of contribution needed is two-fold. On the one hand the knowledge that coaches bring into the teams is of great importance. In fact, external support that is explicitly used for its specialist expertise is associated with an effective collaborative learning process (Cordingley, Bell, Evans et al., 2005; Cordingley, Bell, Thomas et al., 2005). Coaches bring into the team often new 'formal' knowledge and up to date developments (Erickson, Brandes, Mitchell \& Mitchell, 2005). This gives the team new options and venues for development, and enriches the discussion in the team. Not only is this helpful in the discussion and work itself, but it also helps teams in the justification of choices and the production of theoretically defensible curricula (Johnson, 1993) thus helping the team with the increasing demand for accountability. 
Coaches also have an important role in supporting the work and collaboration process of the team. Teachers that are new to intensive collaboration have few tools to use and little competencies for structuring the work of the team and solving difficulties they encounter in the design process or their work as a team. The coach therefore has the role to help the team in this encounter. Grossman et al. (2001) show that as communities threaten to split into subgroups of like minded people within the community while maintaining the 'façade' of a team, a coach can identify these processes and help keep the team together by addressing these issues. Rousseau (2004) suggests that the coach has an important role in facilitating conflict handling in the team (between teachers in the team and between the innovation and current practice). This facilitation should both bring these conflicts to the surface of the team work and resolve them in a fruitful way. Because the coaches are outside the school culture they can mediate conflicts in different ways than those inside as they are not bound by existing behavioral patterns (Thomas, Wineburg, Grossman, Myhre \& Woolworth, 1998).

Considering the work of an external coach with teacher teams, Erikson et al. (2005) address three necessary points in the coaching's process. First, there should be an agreement on the purpose of the common work. Although this seems obvious, that is not always the case. Teachers and coaches often bring other agendas to the table which can hamper the work. The external coach has an educational vision and agenda and wants to see teachers develop in a certain direction while at the same time empowering teachers to shape the reform. These same teachers might make other choices than the coach. The way the coach and teachers perceive their role in the work of the team might also differ. Second, the ownership of the team agenda and daily work needs to be decided. Does the coach steer the meeting and decide what is discussed or do teachers, depending on their needs at that moment, steer the process? While there is no clear recommendation here on how this should be done, this should be discussed. Third, external coaches bring the role of 'formal' theory into the work of the team. This might be a source of conflict as teachers need time to reconcile the coach's theoretical perspective and their practical perspective, shaped by experiences in the classroom.

What coordination mechanisms are needed in the school?

When there are one or more teams within a school working on a reform project, there is a need for cross-over structures to create exchanges between the teams which do not occur naturally. The connection between teams is important in 
order to reduce the potential negative consequence of a rigid team structure that can lead to fragmentation as teams concentrate on their own goals and work and lose sight of other developments (Kruse \& Louis, 1997; Witziers et al., 1999). It seems that when these interactions are not facilitated, teams concentrate on their internal developments and process and do not seek new information from other teams in the school. This might be due to what Berger, Boles and Troen (2005) describe as miscommunication between teachers. On the one hand, outsiders of a specific team think that the team, when encountering something interesting, will inform them ('if it was interesting, they would have told us'). On the other hand, the teachers in the team are waiting for the outside world to show interest in the work of the team ('if they had been curious, they would have asked us').

Kruse and Louis (1997) suggest a central decision making group that attends to cross team issues as a major vehicle to coordinate and create cohesiveness in the reform process. This is then a cross-team decision making structure which should consist of both formal and informal components. The formal component is made up of a coordination team which discusses cross-team decisions. But as formal cross team structure cannot mandate communication, the informal component is of crucial importance. There is a need for multiple opportunities for informal communication. This can be done by matching teams that are struggling with similar problems or can help one another or by creating ad-hoc committees and study groups on a specific subject. This should be done by an actor who has an overview of the subjects that occupy the different teams.

Another team-coordinating aspect is their autonomy level. Scribner, Sawyer, Watson and Myers (2007) suggest that if teams have too narrow a purpose and high independence from other developments in school, they can narrow their focus to instrumental and procedural issues and avoid fundamental issues which are common to all teams. Isolation from other teams due to high autonomy does not challenge the team to consider other options and therefore hampers the creativity of the team. It can therefore lead to a replicative reform process that leads to applying only known solutions to the design problem and not rethinking the logic of the solution.

What are the roles, responsibilities and activities of the school and school section leaders? Considering any reform effort in school, formal leadership has an important role. Although the teacher is seen as central in the process, school leaders need to play a variety of complex roles from the designer of the school structure to facilitator of teachers' work (Kruse \& Louis, 1997). Silin and Schwartz (2003), writing about 
leaders of reform in school, contend that they play a crucial part in mediating between teachers and the external world. In this, they fulfill three major roles:

1. Strategist-helping make the connections between the outside demands and the wishes of the teachers themselves. Reconciling the difference and mediating.

2. Translator - translating the reform demands to the teachers' practice and simplifying them.

3. Advocate-representing teachers' professional interests with the administrators and others outside the classroom.

Although Silin and Schwartz (2003) do not directly refer to these reform leaders as school leaders, they refer to these actors as formal leaders within the school. These roles can be a part of the work of the school leader or delegated to a separate individual in the school. In the context of this study, the role of leader is assigned to the formal leadership level above the teacher teams. This implies that in the context of the Dutch lower secondary reform, the leader of the lower secondary subunit of the school, or in some cases the leader of a certain track of this subunit, is regarded as the leader. This is done because this layer of leadership is the one that the teacher teams encounter most often and it is responsible for the daily management of their work. Later in this section the term leader is used to describe this management layer.

The roles of leaders can be seen in two ways: That of an organizational facilitatormanaging the 'technical side' of reform - and that of a cultural agent that needs to re-culture the school and inspire the teachers. The latter can also mean that the leader addresses the 'technical side' to enable or discourage certain behavior.

Considering the role of facilitator it seems that change efforts in school should address explicitly the choices teachers find central-materials, teachers' roles, and content (de Kock et al., 2005 - see section 2.3.2). Therefore, the facilitators should concentrate their effort on these elements, both in setting the reform framework and in making sure that teachers have the means to work on these: funds to develop or buy new teaching materials, possibilities to explore new roles in their teaching and interventions that concentrate on these elements. In this respect, Silin and Schwartz (2003) touch on a continuous tension that exists in this leadership role. The leaders need to enable two possibly contradictory demands in their facilitation. They need to enable teachers to try out and develop new ideas, on the one hand, whilst still maintaining the work of the school in the 'old' 
system, which might be contradictory to the reform goals, and even, by its nature thwart any change at all as it is aimed at securing stability. According to them, this is a paradox that needs to be engaged through the entire reform process.

Considering the leader as a cultural agent, much is expected of the leader as the one who brings about cultural change to enable team work by the teachers. This is true both prior to the initiation of team work at the school as well as during the team work, through interaction with the team (Friedman, 1997). The leader can do this by creating the kind of conditions that foster commitment and trust between teachers that enable collaboration and learning (Stoll, Bolam, McMahon, Wallace \& Thomas, 2006). These material conditions need to go hand in hand with the human side of leading as Stoll et al. put it. Because change is complex and brings about uncertainty, the leaders have to provide a kind of emotional support for the staff. This refers to the need of teachers to be heard and understood in the school. This can hardly be captured in an organizational structure but is greatly dependant on the personal traits of the leader.

This subject is connected to the fact that there is a need for a leader who is a simulator and inspirator for the teachers when considering the reform. The leader should project vision and a personal attitude towards reform as a whole and the specific reform the school is striving after (Geijsel et al., 2001). This is not only important during the beginning of the reform but also during the process, as the leader needs to keep reminding the stakeholders of the goals and visions of the reform (Hord, 2004). The buying-in of the leaders is of great importance because teachers are more likely to buy-in when they believe that leaders support the reform (Turnbull, 2002). Sandholtz and Scribner (2006) warn us, though, that this buy-in cannot be 'acted' as it becomes exposed in the actions of the leaders during the reform and would lead to the teachers returning to their older work patterns.

In this context the position of the leader in relation to the team is essential. Leaders need to resolve several dualities in the role they have in relation to the team process: - Insider vs. outsider - on the one hand, they should be facilitators of the team processes, supporting them from within, but at the same time, they cannot be 'just another' team member. This is important because they need to recognize and articulate conflicts in and around the team without being a part of them (Kruse \& Louis, 1997). 
- Collegiality vs. authoritarian-owing to the culture change literature, a collegial approach when fostering a collegial culture seems more relevant. At the same time, as part of the school structure, power differences stay. Even collegial leaders need to sometimes invoke authority to get things done that would not happen when left to free will. (Lieberman, 2001).

- Bottom-up versus top-down processes-leaders find themselves in the paradoxical position of espousing the importance of bottom-up change and encouraging reform by the teachers but at the same time working in situations

they themselves have entered through administrative fiat, delegating authorities to others, or other more subtle forms of top-down processes (Silin \& Schwartz, 2003). In any situation, the extent to which power is distributed to teachers is disputed. Especially in cultures of high accountability, the ultimate responsibility would always rest with the principal (Muijs \& Harris 2006). So in this sense bottom-up processes are limited.

Considering this, Sandholtz and Scribner (2006), while researching alternative modes of reform and professional development, found that leaders over time revert to traditional reform approaches although they set out to encourage alternative processes. Although the leaders adhered to the alternative model, their actions adhered to something else. Sandholtz and Scribner offer several reasons for this divergence:

- a desire for control by the leaders;

- a narrow view of teacher expertise held by the leaders;

- pressure to increase standardized student results which leads to quick fix solutions and lack of substantial processes. This plays a major role in current American policy.

\subsection{FRAMEWORK FOR DESCRIBING COLLABORATIVE CURRICULUM DEVELOPMENT}

The concepts described and elaborated in this chapter and seem important for the collaborative curriculum development process led to the formulation of a conceptual framework for the description of the work of each of the teacher design teams in this study. The intention of the study is to add to the insights concerning the concepts included in the framework. This framework consists of four elements: 
1. Description of team characteristics.

2. Description of the curriculum design process in teacher design teams.

3. Description of the organizational conditions of the teams (consisting of infrastructure, coordination, support and school leadership).

4. The curricular results of the team.

These elements were the basis for the observation, interview and analysis instruments that will be further discussed in chapter 3. These descriptive elements are also the basis for answering the research questions of this study. In this section, the elements of the conceptual framework are discussed in light of the theoretical notions in this chapter.

\subsubsection{Description of team characteristics}

Based on the discussion in section 2.3.1 and 2.3.2, eight team characteristics description categories were formulated. They provided a report of the starting point of the teams being followed in this study. These categories were:

1. Subject area(s) - team subject compositions.

2. Size of team - number of participating teachers and subject affiliation.

3. Common team history/curriculum-common practice (if any) and past experiences with team members.

4. Background of team members - experience, reform ambitions, cooperation ambitions - a registration of the individual characteristics of the different teachers participating in the process; their background in the schools and in education, their personal reform goals and their goals for the cooperation with their colleagues.

5. Teams' perception of collaboration - task and process - a registration of the common perceived teams' task and how it relates to the perceived reform goals. This included the expectation of the teachers towards the development course of the team.

6. Formal team structure-what was, if any, the intended work organization including role division, plans for the meetings and the development work?

7. Planned external support-what external support, if any, was expected to be available for the team during the development process?

8. Initially provided means - what were, if any, the planned time and funds made available for the teams for their work? 


\subsubsection{Description of the curriculum development process in teacher design teams}

For the description of the curriculum design process in the teams themselves, categories were formulated based on several discussions. Initially, based on section 2.1.1 and section 2.3.2, several categories based on curriculum typologies and curriculum development processes were defined.

1. Development activities - the first category is an open description of the activities teams undertake.

2. Curriculum development stages - based on the five general stages of curriculum development (analysis, design, construction, implementation, evaluation) the different activities and discussions in the teams were described.

3. Curriculum components in discussion and work-the different activities and discussions in the teams were described on the basis of ten curriculum components (rationale, objective, content, learning activities, teachers' role, materials, grouping, location, time, assessment).

4. Substantive consideration-the different activities and discussions in the teams were described on the basis of the substantive considerations that can be made in curriculum discussion (subject, society or student).

5. Main quality considerations - the different activities and discussions in the teams were described on the basis of different curriculum quality criteria considerations that the teachers make in the process (validity, practicality, effectiveness).

Next, several categories were added based on the insights discussed in section 2.3.2 considering the general guidelines for collaborative curriculum design.

6. Sequence of activities - this is an analytical category that examines patterns in the described activities. Based on the other categories and the meetings description, recurring patterns in the work of the team are described.

7. Place of activities - this descriptive category refers to the location of the teams' work on the collaborative development task. Because the location is often related to the schedule of the meetings, some reference is made to the time in which the activities take place.

8. Participants and their role-this category is based on the taxonomy of collaboration discussed in section 2.2.3 on levels of cooperation (story telling, helping, sharing materials and joint work) and extending it to the nature of the joint work itself -is it about ideas, materials of the practice itself. It also notes the participants in the different activities, their role in the team and the extent to which the roles are formally or informally divided. 
9. Work orientation-this category covers how teams related to the general reform framework and school organization in their work and the motivation for the actions. This element was described in relation to the process as a whole and for specific motivation for specific meetings and activities.

10. Organization of work - this category is similar to the organization category under the 'team characteristics' section. The difference here is that the organizational aspects of the work (planning of activities, structuring of activities, taking minutes, etc.) is related to the developments during the work of the team and not to the planned process as teams depicted in the initial phases.

\subsubsection{Description of the organizational conditions of the teams}

Following the categories defined in section 2.3.3, during the process, several elements of the environment of the team were observed and registered. This meant that in team activities and interactions with the teachers these elements were explicitly registered, and when needed, discussed with the teachers in the teams.

1. Infrastructure-what resources in time and funds were provided to the team? If the team experienced changes in these elements this too was noted.

2. External support and role of researcher in work of team - what was the role and involvement of external support in the team meetings? What, if any, was the involvement of the researcher? And how did these two vary?

3. Coordination mechanisms $\mathcal{E}$ contact with rest of school/teams-what is the relationship between the team and other teams in the school? Is there any explicit or implicit indication for contact with a specific teacher, team or other organizational unit? Is a need for that indicated in the team meetings? Which formal coordination mechanisms are realized by the school and how do teachers perceived their function?

4. Role of school leaders and school-wide framework - what is the relationship with members of the school management team (depending on the context varying from school section leader to school leader)? What do they do when and if they are present in meetings? How are their (in)actions discussed in the team and how do they influence their work? Additionally, how do the teams interact and refer to the reform framework? 


\subsubsection{Description of the curricular results of the team}

Finally the framework included the result of the work of the TDTs. These are based on the curriculum typologies presented in section 2.1.1. They capture the main characteristics of the new curriculum and some insights from section 2.2 considering the possible benefits of collaborative curriculum development in relation to teacher and school.

1. Appraisal of result by participants and by other stakeholders-how do the practitioners involved think about the result of the collaborative work? What are its stronger and weaker sides?

2. Relationship with reform goals-how do the (new) materials compare to formulated goals on school and team level?

3. Main differences with former curriculum - how do the (new) materials compare to curriculum at the start of the process?

4. State of product-how far have the materials of the teams been developed? Are they written, implemented, attained, evaluated or has the team failed to reach a certain product?

5. Perception task and goals - at the end of the year, what is the perceived teams' task and how do teachers see their role in it? This includes how teachers perceive the reform goals at the end of the year.

6. Perception of process and reform-how do the teachers look back on the development process? What were the stronger and weaker points and what, if any, was the added value of the collaboration?

7. Personal gains - what was the personal benefit of the development process for the involved practitioners? What did they gain from it? These gains can vary from specific gains in content-related domains to general effect on teacher attitudes. 


\section{CHAPTER 3 \\ Case study design and methodology}

This study is a descriptive and interpretive study aimed at analyzing the work that TDTs undertake in schools and identifying those activities and conditions that are specifically conducive or hindering for teachers in reaching their curricular goals. This was done by applying a case study approach in which TDTs were central. Section 3.1 gives a description of the research questions in this study and their background. In section 3.2 the case study approach applied to answer the research questions is stipulated. Following this, Section 3.3 discusses the specific research instruments and methods. Section 3.4 describes the analysis procedure followed in this study, explaining the different stages. Finally, section 3.5 discusses several measures that were taken to increase the quality of data collection and its interpretation.

\subsection{RESEARCH QUESTIONS}

The main research question presented and elaborated on in chapter 1 was as follows:

What are conducive (or hindering) approaches and conditions for collaborative curriculum development by teacher design teams in view of school-wide reform?

In order to answer the main research question it was necessary to explore three aspects of the processes undertaken by the TDTs: (1) the course of the curriculum design process itself, (2) the conducive and hindering activities that took place, and (3) the conducive and hindering conditions that the team experienced. Based on this division, three lines of inquiry were formulated, each resulting in separate sub-questions: 
A. How do teacher design teams address and carry out collaborative curriculum development activities?

The first sub-question focused on the description of the activities and overall rationale that teams apply in their efforts to redesign their curriculum. This description included also the sequence of activities and the kind of curriculum considerations discussed in these teams. This was done by applying the conceptual framework described in chapter 2. In this framework, different perspectives of the collaborative curriculum development process and the background and results of the team have been stipulated. These were used in order to describe the activities in the teams. The process itself was described in detail according to the following questions:

- What activities were undertaken and what were their characteristics?

- When were activities undertaken?

- Where did activities take place?

- With whom were activities undertaken?

- Why were (specific) activities undertaken?

- How was the work organized/ structured?

Additionally, the overall rationale of the teams' work was explored from two perspectives. On the one hand, the explicit considerations made by the teams during the process of the design were examined. On the other hand, the patterns that emerged when teams were designing (the sequence of activities) were explored. Next, in the analysis phase, schemes of relationships were drawn between different aspects of the activities and the TDTs backgrounds and results of their work, thereby trying to uncover systematic relationships.

B. What are conducive (or hindering) approaches and activities for teacher teams engaged in this collaborative curriculum development process?

The next step was identifying the activities that were conducive or hindering for teachers and teacher design teams in their design effort. It was, in a sense, a first analysis of the collected process data. The main criterion for impact in this study was the extent to which the teachers themselves perceived the activities conducive or as hindering to their efforts to redevelop their common curriculum. The perspective of the teachers was supplemented by an analysis of the teams' work process as well as examination of the results of their work. The conducive or hindering activities were analyzed both on the level of specific design-activities and their direct results, as well as on the level of the overall design approach of the team. In this process analysis, the main criteria for 
conduciveness or hindering were changes in the work patterns of the team (such as an increase in frequency of activities in the team) and the formulation of crucial design decisions in the process. The two lines of establishing conduciveness were therefore as follows:

- teachers' perception of the design process and the specific design activities;

- change in the patterns of the design process and its content, and its influence on the results of the teams' work.

C. What school conditions contribute to (or hinder) the work of teacher design teams involved in a collaborative curriculum development process?

The exploration of the school conditions added to our understanding of the work of the TDTs as the cases (the teams) in this study are embedded in their context (the school and the reform). Their design process was therefore influenced by the conditions they experience. Specifically, four categories of conditions have been examined, based on the analysis framework (see chapter 2):

- infrastructure for the work of the team;

- external support;

- coordination/interaction with other teams or teachers;

- interaction with school leaders and school-wide framework.

These conditions were assessed to constitute the direct environment of the teams, the context in which they work. Beyond that, these conditions can be manipulated quite directly by school leadership. Therefore, gaining insights into the manner in which these conditions influence the teams has the most potential to be of use in school practice. Again, similar to sub-question B, this was done by exploring both the teachers' perspective as well as by conducting a process analysis of the influence of those conditions on the patterns of the design process and its results.

\subsection{CASE STUdy SETUP}

Collaborative curriculum design takes place within the context of the school. Under these circumstances, when the borders between the phenomenon and its context cannot be strictly drawn, a case study approach is considered to be most suitable (Yin, 2003). The cases in this study were the teacher teams redesigning their common curriculum within the context of the school organization and 
educational reform. Each case was built around one of the teams followed in the study. In regard to case studies, Miles and Huberman (1994) stress the importance of a well defined 'heart' of the study, focus of the study, and boundaries of the study. The 'heart' of this study is the TDT. This includes their activities and developments during the redesign efforts. Included in this study are the boundaries of the case, which are the organizational conditions confronted by the teams and their interaction with their professional environment in the course of the reform. Every case (team) was therefore seen in the context of its environment. This meant that the teams were studied within their natural context and those developments in the environment were seen as interacting with the team.

Qualitative research methods were used to explore the cases as the object of the study and the characteristics of the processes that were followed seemed better served by a qualitative approach. The object of study was broad and complex and touched on many different themes. It dealt with interrelating processes in a school context (curriculum design, professional development of teachers, and school development, for example). The relationship between the different themes has not yet been explored extensively in research literature, and therefore there were few theoretical frameworks to consider. Consequently this research was explorative in nature, open to various explanations and developments and aiming to capture different factors playing a role in the process. Additionally, a large part of the study involved describing and explaining a dynamic and evolving design process where great emphasis was placed on the perceptions and experiences of the participants. The circumstances and conditions for the work of the team were also constantly evolving. By nature, these processes and experiences are difficult to capture in a set scale.

The emphasis on perception of the participants in this study in describing and valuing the experiences is in line with narrative research tradition. Here, the stories of practitioners, and the manner in which they relate specific events to the larger picture, are crucial to understanding a phenomenon (Gergen \& Gergen, 1988).

The study was a 'multiple case study research' which was comprised of several case studies, nested in different school settings. The relationship between the cases (the teams) is that of 'theoretical replication' (Yin 2003). The assumption is that cases have some commonalities and many differences and that the differences might explain the different processes and results they show. An attempt was 
made in the course of the study to identify, understand, and explain these commonalities and differences, as well as determine their relationship with the process and results. In this way, multiple case studies offer the possibility to gain deeper understanding of processes and outcomes of the cases in their context and can give a better picture of locally grounded causality in the cases (Miles \& Huberman 1994). Case selection was done on three levels:

\section{First selection level: School sites}

The first selection tactic in this study was a theory-based sampling strategy (Miles \& Huberman, 1994). The main focus of the study, in line with insights from literature, was on schools that worked on a school-wide reform in which all teachers are in some way involved in a TDT and where there is a general or emerging organizational framework that teams needed to take into account in their work. Both school-sites in which the study was conducted (Copernicus High school and Kepler High School) represented this approach. Within this 'theory-based sampling' some opportunistic and convenience sampling strategies were applied (Patton, 2002). The researcher had information that the schools were initiating the reform projects. The choice to use two sites with some commonalities was made in order to validate the findings and see how diverging (although comparable) contexts influence the work of teams.

\section{Second selection level: Cases within sites}

The central perspective in this study is that of the teams. As different teachers and teams interact in a different manner within similar organizational conditions there is a need to follow multiple teams within the same context. It might even be the case that the nature of certain subject areas influences collaboration between teachers and the kind of curriculum solutions found (Hargreaves, Earl, Moore \& Manning, 2001). Although the difference between subject areas is not within the focus of this study, it seemed to add to the findings as different perspectives on the same issues could have been accounted for. In the case of Copernicus, all active teacher teams have taken part in the study. In Kepler a combination of several purposeful sampling strategies was used (Patton, 2002). First, some criterions-based sampling was applied. As the study focused on teams in their first year of cooperation, this criterion was applied when teams were selected for the case studies.

Additionally, the selected teams did not represent extreme or deviant examples (typical case sampling). Teams facing very extreme circumstances (for instance 
very bad collegial relationships or a very long history of collaborative work) present different challenges and would probably interact in a different way with the reform process. At the same time, some convenience sampling occurred. Teams had to agree to open their activities to close scrutiny. They had to allow for the presence of the researcher in team meetings and periodical interviews. Teams that preferred not to collaborate with this study were excluded from the research. This only occurred in one case within the whole study.

Third selection level: within-case sampling

'Within-case sampling' refers to the sampling of activities, processes, events, times, locations and respondents in the research process itself (Miles \& Huberman, 1994). This sampling level, in contrast with case sampling, is always theory-driven. The selections are made on the basis of conceptual questions and decisions and were not based on 'representativeness'. The researcher is interested in a certain construct in different moments, different places, and with different people and that is what drives the selection. Because the focus in this study is on the design processes, and the way teachers perceive them, activities related to those issues have been chosen. This meant that research activities were concentrated on meetings in which the teachers (re)designed their curriculum or discussed issues related to the (re)design. There was also focus on how teachers perceived their curriculum development process (more on the specific methods in sections 3.3). Within-case sampling is also iterative by nature. As a result of certain research activities, the researcher may come to new insights and 'leads' as to where additional information can be found. This leads to new samples of informants, observations, and documents. At each step in the research process the researcher makes these sampling decisions. This can also lead to new insights into the kind of activities that need to be followed which may have an effect on the broader methodological setup. In this study, the insights gained at Copernicus High School led to changes in the methodological setup in the study at Kepler High School (see section 3.3.4).

\subsection{RESEARCH METHODS}

As the main goal of this study was documenting the activities of the teams and finding explanations for the patterns found, most research activities were aimed at getting a full image of the curriculum design process. Additionally, in order to increase the explanatory power of the study, the background of the teams and 
the teachers as well as the results of their work (mainly in the form of their curriculum products) were considered. In doing so, the findings were related to both the 'input' and the 'output' of the teams. It was examined if teams with certain similar characteristics systematically show similar patterns of work and products. This contributed to establishing possible explanations of the findings.

Multiple research methods were use to explore the cases. Among them document analysis (minutes of team meetings and curriculum materials), observations of team meetings (both subject teams as whole school teams), and semi-structured (group) interviews with school leaders, innovation managers, the teachers, and coaches when these were involved.

Generally, the cases studies had three stages. Initially a baseline study was held in order to get a clear picture of the curriculum, the school, and the team at the starting point of the cooperation. Next, the process the teams undertook was followed and documented. The manner in which this was done varied somewhat between the schools. Finally, an 'exit point' study was conducted. This dealt with the outcomes of the process of the team. It also gave an opportunity to get more process details and members' perceptions of the process and its outcomes.

\subsubsection{Baseline study}

At the early stages of the study there was a need to establish the starting point of the team and school on different aspects (their current curriculum, current change perspective, and current school structure and culture). This input was used to contextualize the developments in the school during the teams' work and helped in interpreting them.

As a first step, different documents were studied. This included external reports made by the inspectorate and intern school documents on the reform, state of affairs in the school, and plans for the near future. This was done to get a general image of the school and the reform plans that were made. Next, several teachers from each team that participated in the study were followed during an average school day. This included observation of at least three lessons and an interview.

During the observations an "observation sheet" was used to record information on the general characteristics of teaching (see CD section 1.1). This observation sheet was structured on the basis of the ten curriculum components suggested 
by Van den Akker (2003). The goal of the observation was not so much to ascertain very specific information on one subject but to get a general impression on how the teachers conducted and organized their lessons and to provide input for the interview.

The interviews with the teachers were conducted at the end of a school day on which the teachers were observed. The interviews were at least 45 minutes long (the longest being 90 minutes). These were semi-structured interviews based on the analytical framework of the study, aiming specifically at gaining a better image of the team and teachers characteristics. During the interviews several themes were discussed (for the interview guide see CD section 1.1):

- Teachers' background.

- The current school organisation and the collaboration patterns between teachers and subjects.

- General characteristics of teaching practice based on the observations. For this a form was used in which teachers could fill in their perception of the current state of affairs in relation to the ten curriculum components (see CD).

- Wishes of teachers for curriculum reform-both personal and those perceived by them to be a part of the work of the TDT.

- Expected and preferred manner for the work of the TDT and the support that is expected and needed.

All the interviews were audio recorded and processed on the basis of the themes discussed. Together with the observation data a report was constructed for each of the teachers observed (see CD section 1.1). These reports were then sent to the teachers for validation. In cases where more than one teacher per team was followed, a team portrait was constructed. This portrait was discussed with the teams.

In all schools, school leaders who were directly involved with managing the work of the TDTs were interviewed on the same themes that were discussed with the teachers but at the school level. Here too, all interview reports were validated by the participants.

Based on all the data collected in the baseline study, a school portrait was constructed. It was then presented to the teachers during a plenary staff meeting. Teachers were asked to respond to the portrait presented and propose adjustments or additional information or insights. 
Besides gathering information, the baseline study also served an important relational goal. In case studies where teams are followed intimately for a long time there is a need to establish a close positive relationship with the practitioners from the start. This is crucial for the cooperation of the practitioners in later stages of the research and for ensuring their willingness to share their thoughts and practices with the researcher. The research activities (multiple observations and interviews) were considered useful for establishing that relationship with the practitioners. Through engaging with practitioners and joining them in their practice in a non judgmental interaction, and showing genuine interest in their perceptions, the researcher was able to build a relationship of trust rather rapidly, enabling further interaction.

\subsubsection{Process documentation}

The work process of the TDT was documented while they worked. This was done by conducting various observations of meetings, informal contact with team members during and in between meetings, and analyzing documents produced by the team members.

\section{Observations}

During the study the meetings of the TDTs and other various meetings in school were documented. The meetings included school staff meetings, school visits, and other meetings connected to the process, such as meetings for piloting of materials. The meetings were followed and audio recorded. During the meetings notes were taken of discussions held and decisions taken. On the same day of the meetings, the recordings and notes were used to fill in a Contact Summary Sheet for that meeting (Miles \& Huberman, 1994) (see CD section 1.2). In this overview of the meeting the main issues of the encounter were summarised:

- What were the main activities and themes of the meeting?

- How can these activities be characterised based on the analytical framework for curriculum development?

- How was the meeting structured?

- What were the roles of the different team members?

- What were the formal and informal results of the meetings? 
Following that, the process data was registered on the Process Scoring Sheet (see CD section 1.2 and appendix 1). This document was essentially a large table including all the elements of the conceptual framework for the analysis of the process. Following each meeting the findings were recorded in the Process Scoring Sheet. Each row of the table represented a meeting or event in the team's work. After several meetings the table gave a quick overview of the work and developments in the team.

The presence of the researcher during the meetings was crucial for understanding the developments in the team. What people report in retrospect is often different from what happens in the meeting itself as the incidents in teams depend on the interactions and the specific context in the team at that moment (Little, 2003). Being present at meetings and recording events as they unfold adds a dimension to documenting the process. Being present in several consecutive meetings has the added value of being able to see processes unfold and developments in events and in people that a single meeting does not make transparent (Thomas et al., 1998).

Next to the primary goal of process description, meetings, observations, and documentation had three added goals:

- Input for interviews-the process description was used as input for the interviews held with the practitioners. Through communicating the observations and possible interpretations, responses of the practitioners were elicited. Having knowledge of the events enabled the researcher to communicate with the practitioners more easily about them and to concentrate on the meaning of the events and not on their particular description.

- Triangulation-the observations functioned as an added data source complementing the data gathered in the interviews.

- Result description and evaluation-when possible, the piloting or implementation of the redesigned curricula was observed. This was used to communicate with the practitioners about the results of their efforts and to compare with the observations undertaken initially.

\section{Informal interaction}

During the entire involvement in the school the researcher interacted informally with the teachers and other practitioners involved in the reform process. These interactions had different goals. To a great extent they were aimed at obtaining 
process information that the researcher may have missed. This could consist of interactions among teachers concerning the reform process outside of the meetings or other relevant events that took place in the absence of the researcher. Additionally, these interactions concerned the perceptions of the different actors of the events as they unfolded. As these perceptions were closer to the events themselves, they had the added value of not yet being clouded by events to follow. These interactions were recorded in the researchers' logbook and were used to supplement the other process information obtained.

\section{Document analysis}

All documents produced by the team or its members were collected by the researcher. This included team agendas, team minutes when available, and curriculum products made or discussed by the team. These were also used to supplement the observation data.

\subsubsection{Process reconstruction}

At the end of the each of the site studies (which was not identical to the end of the reform process which went on for several years) an 'exit' study was conducted. This consisted of (group) interviews and document analysis. Between the two schools there was some variation in the application of the process reconstruction (for description see methods section in chapters 4 and 5).

The closing interview consisted of a reflective conversation with the teachers and other participants (such as coaches and members of the school management) on the process they had gone through with the TDT in that year. The semi-structured interviews (see CD section 1.3) were concentrated on three themes (in accordance with the analytical scheme and research questions):

- Perception of the work process of the TDT and identification of critical events in the process that led to certain outcomes and developments.

- Perception of (conducive or hindering) school organisational conditions.

- Perception of the curricular results of the work.

The main thrust of these interviews was gaining insight into the beneficial and hindering elements in the collaborative curriculum design process mainly from the perspective of the practitioners themselves and in light of the process as a whole. This is in line with the narrative research tradition. In such a research 
orientation, teacher knowledge and perception is examined in the temporal and contextual environment (Gergen \& Gergen, 1988). Here extensive use is being made of the stories teachers tell about their practice (Beijaard, van Driel \& Verloop, 1999). The importance of these stories is that human beings experience the world through construction and reconstruction of their personal and social narratives (Clandinin \& Connelly, 1990). Narratives connect events to the larger story and focus on the temporal transformation in phenomena. From this perspective, if events are not tied to the larger story, they lose their significance to the practitioner (Gergen \& Gergen, 1988).

A way of capturing this narrative is with the storyline method employed in Kepler. In this method practitioners reconstruct their experience in a certain domain through constructing a line of development. The events are places in a two dimensional space along an $X$ and $Y$ axis: $X$ representing time and $Y$ representing an evaluative value (Figure 3.1). Teachers start off by evaluating their current position on a certain aspect, giving it a mark (for example on a scale of 1-5 ranging from very negative to very positive). Following that they draw a line describing the developments and highs and lows over a period of time. The story represents then the evaluation of a series of experiences or events along a temporal line. This method was extensively used and articulated by Gergen and Gergen (1988) and was applied by Beijaard et al. (1999). According to them, the main advantages of this method are as follows:

- respondents can evaluate experiences and events themselves, which seems to be difficult for the researcher in other narrative research methods;

- storylines are relatively quick and easy to make and are seen as a creative mode of self expression.

Additionally, storyline method is a way of making experiences visual. They make turning points and changes in process more accessible for discussion and reflection with and among the respondents.

Through the teachers' storylines different points in the story can come into discussion. These are the highest and lowest points of the story or where the line changes direction or inclination. As these points have apparently caused changes in the direction of the process, they can be defined as critical events in the course process. They apparently had great influence on the development of the process. Tripp (1993) points out that these events do not exist independently of an observer. Like all data, incidents are created. According to him, critical events are produced by the manner in which we look at a situation. It is an interpretation of 
the significance of an event according to the participant. So, in the same way that a narrative or a story is constructed based on the current perspective of the respondent, pointing out an episode or an incident as being important, and therefore critical, it depends on the interpretation of the event in hindsight. They can be incidents that are seen at the time as defining moments in that they had an immediate impact on the course of the development. They can also be events recalled in hindsight that were first deemed trivial. The very fact that we have recalled them, of all other events in the process, means that there is probably something important about them, something which has made them salient for us in one way or another (Tripp, 1993).

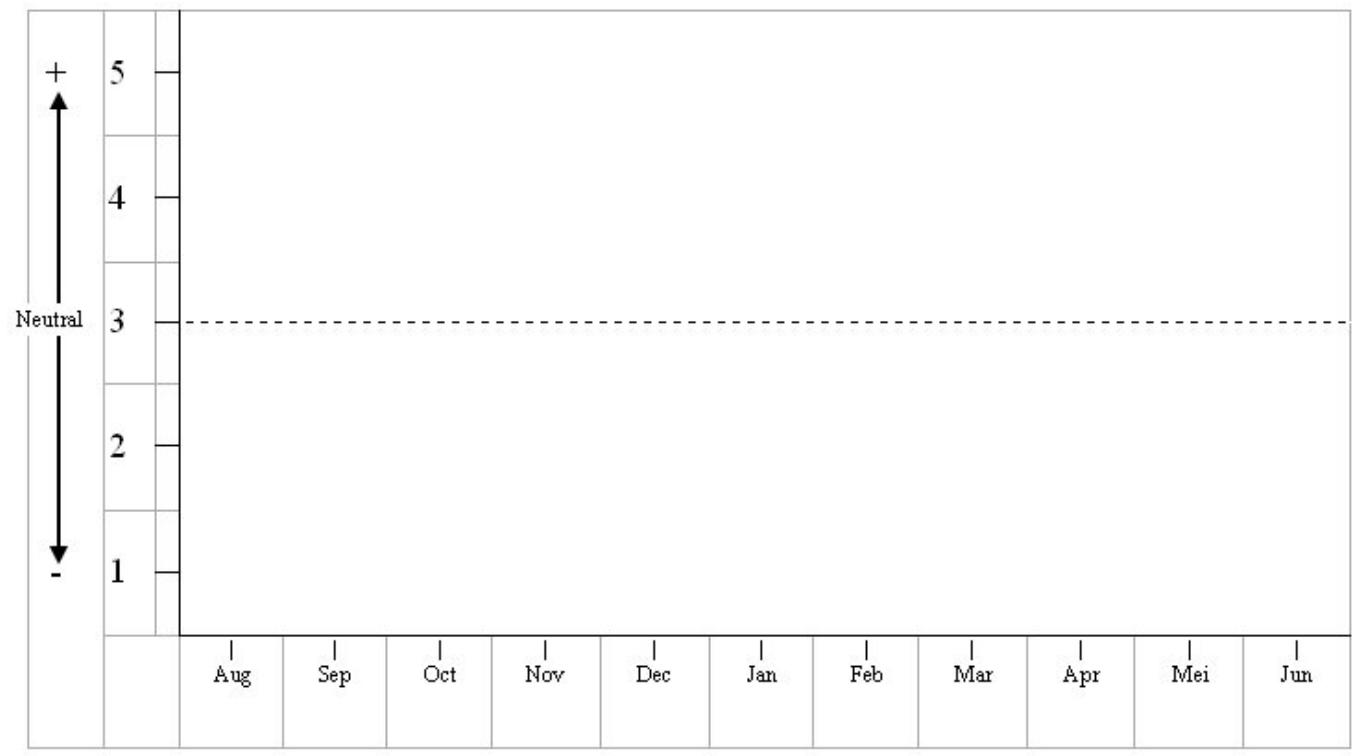

Figure 3.1 Storyline form used with practitioners

For the purpose of this study a critical event was defined as an occasion or condition that significantly influenced the course of the work of the team and its outcomes. Given the focus of this study, these outcomes were sought in the curriculum the team has developed.

All the interviews that were based on the storyline method were group interviews that included as many of the team members as possible. In each of the interviews participants discussed two storylines concerning different aspects of the process: working as a team and the curriculum development process. Interviews consisted of each of the team members filling in the storyline forms on their own. After this was completed (all the storylines, representing the themes to be discussed were 
filled in), the interpretations of the teachers were shared and discussed. This led to exposing points in the process where teachers experienced a change and articulating the reasons for it from different perspectives. It also brought forward differences of interpretations and perceptions which elicited more discussion. In order to save time and avoid the issue of just trying to remember which actions had been taken during the process (which often encompassed 8 to 10 months), the members where supplied with a list of their meetings or other collaborative activities (see CD section 1.3.2 for examples). This aided teachers in remembering the temporal order of work without leading them in discussion on the content of their work's meaning. All the interviews were 60 to 90 minutes long and were audio recorded. The interviews were processed on the basis of the themes and questions discussed, depicting where teachers were in agreement and where they were not. The reports of the interviews were sent to the teachers for validation and they had the opportunity to alter or supplement the data.

When available, the curriculum products of the team were collected and analysed. This analysis was done based on three themes from the analytic scheme:

- relationship with reform goals defined by either the school or the TDT;

- relationship with the former curriculum of the team;

- stage of production (how much of the materials/planning is ready for use).

Due to the different character and possibilities in each of the studies the specific methodology applied to gain insight into these events is somewhat different. The different methodologies are described in the following section.

\subsubsection{Variations in research methods}

The research methodology evolved during the course of the study. This means that the methods applied in the two sites differed somewhat, due to three reasons. First, the two sub studies were held in different schools in successive years. The circumstances in the schools and the teams varied somewhat and that meant that the applicable methods also varied. In Copernicus coaches were involved in the work of the TDTs, while in Kepler they were not. The involvement of the school leaders in the teams' process varied, making them not always relevant to interview. All these factors and others have led to some variation of the specific methods used. Second, as the study proceeded, the researcher gained experience with the use of the different research tools. The insights gained in one study were 
then used in the following study, in order to adapt the instruments, or making better use of them. Third, during the study the focus of the study itself evolved. In the first sub study (Copernicus) the focus was more on the broad process (including curriculum, professional development, and school development) with a primary view of the teachers' perspective in retrospect. This focus was narrowed to the curriculum development process with additional attention to the documentation of ongoing activities and process. This led to some adjustments in the methodology used. The specific methodological issues are discussed at the start of the two results chapters (chapters 4 and 5).

\subsection{ANALYSIS}

The analysis of the data was done in three stages. In each stage the conclusions of the former analysis stage were compared between different teams or sites.

\subsubsection{First analysis stage - within case analysis}

For each team a case file was compiled including all the available data collected on the team and two summary documents (see CD section 1.4 for the case files):

- the Process Scoring Sheet (see 3.2.2) for the whole year;

- the filled-in analytical scheme, summarizing the findings on each of the elements based on all data sources.

Following that, a case analysis was done. The starting point for this were the two summary documents. First the Process Scoring Sheet was examined to detect patterns and changes in the process. This constituted, for example, the division of the kind of activities undertaken by the team in various points of the process based on the typology of the curriculum development model. Here the central question was which of the stages was the most prominent in the various time points of the work. This pattern analysis was done for each category in the Process Scoring Sheet. Following that, the available data on each of the aspects of the conceptual framework were examined and conclusions were drawn based on the whole data set. The conclusions were drawn in relation to the three research questions of the study (e.g. what the team did, which activities were conducive or hindering, and which school conditions were conducive or hindering). This yielded a document summarizing the findings for each team 
based on the research questions and showing both conclusions based on the perceptions of the participants and the process data collected by the researcher. In this analysis process three levels of conclusions were defined:

- level A conclusions-conclusions established clearly by the data, based on multiple data sources;

- level B conclusions-conclusions that are traceable in the data but are supported mainly by one data source;

- level C conclusions-conclusions that are not directly founded on concrete data sources but have some 'circumstantial' evidence and are considered as possible explanations for a phenomena.

The categorisation of the conclusions was done in view of the cross-case analysis where conclusions from the different cases would be compared. There was a need to discern the level of certainty in which a conclusion about a case can be made in order to compare them across cases.

\subsubsection{Second analysis stage - cross-case analysis within the school sites}

Here a similar procedure was followed as in the analysis of the teams. The teams were compared on the basis of the background of the teams and the teachers as well as the results of their work (mainly in the form of their curriculum products). Additionally, in trying to detect similarities and differences, the conclusions from each team on the three research questions were compared. The process-related findings were then related to both the 'input' and the 'output' of the teams. It was examined whether teams with certain characteristics show similar patterns in their

processes or results. This contributed to establishing possible explanations of the findings. These explanations were then based on both the arising patterns (systemic relationship between characteristics, processes, and results) and the explanations teachers gave to why a certain aspect or activity occurred or had strong influence on the process. Here too, three levels of conclusions were defined:

- level A conclusions-conclusions established clearly by the data, based on several teams;

- level B conclusions-conclusions that are traceable in the data but are supported mainly by one or two teams;

- level C conclusions-conclusions that are apparent in one or two teams but are deemed possibly to have added value for exploration in other contexts. 
After this initial cross-case analysis stage the patterns found concerning the research questions were compared to the patterns found concerning team characteristics and results across the school. When a similarity became apparent this was added to the conclusions concerning that specific research question. The result of this analysis was a cross-case conclusions document (see CD section 1.4). This document was the basis for the results chapters (chapter 4, 5, 6 and 7).

\subsubsection{Third analysis stage - cross-study analysis}

This stage consisted of comparing the findings from the two school sites in order to see which similar or different findings occur across the two sites. The aim of this comparison was to distil principles for the collaborative curriculum development of teachers. This also gave rise to the detection of critical differences between the different school site case studies and to the emergence of a contingent structure implying the adequacy of certain principles to certain contexts. In this study the assertion was made that the overall organization of the reform trajectory and the innovation framework influences the way the teacher-teams work. This led to the initial decision to look at two sites where collaborative curriculum development took place. The intention was to analyze the teams from Copernicus and Kepler in a one cross-case endeavor comparing them thus on a team level and not on the level of the conclusions of the whole school site. This was found not to be fitting, however, as the methodology used in each of the schools was too different (see section 3.3.4). In the Copernicus study the main source of information was interviews and not direct observations. Therefore the process description is of a more general level and not detailed to the level of specific meetings. This meant that the analysis of work patterns based on observation data was not applicable. In the Kepler study this was adjusted. Due to the differences this created at the data level, a decision was therefore made to first conduct the cross-case analysis in each of the schools independently and only afterwards to conduct the cross study analysis on the basis of the conclusions from each of the school sites.

\subsection{MEASURES TAKEN TO SUPPORT RESEARCH QUALITY}

In this study different tactics were employed in order to increase the quality of the collected data and the quality of the analysis. Although some measures taken affect several quality criteria, they are discussed under those criteria for which they are most central. 
Reliability in qualitative case studies concerns the consistency and stability of the data collection methods (Miles \& Huberman, 1994) so that the study can be repeated with similar results (Yin, 2003). In order to increase reliability of the data collected in each of the sub studies, a consistent set of research instruments was used and a protocol for collecting, recoding, and processing the data was developed. All interviews and meetings were taped and these recordings formed the basis of the write-ups of interviews and meetings. The instruments and case files produced, based on the primary data, have also been made public as part of this dissertation (on the accompanying CD). To diminish the chance of bias from the researcher following the team, his role in meetings and interaction was made explicit and when it had an effect on the development of the team, this too was made explicit.

In order to increase the internal validity of the findings, that is increase the "truth value" of the findings for the participants and the readers of the study (Miles \& Huberman, 1994), several measures have been taken.

- Triangulation - in all studies triangulation of data and methods was applied. Data were gathered through interviews, observations, and school documents all aimed at exploring similar issues. Additionally, different participants in the TDTs were interviewed and thus different perspectives of the process are explored. In one sub-study (Copernicus) this meant that both a teacher and a coach from each team were interviewed. In all other sub studies several teachers of each team were interviewed. In all studies members of the school management were also interviewed.

- Long-term involvement of the researcher in the research contexts - the empirical studies were longitudinal studies of approximately ten months. Therefore findings were brought into the perspective of time and multiple contacts with the participants and were not dependant on single, incidental contact.

- Member checking - this was done in three ways. All interviews reports were sent to the respondents for verification. They had the opportunity to correct any interpretation or possible factual mistakes made by the researcher. In case that they had additions or corrections to provide, these were added to the report. Additionally, during the process itself tentative explanations of the developments in the teams were discussed with several key informants and their reactions and ideas were added to those developed by the researcher. Third, case reports were sent to the teams for feedback on their content. Teachers had the opportunity to correct or add to the report. No team had made use of this opportunity. 
- Peer debriefing-during data reduction, analysis and interpretation critical discussions with a colleague researcher who had knowledge of the cases were held. During these discussions rival explanations for the same data were explored. Additionally, the argumentations for casual relationships implied in the interpretations were regularly challenged and if lacking in details were elaborated on, or left out.

The external validity or transferability of the findings of the study was supported by the characteristics of the selected cases. The chosen school sites were 'run of the mill' schools, with few complicating or extreme circumstances. No deviant or extreme cases were included in the study. Therefore findings from these schools should not differ radically from how the processes studied may play out in many schools. At the same time, the logic in considering how the findings would apply to other cases was that of analytical rather than statistical generalization (Yin, 2003). The extent of how representative a case is of the population is not perceived to be the central carrier of external validity in case study research. Three elements contribute to this analytical generalization. First, by conducting the study in two sites with comparable conditions the applicability of the findings from one site to the other can be examined. Second, by offering rich case descriptions and exploring the causal explanations for findings, the mechanisms leading in these processes are made explicit. This makes the projections of these findings in other contexts where comparable situations play out more robust and plausible. Third, by contrasting the findings in this study with other studies done on the subject, the applicability of the findings in different contexts can be examined. This enables a better analytical generalization of the findings. 


\section{CHAPTER 4}

\section{TDTs in Copernicus High School}

This chapter describes the cross-case analysis of the case studies conducted in Copernicus High School in the school year 2002-2003. The design work of seven TDTs was followed, described, and analyzed. Section 4.1 starts with a short description of the research methods applied in the study of the school. Next, section 4.2 introduces the school, the general characteristics of the school-wide reform initiative, and the school-wide reform process. Following that, sections 4.3 through 4.5 describe the findings for these TDTs on the three research questions of this study. The findings start with a short summary followed by a more extensive description. In order to keep the text compact, the full descriptions of the case studies are not included in the chapter but can be found on section 2 of the accompanying CD. Finally, in section 4.6 a short summary of the findings on the school level is given.

\subsection{Methodology OF THE STUdy IN COPERNICUS HIGH SCHOOL}

The study in this school site followed the general description of the methods used (see section 3.3) with several specific characteristics. The baseline study here was done with key informants of each of the participating TDTs. The informants in this case were interviewed about their practice and the general practice of teaching and their views of the reform in their TDT. This resulted in seven team portraits and a general portrait of the curriculum of lower secondary education in this school.

During the development process, some team and school-wide meetings were followed. The involved researchers took field notes about the discussions and developments. These notes were used for getting a general picture of the process and activities of the teams. During these contacts, the researchers had informal conversations with participants and collected documents made by the teams. When teams organized pilots or other activities (such as school visits), the researchers joined the team as observers. 
At the end of the TDTs' first year work, interviews were held with several of the participants. In each TDT the teacher that was involved in the baseline study was interviewed. Additionally, all team coaches, the innovation manager, and the school leader were interviewed. This was done to get their perspective on the work of the teams as well as on the broader, school-wide issues. All interviews were semi-structured open interviews (see CD section 1.3) based on the study's main themes. Participants were explicitly asked to try recalling critical events and factors that influence the teams' work. Based on the data team descriptions were constructed on all themes of the conceptual scheme. These team descriptions formed the basis of further analysis.

\subsection{INTRODUCTION TO COPERNICUS HIGH SCHOOL}

\subsubsection{The school}

Copernicus High School is a relatively small school with 498 students, aged 12-17 years, located in a city in the eastern part of the Netherlands. It is part of a larger school organization active in the city that had in total 3,600 students and seven schools in 2002. Copernicus High School offers only several of the educational levels available in Dutch secondary education. While in lower secondary education it offers almost the whole breadth of levels (VMBO-T to VWO), in higher secondary education it offers only pre-vocational secondary education (VMBO-T) and the senior general secondary education (HAVO). In lower secondary education, each year group has four classes and 20 teachers teach about 250 students.

An assessment of baseline practice showed that at the start of the work of the TDTs (October 2002), the classroom practices at this school were rather traditional with conventional textbook-driven lesson patterns. To the learners, the overall curriculum showed little coherence and the day-to-day practices were fragmented and hardly challenging. However, the school had a pleasant and orderly atmosphere and the relationships between teachers and pupils were good. The experienced and dedicated teachers were working in small and rather passive subject departments. Only limited collaboration occurred between the teachers and professional debate and deliberations were rare. Although each individual teacher had some (reform) aspirations, there appeared to be a great gap between their articulated aspirations and their daily practices. 


\subsubsection{The reform background}

Since 1999, the broader school-organization has initiated several educational reform projects in some of its schools. The two major focal points in these projects were subject integration and self-steering of students. In 2002, the schoolorganization initiated a pilot project in collaboration with SLO (Netherlands Institute for Curriculum Development) which concentrated on reforming lower secondary education, aiming for more self-steering and subject integration for students in several subjects. This was in light of the expected changes in the national curriculum of lower secondary education. The overall schoolorganization management expressed a desire to realize an integral school-wide reform in one of its schools. This was due to the experiences in different previous reform projects. It seemed that even when the projects were successful and achieved their goals with the students they remained limited to the teachers who were directly involved in the projects and did not spread to the rest of the school. Beyond the scope of the previous reform projects, it remained 'business as usual'. Moreover, teachers who participated had experienced an increase in workload, as it all had to be done in addition to their regular work and within the confines of the existing organization. It was assumed that in order to solve these problems, reform needed to be initiated on a school-wide organizational level. By doing this, the organization of the teachers' work would change so that teachers would have more time and possibilities to work on renewing their education.

The choice of the overall school-organization management for Copernicus High School for this school-wide initiative was made for several reasons. First, it was assumed that the modest size of the school would make communication and implementation relatively easy. Second, the school building was perceived as easy to modify, based on the reform wishes that were deemed plausible. Third, the teachers of the school were perceived as experienced and committed, which would be conducive to the implementation process. Parallel to the top-down initiative, the school leaders and the teachers of Copernicus High School were already developing initiatives for a school-wide reform to help the school create a distinct profile that would attract students.

\subsubsection{School-wide reform process}

At the start of 2002, a project team was formed in the school with the goal of exploring the possibilities and drafting a tentative framework for a school-wide 
reform in lower secondary education. The project group consisted of the school leader, a newly appointed project leader, and several volunteering teachers. Form January to June 2002 the project group worked both on the tentative reform framework as well as on the implementation strategy for realizing the reform. The suggestions of the group were periodically presented to all the lower secondary teachers for feedback. The main aspirations of the reform initiative as formulated by the group were as follows:

- A move from a teacher-oriented program towards a student-centered approach;

- More coherence within and between subject domains;

- More activity-based learning, more responsibility, and more options for learners (self steering);

- Less fragmented time-schedules, longer time periods for learning;

- Task differentiation for teachers and support staff;

- More integration of ICT-use.

From the start, the idea of initiating TDTs for the whole of the lower secondary education was a central element in the projects groups' thinking. This was perceived as important for both the substance and the strategy of the reform. From a substantive perspective, it meant a move towards more integration of subjects, which would contribute to curricular coherence. From a strategic perspective, it was seen as a way of giving teachers a more central role in shaping the reform by redesigning their curriculum in the context of the TDTs. This was expected to increase their involvement in the reform and therefore their commitment as well to help create a reform that would better suit the preferences of the teachers. Initially, four teams were defined: Sciences, Languages, Social Studies, and Arts.

In the spring of 2002, SLO coaches and researchers from the University of Twente joined the reform project. SLO would make subject experts-coaches available for the TDTs for curricular support. The university was asked to conduct research to the work of the teams and their support process. The university researchers assessed the baseline practice in October 2002.

At the start of the 2002-2003 school year the project leader initiated several activities with all the teachers involved in the TDTs, trying to gauge how the teachers perceived the reform and to define a common reform framework in which all teams would operate (consisting of the organizational characteristics of the reform). 
As part of the reform, all teachers involved received some allocated hours in their yearly planning to work in their TDTs. The teams were invited to formulate their wishes, demands, and plans before December 2002. The plan was to come to a common framework by January 2003, which the project team would create based on the team plans. During this preliminary stage, the composition of the teams changed due to wishes of the teachers. Dutch and Mathematics were separated from the teams Languages and Sciences. Moreover, the Sciences team was divided into two teams: 'Nature \& Technology' and 'Nature \& Health'. By January 2003, there were seven TDTs (Table 4.1). All teams were assigned a coach (an external expert in pedagogical content knowledge and curriculum).

Table 4.1 TDTs and their composition in Copernicus High School

\begin{tabular}{llc} 
TDT & Subjects included & $\begin{array}{c}\text { Number of } \\
\text { teachers }\end{array}$ \\
\hline Foreign Languages (FL) & English, German, French & 3 \\
\hline Social Studies (SOS) & $\begin{array}{l}\text { History, Geography, Home } \\
\text { Economics, Religious Studies }\end{array}$ & 5 \\
\hline Nature \& Technology (N\&T) & Physics, Technology & 2 \\
\hline Nature \& Health (N\&H) & Biology, Health Education & 3 \\
\hline Arts & Music, Drawing, Craft & 3 \\
\hline Dutch & Dutch & 2 \\
\hline Mathematics (Math) & Mathematics & 2
\end{tabular}

In January 2003, during a meeting of all the teachers, the official decision to continue with the reform project was taken, although not all organizational consequences were decided upon as different teams had different wishes. In the months leading up to March 2003, this was an issue of discussion in the project group that kept meeting regularly throughout the school year. The most significant organizational decision taken during this period was to set up a central open learning environment in which students would spend $40 \%$ of their school day, working independently on their schoolwork. This was not in line with the wishes of all TDTs but was rendered by the project group as the only school-wide solution possible within the limitation of time and budget and at the same time answered the major intention of the reform. From January 2003 on, the TDTs worked on their individual plans, periodically coming together with the other TDTs to discuss school-wide issues. In September 2003 the (re)designed curriculum of the teams was to be implemented in year one of lower secondary education. 


\subsection{HOW THE TDTS ADDRESSED AND CARRIED OUT THEIR DEVELOPMENT WORK}

As mentioned earlier, seven TDTs were active in Copernicus (Table 4.1). As an introduction to the analysis of their work, the general outlines and prominent elements of the work of each team are briefly presented here:

Foreign languages - the intention of this team was not to integrate the different subjects but merely to develop more coherence in the school's foreign language pedagogy. From the start, the coach took a proactive approach and initiated meetings and activities (e.g. a field trip to a school that had innovative language teaching). The team never met without the coach. The team found the crosscurricular discussions difficult and spent much time discussing the "time" and "place" elements in the new curriculum. Toward the end of the school year, all teachers worked on their own planning with little interaction among them. The team had no representative in the project team at the school level and suffered from a lack of process-information. The French teacher had a different orientation from the start and actively worked on changing his teaching. He even piloted new teaching materials. However, his colleagues did not explicitly benefit from the developments in his work due to their limited involvement in the pilot.

Social studies - this team planned to completely integrate $50 \%$ of the content of their subjects: half by implementing an existing learning project and half by designing a new project. Not all teachers in the team were committed to the goals of the reform or the work of the team. After a long period of orientation in which they repeatedly discussed their goals and intentions, and explored the organizational limitations, only two teachers actually constructed new curriculum materials. The transition from design to construction happened when one of these teachers, on his own initiative, produced a written summary of their ideas and a tentative general outline for the new curriculum.

This team was the only one with a well-defined chairperson's role that was supported by the coach. The external support had an important role in structuring discussions and activities of the team and the coach actively helped with the construction of the learning materials. 
Nature \& Technology - the two teachers had a clear image of their new curriculum even before the formal reform started. They have been discussing it in the years past. They planned not to use any available textbooks and to write a complete set of new and integrated materials. They went straight into a repeating cycle of design, construction, and revision. One teacher did most of the actual construction and the other regularly gave feedback and discussed different matters. The vagueness of the school-wide reform did not have an effect on their work as they mainly followed their own ideas. When they had questions, they actively sought out the project leader to get answers as one of the teachers had a good personal relationship with him. This was the only team that had no coaching, as they could not resolve their own views with those of the coach that was initially assigned to them.

Nature \& Health - this team had very modest ambitions for their work: fitting their teaching materials to the new school-wide framework and bringing both subjects under this one label (with limited actual integration). The three very experienced teachers had strong informal and formal (role in the school organization) ties to both the school and project leaders. Although the vagueness of the school-wide framework did lead to some delay in their work, when the team had questions they approached the school leaders for answers. When they had some clarity on the setup they went into several short cycles of design of the general framework and construction of specific lessons plans. They then divided the construction tasks and continued with a little feedback on one another's work. Their work was unstructured and it was often unclear what their meetings would be about. Meetings were almost exclusively held when the coach came to the school. The coach tried to supply the team with some new ideas for the setup. The teams' greatest need and wish for coaching (supply of actual teaching materials) was not fulfilled. However, this was not discussed with the coach before the end of their cooperation.

Arts - this team had no initial common ambition for the reform and the teams' composition was not based on the wishes of the teachers. This led to the music teachers' effectively stepping out of the team. The two other teachers (drawing and craft) did share some ambitions in combining their disciplines. An important factor in their work was the fact that they would not take part in the new open learning environment and did not need to adhere to the new guidelines for time division. At the same time, until the school-wide framework made this clear, 
their work was delayed. They had a long orientation period in which they discussed the manner in which the content of their subjects could be combined. This was greatly influenced by the active involvement of the coach, who was often the main trigger for holding meetings and often put the ideas on paper. At the end of the school year, the team had few concrete teaching plans ready.

Dutch - the teachers had a clear initial common ambition for reform and work. They aimed both at developing new teaching projects and at adapting their 'regular' teaching along several pedagogical guidelines. The team displayed much collaboration with both teachers taking turns in working on the same teaching materials and constantly gave one another feedback. They met often, continually working on concrete teaching materials and adjusting the general outline of their design along the way. The team followed its own plan and was not affected by the vagueness of the school-wide framework. When they did have questions, they proactively approached the management for answers. The team piloted a part of their design and was the only team that also considered the effectiveness of their design. The coach was very active, helping them plan and structure the process, actively supplying them with pedagogical insights and actually helping construct materials.

Mathematics - although consisting of two teachers, one teacher would retire the following year and therefore only partly participated in discussions and development work (there was, therefore, little cooperation in their work). Although they had vague ambitions, the main outlines of the design were discussed in the first two meetings. The team did go through a long orientation phase, which was also influenced by the vagueness of the school-wide framework (specifically regarding organizational conditions). Toward the end of the school year, they went on a field trip to see how another school was utilizing learning planners. This led to new insights and they went on to construct several planners before the summer vacation. The team displayed highly unstructured work and the coaching was not seen as effective as it did not help the team to produce materials, which was their greatest need.

\subsubsection{Recurring curriculum development activities}

Aside from holding team meetings and the individual work of teachers' inbetween meetings, several development activities have been observed in more 
than one team and are therefore discussed here shortly before they are subjected to a more detailed analysis of different aspects:

- All teams produced a general team plan, which was mandated at the school level. These plans were adjusted only when coaches took initiative.

- Most teams purchased new textbooks but their choice/selection procedure was disconnected from the goals of and discussion on the school-wide reform.

- Four teams produced some original teaching and learning materials.

- Two teams conducted field trips to other schools that implemented similar reform initiatives.

- Four teams conducted pilots of parts of their new teaching and learning materials.

Using a format supplied by the coaches, all of the teams produced a general team plan in December 2002 at the request of the school leaders. After this, those plans were only adjusted and updated when the team coach took the initiative to do so. Teachers did not do it of their own accord.

Six of the seven teams decided to select new textbooks at the start of the reform. This choice was done prior to the work in the TDT with the coach-it was not discussed in the reform context and the choice was not based on criteria formulated in the team or the reform. One TDT (N\&T) decided to design their own teaching and learning materials and not use any textbooks. Besides N\&T, three teams produced original teaching materials, to be used next to the selected textbooks. The materials ranged from a short project covering several school-weeks (Dutch, French) to about $25 \%$ of the common teaching time of the team (SOS).

Two of the TDTs conducted field trips to other schools in order to observe reform efforts there. All of these field trips were conducted on the initiative of the coach (Math and FL).

Four teams piloted parts of the teaching and learning materials. In two cases (Dutch and French) this consisted of piloting new teaching materials/approaches that coincided with the intended redesign. In one case (SOS), the pilot was a trial of a short learning activity that would potentially be used as a kick-off activity for their project. In the case of Arts, a teacher tried out a learning activity she used in the past as preparation for a new curricular setup. 


\subsubsection{Curriculum development stages}

Considering the curriculum development stages, several patterns arose:

- Analysis was mainly aimed at organizational conditions such as time division and the form of the learning environment.

- Design and Construction were the most prominent in the work of the TDTs.

- Major design decisions were set before or immediately at the start of the process.

- The larger and more varied in composition the teams were, the longer the orientation period was.

- Construction was often a matter of division of tasks and individual work of teachers with little further cooperation. However, interdependence between subjects and teachers in design and enactment led to more cooperation in construction.

- No explicit evaluation activities were conducted. Implicit evaluation was aimed at usability issues.

The following section elaborates on the main patterns:

Analysis - this was aimed at the organization of the process and the future teaching and learning environment. In two cases (Math and FL), following the initiative of the coach, teams went on field trips to other schools implementing similar curricula. Here too the organizational aspect played a major role. Coaches experienced difficulties in stimulating discussions on more abstract topics related to the reform such as pedagogical goals of the school and the teachers.

Design-the main design decisions were made early in the process, either in the first two meetings or even preceding the start of the work of the teams (N\&T, Dutch, N\&H, and Math). Two teams (SOS and FL) went through a longer period of orientation and discussion on their reform. Even in these latter teams, the main design decisions have been discussed in the first two meetings and eventually turned into the main guiding principles of their product.

The larger and more varied in composition the teams were, the longer the orientation period was. The smaller and more subject-homogenous teams made their major design decisions quickly. The most extreme example was N\&T, which even before the official start of the design process already had a general design set-up (that had been developed by the teachers in general discussions in preceding years). 
Construction - after the main design decisions had been made, construction of materials and lessons plans was done individually with little interaction or feedback. In five of the teams, there was hardly any cooperation on the construction of these materials. Once the tasks were divided, teachers worked on their own tasks. These were then bundled together to create the final product.

In two teams (N\&T and Dutch) there was some form of feedback cycle in which teachers discussed the work of one another. These teams were also the teams with the most interdependence in the design and enactment of their curriculum. SOS, which also aimed at an integration of subjects, displayed less cooperation in construction. This can be explained by the varying level of participation in the work of the team, where not all the teachers were seen as committed to the process. The teams that displayed more cooperation are also the ones with the strongest initial ambition for collaborative design (N\&T and Dutch).

Evaluation - none of the teams conducted explicit evaluation of their design work. Only two teams (Dutch and French) conducted pilots of materials they planned to use in their new curriculum. The focus during the piloting was on usability issues (whether there is enough time/space). In the Dutch team the feedback cycles of the team also functioned as a kind of an evaluation method as the coach helped the team define several criteria for feedback, based on their reform goals.

Implementation-aside from the piloting, no team implemented any of their materials during the preparation year.

In section 4.2.6 the relationship and sequence of activities is discussed.

\subsubsection{Curriculum components in discussion/work}

In examining how the different curricular components were expressed in the TDTs' work, the following general conclusions can be drawn:

- Time and Place are the most prominent at the (beginning of) development discussions of the teams. The clearer the reform ambitions of the TDT were and the better the overview of the process was, the less conditional Time and Place became for their work.

- Content of teaching is mainly taken for granted.

- Rationale, Goals, and Teachers' Role are often absent in team discussions.

- Use of blueprints and paper products led to discussion of more curriculum components. 
Time and Place-these two elements were discussed most often in the teams. In the beginning of the process, they played a central role in the meetings. In three of the teams (FL, Math, and Arts) the process did not proceed until this was resolved; they were conditional for further work. In other teams (Dutch, N\&T, and French), the two elements only functioned as a delaying factor, but the teams worked further even before this was resolved. These teams were the ones that had the clearest reform aspiration initially. Moreover, members of the Dutch and N\&T teams were a part of the project group. Therefore, they had a better overview of the possibilities and developments, and therefore less uncertainty in their work.

Content-content was taken for granted in most teams. Three teams discussed the content of their future curriculum, considering which content elements will or will not be used (SOS, N\&T, and Arts). These three teams are those who strived the most for subject integration in their design. In other cases, the used textbooks seemed to dictate the content.

Rationale and Goals - these were rarely discussed in the work of most of the teams. Only two teams discussed this subject explicitly. In the Dutch team, during the start of the process, a discussion on rationale and goals was initiated by the coach; it was also a recurring discussion in the SOS team. The findings in SOS might be explained by the long orientation stage. All coaches encounter difficulties when trying to initiate the discussion on the subject. Their explanation for this is that teachers found it difficult to discuss abstract concepts of education and that teachers rely on the curriculum materials they use to account for this aspect.

Materials - the teams that designed all or some new materials (SOS, N\&T, and Dutch) were the teams where explicit discussion occurred on the form and content of the teaching materials. In the other teams, the new textbooks are the only reference to learning materials.

Teacher's role - teachers played a role in the discussion in two teams (N\&T and Math). In both teams this element played an important part of the reform aspiration of the teachers prior to the start of the reform.

The other curricular components (such as Grouping and Assessment) were discussed sporadically if at all and were not present in all the teams' discussions. 
When teams discussed concrete paper products (such as general planning of the curriculum, team plans, or blueprints of learning materials) this led to discussion of more curricular components. However this discussion was in line with the above mentioned, 'time' and 'place' getting most attention and the other components only being discussed briefly.

\subsubsection{Substantive consideration}

Of all the discussed substantive considerations (Subject, Society, and Studentsee chapter 2) one stands out:

- Subject coverage is the main consideration of the teams. Other considerations play no role in the discussion.

The Subject consideration, although often very implicit (see 4.3.3), was the most vivid in the work of the teams, concentrating on content coverage by covering all sections of the used teaching materials. As mentioned above, this was mostly a short discussion, using the textbooks as the main guide for decision. In the two teams that displayed the most subject integration (SOS and N\&T) most of the discussion was on which content was covered, in what way, and how to connect the content from different subjects. The Society and Student considerations hardly came into the discussions of the teams.

\subsubsection{Main quality considerations}

Considering curriculum quality criteria (validity, practicality, and effectiveness see chapter 2) one issue is central:

- Practicality was the main criterion discussed for TDT products.

The issue of practicality was the main and recurring quality criterion in the discussion of the TDTs. This was evident both in the analysis of the different cases as across the TDTs. Only one team (Dutch) also discussed the consistency of their design and its effectiveness in achieving the reform goals. 


\subsubsection{Sequence of activities}

Considering the process in the different TDTs, several general design sequences become clear:

- Smaller teams, with a stronger initial ambition for common work and a positive stance towards the reform goals display multiple short cycles of design on the meso-level followed by construction of concrete learning materials. These teams incorporated the pedagogical reform goals most explicitly in their products.

- Teams with less initial ambitions and support of the reform display a long design phase with limited analysis activities, followed by a short construction phase at the end of the school year.

- Organizational clarity was decisive for continuation of the development process in teams with little initial ambition.

- Paper products were transition markers from design to construction.

- Teams were passive in gathering information and waited for action of school and project leaders.

First, two general design sequences emerge:

- Multiple short cycles of design on the meso-level (whole subject, general guidelines, and division) followed by construction of concrete learning materials on the classroom level and then again adaptation and discussion of the design on the meso-level (Dutch, N\&T, N\&H, and French). This kind of sequence was found in smaller teams, with a stronger initial ambition for common work and a positive stance towards the reform goals (in two casesDutch and N\&T-one of the team members was part of the project team that formed these goals in the first place). These teams were also the ones that seem to have incorporated the pedagogical reform goals most explicitly (and successfully) in their final product.

$\mathrm{N \& H}$ was an exception to this because of its size and lack of strong ambition or participation in the project group. Their final product also did not demonstrate an explicit relationship with the pedagogical reform goals. At the same time, the team members formed a cohesive team that had worked together often in the past and all generally supported the reform from its beginning.

- A long design phase with some analysis activities followed by a short construction phase at the end of the school year (FL, Arts, Math, and SOS). This process was associated with teams that had less initial clarity about their ambitions in the reform and in which the support of the reform was not common. 
Moreover, three other sequence elements arise from the data. First, teams with little initial clarity on the reform and poorly defined reform ambition started concretely working on the design and construction (moving beyond the general discussion) only after organizational clarity was achieved (Math, Arts, parts of FL, N\&H, and SOS). Construction began in these teams after teachers had a concrete image of possible future practice and conditions. In practice, it meant for most of these teams construction began at the end of the school year. Second, the transition from the design to the construction phase was associated with the production of a paper outline of the meso-level design or a rough paper sketch of the construction format that the teachers needed to follow. It is not clear if this was a causal relationship in which the paper product brought clarity to the team members and enabled the construction work. Alternatively, this might have been a sign of the completion of the design phase in the team, which then naturally moved to construction. Third, only a few teams actively searched for clarification when they confronted lack of clarity (Dutch, N\&T, N\&H, and French). These teams had strong organizational connections to the school leadership and made use of this in these situations.

\subsubsection{Place of activities}

Most of the work of the team occurred at the following times:

- Teams met at school between lessons and at the end of the school day.

There were no fixed days or locations for work. Construction was done (individually) at home at the discretion of the teacher.

\subsubsection{Participants and their role}

Analyzing the participation and collaboration patterns the following points become clear:

- The only formal role was that of the chairperson.

- Informal role division was based on the participation in the development process (how involved teachers were).

- More interdependence in curricular products led to more joint work (only when there is a clear formal role division or equal roles. Otherwise, it was limited to joint work on the general framework).

- Small, homogeneous teams need less coordination and display less relationship problems. 
Looking more closely at the data shows that in many of the teams, only a chairperson role was formally defined. This person often attended the project group meetings (although not all teams were represented in this group). No other formal roles were set. At the same time in all but one team (SOS), the task definition of chairperson was not clear but was not an issue of discussion in any setting (in or outside of the team).

Although no other formal roles were often defined or divided, in four of the seven teams (SOS, N\&H, Arts, and FL) an informal role division developed. This occurred mainly in relation to the generation of design ideas and an active role in the design and construction phase. In these teams, there was a differentiation in the level of involvement of their members in relation to this aspect, some being more active than others.

Considering the level of joint work in the teams (for example, construction of materials that was discussed earlier), there was a great variety in the teams. Figure 4.1 shows the different forms of joint work that took place. They ranged from discussing and sharing ideas (the left side of figure 4.1) to construction of actual learning materials (on the right side of figure 4.1). Whereas all teams had some form of joint work in discussing ideas, planning, and even in selecting textbooks, joint work on design and construction of materials was less common.

\begin{tabular}{|c|c|c|c|c|c|c|c|}
\hline $\begin{array}{c}\text { Ideas } \\
- \\
\text { guidelines } \\
\text { for deve- } \\
\text { lopment }\end{array}$ & $\begin{array}{c}\text { Ideas } \\
- \\
\text { general } \\
\text { framework }\end{array}$ & $\begin{array}{c}\text { Materials } \\
- \\
\text { selecting } \\
\text { textbooks }\end{array}$ & $\begin{array}{c}\text { Materials } \\
- \\
\text { selecting } \\
\text { materials }\end{array}$ & $\begin{array}{l}\text { Materials } \\
- \\
\text { construc- } \\
\text { ting plan- } \\
\text { ning }\end{array}$ & $\begin{array}{c}\text { Materials } \\
- \\
\text { comments } \\
\text { on each } \\
\text { others } \\
\text { design }\end{array}$ & $\begin{array}{c}\text { Materials } \\
- \\
\text { alternate } \\
\text { construc- } \\
\text { tion of } \\
\text { same } \\
\text { materials }\end{array}$ & $\begin{array}{c}\text { Materials } \\
- \\
\text { construc- } \\
\text { ting } \\
\text { materials }\end{array}$ \\
\hline $\begin{array}{c}\text { FL } \\
\text { Math }\end{array}$ & $\begin{array}{l}\text { N\&H } \\
\text { N\&T } \\
\text { Dutch } \\
\text { SOS } \\
\text { Arts }\end{array}$ & $\begin{array}{l}\text { N\&H } \\
\text { Dutch } \\
\text { SOS } \\
\text { Arts } \\
\text { Math }\end{array}$ & SOS & $\begin{array}{c}\text { N\&H } \\
\text { N\&T } \\
\text { Dutch } \\
\text { SOS (part } \\
\text { of) }\end{array}$ & $\begin{array}{l}\text { N\&T } \\
\text { Dutch }\end{array}$ & Dutch & \\
\hline
\end{tabular}

Figure 4.1 Levels of joint work in the TDTs in Copernicus High School

Those teams who showed more joint work concerning materials were those teams that had more interdependence in their design product. The role division in these teams influenced how far this went. When the role division was strict and defined (N\&T) or when the teachers had a clear equal role (Dutch) there was more cooperation on the materials themselves. In teams where there was informal role definition, even when there is interdependence on the design (SOS), 
joint work stayed at the level of constructing of the planners. When there was no interdependence in the design product, cooperation did not move beyond general discussion on the framework, and even then, it needed to be strongly facilitated by the coach.

Small, subject homogeneous teams (Dutch, N\&H, N\&T, Math, and part of the Arts) had a 'smoother' process with less coordination and relationship problems. Larger, heterogeneous teams (SOS and FL) had to deal with the internal relationship issue as part of the work. What are the work relationships? Who is responsible for what? How does one deal with passive members? Because of this, the role of the coach in steering the team was more prominent as the team had little independent steering capacity.

\subsubsection{Work orientation}

The work orientation of the teams showed the following pattern:

There was a variety in the extent to which teams were oriented towards the actions/input of the school management and school:

- Teams with a clear initial ambition and a positive stance toward the reform followed their own development line.

- In teams with less clear initial ambition, the degree of vagueness/clarity of the school-wide reform framework had a great impact on their work.

Teams, thus, displayed different orientation towards the actions/input of the school management and school framework. There were three types of noticeable orientation:

- Teams that had their own development line were bothered/disturbed/ annoyed by the lack of clarity or changes in the framework but did not seem to suffer and had no delay in their work. They drew their own lines. When they did have problems, they actively searched and negotiated with the leaders (N\&T, Dutch, and French).

- Teams that suffered from lack of clarity of the reform framework but started their design work despite its experienced vagueness. When they eventually received more clarity they accepted it as a given and utilized it $(\mathrm{N} \& \mathrm{H})$.

- Teams for which the school framework was very dominant and had significant impact on the extent to which the team could proceed with the development. Even when they did have their own wishes they waited for the school framework (Arts, Math, FL, and part of SOS) 
This orientation on the framework provided by the school leaders was influenced by the initial ambition of the team and its stance towards the reform (the stronger the ambition, and the more positive they were, the less they were oriented to the framework). Although $\mathrm{N} \& \mathrm{H}$ had a less defined initial common ambition, the teachers were in general positive about the reform and school. Therefore, they needed more clarity on the reform before they could move on. However, when that was supplied, they complied and used it.

\subsubsection{Organization of work}

Turning to the organizational aspects of the work of the TDTs the following patterns come forward:

- Teams did not work in a planned and structured manner.

- All teams have regular meetings with the coaches (once every 3-4 weeks) and keep up with it.

- The coach is the main trigger for getting together. In between that teachers come together if:

- they perceive an urgent need for it (such as development in the school that had influence on their plans)

- there is a concrete task defined at the meeting with the coach.

The data shows that no team explicitly planned the design process, even though they produced a general team plan in December 2002 in which most teams stated a general goal they wanted to achieve by the end of the school year (in most cases it was a curriculum for year one of lower secondary). At most, teams decided before a meeting what the meeting would be about (FL, Dutch, and SOS). This was often done due to insistence from the coach. In some teams, it was not even clear ahead of time what the team would do during a meeting ( $\mathrm{N} \& \mathrm{H}$ and Math). Only one team (Dutch) worked on a more structured approach both in planning ahead and in structuring the meetings and work. This was strongly influenced by the coach who made the planning and kept adjusting it. Teams did not make minutes of meetings. In some cases, the coaches even took this task upon themselves (FL, Arts, and Dutch). All teams had regular meetings with the coaches (once every 3-4 weeks) and kept up to that. These meetings were the main trigger for coming together. 
Teachers came together if:

- they perceived an urgent need for it. This was done incidentally during the school day, between lessons. This seldom happened in most teams. An exception to this were teams that experienced a strong initial reform motivation and joint task (N\&T and Dutch);

- there was a concrete task formulated in the meetings with the coach $(\mathrm{N} \& \mathrm{H}$, Dutch, and Arts).

\subsection{CONDUCIVE OR HINDERING ACTIVITIES AND APPROACHES}

After describing the kind of activities and process that took place in the different teams, the focus turns to the characteristics of activities that were conducive and/or hindering for the TDTs. These were identified both from the interviews in which teachers could reflect about the process as well as from the process data itself. In the case of Copernicus High School, the study was aimed at conducive activities and approaches (see chapter 3) and therefore the findings are formulated in the positive (conducive) form. A negative formulation of the same findings can be considered as a hindering element. The main findings are:

- Activities were conducive when they helped the TDT and the teachers create a concrete image of a possible future practice and when they tackled a major concern of the team.

- Division of the construction tasks increased the 'speed' and production in the development process but often led to less collaboration and alignment.

- Teams with clearer initial ambitions experienced a gradual process and had a clear focus. Teachers experienced few major obstructions but also fewer 'breakthroughs'.

To elaborate, it seems that, overall, activities were conducive when they helped the team and teachers create a concrete image of a possible future practice. This could be by clarifying the conditions under which they worked, giving an example of a possible practice or formulating their abstract plans into a concrete setup. This finding is confirmed by both the interviews and the process data.

Several concrete examples are:

- Exposure to other schools that were implementing similar reforms or organization. Two of the teams (SOS and Math) that were exposed to innovative practice in other schools (through either a field trip or a presentation) found it conducive and were either inspired by what they saw or used solutions they encountered in their design. 
- Drawing up a concrete plan or a first blueprint on paper (SOS, Math, Dutch, and N\&H). This gave teachers a common artifact that steered and focused the discussion. It also eliminated some uncertainties. This was mentioned several times in the interviews and was detected in the process data. As the description in 4.2.6 shows, after a paper product was produced, the design process often progressed more rapidly. This also led to a discussion of more curriculum components (cf. section 4.3.3).

- Team meetings in which the project manager was present and participated in the discussion (Dutch and N\&H). The information the project manager supplied answered a concrete question that preoccupied the team. It enabled them to continue with their design work.

A less clear-cut conclusion concerns the pilots. Piloting of teaching materials was mentioned as helpful in several cases. In cases where the piloting consisted of new experiences that touched on the essence of the redesign, teachers reported significant impact on their position in the reform and changes made in the planned curriculum of the teams (Dutch and French). This was confirmed by process data showing concrete adjustments of the design of the team. When only one teacher was involved in the pilot (as the case of French within the team FL), the effect seemed to be limited to the one teacher. There is little evidence that it had an impact on the work or perception of other teachers in the team. At the same time, in two cases the pilots had little impact on the teachers or the process (Arts and SOS). This might be because they dealt with an issue that was not central to the reform (trying out a possible kick-off activity in SOS and reexecuting an activity that was already undertaken in past years in Arts). Additionally in both of these cases, only one teacher executed the pilot and reported experiences in team meetings.

A tentative explanation of why activities are conducive in some teams and are less effective in others is the relationship between the activity and a 'major concern' or difficulty of the team. Because many teams had difficulty creating a concrete image of their future practice (also due to the vagueness of the school framework in the beginning), activities that aided were helpful. Teams that undertook activities (fieldtrip by FL, pilot in SOS and Arts) without a clear need or question did not find them useful in the process. 
In several cases, it seems that when the (construction) tasks within the team were divided and established (in contrast to informal division), the process seemed to proceed 'faster' in the sense that more materials were produced more quickly (SOS and N\&H). This might be due to the fact that most of the work from that moment was done individually by (several of) the teachers.

The initial ambitions of the teams had an influence on the manner in which they proceeded through the process. Dutch, N\&T and French, having had the most crystallized initial ambitions, went through the design process gradually, experiencing little obstructions and also fewer breakthroughs. In their cases, an activity described as conducive helped them but was not deemed crucial or something without which they could not have proceeded. Because of their focus, they were not dependent on breakthroughs.

\subsection{CONDUCIVE OR HINDERING SCHOOL CONDITIONS}

After describing the activities of the TDTs and trying to identify conducive activities, the organizational conditions of the TDTs were explored. This was done in order to find those conditions that contributed to their work. By considering the teams' characteristics and results during the case and cross-case analysis, explanations were sought for commonalities and differences in how conditions affected the TDTs' work.

\subsubsection{Infrastructure}

Considering the infrastructural element of the work of the team, the following main findings were encountered:

- Time allocation was considered an important factor in facilitating the work. However, time allocation was not always in proportion to the task of the teacher in the team.

- The less committed the team was to the reform process the more important time allocation was experienced.

- Organized common planning time during school hours was helpful in facilitating regular meetings. The more a team shared a common reform ambition, the less scheduling was a hindering factor in their work. 
When the issue of infrastructure in Copernicus was explored with teachers, two subjects, both pertaining to the time factor, were identified: allocation and scheduling.

Almost all teachers were allocated time for working in the TDTs. All the participating teachers received the same number of working hours for this goal. All interviewed teachers contend that the design work itself exceeded the allocated time. This was the case in all the teams, irrespective of the process or its result. In the TDTs of N\&T, Dutch and French teacher, this was less of an issue and teachers found it less problematic. These teams had a higher and more defined level of common ambition for the reform. They may have been more committed to the process and therefore less inclined to see time as an obstacle.

When there was a perceived discrepancy between time allocation and the contribution of the different teachers to the team, time allocation formed a disturbing element. This was the case in one of the teams where the teacher most involved, and actually, the main participant in the team had gotten (due to different factors) no task hours allocated for the development. This was in contrast with her central role in the design process and the expected implementation. In SOS, although two teachers were active in the design and construction process, all teachers were allocated the same amount of task hours. This was deemed unfair and was a constant source of irritation (especially to one of the involved teachers).

Concerning the scheduling of meetings, no formal school-wide decisions were made. In observing the scheduling of meetings, three patterns arose:

- Teams that had no planned common meeting time and therefore had trouble scheduling meetings (SOS, N\&H and FL).

- Teams that had no planned common meetings times but teachers had for at least a part of the year parallel 'lesson-free hours' during school days. The teachers used this for meetings. These teams met on a more regular base, on regular intervals. (Math and Arts).

- Teams in which scheduled meetings were not even an issue of discussion. They met in high intensity (almost weekly). This happened after school hours, before school hours, or during breaks; whenever they could find the time.

A tentative conclusion here can be that allocation of time and organized common planning time during school hours is helpful in facilitating regular meetings, which are necessary for common work. At the same time the more a team shares 
a common reform ambition, the less this is a problem and they find ways to work around it. This is especially important for those teams that have trouble in defining common goals and designing a common curriculum.

\subsubsection{External support and role of researcher in work of team}

The presence and work of the external support was a major change in the work of the teachers on the reform. Findings show that the external support had a big impact on the work of the teams. When exploring the issue of external support the several findings become apparent:

- The coach had a central role in the production of planning documents.

- The coach was the most important trigger for organizing meetings.

- Support was appreciated when it answered a specific need of the team/teachers. The most prominent need was for a concrete, tangible contribution to the development process in the form of curricular products.

- Common explorative activities preceding the development process helped build a strong positive relationship between the teachers and the coach and had a positive effect on the experienced support during the design process.

- Support role was seldom an issue of discussion in the team even when difficulties were encountered.

All but one team (N\&T) made use of the coaches of the SLO. In three teams, the university researchers attended the team meetings. The researchers had on several instances a coaching role in the team by actively being involved in the work of the team: either by giving advice on different issues or helping construct or giving feedback on planning documents. The discussion here concerns the coaching role, whether done by the official coach or the researchers.

The external support fulfilled different roles in the different teams, ranging from discussion partner on general subjects, through helping the team to structure discussions and work, to a working member of the team who contributes to teaching material construction. In all the TDTs the coaches played a central role in the production of planning documents. They were often the ones writing the documents (based on discussions in the team and pieces produced by teachers) and only if they pushed for it these documents were updated in line with the developments in the team. Additionally in some teams, the regular attendance of the coach urged them to meet, which would have occurred less frequently if the coach did not attend (SOS, N\&H, and FL). 
The role of the support (either by the coach or by the researcher) was appreciated and perceived as helpful when it answered a need of the team/teachers. Therefore, the perceived conducive activities varied between the teams:

- SOS-organizing and structuring the discussion, support of the chairperson, eventually helping produce teaching materials.

- Dutch-providing a grip on the development process (how to do it), providing pedagogical expertise, helping with teaching materials design and production.

- Arts-helping in writing their plans and opening the discussion.

- N\&H-supplying ideas for use in their materials redesign and feedback on ideas, supporting team in negotiation with the school leaders about laboratories.

- FL-supplying a common reform framework, urging team to meet and work.

- Math - coach failed to answer the need of the teacher involved.

Although some support provided was often perceived as conducive, in almost all cases teams had expectations of the coaches' role that were not realized. This led to varying levels of dissatisfaction, depending on the overall support. When the support answered at least one major need of the team, other discrepancies were tolerable.

The most often articulated need for support was a concrete, tangible contribution to the development process-i.e. supplying materials, supplying concrete examples of alternative practice, and helping producing those materials (FL, N\&H, Dutch, Math, and SOS). When this role was (partly) fulfilled (SOS and Dutch), this led to great satisfaction. Only in one case did this kind of discrepancy lead to termination of the support relationship at a very early stage (N\&T). This was due to very explicit reform ambition and views of the teachers and the feeling of the team that the provided coach had explicit different ideas.

It seems that common explorative activities (preceding the concrete development process) helped build a relationship between the teachers and the coach or researcher, which strengthened the support role during the design process. Due to the common history, teachers had a feeling that the support 'better understood them' and therefore their contribution was more often appreciated. In one case the teachers and the coach worked on a prior reform project (Dutch) and in three other cases the researchers who followed the teams' work were involved in the baseline research with these teams (SOS, N\&T, and N\&H). In the latter, the relationship 
built during the baseline research seemed to be so dominant that it led to role confusion. In these teams, the teachers showed a preference for the support of the researchers and approached them on several occasions with support questions even though this was not the original setup.

It is striking, considering how much influence the support had on the teams, that the role of the coach was seldom an area of discussion in the team, neither before the beginning of the work nor during the work itself. Even when there was a discrepancy between the needs of the teachers and the established role of the coach, this was not discussed and some dissatisfaction remained until the end of the process (SOS, Math, N\&H, and FL).

\subsubsection{Coordination - contact with rest of school/teams}

An added level is that of the relationship and coordination between TDTs and the impact it (might have) had on their work. Considering this aspect several major findings are revealed:

\section{Interaction between teams and teachers:}

- organized interactions with other teams on plans and results were highly appreciated. It was seen as more relevant when based on reporting of concrete experiences.

- informal interaction on reform issues hardly occurred.

- School-wide schooling days were helpful only when resulting in concrete contribution to the work of the TDT.

The project team:

- was a major source of information for the teams (less important for teams that had good connections with leadership).

- helped in assessing the developments in the TDT in relation to the school-wide process.

- supported the function for the TDT chairperson.

- precise function was unclear - this led to dissatisfaction with results of discussions.

During the school year, several school-wide meetings were organized. These interactions with other teams in which they presented their plans and results were highly appreciated by the teachers and contributed to the cohesiveness between the teams. The main contributions of these occasions were as follows:

- An overview of the developments in school - teachers expressed a need for an 'overview' of the developments in the different teams and they missed more opportunities for this (Fr, Arts, Dutch, Math, and SOS). 
- increased feelings of a 'joint venture' - seeing what others are doing, what problems they encountered, and how they solved them (Fr, Dutch, and N\&T). There are some indications that interaction between teams was seen as more relevant when it was based on reporting concrete experience with students (pilots).

Only one team noted that these meetings had no contribution to their work (Arts). This can be due to the fact that the reform in Arts was different in character from the other teams because they did not have to adhere to the organizational changes that were central in the reform in the other teams (they did not participate in the common open learning environment which was central to the reform).

Outside of these organized meetings, teachers informally interacted on reform issues only with those peers that they perceived as having a similar commitment level (this was the explicit motivation of one of the Dutch teachers and the French teacher). Otherwise, teachers stated having little informal interaction on reform issues with other teachers.

School-wide schooling days (when all the teams met and followed organized activities on several themes) were helpful for the teachers only when they resulted in concrete products contribution for the design process in the teamproviding a possible framework and resulting in a plan or a product that they can use in the next meeting. General discussion themes did not contribute to their work and were seen as irrelevant (Arts and N\&H).

The project team, which met regularly, had several important coordination functions:

- Major source of information - the project team enabled teams to anticipate and follow developments. Teams that had no representative in the project team found that they missed necessary information for the design work (FL and Math). The need for the project team as an information source was less prominent with teachers who had strong informal relationships with the school management (N\&T, N\&H, and Dutch).

- Assessing the developments in the TDT in relation to the school-wide processthe interaction with the other TDT chairpersons enabled teachers to estimate their teams' place in the general development (Are they lagging behind? Are they coming to very different conclusions than the rest of the teams?). 
- Support function for the TDT chairperson-one chairperson indicated that interacting with other chairpersons helped her consider her role and share experiences about this new experience (Arts).

At the same time, the precise functions and jurisdiction of the project team was unclear. This led to dissatisfaction with some of the results of their discussion because different actors expected different results. According to several participants, the project team did not function as a decision-making institution but as an information conduit from the management to the TDTs.

\subsubsection{Role of school leaders and school-wide framework}

Both the school-wide framework and the manner in which the school and project management interacted with the team influenced their orientation towards the reform as a whole. Examining the data leads to several conclusions on these issues:

School-wide framework:

- The vagueness in the school-wide framework had a varying influence

- When initial team ambition was unclear it led to overreliance on the availability and clarity of the school-wide framework and a passive disposition of the TDT.

- Clear initial ambition and access to the project manager led to less dependence on the availability of a clear reform framework.

- The relationship between the teams' wishes and school framework was unclear. This created some friction. It had less effect on teams with a strong connection with leaders.

School and project leaders:

- Direct, face-to-face interaction of teachers with project manager was the most effective communication form. Presence of leaders in team meetings was greatly appreciated and provided direct answers and solutions. This also had an important relational role as it implied involvement and interest.

- Teams with unclear initial ambition were more reactive and therefore more influenced by the (in)activity of the leaders.

- Leaders applied little 'control' on the work and results of the teams.

Also in considering this aspect, it becomes clear that there was a difference in orientation between those teams with a strong initial ambition and those with a weak initial ambition. Considering these conclusions more extensively makes this difference clearer. 
The (long-perceived vagueness of the) school-wide reform framework had a varying influence on the different TDTs. It seems that those teams that had less defined initial ambition were more oriented toward the presence and clarity of the framework (see section 4.3.9). The perceived vagueness led these teams to a somewhat passive disposition. They waited for the framework to be set. Teams that had well defined reform goals (Dutch, N\&T, and Fr), or very modest reform goals (N\&G) within the reform, and had easy access to the innovation leader, were less dependent on the presence of a clear school-wide reform framework. Teams with great(er) intrinsic ambition even seemed to benefit from (or were not disturbed by) the lack of boundaries. They had room to follow their own ideas (N\&T and Dutch).

As the development of the school-wide framework was somewhat dependent on the developments of the teams' plans, this had an additional effect on the teams. Teams were asked to articulate their wishes and were promised that by doing so they would get some influence on the school-wide framework. The exact relationship between the teams' wishes and school framework was unclear. This created some turmoil and was a source of irritation for some teams when they took the time to come up with plans that were consequently dismissed because the school framework could not allow for it. (FL, SOS, Math, and Arts). This dismissal of the teams' plans in favor of the school framework had less effect on several teams (N\&T, N\&H, and Dutch). These teams had strong connection with the school and project management and were inclined to recognize the possibilities and limitations of this process from the beginning, realizing that they needed to make concessions.

The Arts teams, that did not partake in the organizational reform (and thus were not expected to participate in the students' work in the open learning environment), felt therefore no 'structural' pressure to work on the reform. It meant that for this team nothing necessarily had to change.

The planning and process documents that were produced by the teams were (almost) solely produced at the request of school management and with intensive support of the coaches. They were not perceived as beneficial on their own (FL and Arts). However, when the teams did produce these documents, they expected timely feedback from the project manager. Teams found that this did not happen and it led some of them to perceive it as a token of disinterest and 
that their plans were unimportant. The feedback was then also seen as irrelevant (N\&T, Arts, SOS, and FL).

Direct, face-to-face interaction with project manager was the most effective means for teams to acquire information and solve problems that arose during the work process. This occurred in two manners:

- when team members had what they described as a positive relationship with the project manager. In this case they actively approached him, outside of organized activities, with questions and requests (N\&H, N\&T, Dutch, Math, and French);

- when the project manager sat in on team meetings. This was greatly appreciated by the teams as it provided direct answers and solutions in the presence of all team members (N\&H, N\&T, Dutch, Math, and SOS).

The direct interaction seems also to have fulfilled a relational role because for some teachers the presence of the school leader or the project manager at team meetings indicated school management involvement and interest in the process of the team (SOS and FL). Teams with a less defined initial ambition in the process seem to have been more dependent on the (in)activity of the school and project management (FL, Arts, and Math). They were not proactive and mostly reacted to actions or requests of the management.

Finally, there was little 'control' of the realization of the reform goals in the work of the teams; they were not evaluated based on their work on achieving the reform goals. (SOS, N\&T, Math, and N\&H). This was the case both in personal and team interactions with the management.

\subsection{SUMMARY OF THE COLLABORATIVE CURRICULUM DEVELOPMENT IN COPERNICUS HIGH SCHOOL}

The description of the process TDTs were engaged in demonstrates how even in a relatively small and cohesive school great diversity still exists in how teachers and teacher teams engage in school reform. The reform started from a general idea at the school level and then developed along parallel lines. Alongside the developments of the curricula of the teams, the concrete school-wide framework took form. This was a conscious decision by the school leader and innovation manager, as they wanted to let decisions on the team level influence the reform at the school level and not start with a rigid and obligatory framework. Leaving 
many ends initially open did lead to many teachers finding the framework vague. This had a varying effect on the teams. It seems that those teams that had less defined initial ambition and were larger and less cohesive in composition, were more oriented toward the presence and clarity of the framework, which inhibited their work for some of the time. Additionally, the vague relationship between the developments of the plans on the team and school level created some turmoil and was a source of irritation for some teams that were disappointed when their plans were dismissed when the school framework did not allow for them. By far the most effective instrument for the innovation manager in tackling this and supporting the work of the TDTs was direct, face-toface interaction during team meetings. This had both an informative and a relational effect. Other activities on the school level that were also aimed at informing teams on development were appreciated but only seen as functional when they provided teams with concrete instruments/ decisions that they could use in their development work.

Considering the work of the teams, it was rarely structured or planned. The teams work from one meeting to the next. In this work, two emerging sequences of activities become apparent:

- Small teams with clear reform ambitions and a generally positive view of the reform conduct multiple short cycles of design a meso-level followed by construction of concrete learning materials on a classroom level.

- Teams that initially have more vague ambitions and mixed support of the reform among the teachers display a long design phase with some analysis activities followed by a short construction phase at the end of the school year.

In general, all teams were oriented towards rearranging existing teaching materials. One team chose to completely develop their own teaching materials and three other teams developed a part of their materials. All teams concentrated on developing and constructing the planners or materials, mostly spending little time on the analysis and planning of their curriculum development task of the characteristics of the curriculum itself. Often, the main orientation was dividing the available materials across the 'Time' and 'Place' available. The other curriculum components (like 'Teachers' role' and 'Learning activities') which are a prominent part of the school-wide reform goals are discussed less often. In teams where they develop new materials these components do get attention that is more explicit during the development process. Overall, activities were seen as 
conducive for the teams when they helped them in acquiring a more concrete image of a possible future practice. This could be by clarifying the conditions under which they will work, such as providing an example of a possible practice or the concretization of their abstract plans into a concrete setup. Examples of these activities are taking field trips to schools that are implementing similar reform ambitions, drawing up a concrete plan or blueprint on paper, or getting direct information from project management. Pilots had a conducive effect only if they were concerned with new activities that were central to the reform and only by those teachers participating in the pilot.

Considering the role of the team's coaches a diversity of roles is apparent. Their contribution to the work was most appreciated when it responded to a need of the team/teachers. Therefore, the perceived conducive support varied between the teams. It is surprising then that the need of the teams and the role of the coaches in the teams was seldom a subject of discussion.

At the end of the first year of work, all teams had at least guidelines as to how they will work the following year. All adhered to the new timetable division. Only four teams had translated the guidelines to concrete lesson planners for (part of) the school year. The other teams had to do this during the summer vacation or at the start of the following year. The School-wide reform goals were explicitly applied and translated to concrete measures in the lesson plans in the design of two of the teams. In the case of the other teams, the plans were either not ready or did not address the school-wide reform goals.

In the following three years, the researcher revisited Copernicus High School annually. In each of the visits, the same original respondents (a teacher from each of the TDTs, the coaches, the innovation manager, and the school leader) were interviewed about the work of the TDTs and the developments in the implementation. The goal of this implementation study was to gain insight into the sustainability of the TDTs and the school-wide reform. The results of this implementation study (Handelzalts, 2007) are used in chapter 7 to reflect on the long-term perspective of TDTs. 


\section{CHAPTER 5}

\section{TDTs in Kepler High School}

This chapter describes the cross-case analysis of the case studies conducted in Kepler High School in the school year 2006-2007. The design work of five TDTs was followed, described, and analyzed. Section 5.1 gives a short description of the specific research methods applied in the study of the school and the adaptations that have occurred. Next, section 5.1 gives a short introduction to the school, the general characteristics of the school-wide reform initiative, and the school-wide reform process. Following that, sections 5.3 through 5.5 describe the findings on the three research questions of this study. These sections start with a short summary of the main findings followed by a more extensive discussion. In order to keep the text compact, the case-study descriptions are not included in the chapter but can be found in section 3 of the accompanying CD. Finally, in section 5.6 a summary of the findings on the school level is presented.

\subsection{MeTHODOLOGY OF THE STUDY IN KEPLER HIGH SCHOOL}

Following an evaluation of the data collection in Copernicus High School, three issues became clear. First, the process data, although capturing the main events of the process, was on a general level, making it difficult to determine the exact content and sequence of events. The general image was useful but lacked in giving sufficient insights into the daily developments in the teams. This meant that following sub-study needed to capture more process information, probably by documenting more meetings. Second, during the interviews it became clear that participants had difficulty recalling the process as a whole. Often only a general impression of the process and an incidental occurrence were recalled spontaneously by the participants interviewed. When the researcher mentioned specific activities that were recorded as part of the process documentation, participants often did recall them and could attach some meaning to them. This implied that participants might require a more structured manner to jog their memories considering the chronological events. Third, the process documentation 
was based on the perspectives of the key-informant teachers. While this proved to be a rich source of information, it also made it vulnerable. This vulnerability is two-fold. In the first place danger arises from overstressing one dominant perspective on the process of the whole team. Although this can be somewhat compensated by using the process data of the interviews of the coaches and school leaders, this can sometime be problematic. Additionally, using one main informant could endanger the collection of data when and if this informant drops out. This, however, did not occur in the Copernicus High School.

Based on this evaluation and additional piloting of the research instruments, the methodology was somewhat adapted. The baseline study methodology stayed consistent but at least two teachers from each TDT were followed. This was done in order to increase the validity of the findings concerning the teams' characteristics and practice. The school section leaders were interviewed for their perspective on the process and the teams involved.

During the process, all team activities were attended and documented by the researcher. The Contact Summary Sheets and process scoring sheet were filled in after every encounter (see CD section 1.2). This enabled a more detailed and complete registration of the process the teams undertook.

The exit interviews (at the end of the first year) were held with all teachers involved in the team. These interviews followed the storyline methodology described in section 3.3.3. Teachers were requested to draw two storylines: one concerning their general experience of the TDT and the other concerning the curriculum development process. After filling the diagrams independently, the descriptions of the teachers were compared and discussed. Additionally several explicit questions concerning several elements of the analytical scheme of the study were added in order to insure coverage of the issues. At the start of the interview teams received an overview of all of their common activities with a short description of the content in these meetings. This helped them remember the occurrence of events. At the same time no interpretation of the researcher of the activities was given so as not to influence their perception of the event's effect. The interviews were audio recorded and processed on the basis of the themes discussed and submitted to the teachers for approval. Additionally, the school section leaders were also interviewed for their perspective on the developments in the TDTs. Again, based on all of the data, team descriptions were constructed on all the themes of the conceptual scheme. 


\subsection{INTRODUCTION TO KEPLER HIGH SCHOOL}

\subsubsection{The school}

Kepler High School is a large high school with about 1,250 students in the east of the Netherlands. It is part of a larger school-organization with a total of about 4,750 students and five schools, two of which are exclusively lower secondary and three which have both lower and upper secondary sections. In the lower secondary levels Kepler offers all educational levels, organized in mixed classes ('combinatieklassen') ranging from pre-vocational secondary education (VMBO), through senior general secondary education (HAVO) to pre-university education (VWO). In total, each year group in the lower secondary level has nine classes and about 50 teachers take regular part in teaching. After the two years at the lower secondary level students are then assigned to one of the educational levels. In the higher secondary level the school offers exclusively the higher levels of secondary education: senior general secondary education (HAVO) and preuniversity education (VWO). Students that are assigned to other levels transfer to another school in the school-organization.

A baseline study conducted in October 2006 showed that the general classroom practices at this school could be typified as rather traditional with mostly textbook-driven lesson patterns (with one exception being the Visual Arts, which used no textbook). The classroom atmosphere and pedagogies varied and were strongly teacher dependant. The overall curriculum was in line with the traditional nation-wide lower secondary curricular framework, showing little coherence between the subjects. The school had a pleasant, although busy, atmosphere partly influenced by the school-building that has become too small to contain the amount of students. The teachers worked in small single subject departments in which the main common orientation and work was on organizational elements (division of learning materials across available time and space). The responsibility for the planning of different year groups and levels was divided among the members of the department. Other teachers were expected to follow the plans that were made. Between the teachers only limited collaboration took place and professional debate and deliberations were rare. Departments collaborated seldom. Although each individual teacher had some (reform) aspirations, there appeared to be a gap between those articulated aspirations and their daily practices. There were mixed feelings toward the school-wide reform 
initiative. The teachers supported the general reform goals but some were ambivalent about the form they were getting in the school-wide reform. However, all teachers were to participate in the realization of the school-wide reform.

\subsubsection{The reform background}

In light of the developments concerning lower secondary education in the Netherlands the school-organization management has initiated several reform plans in its different schools. As part of these plans it defined, together with representatives of the different schools, general reform goals for the whole school organization. Next to the national framework, central elements in this were a concentration on more choices for different schools and more choice and self steering for the students within the school framework. Regarding this the curriculum needed to become more flexible, enabling students not only to have some choice in what they learn but also on how they learn it (within certain boundaries). The translation of these general goals in concrete plans was delegated to the different schools.

\subsubsection{School-wide reform process}

In 2003, Kepler High School decided (in consultation with the school-organization management) to build a new school building as the current building had become too old and too small for the current student body. In the school year 2003-2004 a taskforce of school management members and teachers representing all school sections was formed. This taskforce's assignment was to develop a new curricular framework and with it to generate guidelines for the new school building. This was to be done based on formal and informal consultation with the teachers in the school, the broad school organization educational guidelines (that were being formulated at the broad school organization level at the same time), and the national curricular guidelines. During the work of the taskforce it organized regular discussions with teachers in order to develop a common vision and to inform them on the developments. Based on the recommendations of this taskforce, the school management was to make decisions and build the new school building and the teacher teams (which at that point had yet to be formed) were expected to develop their curriculum. This task force was divided in two teams - one for the lower secondary level and one for the higher secondary level. The most significant design element decided upon by the task force for the lower 
secondary level was the construction of a semi-open learning environment, called 'home base' in which most of the subjects would be taught. This open learning environment would consist of a closed learning environment for each section with five instruction rooms and a large semi-open learning environment with flexible (ICT) work places for students. The learning would take place in this environment and teachers will utilize the different facilities, depending on the specific learning goals. The students' time in the 'home base' will be divided between the different subjects and students will spend at least two hours in the home base in order to diminish the commotion related to students moving between classrooms after every teaching period (which were then 50 minutes). This was deemed to enable more possibilities for student and teacher flexibility and therefore more possibility for differentiation and self steering for students. The 'active' subjects (Arts and Physical Education) and subjects needing laboratories (Physics and Biology) would not take place in the home base but would have dedicated learning environments tailored to their needs and wishes. At the same time, they too were expected to strive after the school-wide reform framework.

Two other developments took place during this period. In the school year 20042005 the school also made the transition to working in section teams. This meant that subject departments were not the basic organizational unit anymore. The sections were organized around an educational level and stage (for example: Lower-secondary HAVO/VWO). Each of these sections was appointed a section leader that was also a member of the school-management team. The second development was that the school decided to strive for more subject integration. Instead of the division of the content into subjects, the school aimed to organize it into learning-areas by the year 2010, which was expected to lead to less fragmentation in the curriculum. How far integrated these learning-areas would be and how quickly that would happen was left to the discretion of the specific team of teachers responsible for it. Since 2004 different teams have started experimenting with possible new designs. The Social sciences and the exact sciences (physics, chemistry, and technology) have been especially active in this.

In the school year 2005-2006 the decision was made on the design of the school building and the general curricular framework and the school year 2006-2007 was seen as a preparation year in which the school building would be built, the schoolwide framework would be further developed, and the learning-areas teams would work on developing concrete teaching plans on both the meso and micro level. 
The work of the learning-area teams was initiated in October of 2006. Initially 7 teams were formed, common to both sections of the lower secondary (VMBOHAVO and HAVO-VWO). Each of these teams had a chairperson who was a member of a coordination team that met on a regular basis with the two schoolsection leaders in order to follow the developments. During this stage the researcher was introduced to the school. It was then decided that he would follow two teams - Languages and Arts. These teams were seen as most fitting for the study as they were cross-curricular teams at the start of their cooperation. In October and November of 2006 a baseline assessment of the curriculum of both teams was conducted. However, even in November of 2006 it was already clear that both the Languages and Arts teams did not perceive the cooperation as productive and preferred to work in smaller subject-oriented teams. In the Languages this led to splintering of the teams based not only on the language to be taught but also on the educational level. Eventually this study followed five teams (Table 5.1).

Table 5.1 TDTs and their composition in Kepler High School

\begin{tabular}{l|l|l} 
TDT & Subjects included & Number of teachers \\
\hline French - VWO (Fr) & French & 2 \\
English - VMBO (En) & English & 2 \\
Dutch - VWO (Du) & Dutch & 2 \\
Visual Arts - All levels (VA) & Drawing, Craft & 3 \\
Music - All levels $(\mathrm{Mu})$ & Music & 2
\end{tabular}

From November on the TDTs worked on their individual plans. About once a month there was a section or school-wide meeting in which general issues related to the reform were discussed. In September 2007 the school would move to its new building and the teams' (re)designed curriculum was to be implemented for all the students.

\subsection{HOW THE TDTS ADDRESSED AND CARRIED OUT THEIR DEVELOPMENT WORK}

As mentioned earlier, five TDTs were followed in this study in Kepler High School (Table 5.1). As an introduction to the analysis of their work, the general outlines of the work of each team are presented here briefly: 
French VWO-during the first team meeting, the team discussed ambitious plans for changing their curriculum. This, however, got no follow-up and the team met only sporadically in the following months. In these rare meetings they discussed general issues and the effect of forming a school-wide framework for their subject. Only when the framework was clear about the organizational conditions did they started working (during a short period of consecutive meetings) on concrete lesson plans that were based on division of their textbook assignments across the available time and space. This construction was mostly done individually with little feedback. Although one of the teachers participated in a common pilot with other language teachers on more integration and even tried out one of her new lesson plans with students, this did not come up in team discussions. The work of the team was unstructured and the role division was informal as it was based on one of the teachers being more dominant in discussions and in taking the initiative for activities. At the end of the school year, only a small part of their lessons plans was ready.

English VMBO-this team had a hard time starting up after the languages team split up. They did not know how to handle this development assignment. Although they expressed this several times to both section leaders they felt they got little support. When they eventually started working on their design (towards the second half of the school year) they concentrated on exploring the organizational conditions and then coming up with a division of their current textbook assignments over the available time and space with some critical consideration of which assignments could be left out. They divided the work and each teacher was responsible for the processing of the assignments of a particular chapter in the new planners. Once this division was made there was little feedback among them. The communication between the teachers was hindered by their different background. While one was a very experienced teacher with a conservative view on teaching, the other was young with a little defined view on teaching. However, this subject was not addressed in their conversation. The more experienced teacher was much more dominant in the team meeting. The team found it difficult to find available times for meetings and met only several times during the year.

Dutch VWO-in the very early stages this team decided to stay as close as possible to their current teaching and up until late in the school year (April) they worked very little on the new planners. Instead they worked on the plans and teaching of the current school year. This can be ascribed partly to the vagueness 
of the school framework and need for organizational clarity before commencing development work. When they start planning the teachers spend an afternoon together on making one of the planners. This will then form the backbone for further individual construction of specific chapters. Although one of the teachers was involved in a pilot with other language teachers on more integration, this has little impact on the work of the team.

Visual Arts - this subject department (including the upper secondary) had been piloting several setups in the years before. These pilots were aimed at stronger integration of the different arts and more choices for students. They also had a tradition of not using set textbooks but making their own teaching materials. At the start of the work the team considered how to translating this into their new setup. Although at the start organizational conditions were explored and discussed they played no central role in their work. This was because as part of the reform they would get their own wing at school with control over its design. Initially they started working on the details of their setup (how content would be organized and which learning activities would be central). In that period, meetings were sporadic and often only partially planned ahead of time. Most of the materials and concrete plans were produced during the span of several meetings toward the end of the year when the pressure to produce materials grew. Construction was mostly individual with each teacher working on a specific part of the program with little feedback from colleagues, except from one occasion when two of the teachers worked collaboratively on one of the units. This team had most of the first year materials finished at the end of the school year. At the end of the year it seemed that the new school-wide roster might make some of their plans impossible. Although this lead to great disappointment, the team had the confidence that they could adapt their plans.

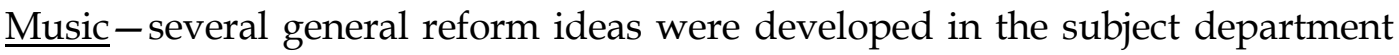
in the years prior to the school-wide reform. During the first two meetings these were discussed in more detail. Although they did discuss the organization conditions, these were not central in their work as they too were assigned to a separate wing at the school where they had some control over the design of the learning environment. Half-way through the year the team considered changing their choice of textbooks (which up to that point had been used for 18 months) due to growing dissatisfaction with several elements of it. When they reported this to the school-section leader, she asked for details, reasoning on paper, and organized a meeting with the publisher. Eventually this led the team to keep 
their textbooks following a detailed consideration of the options. This contributed to the fact that they were the only team that had two periods of intensified activity-one prior to the reconsideration of the school books and one after. In general they met irregularly and had an informal role division with one teacher being more dominant in arranging activities and meetings. The teachers also had a somewhat different orientation toward the process, one being more compliant to the wishes of the school management and one being more critical. The construction work was done individually, mostly at the end of the school year. Before the summer vacation, the team only had the general setup ready which due to the school-wide roster was rendered unworkable.

\subsubsection{Recurring curriculum development activities}

Considering the curriculum development activities in the TDTs, several design activities have been observed in more than one team and are discussed here shortly before they are subjected to a more detailed analysis of different aspects. The following general observations can be made:

- There were only a few (development) activities that have been observed in more than one team.

- Three teachers were involved in pilots of learning activities, mainly aimed at organization of the learning.

- One teacher individually conducted a short pilot of a new setup.

- Two teachers visited a school experimenting with a flexible roster.

- All the teams had a meeting with the management team concerning their plans.

As stated, aside from team meetings and individual teacher work in between meetings, there were only a few (development) activities that have been observed in more than one team. These activities, and those undertaken by single teams that diverted from the 'usual' pattern of team meetings, are described here briefly.

Several teachers from the design teams were involved in pilots of learning activities, mainly aimed at organization of the learning (thus varying times and sequences of learning activities). These pilots (VA, Du, and Fr) were parallel to the work of the teams and there was no explicit or traceable implicit connection with the work of the teams themselves. Only one teacher (Fr) held a small pilot with the setup the team wanted to use. She did this individually and on her own initiative and there was no feedback on the work of the team. 
Two teachers (one form $\mathrm{Du}$ and one from Fr) visited a school experimenting with a flexible roster for the students, similar in some aspects to the one of the school. There was no follow-up activity for this visit. There was no traceable effect on the plans of the teams.

One team contemplated the subject of choosing/changing textbooks (Mu) as part of the reform process. This was due to the fact that this was their first year of using a new textbook, and they had mixed feelings about its quality. As part of this inquiry the team met with the publisher and designers of their textbook in order to discuss different aspects of the textbooks. This meeting was initiated by the school-section leader who asked for a stronger argument for changing textbooks. This meeting and its content played a major role in the decision of the team to stick with this set of textbooks.

Towards the end of the school year (March/April 2007) all the teams were invited for a meeting with the school management team (school leader and section leaders). The meetings were held with each of the original crosscurricular teams (with representatives of the newly created subject-oriented smaller teams). In each of the meetings the different sections presented their individual plans.

\subsubsection{Curriculum development stages}

The main patterns apparent when considering stages of development are as follows:

- Analysis is mainly aimed at the organizational conditions, with the Time and Learning environment as main issues. This is stronger with teams with a vague initial ambition and mixed support of the reform.

- Major design decisions are either already in place at the start (clear ambition teams) or are made during the process, but then these are aimed at preserving much of the current practice of the team.

- Construction, when the teams get this far, is mainly individual.

- Teams with a clearer initial ambition go quicker to the meso design stage of refining their design and investing less time in analysis.

- In teams with a vague reform ambition the design and construction phase are almost simultaneous. 
Analysis -in all cases the first orientation of the teams was towards organizational conditions (some of this analysis was conducted in the first meetings when they were still in the cross-curricular teams). There were few analysis activities besides this. In three teams the exploration of conditions was conditional for the work of the team (Fr, Du, and En) and until there was some certainty on it, the design work was delayed. In the other cases (VA and Mu) the analysis of the organizational conditions was not as central. There was much talk of teaching time but this was not translated into consequences for the curriculum. This difference can be attributed to the fact that the latter (VA and Mu) started their work with a setup that had been discussed and partly developed in the years preceding the reform initiative (figure 5.1).

\begin{tabular}{l|l|l|l|}
$\begin{array}{l}\text { Fitting the teaching materials } \\
\text { to the new organizational } \\
\text { framework }\end{array}$ & $\begin{array}{l}\text { General } \\
\text { ideas }\end{array}$ & $\begin{array}{l}\text { Certain } \\
\text { themes are } \\
\text { articulated }\end{array}$ & $\begin{array}{l}\text { General } \\
\text { plan is } \\
\text { defined }\end{array}$ \\
\hline $\begin{array}{l}\text { En } \\
\mathrm{Du}\end{array}$ & $\mathrm{Fr}^{1}$ & $\mathrm{Mu}$ \\
$\mathrm{Fr}$ & & $\mathrm{VA}$ \\
\hline $\begin{array}{l}\text { Note: }{ }^{1} \text { Team Fr had a main orientation towards the organizational framework but additionally } \\
\text { expressed a general ambition to renew the structure and pedagogy of the subject. }\end{array}$
\end{tabular}

Figure 5.1 Initial ambition for common work in the TDTs in Kepler High school

Additionally, the teachers in these teams were supportive of the specific reform goals in the school and at the same time, as part of the move to the new school building, would be located at a separate wing, in which they would have much say about the design of the environment and were, therefore, less dependent on school-wide decisions.

VA had also piloted their planned reform in the past few years. This formed the main basis for the design and might also explain less of a need for an analysis.

Design - the division that emerged in the analysis stage continued in the design approach the teams depicted. VA and $\mathrm{Mu}$ had their major design guidelines early in the process (VA before the reform started; $\mathrm{Mu}$ within a meeting). The language teams showed some variety with Du deciding at the start to keep very close to current practice and Fr and En spending more time (until about march 2007 ) to make the decision to stay very close to their current practice. 
Considering the design, only two teams were consciously busy with thinking about and designing at the meso-level, thus rethinking their whole curriculum setup at the school level (VA and $\mathrm{Mu}$ ). They went through a separate design stage. The other teams were, when designing, immediately busy with micro design/construction of specific lesson plans based on the assignments in textbook (Fr, En, and Du). This was due to their principal decision of keeping the meso design (the use of materials and orientation) the same. Therefore, there was little need for discussion on the design of their curriculum. In these teams the 'design' and 'construction' phases were actually one activity.

Construction - construction started when the team had a framework or general plan for teaching-either a new meso design or a principal decision to stay very close to the current practice. In most cases construction was individual with little or no feedback on partial products. While the teams with a common meso design showed complete individual construction with little feedback on products ( $\mathrm{Mu}$ and VA) based on task division, the teams (En, Fr, and Du) that stayed closer to their current practice reviewed each other's plans and gave short feedback more often. In one case $(\mathrm{Du})$ the teachers collaborated on the construction of the planning. A possible explanation for this is that the Dutch teachers have worked closely together in the past and were more used to collaboration.

In regard to construction, most of the teams had few concrete products at the end of the preparation year: no written lesson plans and only an agreed upon setup and general division $(\mathrm{Mu})$, through several chapters ( $\mathrm{Du}, \mathrm{Fr}$, and $\mathrm{En}$ ) to one year of plans (VA).

Evaluation - Teams showed few evaluation activities. Only one team $(\mathrm{Mu})$ paused during their process to evaluate their choice of textbooks. The main reason for this evaluation was experience with the textbooks during the school year. An important actor in the evaluation process was the school-section leader that insisted on an explicit consideration of the choices that the teams intended to make. This forced the team to pause and rethink their decisions based on several explicit criteria.

Only one teacher piloted the future setup during the year ( $\mathrm{Fr})$. This pilot was an individual initiative with no feedback or impact on the design process. 
Implementation - the curricula had not been implemented yet at the end of the first year of work. In two cases (VA and $\mathrm{Mu}$ ) implementation factors (setup of time table) were considered only at the end of the year after the meso design had already been set. It turned out that the plans that they made could not be realized within the intended school-wide roster drafted. This might be due to the fact that they were not completely a part of the organizational change as they have separate wings in the new school building. Therefore they were possibly less focused on the implementation factors.

\subsubsection{Curriculum components in discussion/work}

Regarding curricular components in the discussion and work of the teams, the following general observations can be made:

- Time and Place play a central role as conditional elements in many teams. This is less prominent in teams with clearer initial. Ambitions and more control of their future learning environment

- Rationale and Goals are hardly discussed and when they are it is mostly in the initial phases only.

- The content, materials, and learning activities (which seem synonymic) are often a given (through the school books) or discussed shortly.

- Discussion of the concrete on-paper work schemes led to a superficial discussion of more curricular components.

Time and Place - as discussed in 5.3.2 the organizational conditions of time and place played a major role in three of the teams ( $\mathrm{Du}, \mathrm{En}$, and Fr). Until these elements were somewhat clear, the team did not proceed with development work. These elements were seen as a given that had to be made clear by the management and not as something negotiable or dependent on the plans of the team itself. When these elements were given they play a central role in the curriculum development process of the team because they used these constraints to divide their teaching materials across available time and place. VA and $\mathrm{Mu}$ started with an exploration of these issues but afterwards continued with little consideration of the results. Their designs were not dependant on it. The difference between the teams can be due to the fact that the latter teams stayed somewhat outside the learning environment change. As they were assigned to their own school wing, there were fewer constraints on their design as they had to pay less attention to changes made in other subjects. When needed, they could 
also fall back on their old framework and the time constraint was only important for division of their materials.

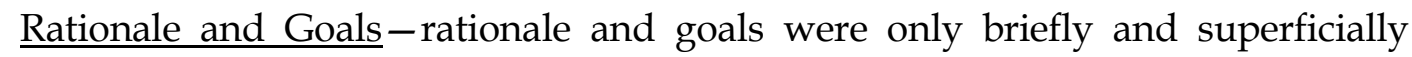
discussed. This happened mainly in the beginning, during the meetings of the cross curricular teams and mainly in relation to the cooperation itself: 'what is the rationale for cooperating?' This discussion did not lead to a satisfactory answer, which might explain why the cross curricular teams did not hold. In the subject teams the rationale and goals got little attention. They were only raised in a reflective/evaluative manner: 'does our idea fit with the reform goals?' In all the cases where this occurred, the question did not get answered nor had impact on the design decisions.

Only in one case $(\mathrm{Mu})$ the team evaluated its design decisions based on the teams' goals. This was done in combination with a decisive intervention of the school section leader who asked the team to rethink their decision and come up with a strong argumentation for action.

Content - in all but one team content was taken as a given and was tantamount to learning materials. These were discussed in relation to the division of the learning activities that were enclosed in them over the available time. The only exception to it was VA, which discussed (during the initial discussion on the general setup) which content and in what order they wanted to teach it. This was partly a continuation of a discussion that was already present in the team (from years before) and limited itself to one meeting. They were also the only team that did not make use of a set of textbooks but used self-made materials they have been developing over the past few years. In $\mathrm{Mu}$ content was tantamount to materials but the material choice itself was subject to discussion when the team was unsure about their textbook choice.

Grouping-grouping was only discussed in one team $(\mathrm{Mu})$ as it was a central element in their design.

Discussion of the concrete work schemes or design on paper led to discussions on more components than the team usually discussed (VA, Mu, Du, and En). At the same time this was a superficial discussion aimed at making immediate decisions in which the default was the current practice of the team. The languages teams' 
discussion with the school-section leader on the concrete school-framework also led to discussion on more curriculum components which translated to consequences for the framework of the team. The reason for this was that these teams were more oriented to school organizational framework.

\subsubsection{Substantive consideration}

When considering the content considerations of the team the following is clear:

- Subject coverage is the main consideration of the teams. The students' perspective is discussed shortly in two of the teams.

The subject consideration played the greatest role in the orientation of the teams. This was visible in the teachers' choice to mainly work within subject teams and not cross curricular teams. Additionally this was evident in the work of the subject teams themselves. Teams either planned to cover the textbooks within the time available by dividing the school years into the chapters of the books (En, Du, and $\mathrm{Fr}$ ), to cover the content of the book within the new setup (Mu), or to decide on content and then division in the year (VA).

The student perspective was taken into account explicitly in two cases:

- In coming up with a new meso planning which was different from their current practice. In MU there was consideration of what benefits student development and what gives more room for students' own learning preferences.

- In one case, when discussing the lesson plans, teachers considered what students needed or found interesting as a criterion for their choices (En).

\subsubsection{Main quality considerations}

The main quality consideration of the discussed curriculum quality criteria is as follows:

- All teams considered practicality as the main criterion for their products.

All teams aimed at a feasible planning/work scheme in the new building framework-that was the main orientation of their work. Very little consideration was given to other curriculum quality criteria. 


\subsubsection{Sequence of activities}

In view of the whole curriculum development process, some conclusions can be drawn in relation to the development sequences in the TDTs:

- Process seems to advance in a burst of a few consecutive meetings in a short span of time at the end of the year.

- In teams with a vague initial ambition, perception of more organizational clarity is conditional for these bursts.

- Two development patterns are evident:

- Teams with a vague initial ambition - little conscious design before the construction burst. Design and construction happen simultaneously.

- Teams with clearer initial ambitions - spend more time on meso design and less time on construction.

- The scheduled meeting with the school management team led to acceleration of work in all teams.

- Irregular meetings led to loss of reform ideas.

- At the end of the year there are only few concrete materials/planners ready for use.

The most prominent pattern in the development process in the teams is that the process seems to have advanced in bursts of a few meetings in a short span of time at the end of the year. In all of the teams a long period of time went by where they did not meet and were less active, and then a short period went by when they met quite often (at least once a week). In these bursts most of the design/construction work was done. Mu displayed two of these burst while the other teams had only one.

These development bursts occurred most often towards the end of the school year (from March onwards). They were mainly guided by a feeling of urgency, when teams realized they had a short time to work (in all teams). In the languages teams, these bursts were also preceded by a feeling of more clarity concerning the organizational constraints. Most of the teachers also asserted that they then also had more time available to develop, whereas before this was not the case.

There were two patterns of design process. In all the languages teams there was little development work before the construction burst. They withheld design decisions until organizational conditions were clearer. They then went through a period of design/construction in which the current practice was dominant in the 
design. The VA and Mu team started the year with a period of meso design, considered how their general setup would be, experienced a period of little activity, and at the end of the year went through a short burst of construction activities. Mu was the only team that showed a repeating cycle going through design, construction, and again, design and construction.

The difference between these two patterns can be explained by the different starting point of the teams. While Mu and VA started off with a general design they had been contemplating for a few years (and VA had been piloting) and were generally sympathetic to the design goals, the languages team did not have a clear view of their goals, and concentrated mainly on fitting their current practice into the new organizational scheme. For these teams organizational clarity was a crucial transitional element needed for starting design/construction.

In two cases teams started the year by brainstorming about possible meso designs much different from their current practice and in line with the reform goals stated at the school level ( $\mathrm{Mu}$ and Fr). Following these meetings the process and discussion came to a halt in which teams seemed to wait for development. After a period of several months the process resumed but then the ideas and possibilities expressed in the brainstorm sessions were not used or discussed further and the team reverted to more 'conservative' plans.

At the end of the year the teams had only constructed a small part of the materials and planners required for the following year. Although this can be seen as a result of the short time allotted for construction, teachers explained it also by saying that they first needed to see how materials worked out in practice before they could proceed with development.

In all teams the scheduled meeting with the school management team led to the acceleration of the development work. In some teams this happened in preparation for the meeting ( $\mathrm{VA}$ and $\mathrm{Mu}$ ) and in others ( $\mathrm{Fr}$ and $\mathrm{Du}$ ) as a direct result of it.

\subsubsection{Place of activities}

Considering the location and time of the work of the teams, it is clear that:

- When held, meetings are exclusively in school, during the allocated hours.

- Individual construction work occurred at home at the teachers' discretion. 
Team meetings/discussions were exclusively held during the allocated hours in an available classroom. Many of the allocated meeting times during the school days were not used (teams did not meet when the school-wide planning showed they should). When teams had not made an explicit agreement to come together ahead of time, teams did not meet during the allocated hours. The individual construction work was done at home at the teachers' discretion.

\subsubsection{Participants and their role}

When observing the participation patterns in the TDTs several points come forward:

- No formal role division.

- Several of the teams had an informal role division based on involvement in the development process.

- Teams worked jointly on the meso design materials division and general content of work scheme. Construction of work schemes was divided between the teachers and was done individually.

- When section leaders were present in the meetings they had a steering role in the interaction.

During the initial phases of the work the grouping was unclear. Teachers were assigned to cross-curricular teams which were seen as irrelevant. The work started for the teachers when they sat in the subject specific teams.

In the subject teams there was no formal role division. Several of the teams did display informal role division which was expressed by one of the teachers being more dominant in the curriculum development process either by being more active in arranging meetings and activities ( $\mathrm{Fr}$ and $\mathrm{Mu}$ ) or by being more dominant in the groups discussions (En). The other teams displayed much about equal participation considering the development task.

At the same time, in none of the teams was there a 'leader' who took responsibility for the work of the team, keeping other members at bay and managing meetings. When school-section leaders were present in meetings they were the leading and central steering element in the meeting both by actively leading the discussion and by attracting the attention and questions. 
Considering the joint work of teachers on the design and construction it becomes apparent that construction work (making the teaching plans of specific chapters/lessons) was done individually (Figure 5.2). Teams worked jointly on the teaching framework, materials division, and general content of the work scheme (mostly division of textbook in the new framework). The work of making concrete work schemes was divided between the teachers and done individually (Fr, En, and $\mathrm{Mu}$ ). When teams did make appointments and concrete task divisions (with date of completion), this stimulated the work of the individual teachers (En, Fr, Mu, and VA). There was little and very basic feedback on each other's work, mainly concentrating on the fit with the general plan. VA was the only team that had an extensive feedback session on materials among two teachers. This was based on a personal positive relationship between the teachers and during one occasion.

\begin{tabular}{|c|c|c|c|c|c|c|c|}
\hline $\begin{array}{c}\text { Ideas } \\
- \\
\text { guidelines } \\
\text { for deve- } \\
\text { lopment }\end{array}$ & $\begin{array}{c}\text { Ideas } \\
- \\
\text { general } \\
\text { framework }\end{array}$ & $\begin{array}{c}\text { Materials } \\
\text { - } \\
\text { selecting } \\
\text { form/ of } \\
\text { textbooks }\end{array}$ & $\begin{array}{c}\text { Materials } \\
- \\
\text { selecting } \\
\text { existing } \\
\text { other } \\
\text { materials }\end{array}$ & $\begin{array}{l}\text { Materials } \\
- \\
\text { construc- } \\
\text { ting plan- } \\
\text { ning }\end{array}$ & $\begin{array}{c}\text { Materials } \\
- \\
\text { comments } \\
\text { on each } \\
\text { other's } \\
\text { work }\end{array}$ & $\begin{array}{c}\text { Materials } \\
\qquad- \\
\text { alternate } \\
\text { construc- } \\
\text { tion of } \\
\text { same } \\
\text { materials }\end{array}$ & $\begin{array}{c}\text { Materials } \\
\quad- \\
\text { Construc- } \\
\text { ting } \\
\text { materials }\end{array}$ \\
\hline $\mathrm{Fr}$ & $\begin{array}{l}\text { Fr } \\
\text { En }\end{array}$ & En & $\mathrm{Fr}$ & & $\begin{array}{l}\text { (Fr - short } \\
\text { an basic) } \\
\text { En }(-/+) \\
\text { only one } \\
\text { sided }\end{array}$ & & \\
\hline $\begin{array}{l}\text { VA } \\
\mathrm{Mu}\end{array}$ & $\begin{array}{l}\mathrm{Du} \\
\mathrm{VA} \\
\mathrm{Mu}\end{array}$ & $\begin{array}{l}\mathrm{Du} \\
\mathrm{Mu}\end{array}$ & VA & $\begin{array}{l}\mathrm{Du} \\
\text { VA }\end{array}$ & VA & & \\
\hline
\end{tabular}

Figure 5.2 Levels of joint work in the TDTs in Kepler High School

In only two cases did teachers work together on the specific lessons plans (Du and VA). VA was a team with a common history of collaborative work on curriculum, as was the team of $\mathrm{Du}$ to a lesser extent (they also have a positive common work history). The cooperation in DU might be explained by the fact that they have postponed the development until the very end, as they were uncertain of what to do and when time was pressing, it was easier to sit together and work in a manner that compelled them to work (this was partially confirmed by one of the teachers). 


\subsubsection{Work orientation}

Considering both the general and per meeting work orientation of the TDTs, the following general conclusion can be drawn:

- Teams varied in their orientation towards the school-wide constraints:

- Teams with clearer initial ambition and a positive stance towards the reform followed their own line, and the framework played a role in the background.

- Teams that had vague initial ambitions and a mixed support of the reform found the school framework dominant in their work.

- Meetings of teams were dependent on school-wide schedules for team meetings. But teams came together only when they had a concrete appointment.

- During the 'activity bursts':

- the results of one meeting led to the next.

- a sense of urgency in the teams led to making concrete appointments to meet.

In view of the general orientation of the teams toward the school framework, two patterns arise. The languages teams ( $\mathrm{Du}, \mathrm{Fr}$, and En) were anxious about the organizational framework and were attuned to it. Their development work started after:

- the general guidelines were clear;

- one of the school-section leaders lowered expectations pressing the teams to stay closer to their current practice and therefore making the task simpler and more manageable.

VA and $\mathrm{Mu}$ were also oriented initially towards organizational constraints (time), but they solved the vagueness by making assumptions about the organization (specifically the possibility to teach parallel classes) and therefore could work on their redesign. They could do this because they could always fall back on their old practice (as they were not part of the school-wide learning environment change), allowing teachers to consider other possibilities. Additionally, both of these teams had a more positive initial stance towards the reform and the more defined initial reform ambition (see figure 5.1).

In two teams the cooperation was initially oriented towards discussing the curriculum of the current school year $(\mathrm{Du}, \mathrm{VA})$. In these teams cooperation seemed to be more a part of their routine. This also led to somewhat more cooperation on the construction of the planners (see 5.3.8). 
Considering the immediate orientation of the teams (at meeting level) it appears that meetings were directly dependent on school-wide schedules. But teams came together only when they had a concrete appointment or an explicit impulse from outside the team (the school-section leader asking for specific information). When these conditions were not fulfilled, teams did not meet or used the time to discuss other matters $(\mathrm{Du})$.

When the burst of activities took place (see 5.3.6), one meeting led to the next. There seemed to be a dynamic in place whereby the appointment made in one meeting gave rise to the next meeting and made it necessary. In these bursts there was a sense of urgency in the teams, which led to pressure to produce materials and plans.

\subsubsection{Organization of work}

As for the organizational element of the TDTs' work, the following can be stated:

- Both at meeting and whole process levels the work of the team was not planned or structured.

- In the cross curricular teams, meeting agendas were supplied by the management team.

- During the 'activity bursts' the results of one meeting led to the next.

As mentioned in 5.3.6 teams met irregularly and had no long term/short term planning. Their goal was implicit - 'making a plan for next year'. Teams also did not plan specific content for meetings. When teams had several meetings in a short period (bursts), the tasks divided at the end of one meeting were the content of discussion of the following meeting ( $\mathrm{Fr}, \mathrm{En}, \mathrm{Mu}$, and VA). At the end of the school year, when most of the teams were busy constructing concrete planning, these were the content of the meetings. There was also no discussion on the planning of the work (when what should be ready...).

When and if documents/concrete products were brought into the meeting, they formed the main structural element in the meeting - they were discussed linearly.

During the first period of the team work, while they were still sitting in the cross curricular teams, the agenda for the meetings was dictated by the management team who thought up relevant issues for discussion. These discussions were often seen as irrelevant for the teams and were discussed superficially. 


\subsection{CONDUCIVE OR HINDERING ACTIVITIES AND APPROACHES}

Based on analysis of the described processes and interviews with the involved practitioners, several conducive and hindering activities and elements were identified. The main findings are:

- Conduciveness of activities is determined by perceived contribution to production of materials.

- The following were found conducive:

- Discussion centering on concrete subject level of concrete materials/plans.

- Pilots and presentation benefit only the teachers who participate.

- Intervention of the school-section leaders in the work of the teams and information they provide during meeting.

- Meeting with school management increases activity in the teams.

- Task division heightened productivity.

- Holding several meetings in a short(er) period of time led to a sense of dynamic and progressed the work.

- Personal experience of teachers with elements of the reform was dominant in decision making.

- Sense of urgency towards the end of the year led to frequent meetings and sense of dynamic in the process.

Hindering factors:

- Vagueness of school-wide framework delayed work of teams with vague initial ambitions.

- Early choice for use of current textbooks seemed to produce more conservative design in line with current practice.

When interacting with teachers it became clear that the kind of activities deemed conducive for their work were those that contributed to the task they perceived as central-producing concrete curricular plans for the following school year. This 'colored' their perception in a sense.

One kind of critical moment in the curriculum development process was assigned great importance by most of the teachers. That was the discussions on concrete subject level in plans for the following year (VA, En, Du, and Fr). The mentioned benefits were:

- Making the reform more concrete and clear (Fr, En. Mu, and VA);

- Feeling of progress in the work towards the goal of producing concrete work schemes (Fr, En, VA, and Du); 
- Helping build relationships in the team through discussion (VA and Du);

- Hearing ideas from other teachers on the reform and gaining insight into their own view of the reform $(\mathrm{Fr})$.

These benefits were stressed even more in cases where teachers worked together on the planning of concrete lesson plans. This was mentioned as very stimulating and conducive to rethinking of ideas (VA and Du).

Piloting only benefited those teachers who participated in the pilots. It helped them gain a more concrete image of the reform, but at the same time it was not translated into the team discussion and its results ( $\mathrm{Du}$ and Fr). This was the same for seeing how other teams were working and with what results. This exposed the teachers to other options and ideas (Fr and $\mathrm{Du}$ - exposed to plan of languages in upper secondary) but did not translate into their own setup.

Intervention and information from school-section leaders in the work of the team gave teams an impulse. It supplied information on the development and challenged the teams' thinking by questioning their decisions and forcing them to articulate their thoughts ( $\mathrm{Fr}$ and $\mathrm{Mu}$ ). This happened even more in the meeting with the school management team. This stimulated the team to articulate and produce concrete plans $(\mathrm{Du})$.

As stated, it seems that a conception of the conduciveness of activities was dependant on the orientation of the teachers, e.g. what was seen as the goal of the work. This was articulated best in one of the teams $(\mathrm{Mu})$. Teachers had a very different perception of conducive activities. While one of the teachers found the concrete planning and the choice of book most stimulating and effective, the other teacher found the negotiation with the management on the reform conditions the most important and crucial. When asked for an explanation, it turned out that both had a different orientation in the process. While the first was oriented to the production of a planning within the reform, the second was more concentrated on critically questioning the reform itself and exploring its goals.

When analyzing the patterns of the work process, several activities and elements seem to play an important role in forming the work. Teams do not proceed with design work until they have clarity of organizational conditions. Only at that point do they go on to make a basic plan and move to making concrete planners or materials. This point was different for different teams. Those teams which 
approached the reform with vague ambitions and ambiguous support for the reform required more clarity of conditions than those that used the reform to realize their prior intentions.

It also seems that there was a correlation between the choice of textbooks and the reform product of the team. When teams chose to use the current textbook, it led to more 'conservative' solutions within the new framework. These teams opted for fitting current practice in the new framework, and not tackling the schoolwide reform goals explicitly. An exception to this was the team $\mathrm{Mu}$ that also chose to keep their current book but opted for a new setup. This was explained by the fact that their textbooks were new and they used them that year for the first time, already preparing for a new setup. When the reform tapped into ideas that had been floating/discussed in the subject department for several years, the teams gained increased ownership and focus on the reform process $(\mathrm{Mu}$ and VA). This increased the chance for realizing more school-wide reform goals in the result of the design process.

Experiences of teachers were a major factor in the decision teams made. The strongest arguments in the teams were those based on what teachers have done or seen in the past (Mu, VA, Du, and Fr). In this manner piloting did have some influence on the teams since teachers who were involved in pilot shared their experience in the team. Their experiences carried more weight ( $\mathrm{Fr}, \mathrm{Du}$, and VA). In light of this it was striking that there was no explicit transfer from the pilot to the design.

Several concrete activities seem to have impacted the work process of the team:

- Having a concrete plan on paper or collaborative work on a realistic planning had an impact on all the teams, varying somewhat between them:

- Led to discussion of more curriculum components (En, Du, Mu, and VA);

- Led to positive interaction in the team and more frequent contact (Du and $\mathrm{VA})$;

- Led to more concrete discussion on future practice (En and VA).

- Interaction with school section leaders in team meetings supplied the teams with answers and clarifications. In one case it proved important that the leader enquired into the curricular considerations of the team, compelling the team $(\mathrm{Mu})$ to reconsider a choice that had been made and make the consideration more explicit. 
- Meeting with school management team-in all cases it brought about an intensification of the work, showing an increase in activity in the preceding weeks. Teams also took more time in articulating their plans and choices (VA, $\mathrm{Mu}, \mathrm{Fr}$, and $\mathrm{Du}$ ). In two cases (Fr and $\mathrm{Du}$ ) it created a crossover between teams in upper secondary and lower secondary (which were both in the meeting). That made lower secondary teams eager to adapt elements of the reform initiated by their upper secondary counterparts.

Finally, three more general elements seem to have influenced the work of the teams.

- Sense of urgency had an impact on the wok of the team. Until this urgency came about, teams tended not to seek concrete design or construction. In all of the teams this sense of urgency only developed toward the end of the year and 'forced' developments. It either led them to revert to more 'conservative' solutions (Fr, Du, and En) or to develop initial plans without considering the possible restraints of the time table (VA and $\mathrm{Mu}$ ). This sense of urgency might be connected to ownership of the process. As long as teachers did not feel ownership of the process it did not arise. Only at the end of the year, when they were faced with the possible consequences of having nothing ready, did they seem to have taken matters into their own hands.

- Task division led to process acceleration - when teachers were assigned a part of the curriculum they were responsible for, and concrete appointments were made about completing the task, teachers fulfilled their tasks (En and Fr). This led to less delay in the process which was more 'productive' (in the sense that more planners were produced).

- Regular meetings - when meetings followed each other in short intervals $(\mathrm{Mu}$, VA, and En), the design process seemed to gain momentum, one meeting leading to the next. There was more accumulated work and the team created a bulk of 'products' and decisions. Additionally, less meeting time was spent trying to recall the results of previous actions.

\subsection{CONDUCIVE OR HINDERING SCHOOL CONDITIONS}

\subsubsection{Infrastructure}

Concerning the effect of organizational infrastructure on the work of the team, several effects can be seen: 
- Time allocation and centrally scheduled meetings were necessary conditions for the work of teams - meetings took place exclusively during these time slots.

- Many opportunities for meetings were not used and meetings did not take place on other occasions.

- TDTs convened only when the following conditions were met:

- the time was available

- the team made an appointment in advance

- there was a sense of urgency.

- Organizational aspects of the new learning environment were central in the thinking of the TDTs.

- On several occasions scheduling problems hindered teacher participating in meetings.

All the teams in Kepler had centrally scheduled meeting times (every Tuesday afternoon). This available time was greatly appreciated by the teachers and the teams met almost exclusively during these time slots. Teachers found these time slots crucial for their meetings - without centrally scheduled meetings it became very difficult to work together. When Tuesday afternoon was not available for any reason (vacation, other school activity, sick leave), the team did not meet and did not divert to another day. Teachers complained that many available time slots on Tuesdays were used for other activities initiated by the school management, such as meetings for other subjects. This led to continuing frustration in the team. However, even though teachers expressed appreciation for this offered time, even when the Tuesday afternoons were available, they were not often used for the designated team meetings., Many of the available time-slots were not used or used for other goals than design team meetings:

- meetings of other teams;

- work for the current school year (checking exams, arranging a school trip);

- waiting for input form management team.

The TDTs convened only when the following conditions were met:

- the time was available;

- the team had made an appointment in advance due to a need for the meeting or a clear agenda/goal for the meeting. Otherwise teachers were distracted by other pressing issues and deferred to them;

- there was a need/urgency for the meeting (that was why in most of the teams meetings increased toward the end of the year);

- there were no scheduling problems preventing teachers from attending. (VA and En). 
On several occasions scheduling problems hindered teachers from participating in meetings. This led to inactivity during the available time slots, but also to frustrations in the teams about the organization (VA and En). At the same time teachers and teams did not act to mend this situation or divert meetings to another day; they accepted the situation as a given. Only when the urgency for work rose (towards the end of the school-year) did they take action to mend this.

Organization/infrastructure of new learning environment was central in the thinking of the teams and therefore influenced their process (all teams designed for the new environment). In those teams that had control of the design of the changing learning environment this was less of an issue ( $\mathrm{Mu}$ and VA).

\subsubsection{External support and role of researcher in work of team}

Considering the effect of external intervention in the work of the TDTs, the following was found:

- No external support was available and teams seldom expressed any need for this.

- Teachers appreciated the interaction with the researcher but there were no indications of effect on products or processes.

None of the teams had external support available. The teachers also expressed no need for this kind of support. Only in one case (En) did teachers express a need for external input. This team had difficulty in formulating reform goals and no idea where this was going. The teachers did not know where to begin with thinking about the new setup. They expressed this need to the school-section leader but this did not lead to any action.

The researcher interacted with teachers during and between meetings. During meetings, when asked direct questions the researcher gave direct answers and in some cases asked clarifying questions on the work of the team. When reflected upon in the interviews, this interaction was appreciated by the teachers. Although teachers commented that the interaction with the researcher brought them to reconsider decisions and reflect on their work, there were no indications that it led to explicit results in the products or process of the teams. 


\subsubsection{Coordination - contact with rest of school/teams}

As part of the reform efforts in the school, the school management installed a coordination team that was expected to insure coordination between the teams and an information channel to the teams. Exploring this aspect of the work of the TDTs led to the following findings:

Interaction between teams and teachers

- Teachers missed an overview of the work of other teams and the developments at the school level.

- There was little formal or informal interaction between teachers and teams on the reform.

- Although teams (mostly teams with a vague initial ambition) expressed a need for interaction with other teams, cross curricular team meetings were not relevant or useful.

Coordination team:

- Teams were only partially represented (two of the five).

- Teams with no representative expressed greater lack of information.

- There was some importance for the participants themselves in informing them on different issues.

Teams had no structural overview of the work of other teams in the school and little view of school-wide developments. During the school-year there were very few organized instances for exchange between different teams. This also did not occur informally in between these meetings. Work in the different teams was greatly cut off from work in other teams with little exchange between teams (even in cross-curricular teams) (En, Fr, Du, Mu and VA).

Teachers missed relevant, structural, coordination mechanism with other teams (En and Fr). Presentation of/interaction with other teams on their work on the reform was seen as potentially valuable (Fr, Du, and En). Possibly the reason why the languages teams expressed this need is related to the fact that these teams were very much oriented to the school-wide framework. Therefore they might have had a greater need for hearing how other teams went about this framework and solved their problems. Mu and VA were less directed at the external framework. They had their own unique situation and were, therefore, less dependent on others. 
At the same time, interaction with other teams (in cross curricular ream meetings) was only seen as significant when it served an internal goal of the team and its needs (Fr). As the goal of the work of cross-curricular teams was unclear for the participants (even the chairpersons), it seemed less significant. The status of the decisions in these teams and the usefulness of the cooperation were in doubt by most teachers. This led to limited participation and eventually led to a division into subject oriented teams.

The coordination team had no direct influence on the work of the teams. Three of the five teams in this study did not have a representative in the coordination team. This was a consequence of the change from the cross-curricular teams to single subject teams. As the membership of the team was structured when there were fewer teams, when the cross curricular teams broke off into subject teams, some teams became cut off from the coordination mechanism. Teams with representatives in the coordination team, and therefore more frequent interaction with the section leaders, had less often a lack of information about the school framework. They less often expressed frustration about the subject or were left with questions unanswered.

Considering its function, in the initial stages, the coordination team was an instrument to communicate certain questions to the cross-curricular team level through the participants. It also had some importance for the participants of the coordination team themselves. It supplied them with information on the schoolwide developments $(\mathrm{Mu})$.

\subsubsection{Role of school leaders and school-wide framework}

Both the school-wide framework and the manner in which the school-section leaders and the school management interacted with the TDTs had an effect on the work and orientation of the team. The analysis of the data on this aspect led to the following conclusions: 
School-wide framework:

- Was experienced as vague until late in the process.

- Clearer initial ambition and more control on the future learning environment decreased the orientation towards the clarity of the school-wide framework.

- Teams experienced the framework as more vague than what could be asserted based on school document.

- Teams were reactive in acquiring clarity on the school-wide framework.

Role of school-section leaders:

- Seemed to have little overview and control on the work of the TDTs.

- Teams with vague initial ambitions and a mixed support of the reform were more dependent on the (in)activity of section leaders.

- During presence in TDT meetings they were an important information source and contributed to the curricular discussion.

Meeting with school management team:

- Increased pressure and activity in team-led to more team meetings, increased articulation of plan and more production of materials.

- The meeting itself was a venue for productive interaction between teams.

The school-wide organizational framework was experienced as unclear until March (En, Du, and Fr). The main issues of vagueness in the teams were the organization of the new learning environment and the new rooster. These two elements also had a major influence on how the teams worked. The change in physical learning environment played a big but varying role in the teams. In VA and $\mathrm{Mu}$ it was the motor of change in the curriculum. Their reform ideas (which have been developing in the past years) were dependent on the changing learning environment. As both teams were located in a new wing of the school, which would make their wishes possible, they tried to realize their ideas. In the language teams, the new learning environment was one of the greatest sources of worry. They had no clear image of it for most of the time and found it difficult to work on their reform. In contrast, the time element was seen in all of the teams as a major limiting element. While in the languages teams it had a similar effect as the environmental element, in the arts teams it threatened to interfere with their newly formed plans.

Especially in the languages teams, the experienced vagueness was seen to delay their work as they had to take factors which were still unknown into account $(\mathrm{Du})$. In the VA and $\mathrm{Mu}$ teams that was less of a problem and was less often mentioned during their work or in interviews. This was due to the fact that they 
were working on an existing initial ambition which the school-wide framework would only partly influence.

At the same time, most school-wide decisions were already made and discussed half way through the year (December). The only decision still not taken was the precise scheduling (when all the subjects were scheduled). But this was not an issue of discussion in most of the teams anyway. There was therefore a gap between the actual presence of the school-wide framework and how it was experienced.

In both cases (of orientation toward the school-wide framework), teams were reactive in respect to the framework. The language teams waited until the management gave clarification before going to work on the design. The teachers wanted to have the time and place elements known at the start of their work. The arts teams made their own plans without exploring ahead of time the possible impact of the time-table on their design. Toward the end of the year that seemed to lead to complications as the new roster seemed to make some of their plans impossible. On the whole, the reform was seen as coming from the school management. In one case it was also seen as being organizational and not pedagogically motivated (Fr). The integration goal, captured in the initial organization of the teams, was not relevant for most the teachers themselves (as the change in the team composition demonstrates).

The interaction of school \-section leader with the teams (or lack of it) was perceived as important and influential. In the language teams it was seen as passive and providing no impulse for their work (Fr, En, and Du). This led in two cases (En and Fr) to frustration by the teachers and was taken as a signal of no interest or lack importance which contributed to the inactivity of the team. This was even worse when the school-section leaders did not provide needed information or failed to deliver promised help. This led to disappointment and distrust in the teams (En and Fr) and confirmed their low expectations. This may have happened because these teams had little intrinsic motivation for the reform and were oriented toward the input from the school (see above). Nevertheless, when the school-section leaders were present in team meetings, they supplied the teams with relevant answers and clarifications. It led to a broader discussion of more curriculum components, more organizational consequences and more solutions of problems (En, Du, Fr, VA, and Mu). 
In the arts teams there was less need for or reference to the school-section leaders. In one case one of the school-section leaders intervened on her own initiative in the decision-making process of the $\mathrm{Mu}$ team. This was when they wanted to change textbooks, a decision that had budgetary consequences. She demanded that they articulate their choices with clear argumentation. This added a reflection cycle to this decision and was in retrospect experienced as challenging but positive by the team members.

It seems that the school management and the school-section leaders had little overview of current developments in the different teams at different points of time (Fr and Du). Teams experienced little control of their work and no one was held accountable for the work or quality (Du and VA). This was also reflected in the lack of formal or informal mechanisms in place geared towards following the work of the team. The most remarkable exception to this was the scheduled meeting with the school management team which was initiated after the management team felt that they had little grasp of the developments. It increased accountability pressure and motivated teams to work (VA). Even when it did not result in concrete developments in the work of the team, it pushed them to articulate plans and ideas $(\mathrm{Du})$. Before these meetings took place, there was a higher frequency of team meetings and a higher rate of production of plans and materials.

The meeting itself also led to an interaction between teams as several teams were present each time. In two cases ( $\mathrm{Du}$ and $\mathrm{Fr}$ ) this interaction contributed to the work of the team as it was exposed to new ideas they considered adopting.

\subsection{SUMMARY OF THE COLLABORATIVE CURRICULUM DEVELOPMENT IN KEPLER HIGH SCHOOL}

The starting point of the reform in Kepler High School was a general reform ambition that arose both in and out of the school. These became more concrete in an educational concept that was developed over several years by a steering committee in the school and a plan for a new school building.

Although the initial intention of the school-wide reform was to work in crosscurricular teams, the teams disintegrated within several weeks not only to subject teams but also to teams based on educational level (see section 5.2.3). These were the TDTs followed in this study. 
The design process of all teams started with an analysis aimed at the new organizational conditions, with time division and physical form of the learning environment as main issues. Clarity of these issues was crucial for teams in order to go on to development and construction of their curriculum. Even though many of the organizational consequences were stated in school documents in the first half of the year, teachers experienced the future organizational conditions as vague for a large part of the year. This was, according to them, a central hindering factor in the work of the teams. At the same time, TDTs with a clearer initial ambition (and in some cases already outlines of a common plan) proceeded quicker to the design stage of refining their design, investing less time in analysis of the concrete time and place conditions.

During the school year the work of the teams advanced slowly. Although the teams had meeting times planned, these were often not used for TDT meetings. TDTs met sporadically and in general the work was neither planned nor structured. The most prominent pattern in the teams' development process was that in all teams the development process seemed to advance in a burst of a few consecutive meetings in a short span of time at the end of the year. These bursts were often guided by a feeling of urgency, when teams realized they had a short time to work. Two variants of the burst were visible. Teams with vague initial ambition showed little conscious design before the construction burst. During the burst, design and construction occurred simultaneously and teams produced lesson planners based on the existing curriculum and were mostly concerned with content coverage. Teams with a clearer initial ambition spent more time before the bursts discussing the meso-design and the burst was then more concerned with construction of lesson plans in line with the meso-design. The scheduled meeting with the school management team (toward the end of the preparation year) led in all TDTs to acceleration of work as they were asked to present their plans.

However, coordination and contact among the teams was weak. There was little formal or informal interaction between teachers and teams on the reform at hand. Coordination, if at all, took place between the school section leaders. They had only partial image of the developments in the team and were not visible in their work. When section leaders were present in team meetings they were an important information source for the team on the development and framework. This had an important impact on the work of the team. 
The kind of activities that teachers deemed most conducive for their work were those that contributed to the task teachers perceived as central, producing concrete curricular plans for the following year. This included the discussion of concrete materials, information provided by school leaders on the future learning environment, and task division in the team for materials construction.

At the end of the school year there were few concrete materials/planners ready for use. Only one team had its materials complete while the other teams had only a limited part of the materials ready. The results show a clear division in characteristics of products. The teams that had an initial reform ambition produced materials and plans that differed from their former curriculum and displayed the two central school-wide reform ambitions (differentiation and selfdirected learning). The other TDTs made an early choice for use of their former schoolbooks and produced more conservative designs that were very much in line with their former curriculum and did not explicitly incorporate the reform goals. 


\section{CHAPTER 6 \\ Cross-study analysis}

In chapters 4 and 5 the results of the two cross-case studies were presented. The next step towards answering the research questions was the cross-study analysis. In this analysis the main results at the school-site level of both studies have been compared. In this process similarities and differences were noted. Possible explanations for them were sought. Chapter 6 is the result of this crossstudy analysis. Similar to the results chapters, the structure of chapter 6 follows the research questions.

\subsection{THE REFORMS IN COPERNICUS High SCHOOL AND KEPLER HigH SCHOOL}

Both schools used a flexible reform strategy in which the school-wide reform framework was partly developed in parallel to the work of the TDTs. The choice was made to start the reform from several general reform ambitions after which the TDTs went to work on their own part of the school curriculum, independently from one another. The teams in this study were followed during the preparation year, before the school-wide reform was implemented. There were two notable differences between the school sites. In Copernicus High School the reform process was somewhat more structured. All TDTs had a coach that assisted them in their curriculum development process. Additionally, an innovation manager responsible for coordinating the reform process was appointed. This innovation manager, among his other duties, organized several school-wide meetings concerning the work of the TDTs. In Kepler High School a new school building was constructed during the work of the TDTs. This new building was designed in line with the general reform ambitions of the school. This was a much more radical change than the new learning environment realized in a part of the old Copernicus High School building. 


\subsection{HOW THE TDTS ADDRESSED AND CARRIED OUT THEIR DEVELOPMENT WORK}

\subsubsection{Recurring curriculum development activities}

Examining the recurring activities in both schools (Table 6.1) it seems that there were few commonalities. While multiple teams in Copernicus chose new textbooks and created new teaching materials, this occurred in only one team in Kepler. Teams in Kepler mostly kept to their existing textbooks when redesigning their practice. Possibly because those were single subject teams, just like before the start of the reform process, the need for other textbooks or materials was not as great. There were also fewer available funds dedicated to this goal, whereas Copernicus made funds available for buying new textbooks and other resources.

Despite the great variation in activities, in both school teams displayed one recurring activity, which in both schools was due to an intervention by the school leaders. In Copernicus this concerned the writing of team plans (which were done at the leaders' request) and in Kepler this concerned the meeting with the school management team. The centrally initiated activities had a diverging impact on the team. While in Copernicus this activity was mostly initiated and led by the team's coach and had little impact on activity and discussion in the teams (see section 6.4), in Kepler this management initiative, maybe by lack of a coach, led to one of the most prominent bursts of team activities.

In both schools multiple teams piloted (part of) their new curriculum. In Copernicus this was partly an initiative of the innovation manager as part of the reform process In Kepler these pilots were mostly a continuation of ongoing pilots of new organization of lessons that were started in previous years and were not directly driven by the work of the TDTs (see discussion of the effect of the pilots in section 6.3).

\subsubsection{Curriculum development stages}

The curriculum development process of the teams in both schools displayed some differences (table 6.1). 
Table 6.1 Results of the analysis of the curriculum development process

\begin{tabular}{|c|c|c|c|}
\hline \multicolumn{2}{|c|}{ Recurring activitios } & \multirow[b]{2}{*}{$\begin{array}{l}\text { Copernicus High School } \\
\text { - Producing team plans } \\
\text { - Choosing new textbooks } \\
\text { - Creating new teaching } \\
\text { materials } \\
\text { - Pilots }\end{array}$} & \multirow{2}{*}{$\begin{array}{l}\text { Kepler High School } \\
\text { - Meeting (and } \\
\text { preparation) with } \\
\text { management team }\end{array}$} \\
\hline Recurrin & ctivities & & \\
\hline \multirow{7}{*}{$\begin{array}{l}\text { Design } \\
\text { stages }\end{array}$} & Analysis & $\begin{array}{l}\mathrm{x} \text { - organizational } \\
\text { conditions }\end{array}$ & $\begin{array}{l}\text { X-organizational } \\
\text { conditions }\end{array}$ \\
\hline & Design & - $\quad X$ & $\begin{array}{l}\text { - } \mathrm{X} \text { - not in all teams } \\
\text { conscious }\end{array}$ \\
\hline & Construction & - $\mathbf{X}$ - individual & - $x$ - individual \\
\hline & Evaluation & - $x$ - usability & \\
\hline & Implementation & & \\
\hline & & $\begin{array}{l}\text { Design decisions - } \\
\text { before or at start }\end{array}$ & $\begin{array}{l}\text { Design decisions - before } \\
\text { or at start/ continuation } \\
\text { of current }\end{array}$ \\
\hline & & $\begin{array}{l}\text { - Interdependence in } \\
\text { product - collaborative } \\
\text { construction }\end{array}$ & $\begin{array}{l}\text { Clear ambitions \& } \\
\text { positive to reform - less } \\
\text { analysis more conscious } \\
\text { design } \\
\text { - Vague ambitions - design } \\
\text { equals construction }\end{array}$ \\
\hline \multirow{9}{*}{$\begin{array}{l}\text { Design } \\
\text { compo- } \\
\text { nents }\end{array}$} & Rationale \& Goal & - $x$ & - $x$ \\
\hline & Content & - Taken for granted & - Taken for granted \\
\hline & Teacher's role & - $x$ & \\
\hline & Activities & & - $x=$ Content $=$ Materials \\
\hline & Materials & - $x$ & \\
\hline & Grouping & & \\
\hline & Time & - X-conditional & - X-conditional \\
\hline & $\begin{array}{l}\text { Place } \\
\text { Fvaluation }\end{array}$ & - X-conditional & - X-conditional \\
\hline & Evaluation & $\begin{array}{l}\text { - Rationale \& goals - } \\
\text { difficult to discuss } \\
\text { - Clear ambitions \& } \\
\text { overview of reform- } \\
\text { less influence of 'time' } \\
\text { \& 'place' } \\
\text { - Paper products - } \\
\text { discussion of more } \\
\text { components }\end{array}$ & $\begin{array}{l}\text { - } \text { Rationale \& goals - } \\
\text { superficial } \\
\text { - } \text { Clear ambitions \& } \\
\text { outside central reform - } \\
\text { less influence of 'time' \& } \\
\text { 'place' } \\
\text { - Paper products - } \\
\text { discussion of more } \\
\text { components }\end{array}$ \\
\hline \multicolumn{2}{|c|}{ Substantive consideration } & - Subject (coverage) & - Subject (coverage) \\
\hline \multicolumn{2}{|c|}{ Main quality criteria } & - Practicality & - Practicality \\
\hline
\end{tabular}

Note: ' $\mathbf{X}$ ' stands for prominent recurrence in team discussion and work. ' $\mathrm{x}$ ' stands for infrequent discussion. 
Analysis

In both sites analysis was concentrated on organizational conditions of the future teaching practice (e.g. time and place constraints). However, in Kepler the teams showed higher tendency to undertake this kind of analysis activities. This might be explained by the fact that the Kepler teams faced organizational changes that were much greater (new school building, completely new educational concept) and were therefore confronted with more uncertainties.

Design

In both sites the teams made (consciously or in passing) their major design decisions before or at the initial phase of the development process. These decisions were not based on analysis but on predispositions that the teachers had. In Kepler, several teams seemed to make design decisions very late in the preparation year (thus late in the process). These decisions meant that their new curriculum were in fact a continuation of their former curriculum.

\section{Construction}

The teams in Copernicus spent more time and attention on the construction of teaching and learning materials or study planners. As a result, they had more of their curriculum materials ready at the end of the year. The construction phase was less prominent in Kepler. Here, teams were mostly preoccupied with analysis and design activities, while construction was postponed to the end of the year. In both school-sites construction was mainly an individual phase where teachers, almost independently, worked on different parts of the materials with little or no feedback from their colleagues. In Copernicus there were some signs that the more interdependent the teachers were supposed to be in the enactment of the future curriculum, the more collaboration they had during the construction phase.

In Kepler an interesting pattern arose. Teams that had a clear reform ambition and a positive stance towards the reform seemed to concentrate on refining their general design ideas and paid less attention to the analysis of the conditions or construction of the actual materials. Teams with a more ambiguous ambition were more preoccupied with the analysis of the organizational conditions and then went into a phase of design and construction simultaneously and not as separate stages. This could be explained by their choice to stay very close to their former curriculum and therefore many characteristics of their design were already known. They concentrated on constructing lesson planners for their textbooks. 


\section{Evaluation}

Teams hardly undertook any form of evaluation as part of their work. The only evident example of evaluation was strongly facilitated by the teams' coach (in Copernicus). Implementation was not yet relevant in the work of the teams in this stage as the study concentrated on the preparation year of the teams. The pilots that were executed were labeled in accordance with their goals (in Copernicus they were part of a form of an evaluation, while in Kepler they were part of the analysis and preparation stage).

\subsubsection{Curriculum components in discussion/work}

Time and Place

In both school sites, and across the teams, the 'time' and 'place' components were the most prominent issues in the discussions of the teams. Both in the analysis stage and in the design of the materials or planners they were most often mentioned, discussed and used as the main reasoning for design decisions. In both schools, TDTs with a clearer reform ambition spent less time discussing these elements and concentrated on their own goals. They needed only a general framework and seemed confident that their ideas would be realized within this general framework. In Kepler these teams were also the ones that had more control over the design of their future teaching environment and were not obliged to partake in the centrally designed learning environment.

Content

The content was in most teams taken for granted. In cross-curricular teams (only in Copernicus) content was more often an issue of discussion, as teams had to decide how to integrate it.

\section{Rationale and Goals}

Rationale and goals of the curriculum were minor subjects of discussion in the teams. In Copernicus discussions of those subjects posed great difficulty. In Kepler these discussions were, if at all, short and superficial. The difference can be explained by the fact that the discussions in Copernicus were initiated and facilitated by the coaches. Therefore, they did take place, but posed major difficulty, as teachers struggled with the level of abstract discussion. In Kepler there were no coaches to initiate these discussions at all. 
In Kepler the content, materials and learning activities were often discussed as one element. This phenomenon seems related to the great reliance in Kepler on the existing textbooks that to great extent dictated all of these components.

\section{Measures to broaden the curricular discussion}

Finally, the discussion of paper products (exemplary materials or planners, blueprints of design, meso-design of the curriculum made by one of the team's members) seemed to elicit consideration of more curriculum components. When discussing these documents, teachers asked questions that touched in one way or another on almost all curriculum components.

\subsubsection{Substantive consideration and main quality considerations}

In both school sites, TDTs were first focused on the subject element in their substantive considerations. More specifically, their discussion and work concentrated on content coverage. Coverage was most often defined by the content in the (new) textbooks. In both sites there was one team that independently constructed a list of content to be covered.

The second commonality of the sites is the focus of the teams on the practicality of the materials as the main quality criterion for their work.

\subsubsection{Sequence of activities}

When considering the work patterns of the teams in both schools (table 6.2), some similarities and some differences become apparent. The most noticeable similarity is a development of two work patterns:

- Teams with a clearer common reform ambition and in general more positive disposition towards the reform process started more rapidly with the design itself, and were less dependent on the clarity of the school-wide framework.

- Teams with a vaguer reform ambition and often ambivalence towards the reform needed sufficient clarity of the organizational conditions before starting to work on their concrete plans.

These patterns worked out somewhat differently in the two schools. In Copernicus, the difference between the two kinds of patterns was exhibited by short cycles of design and construction (of the clear ambition teams) as opposed to a long design stage with a short construction period at the end (of the vague 
ambition teams). In Kepler all teams displayed only one design cycle. The clear ambition teams spent most of their time discussing the meso-design with few construction activities at the end of the year. The teams with a vaguer reform ambition worked mostly at the end of the year and then were mainly busy with construction of planners based on their former textbooks.

Table 6.2 Results of the analysis of the curriculum development process patterns

\begin{tabular}{|c|c|c|}
\hline & Copernicus High School & Kepler High School \\
\hline \multirow[t]{4}{*}{$\begin{array}{l}\text { Sequence } \\
\text { of activities }\end{array}$} & $\begin{array}{l}\text { Small \& clear ambition \& } \\
\text { positive to reform - short cycles }\end{array}$ & $\begin{array}{l}\text { - Clear ambition \& positive to } \\
\text { reform - begin with meso - little } \\
\text { construction }\end{array}$ \\
\hline & $\begin{array}{l}\text { Vague ambition \& mixed } \\
\text { support - long design short } \\
\text { construction }\end{array}$ & $\begin{array}{l}\text { Vague ambition - little design } \\
\text { mainly construction. Current } \\
\text { practice is dominant }\end{array}$ \\
\hline & $\begin{array}{l}\text { Organizational clarity - key for } \\
\text { design in vague ambition teams }\end{array}$ & $\begin{array}{l}\text { - Organizational clarity - key for } \\
\text { design in vague ambition teams } \\
\text { - Advance in short bursts of } \\
\text { activities-mostly at end of year } \\
\text { - Scheduled meetings with } \\
\text { management contributes to } \\
\text { bursts }\end{array}$ \\
\hline & $\begin{array}{l}\text { - Paper products - transition from } \\
\text { design to construction } \\
\text { - Teams passive in information } \\
\text { search }\end{array}$ & $\begin{array}{l}\text { - Initial ideas lose momentum in } \\
\text { process } \\
\text { - Few materials ready at end of } \\
\text { year }\end{array}$ \\
\hline
\end{tabular}

In both schools, acquiring clarity on organizational conditions in the future learning environment was an important factor for the teams with a vaguer reform ambition to start working on their concrete plans. That was evident especially in Kepler, maybe because teachers there acquired this clarity late, resulting in the design often meaning adapting their former curriculum into the new organizational framework of the school.

The difference between the patterns in the two schools can be accounted for when considering the school-wide process. In Copernicus High School the process was much more structured and stimulated by the innovation manager at the school level and coaches for most of the teams. This led to a more constant focus on the 
development process. In Kepler there was less stimulation of the process and most of it took place at the end of the year, in a burst of activities during several meetings. This burst of activities was mainly attributed to time pressure when teams realized they had little time left to work on their curriculum.

Furthermore, the teams in the two schools displayed some diverging patterns. While in Copernicus paper products (planners, etc) made by the team marked a transition form the design to the construction phase, this did not seem to happen in Kepler. This is perhaps because in Kepler the two stages were hardly separated. In Kepler, on several occasions, initial reform ideas of the teams that were discussed seriously at the start of the school year, disappeared with no further reference during the process. This could be attributed to the irregular process in which, after the kick-off of the work of the teams, they met sporadically if at all. As teams kept no minutes (see section 6.1.9) the ideas were thus forgotten.

\subsubsection{Place of activities}

In view of the location of the activities undertaken, teams across the two study sites displayed similar tendencies (table 6.3). Design activities, which more often took place in the team discussions, occurred exclusively in the school itself. Notably, construction of materials was something teachers did individually (see section 6.1.7) and then exclusively at home. Only on the rare occasions when teachers had an explicit appointment to construct materials together, construction took place in the school.

\subsubsection{Participants and their role}

The role division in most of the TDTs was, if at all, informally defined as the process developed. Even though the teams in Copernicus had a formal chair person, in all but one of them it had no clear definition and function. The informal role division took three forms. First, and least common, was a strict role division that evolved based on the work preferences of the team members. In the team (of two persons) that took this approach one teacher was the main developer and constructor of materials and the other was more reactive, even if active in the review and feedback on materials. The second form of role division was based on the level of involvement in the process. In this role division some team members took a back seat in the process while others stepped up, were 
more dominant in the discussions and did most of the work. This dominant role did not lead to a formal leadership role whereby the dominant party took responsibility for the work of the team. Thirdly, most teams divided the construction of materials between the team members. In this division there was no differentiation in the kind of tasks the teachers undertook. The roles were divided in the sense that each teacher was responsible for the construction of part of the teaching materials, based on the decisions of the team.

Table 6.3 Results of the analysis of the curriculum development process characteristics

\begin{tabular}{|c|c|c|}
\hline & Copernicus High School & Kepler High School \\
\hline Place & $\begin{array}{l}\text { - Design - school } \\
\text { - Construction. - home }\end{array}$ & $\begin{array}{l}\text { - Design - school } \\
\text { - Construction. - home }\end{array}$ \\
\hline $\begin{array}{l}\text { Participants \& } \\
\text { cooperation }\end{array}$ & $\begin{array}{l}\text { - Chairperson - only formal } \\
\text { role } \\
\text { - Informal role division - } \\
\text { dependant on level of } \\
\text { involvement } \\
\text { - Joint work on meso-design } \\
\text { - Interdependence in } \\
\text { product \& clear roles } \rightarrow \\
\text { more joint work }\end{array}$ & $\begin{array}{l}\text { - No formal role division } \\
\text { - Some informal role division } \\
\text { - Joint work on meso-design } \\
\text { - Section leaders dominant } \\
\text { when present }\end{array}$ \\
\hline Work orientation & $\begin{array}{l}\text { - Clear ambitions \& positive } \\
\text { towards reform - own line } \\
\text { - Vague ambitions - } \\
\text { dominance of framework }\end{array}$ & $\begin{array}{l}\text { - Clear ambitions \& positive } \\
\text { towards reform- own line } \\
\text { - Vague ambitions \& mixed } \\
\text { support - dominance of } \\
\text { framework } \\
\text { - Meetings dependent on } \\
\text { school-wide schedule } \\
\text { - During bursts - one } \\
\text { meeting leads to the next - } \\
\text { concrete assignments - } \\
\text { Sense of urgency leads to } \\
\text { work }\end{array}$ \\
\hline Organization & $\begin{array}{l}\text { - No explicit plans \& } \\
\text { structure } \\
\text { - Coach triggers meetings } \\
\text { - 'Need' - leads to meetings }\end{array}$ & $\begin{array}{l}\text { - No explicit plans \& } \\
\text { structure } \\
\text { - In cross-curricular teams - } \\
\text { management creates } \\
\text { agenda } \\
\text { - Sense of urgency leads to } \\
\text { activity burst }\end{array}$ \\
\hline
\end{tabular}


Considering joint work levels in the teams, it is clear that most teams displayed joint work mainly in the general design decisions. This concerned the drawing up

of general guidelines for their curricula, selecting materials to be used and drawing up the general scheme of teaching planners. There were very few examples of joint work on concrete teaching materials, either of actual mutual work or commenting on one another's work. Construction was mostly an individual endeavor with little feedback. The only teams that did display more joint work in the construction period were those teams that started off with (1) a clearer common reform ambition and (2) had a clearer (informal) role division, either agreeing on equal participation or assigning clearly separate roles. Cooperation in the construction phase did have an added value as it led to adaptations cycles of the general design.

\subsubsection{Work orientation}

In overseeing the work orientation of the teams in both school-sites (table 6.3), a division to two patterns arises. These patterns are in line with patterns that were discussed earlier (section 6.2.5). Teams with a clearer initial ambition seemed to be less 'preoccupied' by the school-wide framework. Because of that, the experienced vagueness of the framework (in both school sites) had less impact on the process in these teams. They did take the framework into account but continued developing their own plans. In Kepler this led to two teams actually taking design decisions that were eventually in conflict with the organizational conditions in the future school building. The teams that started off with a vaguer or absent reform ambition were very much dependent on the clarity of the framework and were more highly oriented to it. Design in these teams hardly proceeded until this issue was solved. In Copernicus this was somewhat compensated by the role of the coaches who were very important for the continuation of the process.

Orientation on the organizational conditions worked also in a different way. The meetings of the teams in Kepler were dependent on school level organizational facilitation. Meetings took place only at the centrally-scheduled timeslots and even then only when there were no distractions in the form of more urgent day-to-day matters. Many of the scheduled meeting time slots were not used for team meetings. 


\subsubsection{Organization of work}

Both studies show that the work of the teams was neither planned nor structured. Even in Copernicus High School, where coaches were available, the work proceeded with little clear steering or planning. Plans were made, if at all, from one meeting to the next with little overview of the whole process.

In both studies team meetings were triggered by external impulses-either by a coach who wanted to set a meeting (Copernicus), or by the school management who set a school-wide time slot for a meeting with an explicit agenda to be discussed. When these external impulses were absent, teams often met irregularly. Even with these external impulses meetings were not always held. All the teams in Kepler had a centrally-scheduled time slot for meetings. Many of these time slots were not used. Only when an internal 'need' or 'urgency' arose, did teams meet on their own initiative. This most often happened at the end of the year when the pressure to come up with plans for the following year became greater. In Kepler this pressure was, for example, also created by the setting of meetings with the school management team that expected to get briefed on the plans of the teams.

\subsection{CONDUCIVE OR HINDERING ACTIVITIES AND APPROACHES}

The main characteristics of conducive activities found had to do with a visualization of the future teaching and learning practice (Table 6.4). While in Copernicus those were activities that helped in acquiring a concrete image of teaching practice, in Kepler the emphasis was on those activities that directly contributed to the production of new materials. Those included the former as images of future teaching practices are needed when designing curriculum materials. A possible explanation for this difference between the teams in both schools is the added pressure experienced in the Kepler TDTs towards the end of the year. They needed to produce many materials in short span of time as only few design activities took place during the year it self.

Considering specific activities that were either perceived to be conducive by the participants or led to changes in work patterns, several commonalities and differences become visible. In both sites pilots have been seen as being helpful and have shown to affect the process. This, however, only applied to those teachers 
who had directly participated in them. There was little to no transfer of insights and experiences to other teachers who did not participate in the pilot. Also, the discussions of concrete plans or blueprints that were on paper seemed to have a conducive effect on the development work in the teams:

- in broadening the discussion (more curriculum components are considered);

- in making the discussion concrete and structured which the teachers experienced as effective;

- in forming a transitional activity between analysis/design to construction of materials.

Table 6.4 Results of the analysis of the conducive and hindering activities and approaches

\begin{tabular}{|c|c|c|}
\hline & Copernicus High School & Kepler High School \\
\hline \multirow[t]{2}{*}{ Conducive activities } & $\begin{array}{l}\text { Discussion of concrete } \\
\text { micro plans/blueprints } \\
\text { - Pilots - only if new \& } \\
\text { central act - only by } \\
\text { participating teachers } \\
\text { - Individual construction - } \\
\text { dynamic \& speed in } \\
\text { process }\end{array}$ & $\begin{array}{l}\text { - Colored by contribution to } \\
\text { productions of concrete } \\
\text { material for team } \\
\text { - Personal experience - } \\
\text { dominant in decision } \\
\text { - Discussing of concrete } \\
\text { micro plans/blueprints } \\
\text { - Pilots \& presentations - } \\
\text { only by participating } \\
\text { teachers } \\
\text { - Individual construction - } \\
\text { dynamic \& speed in process }\end{array}$ \\
\hline & $\begin{array}{l}\text { Clear ambition - gradual } \\
\text { process - little } \\
\text { breakthroughs - include } \\
\text { more explicitly school-wide } \\
\text { reform goals in product }\end{array}$ & $\begin{array}{l}\text { - Intervention from section } \\
\text { leaders } \\
\text { - Meeting with management } \\
\text { team } \\
\text { - Sense of urgency } \rightarrow \\
\text { dynamic } \\
\text { - Regular, frequent. meetings } \\
\rightarrow \text { dynamic of development }\end{array}$ \\
\hline Hindering activities & $\begin{array}{l}\text { Vagueness of framework } \\
\text { delays work in vague } \\
\text { ambition teams }\end{array}$ & $\begin{array}{l}\text { Vagueness of framework } \\
\text { delays work in vague } \\
\text { ambition teams } \\
\text { - Early choice for textbook in } \\
\text { vague ambition teams - } \\
\text { conservative solution }\end{array}$ \\
\hline
\end{tabular}


In almost all cases the teachers described working individually on the construction of materials as one of the most efficient parts of the work. This might be connected to the issue of how teachers perceived the work of the TDT. They seemed to see their production function as more important than reconsideration of the basic ideas of the curriculum. Next, in both school sites the activities that the innovation manager (Copernicus) or school-section leader (Kepler) undertook had an important impact on the team. Their presence in meetings and their supply of information had great impact on the advancement of teams. In the same way, their absence or delay in reacting on team's question had a negative impact (see further discussion in section 6.3.4).

A common finding in both Copernicus and Kepler is that the teams with clearer initial ambitions realized more often explicit incorporation of the school-wide reform goals in their development work. In Kepler these teams refrained from an early choice for use of the former textbooks, while in Copernicus these teams tended to produce more often new materials.

Finally, a point that became clear in Kepler is that regular meetings created some dynamic of the curriculum development process leading to great advancements in a very short span of time. Most of the teams in fact did most of their work within several meetings over the span of several weeks. This was coupled with a sense of urgency and stress as it was at the end of the year.

Concerning hindering elements, the most prominent and cross-study finding is that many teams had great difficulty managing vagueness at the level of the school-wide reform framework. This was the strongest in teams that themselves had a vague common reform ambition. As they were dependent on developments at the school level, as long as that wasn't clear, they felt hindered in their advancement. As several teams in Kepler chose to keep their former textbooks, when they eventually did start developing, they generally chose to continue their former teaching approach with little change within the new organizational conditions of the reform. As all the teams in Copernicus chose to purchase new textbooks, this finding can not be confirmed nor dismissed. 


\subsection{CONDUCIVE OR HINDERING SCHOOL CONDITIONS}

\subsubsection{Infrastructure}

In both schools teachers were allocated time for the curriculum development work (see table 6.5). This was seen by all as a conditional element for the work. An issue raised in Copernicus High School, in light of the informal role division in the teams, was whether or not all teachers should get the same allowance of time. In several teams there was a clear imbalance in the investment of some teachers in the work of the team. The issue was more prominent in the bigger teams where there was more variance in the commitment of the teachers in the team. In Kepler much of the available time (which was scheduled in the weekly timetable of all of the teachers) was not used. Many of the opportunities to meet and work were not utilized. This was partly due to the scheduling of other activities at the same time. Even given this, in many instances teachers preferred to work on other tasks and not on the TDTs' work.

In facilitating team meetings, having a regular scheduled meeting roster seemed conditional but not sufficient. In Kepler, because teams were not 'pressured' by the attendance of an external agent, team meetings took place only if the team had made concrete appointments ahead of time on the goal of the meeting. At the end of the preparation year the added pressure to 'produce' a result also functioned as a stimulator for meetings and activities.

Table 6.5 Results of the analysis of the infrastructure conditions

\begin{tabular}{|c|c|c|}
\hline & Copernicus High School & Kepler High School \\
\hline \multirow[t]{3}{*}{ Infrastructure } & $\begin{array}{l}\text { - Time allocation - needs to be in } \\
\text { relation to design task } \\
\text { - Importance rises in low } \\
\text { commitment }\end{array}$ & $\begin{array}{l}\text { - Time allocation } \\
\text { - Time often not utilized }\end{array}$ \\
\hline & $\begin{array}{l}\text { - Organized meeting time helps } \\
\text { regular meetings. Clear } \\
\text { ambitions teams - less } \\
\text { important }\end{array}$ & $\begin{array}{l}\text { - Meeting only when- } \\
\text { Organized meeting time + } \\
\text { concrete appoint }+ \text { sense of } \\
\text { urgency }\end{array}$ \\
\hline & & $\begin{array}{l}\text { - Future infrastructure - } \\
\text { dominant in work of team }\end{array}$ \\
\hline
\end{tabular}


In Kepler, infrastructure played yet another role. As mentioned before, the school moved to a completely new building. As the infrastructure there was unclear for the teachers, this caused much teacher discussion and had a negative impact on their work progress.

\subsubsection{External support and role of researcher in work of team}

The role of external support could only be explored in Copernicus because the Kepler teams had no such support. The main findings (see table 6.6) were that although the coaches played a varied role in the different teams, their effectiveness in the eyes of the participating teachers was dependent on their ability to cater to the main needs of the teams. The greatest articulated need was support in creating concrete tangible materials for use. In teams where this need was fulfilled teachers displayed greater satisfaction with the support. Even though the coaches, sometimes intentionally, did not match their support to that need, this support role was never discussed.

The presence of a coach had a crucial role in organizing meetings. The fact that the coach made an appointment to come and suggested discussion issues was in many cases the main reason that teachers came together. Additionally, the tasks that the coach summarized or suggested at the end of the meetings were the structuring element for the work of the teachers until the next meeting. The centrality of this role can be seen in Kepler where, possibly because of the absence of a coach, teams met only very sporadically through the year.

One noteworthy finding is the positive impact that common explorative activities (like the baseline study) had on the relationship of the external support with the team. This had a constructive effect in the process, as teachers felt better understood by the external supporter. In the cases where a teacher and a coach were involved in one team, the fact that the researcher participated in the baseline study caused a preference for the support of the researcher although this was not the intention. 
Table 6.6 Results of the analysis of the external support and cross-over structures

\begin{tabular}{|c|c|c|}
\hline & Copernicus High School & Kepler High School \\
\hline External support & $\begin{array}{l}\text { - Appreciated when } \\
\text { answered central need - } \\
\text { central need was tangible } \\
\text { cont in design } \\
\text { - Central in planning docu- } \\
\text { ments } \\
\text { - Central trigger for mee- } \\
\text { tings } \\
\text { - Common exploration acti- } \\
\text { vities build relationship - } \\
\text { positive in process } \\
\text { - Role not issue debate }\end{array}$ & $\begin{array}{l}\text { - None - no apparent need } \\
\text { - Appreciation for role of } \\
\text { researcher - no apparent } \\
\text { effect }\end{array}$ \\
\hline \multirow[t]{3}{*}{ Coordination } & $\begin{array}{l}\text { - Interactions on plans and } \\
\text { results - especially on } \\
\text { concrete experiences } \\
\text { highly appreciated. - gave } \\
\text { overview and builds } \\
\text { communality } \\
\text { - School-wide schooling - } \\
\text { only helpful when } \\
\text { resulting in concrete } \\
\text { products for design work }\end{array}$ & $\begin{array}{l}\text { - Little formal interaction } \\
\text { - } \text { Teams have no overview } \\
\text { relevant } \\
\text { - Vague ambition - express } \\
\text { more need for } \\
\text { interaction/information }\end{array}$ \\
\hline & $\begin{array}{l}\text { - Little informal interaction } \\
\text { on reform - only with } \\
\text { teachers with common } \\
\text { high commitment }\end{array}$ & - No informal interaction \\
\hline & $\begin{array}{l}\text { Project group: } \\
\text { - major source of } \\
\text { information } \\
\text { - give overview of } \\
\text { developments } \\
\text { - support in role a } \\
\text { chairpersons }\end{array}$ & $\begin{array}{l}\text { Coordination team: } \\
\text { - partial representation } \\
\text { - teams with no } \\
\text { representatives - higher } \\
\text { information need } \\
\text { - } \text { support in role a participants }\end{array}$ \\
\hline
\end{tabular}

\subsubsection{Coordination - contact with rest of school/teams}

Considering crossover structures (table 6.6), the school showed a different approach. While Copernicus invested in coordination meetings of the teams and 
a broad project group representing most of the TDTs, this was not the case in Kepler. As a result, the team in Kepler more often asserted that they had little overview of the developments in school and these developments seemed fragmented to them. The only venue for cross-curricular debate in Kepler, the original cross curricular-teams, was not seen as a useful instrument. This lack of overview and need for information was more often and more vividly articulated in teams that had a vaguer reform ambition and were therefore more oriented to the developments at the school level.

The various activities undertaken in the school-wide meetings in Copernicus had varying results. Two kinds of activities were considered effective. On the one hand presentations of the various teams on their progress contributed to the overview teachers had of the developments in school. It also created a feeling of community-everyone sharing a common endeavor and experiencing similar challenges. On the other hand, especially in activities aimed at professional development, teachers had special interest in concrete instruments or products that advanced the work of their team. If the schooling activity did not provide that, it was perceives as less useful.

In both school sites, coordination groups were formed in the initial phase of the reform (before the formation of the TDTs). At the same time, in both sites they had a different effect on the work of the TDTs. The major difference between the teams was the participation. In Copernicus all but one team participated. The coordination team was a major source of information for the TDTs and it contributed to the overview teams had of the developments in school. In Kepler, only two of the five teams followed in this study, had representatives in the coordination team. Because of this, the major cross-over function of the coordination team was not fulfilled and in fact three of the teams were practically cut off from this information source. The coordination teams were deemed effective in supporting the roles of the participants. They gave them venues to discuss their role as chairpersons (Copernicus) and more generally provided them with insights of the developments at the school level and enabled discussion of school-wide curricular decisions. This opportunity was appreciated by the participants.

A salient finding is the almost complete absence of informal interaction of teachers with members of other TDTs. In Kepler no informal interaction on 
reform issues was reported. In Copernicus there was only one example of such interaction. The main motivation given for it was that the two teachers (from different TDTs) shared a high commitment level for the reform and also knew that of each other. Because of that, when one of them experienced a specific difficulty, she sought her colleagues' help.

\subsubsection{Role of school leader and school-wide framework}

\section{School-wide framework}

Both schools applied a parallel strategy. Alongside the development of (part of) the school-wide organizational implications of the reform, the TDTs worked on their own plans. There is a strong similarity between the teams in both schools regarding how teams handled the school-wide plans in development (table 6.7). Teams that started the process with a clearer common ambition for the reform were less dependent on its existence. They asserted that it was vague on some points but continued following their own line, confident that it would be realized. Teams with vague or no common ambition showed a dependency on the level of clarity of the framework. They did not proceed with their work until specific organizational elements were clear. These teams often ended up doing the bulk of their work at the end of the year when conditions were clearer. A clear difference was visible in the vague ambition teams between the schools. While in Kepler the process in these teams came almost to a halt, the work of the coaches in the Copernicus teams secured the continuation of the discussion and work. This difference can be explained by the more structured form of the

process in Copernicus. The teams had coaches that set meetings and helped the discussion continue despite the vagueness of the school-wide framework.

An important difference was in the focus of the vagueness experienced by the teachers in both schools. In both schools teachers were unclear about some school-wide organizational implications. At the same time teachers in Copernicus had more difficulty with the fact that the relationship between their wishes and plans and the school-wide framework was unclear. This was a result of an explicit policy of the school management. They announced that they would hold back several school-wide plans until teams made their preferences clear. Eventually all teams made their preferences clear, but some of those could not be honored. This created a backlash of disappointment on the side of the teams who had invested efforts to develop their own plans. They failed to see how they 
could influence the school-wide framework. In Kepler the teams were more oriented towards the plans of the management. Interestingly, even though school documents available from early in the process showed specific organizational implications, teachers perceived these elements as vague until late in the preparation year.

Table 6.7 Results of the analysis of the role of school leaders and the school-wide framework

\begin{tabular}{|c|c|c|}
\hline \multicolumn{3}{|c|}{ Copernicus High School } \\
\hline \multirow[t]{6}{*}{$\begin{array}{l}\text { School leader and } \\
\text { framework }\end{array}$} & $\begin{array}{l}\text { Framework: } \\
\text { - vague relation between } \\
\text { team and school level } \\
\text { plans - source of irritation }\end{array}$ & $\begin{array}{l}\text { Framework: } \\
\text { - vague until late in process } \\
\text { - difference between existing } \\
\text { \& experienced framework }\end{array}$ \\
\hline & $\begin{array}{l}\text { clear ambition - not } \\
\text { dependent on existence } \\
\text { - vague ambitions - lack of } \\
\text { specific elements of } \\
\text { framework inhibits work }\end{array}$ & $\begin{array}{l}\text { - clear ambition \& control of } \\
\text { environment - not } \\
\text { dependent on existence } \\
\text { - vague ambitions - lack of } \\
\text { framework inhibits work } \\
\text { - teams reactive in relation to } \\
\text { framework }\end{array}$ \\
\hline & $\begin{array}{l}\text { Role innovation manager: } \\
\text { - Late feedback - negative } \\
\text { relationship \& diminished } \\
\text { effect } \\
\text { - Vague ambition- } \\
\text { dependent on (in)activity } \\
\text { of leader }\end{array}$ & $\begin{array}{l}\text { Role school section leaders: } \\
\text { - Had little overview of } \\
\text { development in teams } \\
\text { - Vague ambition \& mixed } \\
\text { support - dependent on } \\
\text { (in)activity of leader }\end{array}$ \\
\hline & $\begin{array}{l}\text { - Little control of work of } \\
\text { teams }\end{array}$ & $\begin{array}{l}\text { - Little control of work of } \\
\text { teams }\end{array}$ \\
\hline & $\begin{array}{l}\text { Direct face-to-face most } \\
\text { effective for teams: } \\
\text { - During team meetings } \\
\text { - Has relational effect on } \\
\text { team }\end{array}$ & $\begin{array}{l}\text { - Presence in team meetings - } \\
\text { info source }\end{array}$ \\
\hline & & $\begin{array}{l}\text { Meeting with management } \\
\text { team: } \\
\text { - impulse for work of teams - } \\
\text { leads to higher 'production' } \\
\text { - creates interaction between } \\
\text { teams }\end{array}$ \\
\hline
\end{tabular}




\section{Role of school leaders}

Considering the role of the leader in school who is directly responsible for the work of the TDT, the overarching finding is that their role was of greatest importance to the teams that were less clear as to their direction. As they were directed toward the presence or absence of a reform framework, they were very much oriented to the activity or inactivity of the leader. The interventions of the leaders had more impact and the perceived inactivity of the leader (not supplying some information, not acting on their request) led to inactivity in the team. In both schools the leaders applied little control to the work of the teams. They had few moments in which they informed on the developments in the work process of the team and their results.

The presence of the leaders in team meetings fulfilled an important role in all teams. It was an essential source of information on the school-wide developments. Especially in Kepler, where several teams had little other sources of information, this was crucial. Another salient finding-mostly evident in Copernicus - was the important relational effect of the presence of the leader in meetings. The fact that he was 'there' and showed interest did much for the teams and encouraged them to go on.

A last finding that stresses the effect of the school management on the work of the TDTs was how teams reacted to a meeting organized with the school management team in Kepler. This inquiry of the management into the progress of the teams spawned a frenzy of activities on the side of the teams that until that moment achieved only little progress. As the meetings were held with several teams at a time, an additional side effect of these meetings was an exchange between TDTs on their plans. For most teams this was the first occasion in which they were exposed to the work of other TDTs. 


\section{CHAPTER 7 Discussion}

This study was set up to gain a better understanding of issues related to collaborative curriculum development in the context of school-based and schoolwide curriculum reform. The work of TDTs was defined as being at the heart of this process and was the focus of the research endeavor. In two schools 12 TDTs were followed during their first year of curriculum development work. The main goals of this study were (1) getting insight into the kind of development processes that these teams undertake and (2) discerning those activities and conditions that are conducive or hindering in their pursuit of developing new curricula.

In this chapter the main findings of this study are discussed. After a short recapitulation of the study (section 7.1), the findings are related to other studies on comparable themes and the guidelines for the work of TDTs discussed in chapter 2 (section 7.2). Section 7.3 presents the conclusions of the study. The chapter ends (section 7.4) with recommendations for schools and teachers, policymakers, and future research.

\subsection{RECAPITULATION}

\subsubsection{Origins of the study}

This study started from the premise that teacher collaboration in curriculum development is well placed in order to bridge the gap between school-level curriculum reform and classroom-level practices. As teachers are at the forefront of all educational reforms, they need not only to be involved in the implementation process, but also be active participants in the development process of a reform. It is assumed that collaboration between teachers in these curriculum development efforts enables (1) more coherent curriculum development across teachers and subjects, (2) professional development processes of the teachers, and (3) development of the school organization as a whole. 
This seems to be even more the case in a context in which curriculum development takes place in a school-based and school-wide context. It is further assumed that collaborative curriculum development of teachers is best realized in teacher design teams (TDTs), defined in this study as 'a group of at least two teachers, from the same or related subjects, working together on a regular basis, with the goal to (re)design and enact a (part of) their common curriculum'.

Next to the theoretical assumptions about the potential of collaborative curriculum development, the policy trend in Dutch lower secondary education supplied a suitable context to study this phenomenon. Following an evaluation of previous reforms, a new direction for lower secondary education was stipulated at the national level. The essence of this reform was that attainment goals have been broadened and made more general and that schools got the freedom, and in fact were encouraged, to shape their own curriculum. This freedom included both subject matter as well as pedagogy. Many schools have delegated at least some of the curriculum development tasks to teams of teachers in the school. At the same time yearly surveys showed that schools still encountered many problems in this reform process in which teachers play a more active role in the curriculum reform process in their school.

Despite the evolving practice in Dutch schools and the expected benefits of collaborative curriculum development in schools, the research base of findings on how teacher teams with curriculum development tasks work or should work is yet limited. This study intended to contribute to this knowledge base by studying TDTs in their first year of development work. The main research question guiding this study was as follows:

What are conducive (or hindering) approaches and conditions for collaborative curriculum development by teacher design teams in view of school-wide reform?

This research question was further divided into three sub-questions: the first aimed at describing the work of teacher design teams, the second concerned with those activities that were specifically conducive or hindering to the teams in striving towards their goal of common curriculum, and the third aimed at exploring the school conditions that promoted or hampered these efforts. 


\subsubsection{Research design}

To answer the research questions a qualitative multiple case study approach was used. Twelve teacher design teams in two different schools (seven teams in one school and five teams in another school) were followed during their first year of collaboration throughout their preparation year. During this first year, many of the TDTs' activities were documented, teachers were interviewed and observed, both at the start and at the end of the study, and (curriculum) documents produced by the TDTs were collected and analyzed. Based on the data, a rich description of the teams' work was obtained. This systematic documentation process and the perspective of the practitioners formed the basis for detecting activities and conditions that had a special (positive or negative) function for the teams. The analysis of the findings, based on the three sub-questions guiding this study, was done on three levels: (1) an analysis of the individual cases (the teams), resulting in detailed case descriptions (see sections 2 and 3 of the accompanying CD), (2) a cross-case analysis of the teams in each of the schools to find common and diverting patterns per school (see chapters 4 and 5), (3) a crossstudy analysis, comparing the findings from the two school sites to detect commonalities and differences between the school sites (chapter 6). By choosing these schools and teams carefully and by comparing the findings with others studies some analytic generalization can be made to TDTs in other contexts.

\subsubsection{Main findings}

Both schools in this study applied a parallel reform strategy. Alongside the development of (part of) the school-wide reform and its organizational implications, the TDTs were working on their own plans. Results show varied work patterns of the teams in the schools. However, several commonalities and explainable differences across the teams arose (for extended discussion see chapter 6).

How TDTs addressed and carried out their development work

With regard to the work of the TDTs it became obvious that it is neither explicitly planned nor organized by any player in the process (in most cases not even by the external coaches). Teams most often proceeded from one meeting to the next tackling issues as they arose. This implied in almost all the teams that only a (small) portion of their curriculum materials was ready at the end of the preparation year. Role division in most teams was informal and not all teachers 
participated to the same extent in the curriculum development activities. Most of the joint work concentrated on developing general design decisions. There was little joint work on constructing concrete teaching and learning materials. In those occasions where collaboration on constructing concrete materials level did occur, this led to realizing more significant change in the curriculum of the team.

In the first phase of their work, teams were very much oriented towards the future 'time' and 'place' components of their curriculum. These issues needed to be somewhat clarified before the team was open to discussing more fundamental curricular questions such as 'content', 'teaching activities', and 'materials'. The major design decisions that teams made in their curriculum development process were done either during the first several meetings of the TDTs or even prior to the commencement of the formal process in school (teams that had already some common plans and did not yet have the chance to realize them took the opportunities given by the reform process). This underlines the importance of this initial phase. The overall process of the teams included only a few of the 'ideal' steps in curriculum development. While analysis activities were somewhat apparent (mainly oriented towards the organizational aspects), design and construction seemed to occur most often simultaneously. Teams conducted little to no explicit evaluation activities and judged the quality of their plans and materials mainly on the basis of their practicality.

In both schools, two work patterns developed. Teams with a clear common reform ambition and a positive disposition towards the reform started more rapidly with the design and were less dependent on the clarity of the school-wide framework. Teams with vaguer reform ambitions and often ambivalence towards the reform needed sufficient clarity of the organizational conditions of their future practice before starting to work on their concrete plans. For these latter teams, this led either to a long analysis and orientation phase followed by a short design phase or to a long period of inactivity followed by a short burst of design and construction activities. These activities then were mainly aimed at adjusting former curricula to the organization conditions of the school reform.

\section{Conducive or hindering activities and approaches}

The most conducive activities were those that assisted in creating a visualization of the future practice of the reform. The activities (such as piloting, school visits, and discussion of blue prints of design) were highly valued by the teachers and 
led to pattern changes in the process of the teams. On the whole it seems that the teams that share clearer initial ambitions realized more often explicit incorporation of the school-wide reform goals in their products. Teams that decided to keep their former textbooks and use these as part of their reform chose in general to continue their existing teaching approach with little change. This might be considered a hindering approach, as it meant that they often did not even reconsider their former practice.

\section{Conducive or hindering school conditions}

Some school conditions that enabled or impeded the work of the TDTs became clear. Allocated development time for the teachers, also in the form of regular scheduled meetings, was a conditional element but not sufficient for enabling team meetings and work. The perceived effectiveness of coaching was dependent on the ability of the coach to cater to the main needs of the TDT, especially in creating or providing concrete tangible teaching materials. The presence of a coach also had a crucial role triggering team meetings by making concrete appointments and suggesting discussion issues.

The parallel reform strategy applied by the schools was conducive for those teams that had a clear reform ambition. Teams with vague or no common ambition showed a greater dependency on the level of clarity of the framework. These teams made, on the whole, less progress in the production of new curriculum plans and materials. When the school-wide process was more structured, this vagueness had less impact on the pace of the work of the teams. The school-wide process in both schools gave only few organized opportunities for interaction between TDTs. However, teachers often expressed a need for such opportunities and when such activities did take place, they had a strong impact on the teams. These kinds of activities gave teams an overview of the developments at the school level. It also supported the commitment of the teachers to the process as it strengthened the impression of a shared endeavor and identification with the work of other teams in the same school.

Another conducive condition was the active role of the school leaders, especially for the teams with vague reform ambitions. Even a seemingly simple act of being present in team meetings carried much weight. It supplied teams with information and had a relational function. All teams found the interest and time investment of the leader important. However, school leaders had only a vague 
overview of the progress of the TDTs as there was little interaction with the teams concerning their work. The importance of this issue was demonstrated when the school management did actively inquire about the development of the TDTs' work. This single incident had a positive impact leading to increased curriculum development activity and materials construction of the TDTs.

\subsection{RELATION TO INSIGHTS ON TDTS FROM OTHER STUDIES}

The previous section gave a short summary of the study and its main findings. In order to examine their validity, the main findings are related to the results of recent studies in the Dutch lower secondary education context with some focus on collaborative curriculum development. To examine the added value of the findings to the knowledge base on collaborative curriculum design, they are also compared with the guidelines discussed in chapter 2 (section 2.3). First, the recent Dutch studies are shortly introduced, followed by discussion of their research findings and the guidelines drawn in chapter 2.

\subsubsection{Related studies into collaborative curriculum development in the Netherlands}

In the past few years several studies have been conducted on the Dutch lower secondary education reforms. The studies had diverging foci but in all of them some form of collaborative curriculum development was explored. These studies are presented here:

- TDTs in a diffused reform context-many schools (49\% of the school, Onderbouw-VO, 2009) do not choose to organize their reform in a school-wide fashion. They opt for organizing cross-curricular learning projects alongside the 'conventional' subject curriculum. This strategy is different from the context of this study in that the emphasis on the school-wide aspect of the reform is diminished. Development is delegated to several project teams (the TDTs), each responsible for a common curricular unit for a part of their teaching time. Handelzalts (2009) followed two of these TDTs that were invited to create short cross-curricular units for designated 'project weeks' in which students participated in project-based education.

- Collaborative curriculum development at school-wide level-another form of collaboration in curriculum development can be the collaboration of the whole 
school teacher team in creating the reform framework itself. The curriculum development is not so much at the level of curriculum materials and microlevel plans but at the meso level of a school curriculum. Nieveen and Handelzalts (2006) studied five whole school teacher teams that cooperated in defining their common, school-wide reform framework with the assistance of external curriculum coaches. They followed these teams during six months and documented their process and results. Their main objective was to explore how whole school teacher teams come to a redesign and/or a justification of their meso curriculum.

- Work of TDTs in relation to the school-wide framework - an emerging issue from the study presented in this dissertation is the relationship between the teams' characteristics and their interaction with the school-wide reform framework. Starting off by studying the work of TDTs that are aimed at farreaching integration of their teaching subjects, Nieveen and Handelzalts (2008) concentrated specifically on this relationship. They followed three TDTs in three schools during three months. These interdisciplinary teams were coached in their process of integrating their subject matter.

- TDTs from a long term perspective-one of the tenets leading the focus on TDTs was the potential for sustainable reform in the long run. This was set in contrast to more vulnerable reforms that mainly depend on the commitment of single teachers within the school (see chapter 2 for more extensive discussion). Handelzalts (2007) examined this premise by following the work of the TDTs at Copernicus High School during a period of four years. The findings for the first year of the TDTs in this school were presented in chapter 3 of this dissertation. Handelzalts (2007) returned to the TDTs once a year in order to explore their further work and progress and the conditions that influence that.

- School-wide reform initiatives in the Netherlands-parallel to the reform initiatives in the Dutch lower secondary education a longitudinal study of the experiences of schools was set up. Voncken, Derriks and Ledoux (2007) followed four schools during a six-year period. Their goal was to register the course of the reform of the schools and the experiences of the school leaders and teachers involved. As part of their study they also explored the role of teacher teams (in various forms) within the school reform. Although their focus was not specifically on the curriculum development activities of the teams, their findings offer a rich source for comparison specifically in relation to the school-wide conditions and differences that seem to arise between different kinds of teams. 


\subsubsection{Related findings on how TDTs address and carry out their work}

As most of the studies and the research literature used in chapter 2 did not explore curriculum development process with the same scrutiny as the study presented here, the issues that are discussed are at the level of the general characteristics of the development process.

\section{Rapid crystallization of design decisions}

A finding that has been confirmed in several of the other studies is that central decisions in the curriculum development process are made before the formal development starts or during the first several meetings. The teacher teams base their design decisions on either an initial ambition or idea (Handelzalts, 2009) or on already existing curricula that are often already partly enacted (Nieveen \& Handelzalts, 2006). These initial decisions then remain stable throughout the development work.

\section{Practical orientation of teacher teams}

In very much the same way as the findings of this study show, the orientation of teacher teams on organizational conditions (e.g. 'time' and 'place') in the future teaching practice is a recurrent finding in many of the studies. Even in curriculum development at the school level, where the emphasis on concrete teaching materials was weaker, teams were more inclined to discuss practical and organizational aspects of the reform rather than pursue more fundamental discussions about the rationale and goals of the curriculum as a whole (Nieveen \& Handelzalts, 2006; Voncken et al., 2007). It is possible that the school-wide character of the reforms encouraged in some sense this emphasis on the organizational conditions, by making the reforms both general and somewhat compulsory. As much of the reform was presented in abstract terms and was not necessarily appealing to all the teachers, the only concrete grip some teachers had was on the organizational issue. This is apparent in the study of a school that had no school-wide reform framework and in which teams concentrated on teaching projects with a restricted scope (Handelzalts, 2009). In that study the reform depended on the ideas and wishes of specific teams. The focus on the organizational conditions was then much weaker and limited to a short episode in the teams' work.

On the subject of practical orientation of teachers, the findings of this study differ significantly from the insights described in chapter 2. While teachers (teams) 
were described as preoccupied with practical matters of learning materials, teachers' role, and general structural conditions, this study shows that the preoccupation is aimed mainly at the 'time' and 'place' components of change. The curriculum development process in many teams was delayed until these components of the school framework were clarified. Additionally, where research presented in chapter 2 indicated that this preoccupation would be more prevalent in the case of inexperienced teachers, this pattern was also apparent in the case of many highly experienced teachers too.

\section{Team characteristics}

Many of the studies concluded that the development process showed great variation between teams. Although some variations in the process were related explicitly to the interaction of team characteristics with the reform strategy of the school (see section 7.2.4), Voncken et al. (2007) found specific team characteristic with productive contribution to the reform process. The more productive teams in their studies were the smaller ones with a clear common goal or task and with a mixed composition. According to them smaller teams encourage an active involvement of all members. By creating or stating a clear common goal or task the engagement of the teachers is fostered. When these teams then have the room to make their own plans, it in turn increases the chances of realizing substantial change. Finally, by creating a mixed subject composition of the teams cross-curricular considerations are promoted and the content of teaching is critically examined.

The teams' characteristics also played a role in teams at the school-level. There, the level of overview that the teams had of the guiding vision and process of their school reform seemed to play an important role. Additionally, the more the teachers were used to working with one another and being open for exchange with colleagues, the more they seemed to be able to cope with the uncertainties related to the process of collaborative curriculum development (Nieveen \& Handelzalts, 2006).

These findings confirm the current study's findings. The teams that had an initial common ambition negotiated the reform better, realizing more new curriculum materials that were more often in line with the reform ambition of the schoolwide framework. They were less 'distracted' by the organizational implications of the reform. These teams were often also smaller, containing two to three teachers. The subject of mixed composition was less evident in the current study. 
Although it seemed advisable from a content perspective (the reform striving for integration), working in cross-curricular teams did add a level of complexity. Teachers had to work with colleagues they did not know well, and make concessions on a central element in their practice which was often the content of the subject. Although cross-curricular teams did produce materials that were significantly different from their former practice, they often needed much organizational facilitation and coaching to do so.

When looking from a long term perspective at the work of TDTs (Handelzalts, 2007) it is striking that the work patterns set in the first year of work continued throughout the four years. Teams that displayed collaborative work with a clear reform ambition continued along that line. Teams that had a more difficult time in starting the development process kept experiencing difficulties. During the implementation years, just like in the preparation year, very few systematic evaluations were executed. Adjustments in curricula were geared mostly towards usability problems. It seemed that the development of the curriculum materials during the following years went easier, especially because the teams could follow up on the decisions already made in the preparation year and the fact that they were more acquainted with the design activities. At the same time, the intensity of the work in the TDTs declined over the years. Teams, in general, met less often, concentrated on producing materials along the lines of their initial plans, and initiated few new developments.

The study's findings concerning recommended characteristics for teacher teams with a curricular task confirm the guidelines described in chapter 2. Smaller teams (in this study, 2 to 4 teachers) that have at least a vague common goal from the start were found to tackle the curriculum development challenge better. There are some indications that the preference for cross-curricular teams, described in chapter 2 , is justified, although this also presents some challenges (see discussion above).

\section{Tension between voluntary participation and school-wide process}

An issue that was raised in chapter 2 but not found in other studies is the inherent tension between the value of voluntary participation and the need for broad school-wide activity. The findings of this study raise the possibility of differentiation in the participation of the TDTs as a mediating factor. By creating the TDTs across the school, broad participation is secured. By allowing for differentiation of specific goals between TDTs and differentiation of roles in 
the team, there is room for teachers with different motivations to realize their goals within the school-wide reform framework.

\subsubsection{Related findings on conducive or hindering activities and approaches}

Examining the findings of other studies on the activities that had an explicit positive or negative effect on the curriculum development process, the main findings of the current study are confirmed: teachers need concrete images of reform in order to work on their curricula and joint work on concrete materials and feedback are conducive to the process and its results.

\section{Creation of a concrete image of reform}

In various contexts, similar to the findings of this study and the guidelines drawn in chapter 2 , instruments and activities that helped teachers create a visualization of the emerging curriculum seemed to help teachers get a grasp on the reform (e.g. Handelzalts, 2007; Nieveen \& Handelzalts, 2006, Nieveen \& Handelzalts 2008). This included discussing blueprints, piloting materials, and making school visits. This relates to the mentioned need for clarity of the organizational conditions of reform in order for teachers to proceed with the curriculum development work. In one study (Nieveen \& Handelzalts, 2006) it appeared that the coach had a crucial role in helping the teacher connect the practical and organizational discussion to a more principled discussion on the kind of coherence they want to realize in school. This helped the team transcend the discussion on practical implication and consider more principle issues.

The issue of using common experiences as a way to create clarity of the future teaching practice in collaboration has already been raised in chapter 2 . There, not only was the importance of the experience stressed, but the reflection on it as well. The insights from this study add the importance of reflection ahead of time in choosing the focal question that teachers are exploring in these activities. In such a way the chances are greater that the results of the activity will have an impact on the work of the teams.

The issue of creating a concrete image of future reform seems to play a smaller role when teams are involved in a more diffused reform in which they have more control over the form of their own future practice (Handelzalts, 2009). In this context, because teams are not dependent on 'the school' for drawing up the conditions for implementation, the kind of activities that help the teachers are not 
related to this visualization. In the context of a diffused school-wide framework, teachers benefited from the kind of activities that led to articulation of their own goals with the project. This created clarity in their process.

\section{Joint work on construction of materials}

The second kind of conducive activities found in the recent studies are those activities that include significant joint work of teachers on concrete materials or in actual teaching. These activities included opportunities when teachers worked closely together on concrete teaching materials or had detailed feedback on one another's materials or practice (Handelzalts, 2009; Voncken et al., 2007). Teachers seem to find these kinds of activities stimulating. This increases their appreciation of the cooperation process, contributes to their motivation (Handelzalts, 2009), and seems to lead to the strongest learning experiences (Voncken et al., 2007). This is in line with the conclusions drawn in chapter 2 that assigned this form of joint work a great learning potential.

An additional argument for joint work on concrete materials can be made from the curriculum coherency goal of the collaborative work. Collaborating on general issues and statements leaves participants much room for their own interpretation. This can lead to 'false clarity' (Fullan, 2007) because the actual meaning of change is not discussed in the team. Working together on concrete manifestations of the curriculum uncovers assumptions and implicit intentions and can make them a subject of discussion. In the current study this increased joint work was found to be conducive to creating more substantial reform in the teams. Teams that displayed more joint work (and thus had more chances for feedback) on materials had greater chances to realize more innovative teaching. However, it is not clear how this relationship operates. These teams had other characteristics (small, cohesive, common ambition) that indicated their potential. Was the intensive feedback a symptom that correlated with characteristics or did it have an independent effect? Bearing in mind Hargreaves' (2003) warning on effects of contrived collegiality, one should be careful in forcing joint work in a team that is not ready for it.

\section{Implementation and evaluation}

The effects of implementation of curricula have not been discussed in the current study as the teams were only followed in the preparation year. There are, however, some indications that this part of the development process holds great promise. In part this potential was evident in the effect that pilots had on the teams in supplying a concrete image of their future practice. Other studies (Handelzalts, 
2007; Handelzalts, 2009) showed that implementation can be very conducive in several respects. The approaching implementation date serves as inducement of an increased tempo of design and construction activities. It forced the team to complete their work (this was also evident in the current study where teams increased their work tempo when the preparation year was almost over). The implementation itself spawns evaluation and improvement activities. It is often only during the implementation that evaluation questions are raised and acted on. This evaluation then leads to the adjustment of the materials. As evaluation activities are seen to hold great potential for (collaborative) curriculum development (see chapter 2), it is then somewhat disappointing that the current study had very little examples of it. Most of the TDTs were not involved in evaluation of their materials. However, the insights from the other studies discussed here warrants additional attention.

The study of the long-term perspective shows that the effect of implementation applies mostly to the first implementation round (Handelzalts, 2007). After the first implementation and the changes that follow, curricula seem to stabilize and the learning effect for teachers also becomes limited.

\subsubsection{Related findings on conducive or hindering school conditions}

In view of the school conditions, different studies validate the findings of the current study to a large extent. In this discussion, however, the role of external coaches is somewhat undeveloped. This is partly due to the current study's methodology. As the sub-study in Copernicus High School (where coaches were active) was mostly reconstructive, their day-to-day role was less articulated. Additionally, the role of coaches was not a central theme in the other studies discussed. This issue is then discussed shortly as a comparison between the general guidelines described in chapter 2 and the findings of this study.

\section{Infrastructure}

The importance of not only availability of time for meetings but also the frequency of meetings which was stressed in chapter 2 and found in this study is confirmed by two of the other studies discussed (Handelzalts, 2009; Nieveen \& Handelzalts, 2006). This importance seems to hold true for different contexts of the curriculum development work. Even when meetings are highly structured and facilitated, the process loses much of its thrust when meetings are irregular or spread out. In a context of a diffused reform that is not school-wide, this played an important but 
less central role, as the whole participation was dependent on the initiative of the teachers. As it seemed they were more committed to the process there was less need for external triggers to make them to come together (Handelzalts, 2009).

\section{External support}

In chapter 2 the role of the coach was described in terms of support of the work process and contribution in terms of knowledge of pedagogy and content. The findings of this study did not demonstrate which role was more important. It did draw attention to the issue of team expectations of the coaching role. They were perceived as effective when the work of the coaches answered the recurring explicit need for the production of concrete materials for the team. This role is different from the theoretical role described in chapter 2 . This might be connected to the focus of the teachers on practical matters. In that sense having an agent that would create good quality materials is very practical. This discrepancy between the theoretically assumed roles of the coaches and the practice of TDTs show a difference in views of the process as a whole. While educationalists seem to depict the teachers as active actors that need to be supported in the development process, there are indications that teachers themselves sometimes seem to prefer a consumer's role, making much use of the services of educationalists/coaches (e.g. Deketelaere \& Kelchtermans, 1996).

\section{Coordination}

In contrast with the current study, in the context of a diffused reform the need for cross-over structures seems much diminished (Handelzalts, 2009). This can partly be explained by the fact that not all teachers participated in the curriculum development activities and the TDTs which were involved were not dependent on the plans of other teams. However, coordination mechanisms between TDTs and between the teams and the school-wide process seem highly important for countering possible tensions between the school and team level. As the work in teams draws the attention of teachers to their local process, this can undermine the whole school reform process, threatening the whole school coherence (Kruse \& Louis, 1997). This line of reasoning, also described in chapter 2, stresses the importance of coordination from the perspective of the school-wide process. The findings of this study supplement this by showing that the coordination mechanism had great importance to the teams' process (e.g. Scribner et al., 2007). This had two components. First, through coordination activities teams were exposed to new ideas and possible solutions for their own difficulties. Second, and just as important, by hearing the struggles and considerations of other teams, 
teachers developed a sense of common process. This was an important part of the cultural change which was a part of school reform.

The importance of coordination in the school-wide reform context is stressed by the stable and central position of the central coordination group in Copernicus High School (Handelzalts, 2007). Despite some problems it kept working throughout the reform and played an important role in disseminating information. It was also an arena for discussion on the shape of the reform.

\section{School-wide framework}

The two work patterns teams displayed were earlier related to characteristics of the teams. Nieveen and Handelzalts (2008) conclude that it is specifically the combination of the school-wide organization of the reform and the particular characteristics of TDTs that determine how the teams work. They particularly highlight the function of the school leadership in facilitating the process of the TDTs. In their study they found three factors that specifically influenced the work of the teams: (1) the level of which the school-wide framework was elaborated on, (2) the extent to which school leadership was involved in the work of the TDTs, and (3) the support that the reform process had among the teachers. They developed, based on their findings, two scenarios that seem to be effective for the work of the teams in a school-wide context:

- Schools that wish to come to a school-wide reform process based on a specified school-wide framework. In this case the school leadership should invest much in the preparatory phase with the teachers, aiming for sense of ownership and support of the teachers. When the TDTs then make the translation from the school-wide framework to the micro level, the school leaders need to monitor the teams' process in order to keep consistency among plans. It is then also the role of the school leaders to make adjustments, if needed, to the school-wide framework and supply the teams with appropriate support.

- Schools that wish to work with a more flexible reform framework in which the plans of the TDTs and the school-wide framework develop somewhat simultaneously. In this case the school leaders need to be much more involved in the work of the team and participate in their process. This is crucial because of the constant adaptations on both sides - that of the school-wide framework and that of the teams. Specific attention should be given to the manner in which the wishes of the different teams are combined. It seems to be advisable in this case to work with a team of more committed teachers. They seem to have a higher tolerance for the uncertainties of this process. 
Voncken et al. (2007) also depict the possible division between flexible and developmental or directive and 'rigid' reform frameworks. They note the drawbacks of the latter, possibly leading to a feeling of a top-down reform and therefore less commitment from the teachers. However, they found that an open approach led to much slower progress and often to little actual change in the curriculum. They concluded that within an open approach a form of top-down steering or guidance seems to have some advantages. It confronts teachers with having to do something. They could not avoid the reform.

Both schools in the current study had an open and flexible reform framework. At the same time, the role that the school and school-section leaders have fulfilled was not on par with the guidelines that Nieveen and Handelzalts (2008) and Voncken et al. (2007) suggest for this scenario. This explains partly the findings on the team level. Teams that had an initial common ambition (those more committed to the reform process), and were able to deal with the uncertainty, had less interference in their process and produced curricula that were on the whole more in line with the reform. Teams that had a vague common ambition, and little active involvement from the school leaders, had much more difficulty in initiating and sustaining the development process

The current study examined specifically teams that worked in the context of a school-wide reform. The assumption was that school-wide reform will lead to a more sustainable and coherent change. Within the scope of this study there is no comparison between teams that worked in a school-wide context and those that did not. One finding is that the school-wide approach offers some challenges (see previous discussion on coordination and the differences between how teams react to the reform.). Depending on the school-wide reform strategy itself, different strategies for supporting the teams can be suggested. TDTs working in a school that does not apply a school-wide reform (much like the teams in Handelzalts, 2009) are less distracted by a school-wide framework and can concentrate more on their curriculum development challenges. At the same time the changes realized at the school after a year's work is limited and fragmented in scope.

The role of school leaders

The role of the school leaders emerges as key in the process (Nieveen \& Handelzalts, 2006; Nieveen \& Handelzalts, 2008; Voncken et al., 2007). 
Specifically the role of a school leader that is directly responsible in overseeing the TDTs is pivotal in supporting their work. This role is directly related to the school's choice for reform strategy (see discussion on the reform framework). The main role described is that of a mediator between the school level reform framework and the work of the teams (Voncken et al., 2007). In a reform which is not school-wide the mediator's function is not needed and therefore the leader's role is much more limited, restricted to providing resources and motivating individual teachers in the process (Handelzalts, 2009).

In considering the leader's role, great importance is given in several of the studies to the need for a differentiated approach to different teams, especially when many different teams are operating within the school-wide reform in one school (very much like TDTs in the current study). Voncken et al. (2007) found no specific strategy which is most advisable here but stated that it is very important that the school-leaders realize their role and try to act upon it. The main findings of the current study show that school leaders did not seem to differentiate in the manner in which they steer the different TDTs. Considering the highly influential role that they did fulfill and the different kinds of teams with different needs that became apparent in this study, this point deserves attention. It might be that school leaders perceived not intervening in the work of the TDT as giving the teams room to take initiative and were therefore hesitant in their contact with the teams. However, this was perceived by some of the TDTs as disinterest on part of the leaders. Finally, the great importance of the school leaders' support role continues also in the reform implementation phase (Handelzalts, 2007).

In chapter 2 many different roles were attributed to leaders in a reform process. These cover both the organizational aspects in facilitating and organizing the work of the teams and cultural aspects of mediating the reform and bringing about a culture change in the way teachers work. The findings of this study show that all of these roles are very important. However, a special importance was found in the "cultural agent" role and specifically in the relational aspect of leadership. Through frequent and informal interaction between the teams and the school leaders, teachers perceived the leaders as interested in their work, interpreting the interest as a sign that their work was worthwhile and thus significant. It was also evident from the findings that leaders in the schools that were followed still did not perceive their role as that of cultural agent. 


\subsection{OVERALL CONCLUSIONS}

Taking into account the cross-study findings presented in chapter 6 along with the insights from other studies several conclusions can be drawn. These conclusions are related partly to how TDTs go about the process of curriculum development and partly to those activities and conditions that seem to be conducive for their work.

\section{THE DESIGN PROCESS OF THE TDTS IS HEAVILY INFLUENCED BY CHARACTERISTICS OF THE TEAM ITSELF, ESPECIALLY THE CLARITY OF THE INITIAL REFORM AMBITION.}

TDTs display a great variation of activities and experiences within a similar reform context (see also Voncken et al. 2007). For a large part these variations can be accounted for in characteristics of the teams and their interaction with the school-wide reform. Smaller teams (two to three teachers) seem to operate more easily while cross curricular teams, although promoting coherence across the curriculum, add complexities to the development process and often need additional support in their work. Teams with a clearer common reform ambition and a more positive disposition towards the school-wide reform start more rapidly with the design and rethinking of their curriculum. They are less dependent on the school-wide framework's level of clarity. Teams that start off with a vaguer reform ambition need sufficient clarity of the organizational conditions before starting to work on their concrete plans. The issue of the school-wide framework is central in their work orientation. They either spend more time in exploring the contours of the framework or in waiting for the school leadership to provide details. In teams that operate in a diffused reform context that lacks a school-wide framework, this connection is weaker. In these schools the participation in the project teams (see Handelzalts 2009) is voluntary and teams are formed on the basis of an initial common goal.

\section{TDTS TEND TO ORIENT THEIR DEVELOPMENT WORK TO ORGANIZATIONAL ELEMENTS OF THE CURRICULUM. THE 'TIME' AND 'PLACE' COMPONENTS OF THEIR FUTURE PRACTICE ARE MOST PROMINENT IN THEIR DISCUSSIONS AND WORK.}

Especially teams that start off without having an initial common ambition spend much of their time on these issues or wait until the school leadership comes up 
with some indication towards this end. The development activities of these teams consist mostly of fitting their former curriculum into the new organizational framework (e.g. Voncken et al, 2007). TDTs spend little time on the issues of 'rationale' and 'goals'. These issues rarely come up for an unprompted discussion. Even when a coach introduces those issues, teachers find this discussion difficult and abstract. Likewise, many teams have great difficulty managing vagueness at the school-wide reform framework level. This seems similar to the instrumentality element of the practicality ethic of teachers (Doyle \& Ponder, 1978). Teachers tend to focus on procedural elements of the reform at the cost of discussions on more substantive principles. This issue is also evident in the fact that teams regard practicality of the plans and materials as the main quality criteria for their products. This orientation on 'time' and 'place' is less evident in more diffused reform contexts where schools do not work toward a school-wide reform framework.

The main substantive consideration of the teachers in the development of their curricula is often that of the content that should be taught. This is, however, not a critical discussion of content selection but more an issue of content coverage (again a more 'practical' approach). Content is then defined as what the textbooks contain. Cross-curricular teams seem to provide the only venue in which content is more critically discussed.

This practicality focus has an impact on the kind of activities and conditions that are seen as conducive. Specifically, perception of effectiveness of coaching is dependent on the ability of the coach to cater to the main needs of the team. As the greatest articulated need is support in creating concrete, tangible, and thus practical teaching materials, support of this is seen as most effective in the TDTs' work. Similarly, working individually on the construction of teaching materials is experienced as one of the most efficient parts of the work as it is related to a feeling of real progress in their work.

\section{MAJOR DESIGN DECISIONS ARE MADE (IMPLICITLY OR EXPLICITLY) BEFORE OR AT THE INITIAL PHASE OF THE DEVELOPMENT PROCESS.}

In all teams the major design decision, as reflected in their curricular products, are made very early in the process. Even when teams do not make conscious, 'formal', design decisions, the ideas discussed in the first meetings become the design. In teams with an initial reform ambition these ideas had been developed 
in former years and are articulated in the first meetings. In teams with vague reform ambitions these design decision are seen at first as 'options'. In these later teams the development process then continues either by exploring the organizational conditions of the reform framework or by waiting for clarifications to be supplied by the school leaders. Eventually, though, these teams return to the ideas discussed in the first meetings without critically examining them for their merit. This can be attributed to a weak development process that does not lead the team to significant insights. However, this can also be an expression of the intolerance for uncertainty in these teams. When faced with a vague context they revert to quick and obvious solutions. This confirms the assertion that design decisions tend to rapidly crystallize after the initial development phase (Romme \& Endenburgs, 2006). This emphasizes the importance of the starting phase of development processes.

\section{ANALYSIS AND EVALUATION ACTIVITIES ARE NOT AN INHERENT PART OF THE DEVELOPMENT PROCESS OF TDTS. DESIGN AND CONSTRUCTION ARE HIGHLY INTERRELATED AND ARE OFTEN EXECUTED AS AN INTEGRATED ACTIVITY.}

In contrast to many curriculum development models, the development process does not begin by conducting analysis aimed to produce guidelines for design. Analysis activities, when executed, focus on organizational conditions of the future practice. In the development process, a difference is apparent between the two kinds of teams (dissimilar mainly in having or missing a common initial ambition). Teams that start the process with little direction, and are 'held back' in exploring organizational conditions, get very little construction done during the preparation year. They combine the design and construction phases mostly at the end of the year and often recreate their former curriculum in the new school framework. Teams with clearer ambitions display somewhat more distinct design and construction phases. As they are less dependent on the school-wide framework, they spend some time on developing their general ideas. Construction then follows, although here too much of it takes part at the end of the preparation year, under a great deal of pressure (this element varies based on the amount of school-wide pre-structuring of the process. The more structure there is, the more construction gets done).

TDTs are not inclined to initiate evaluation activities of any sort. Piloting of part of their curriculum materials is the only activity that somewhat resembles an evaluation. However, the guiding perspective of the pilots is that of practicality. 
Other issues of quality (such as validity and effectiveness) are hardly discussed if at all. The lessons learned from the pilots are also limited to the participating teachers (often only one or two from the team). There is little transfer of the conclusions to teachers not directly involved in the pilot.

As the presented study limited itself to the preparation year, little significant implementation activities were documented. Findings from other research (Handelzalts, 2009) do point to the potential catalytic effect of implementation. During implementation teachers come across issues they did not foresee or activities that turn out other than expected. This can be a powerful instrument to elicit more evaluation activities. These evaluation activities need some support in order to make them constructive and transcend organizational issues. Stressing the importance of evaluation activities, Visscher and Witziers (2004) plead for concentrating teams' work on the evaluation of their practice as this underlines the strong connection between the teaching process and the learning results. In a 'data-team approach' the analysis and compilation of data on the effectiveness of (parts of) the school are the starting point and central thrust of the team's work (Schildkamp \& Kuiper, in press).

\section{THE MOST CONDUCIVE ACTIVITIES ARE THOSE THAT HELP TEACHERS CREATE CONCRETE IMAGES OF FUTURE PRACTICE WITHIN THE REFORM.}

Considering the great variations of activities TDTs undertake, those activities that are either seen as conducive or have a significant impact on their work share the characteristics of helping teachers to envision their possible future practice. As was apparent in the discussion on the development process, TDTs have a great need for having an operational image of the conditions in which their teaching would take place. This guides much of their work. Activities that contribute to this are conducive to the process by helping the teams move further, making design decisions, and coming closer to creating a common curriculum. This relates to a variety of activities that also depend on the need of the specific TDT during a specific time. In this context pilots or implementation of (part of) the materials have a positive effect on the teachers in the process. It gives teachers a concrete image of how students interact with the materials. A similar function can be achieved by taking field trips to schools implementing a similar reform or facing similar challenges. As already noted the limitation of pilots is that they often seem to concentrate on the practicality of the plans and not on their affectivity or validity and also their impact is limited to those teachers that directly participate 
in the pilots. Possibly, setting a clear evaluative goal ahead of time and making it a team wide endeavor can make pilots an even more effective instrument.

A second kind of conducive activities is the discussion of concrete plans or products. These design attributes make the discussion concrete and focused. Abstract ideas are set on paper and that makes them tangible and accessible for discussion. Besides structuring the discussion it broadens the scope of the discussions as teachers have to consider all the implications of their decisions in the concrete attribute. This finding is supported by Ametller, Leach and Scott (2007) who experimented with design attributes in the course of reform. According to them, these attributes make design explicit and also enable communication between teachers and designer.

Finally, considering the vagueness that many teams seem to experience in relation to the school-wide framework, instances in which teams receive explicit information on the school-wide framework are considered conducive. Specifically schools or school section leaders that interact with the team in a direct manner during a meeting are seen as having significant potential for helping the team make progress. They can supply new information, help review the decisions already made at the school level, and hear ongoing questions.

This need for concrete images for future practice is a common finding in many of the studies discussed earlier in this chapter. A remarkable exception is that of the TDTs operating in a diffused reform context. Because the organizational conditions are not dependant on the school-wide framework they preoccupy the teams to a lesser degree. The most conducive activities there are those that 'force' the team to define their rationale and goals. This elicits a broader discussion of the curriculum and brings about enhanced development activities.

\section{COLLABORATION IN TDTS TENDS TO BE AIMED AT FORMULATING GENERAL DESIGN STATEMENTS AND NOT AT COLLABORATING ON CONCRETE MATERIALS. HOWEVER, THE LATTER HOLDS MUCH POTENTIAL FOR ATTAINING SIGNIFICANT CHANGE IN CLASSROOM PRACTICES.}

TDTs display a clear pattern in which general design discussions are conducted together in school whereas construction of materials is an individual exercise done at home with little feedback between the team members. Joint work seems limited to general issues and design statements. However, there are indications 
that cooperating on the concrete materials is most effective for attaining curriculum materials which are more in line with reform ambitions and represent a significant change from the former practice. The collaboration on concrete materials there takes two forms: the literal co-construction of materials, with two or more teachers working on the same set of materials (either simultaneously or in turn) or extended feedback on one another's work. This finding can be explained by the fact that this collaboration is more apparent in teams that also have a clearer reform ambition and are therefore more inclined to reach significant reform results. However, this conclusion is also supported by findings from teams that are lacking that reform ambition. In these teams discussion of concrete (paper) products also seems highly conducive. The findings of Voncken et al. (2007) also support the potential of cooperating on materials as an instrument for development of reform and the learning of teachers in the reform. They go even further and conclude that cooperation in teaching activities and undertaking new experiences together can be even more powerful.

Role division in TDTs is in general not well defined and is highly informal. The division is based on either technically dividing the construction tasks between teachers (where in bigger groups some teachers are more active than others) or on some form of function preference of specific teachers for a kind of activity, which makes the team to "assign" it to them.

\section{PRODUCTIVE DEVELOPMENT BENEFITS FROM REGULARITY OF DEVELOPMENT ACTIVITIES.}

Much of the TDTs' work is realized during a short period of time in which the teams meet on a regular basis in which they make the most progress. However, this is not the dominant pattern of work as TDTs seem to meet irregularly. A centrally scheduled regular meeting roster and allocated time are conditional but not sufficient for enabling meetings. Teams require one of two kinds of triggers initiating a meeting. The first kind of trigger comes from outside the team. This kind of trigger comes in the form of a coach or a school leader. When teams have an external coach, the fact that the coach makes an appointment to come and suggest discussion issues is enough to trigger a meeting. Alternatively, when the school or school-section leaders give the TDT a concrete assignment or summons a meeting, this too has the same effect. The second kind of trigger is the internal trigger. This kind of trigger comes from within the team and leads not only to holding a single meeting but to regular meetings. 
This trigger has two possible sources. In some teams when teachers conclude a meeting with concrete decisions and appointments, this leads to a following meeting based on these decisions. This was not a common practice for TDTs in this study. The other internal trigger is a sense of urgency felt by the teachers. This arises mostly at the end of the preparation year when teams need to complete some form of teaching materials. This leads to a burst of activities in TDTs. This urgency can lead to the team reverting to older and less ambitious plans than those they had developed. This conclusion is also supported in other contexts of collaborative curriculum development. However, the more that team teachers own the development process (such as in the case of the diffused reform context) the less need there is for an external trigger for the work of the teams and the more constant the internal trigger is.

The work process of the TDTs on the whole is neither explicitly planned nor structured. Irrespective of the context and support, TDTs' work seems to advances from one meeting to the next without a clear overview of goals or structure.

\section{STRUCTURED, SCHOOL-WIDE MEETINGS AIMED AT SHARING TEAM'S PROGRESS AND EXPERIENCES ARE A NECESSARY INSTRUMENT FOR SECURING A CROSSOVER STRUCTURE BETWEEN TEAMS.}

Considering the apparent absence of informal interaction of teachers with members of other TDTs on issues related to the reform, some structured instruments are called for. Two specific kinds of activities seem effective: presentations of teams' progress and concentrated schooling on relevant reform themes. First, the presentations of the teams' progress give other teams an overview of the development. It gives them insight into how far along other teams are, what problems they encountered, how they solved them, and what kinds of considerations other teams make in their work. This is information teams can use and do use for their own work. The presentations also have a relational function. Hearing how others struggle with and solve problems shows teachers and teams that they are in a sense 'not alone' in the process. This seems quite obvious in a school-wide process but teams tend to see their problems as unique. Creating a bridging function can help teams see other developments. The second kind of activity, schooling days, is aimed at the school-wide reform focus. Teachers need additional information on different aspects. A crucial characteristic in making these school-days effective and appreciated is their practice orientation. Schooling activities are seen as relevant only when they deliver concrete products that teams 
can easily apply in their development work. This includes a framework for their work process and a framework of curriculum materials. When schooling days fail to meet this criterion, they have little explicit effect on the development process.

A coordination group, consisting of representatives of all TDTs, is an important part of the school-wide reform. Aside from giving teams access to an overview of the development and school-wide information, it supports participants of these groups in their role in their own TDT (where they often have some leadership role).

\section{APPLYING A FLEXIBLE AND EVOLVING SCHOOL-WIDE REFORM FRAMEWORK GIVES TDTS ROOM TO CREATE THEIR OWN PLANS, LEADING TO VARIATION OF INTERPRETATION AND EXPERIENCES BETWEEN THE TEAMS, CALLING FOR TAILOR MADE SUPPORT.}

Both schools in this study applied a parallel reform strategy. Alongside the development of (part of) the school-wide organizational implication of the reform, the TDTs were working on their own plans. This kind of choice has varying effects on teams. While teams with a clear reform ambition are capable of dealing with the uncertainties, teams with vague or no common ambition are more highly dependent on the clarity of the framework. When clarity is lacking, the process in these teams is slowed. These teams need more structuring and support (from a coach or the school leadership) in order to deal with this vagueness and not be hindered by it. This conclusion is supported by Nieveen and Handelzalts (2008) and Voncken et al. (2007) who add that this also calls for some form of top-down steering in order to assure that all teams make some progress.

\section{SCHOOL LEADERS WHO ARE DIRECTLY RESPONSIBLE FOR THE WORK OF THE TDTS HAVE A KEY ROLE IN ASSESSING HOW TEAMS ENGAGE THE REFORM AND OFFER CUSTOM- MADE SUPPORT BASED ON THE NEED OF EACH OF THE TDTS.}

Findings of this study concerning the fulfilled role of the school management and the function of the TDTs lead to insights on the role that the relevant school leaders could and should fulfill. In both school sites followed in this study the work of the TDT was the responsibility of a member of the school management team. In one case it was the innovation manager, in the other the school section leaders. Findings show little differentiation in the manner in which these school leaders approached the different teams, while the teams showed great variation in their 
work. Specifically in teams with vaguer reform ambitions the activity or inactivity of the leader steered the developments (or the lack of them) in the team. Presence of these coordinators in team meetings had, for example, great impact on the teams work. They had both a relational function and an information function (see chapter 6 for more extensive discussion). It seems then advisable that the coordinators apply a differentiated approach to teams, based on the teams' characteristics and the development that they show. Certainly when a flexible and developing reform strategy is applied in the case of teams that have a vague reform ambition, a more proactive and involved role for the coordinator is called for. This conclusion is in line with both Nieveen and Handelzalts (2008) and Voncken et al. (2007).

An active role for the coordinators necessitates that they have a good overview of how the teams work, which considering the result of this study is not necessarily the case. In these school there were few mechanisms built into the process of the school through which the coordinators could be informed. But these mechanisms can also have an additional function. Calling teams to account for their work and present its results can have a stimulating impact on their work, pushing them to intensify it and increase efforts in redesigning their curriculum.

\subsection{RECOMMENDATIONS}

\subsubsection{Recommendations for TDTs and schools leaders}

As one of the central tenets of the study is that teachers and schools are central in curriculum reform, the main recommendations are aimed at this level. These recommendations concern several guidelines for the collaborative curriculum development process and principles for embedding the work of TDTs in the school-wide process:

- Plan the reform process, its expected goals and the support (external and internal) on the basis of characteristics of the participating TDTs. Large, heterogeneous teams with a weak common agenda deserve extra attention.

- Undertake a baseline study in order to explore the teams' characteristics. In its course several members of the teams should be observed in practice and interviewed about their practice and ambitions. This gives a detailed image of the team and supplies the team and other parties concerned with a reference for the starting position of the teams. This baseline study is also a way in 
which external coaches can build a strong relationship with the teachers in a relatively short period. Giving external parties a role in the baseline study and ensuring that it is held in a non-judgmental and constructive manner increases the effect this had on participating teams.

- Facilitate team meetings by allocating teachers time for development work, and preferably making team meetings a part of the school schedule. Although this may not be needed for all teams (some meet at their own discretion) this provides organizational structure for development work and emphasizes the importance the school organization places on it. Additionally, in some teams, if inactivity is detected, school leaders should stimulate activities and discussion by direct involvement.

- Invest much time and energy in at the start of the development process in the teams. Many design decisions and work patterns are set within several meetings and stay relatively stable. An early decision to stay close to the former practice (a common inclination) will eventually lead to less significant change.

- Invest much in regular formal and informal interaction between the school leaders that are directly responsible for the TDTs' and the teams. This improves information circulation in school and serves a relational goal for some teams. School leaders need to be highly attentive to the needs of the different teams during the reform process and act upon them.

- Take into account teams' preoccupation with organizational issues in their future teaching practice. Clarify vagueness when possible and acknowledge the tension between the team and the school level. Invest in connecting the discussion on organizational issues with central curricular issues such as rationale, goals, and content. Support by a curriculum expert can be very significant in this respect.

- Invest time and energy in exploring possible forms and variations for future teaching practice based on concrete examples or pilots. Connect this exploration to several guiding questions that are related to teams' curricular goals. In exploring various concrete examples of future practices avoid early adoption of one of the practices. Use the materials mainly as inspirational instruments and not as definitive answers to the needs of teams.

- Encourage some form of collaboration on concrete curriculum materials, either co-construction of a section of the materials or detailed feedback on individual work. This has potential for improving the curriculum and enhancing professional development of the teachers. Such collaborations also increase teachers' appreciation of the process on the whole. 
- Support teams in undertaking analysis and evaluation activities. These activities have important but untapped potential. Formulating several analysis questions, through which the teams explore several issues, can lead to more beneficial results.

- Create crossover structures between teams as part of the reform strategy. This supports the coherence between teams and supports them in their development work. The crossover structures should have at least two components:

- A permanent coordination team with representatives of all TDTs.

- Organized school-wide meetings. In these occasions give TDTs the opportunity to report and share their developments and experiences. When dedicating time for schooling on reform related issues aim to provide or create concrete materials that can be used in the work of the teams.

\subsubsection{Recommendations for policy and support.}

Based on the findings several policy recommendations can be made on how policymakers can enable and support this process.

- Offer support to schools and teacher teams by making a variation of good examples of real practices available to schools. The great freedom of teacher teams giving form to their curriculum has great potential but many teams struggle with envisioning future practice. By supplying several variations of examples for different subjects and pedagogical choices, teams can see possible consequences of their choices. This can contribute to their curriculum development process.

- Support teams by supplying exemplary learning lines in different subjects. The content of teaching is seldom a subject of discussion and teams only implicitly touch on it by choosing a certain textbook. By supplying several possible options, teams can choose the learning line that fits most or be inspired to create their own learning line. The variation also diminishes possible suggestions of compulsion and top-down processes in creating learning lines.

- Stimulate the development of curricular thinking and acting of teachers and school leaders by giving schools easy access to curriculum coaching and stimulating school networks. By doing so teachers can be exposed to ideas and possibilities that lie beyond their own horizon. Stimulating curricular competencies of teachers should also start at the teachers' colleges where future teachers should be introduced to the basics of curriculum design in the context of the school. 


\subsubsection{Recommendations for research}

There is still much to be explored concerning collaborative curriculum development in schools. Based on the current study some questions and issues are raised that are worthwhile exploring in the future. Some of these issues are related to the conclusions of this study while others are of a more general character:

- Initiate a more focused intervention study. This should start with designing interventions based on the characteristics of conducive activities and fitting them to the needs of specific TDTs that are studied. By systematically exploring their effects on the teams, the conducive elements of activities could be further defined.

- Explore how subject affiliation of the teachers is related to the curriculum development process. This was not an issue in the current study but there are indication that subject identification of teachers might affects the manner in which they approach curriculum development and collaborative processes (Hargreaves et al., 2001). Studying if and how this relationship works, can lead to insights into the manner in which different teams need different kinds of support in their work.

- Explore the relation between collaborative curriculum development and teacher learning. Although a strong argument for collaborative curriculum development is made from the assertion that this contributes to the professional development of teachers, the manner in which learning occurs and what exactly is learnt is still unclear. Relating the work of the TDTs to specific learning gains of teachers and studying which activities of the teams are most beneficial for the learning process can contribute to our further understanding of the learning function of collaborative curriculum development.

- Define and explore additional indicators for conduciveness in curriculum development processes. The findings of the study presented here rely heavily on teachers' perception of conducive activities. It can be interesting to try to find other indicators for conduciveness. This can be done by limiting the variation between the teams participating in a study (in respect, for example, to subject affiliation). By doing this, clearer and common criteria for conduciveness on the level of teaching materials or enactment can be defined and more straightforward comparison of activities and their results in different teams can be made. 
- Investigate further the influence of educational setting on the curriculum development activities. This study was carried out in the context of Dutch lower secondary education. In this education level there is no mandatory national end exam. Moreover, most of the teachers have a teaching degree ('tweedegraads lerarenopleiding') as opposed to a master's degree combined with a teaching certificate ('eerstegraads lerarenopleiding'). These characteristics may play a major role in how teacher teams develop their curriculum as the exam pressure and subject matter expertise of teachers are significantly different. Therefore, exploring TDTs at higher levels of secondary education, for example, can contribute to the understanding of how these elements influence the collaborative curriculum design process. 


\section{REFERENCES}

Ainscow, M., Hargreaves, D. H., \& Hopkins, D. (1995). Mapping the process of change in schools: The development of six new research techniques. Evaluation and Research in Education, 9(2), 75-90.

Ametller, J., Leach, J., \& Soctt, P. (2007). Using perspectives on subject learning to inform the design of subject teaching: An example from science education. Curriculum Journal, 18(4), 479-492.

Beijaard, D., Van Driel, J., \& Verloop, N. (1999). Evaluation of story line methodology in research on teachers' practical knowledge. Studies in Educational Evaluation, 25(1), 47-62.

Berger, J. G., Boles, K. C., \& Troen, V. (2005). Teacher research and school change: Paradoxes, problems, and possibilities. Teaching and Teacher Education, 21(1), 93-105.

Black, P., \& Atkin, J. M. (Eds.). (1996). Changing the subject. Innovations in science, mathematics, and technology education. London: Routledge.

Bolstad, R. (2004). School-based curriculum development: Redefining the term for New Zealand schools today and tomorrow. Paper presented at the Conference of the New Zealand association of research in education.

Bryk, A., Camburn, E., \& Louis, K. S. (1999). Professional community in Chicago elementary schools: Facilitating factors and organizational consequences. Educational Administration Quarterly, 35(5), 751-781.

Carlgren, I. (1999). Professionalism and teachers as designers. Journal of Curriculum Studies, $31(1), 43-56$.

Clandinin, D. J., \& Connelly, F. M. (1990). Narrative, experience and the study of curriculum. Cambridge journal of education, 20(3), 241-253.

Clandinin, D. J., \& Connelly, F. M. (1992). Teacher as curriculum maker. In P. Jackson (Ed.), Handbook of research in curriculum (pp. 363-401). New York: MacMillan.

Clandinin, D. J., \& Connelly, F. M. (1998). Stories to live by: Narrative understandings of school reform. Curriculum Inquiry, 28(2), 149-164.

Cordingley, P., Bell, M., Evans, D., \& Firth, A. (2005). The impact of collaborative CPD on classroom teaching and learning. Review: What do teacher impact data tell us about collaborative $C P D$. London: EPPI-Center, Social Science Research Unit, Institute of Education, University of London. 
Cordingley, P., Bell, M., Thomason, S., \& Firth, A. (2005). The impact of collaborative continuing professionial development (CPD) on classroom teaching and learning. Review: How do collaborative and sustained CPD and sustained but not collaborative CPD affect teaching and learning. London: EPPI-Center, social science research unit, institute of Education, University of London.

Day, C., Elliot, B., \& Kington, A. (2005). Reform, standards and teacher identity: Challenges of sustaining commitment. Teaching and Teacher Education, 21(5), 563-577.

De Kock, A., Sleegers, P., \& Voeten, M. J. M. (2005). New learning and choices of secondary school teachers when arranging learning environments. Teaching and Teacher Education, 21(7), 799-816.

Deketelaere, A., \& Kelchtermans, G. (1996). Collaborative curriculum development: The encounter of different professional knowledge systems. Teachers and teaching: Theory and practice, 2(1), 71-85.

Doyle, W., \& Ponder, G. A. (1978). Practicality ethic in teacher decision-making. Interchange, $8(3), 1-12$.

Eash, M. (1991). Curriculum components. In A. Lewy (Ed.), The international encyclopedia of curriculum (pp. 71-73). Oxford: Pergamon Press.

Erickson, G., Brandes, G. M., Mitchell, I., \& Mitchell, J. (2005). Collaborative teacher learning: Findings from two professional development projects. Teaching and Teacher Education, 21(7), 787-798.

Friedman, V. J. (1997). Making schools safe for uncertainty: Teams, teaching, and school reform. Teachers College Record, 99(2), 335-370.

Fullan, M. G. (1993). Why teachers must become change agents. Educational leadership, 50(6), 12-17.

Fullan, M. G. (2001). The new meaning of educational change (3 $3^{\text {rd }}$ ed.). New York: Teachers College Press.

Fullan, M. G. (2007). The new meaning of educational change ( $4^{\text {th }}$ ed.). New York: Teachers College Press.

Fuller, F. F. (1969). Concerns of teacher: A developmental characterization. American Educational Research Journal, 6(2), 207-226.

Geijsel, F., Sleegers, P., van den Berg, R., \& Kelchtermans, G. (2001). Conditions fostering the implementation of large-scale innovation programs in schools: Teachers' perspectives. Educational Administration Quarterly, 37(1), 130-166.

Gergen, K. J., \& Gergen, M. M. (1988). Narrative and the self as relationship. In L. Berkovitz (Ed.), Advances in experimental social psychology (Vol. 21, pp. 17-56). New York: Academic Press.

Goodlad, J. I. (1994). Curriculum as a field of study. In T. Husén, \& T. Postlethwaite (Eds.), The international encyclopedia of education (pp. 1262-1276). Oxford: Pergamon Press. 
Goodlad, J. I., Klein, F., \& Tye, K. A. (1979). The domains of curriculum and their study. In J. I. Goodlad, \& Associates (Eds.), Curriculum inquiry. The study of curriculum practice (pp. 43-76). New York: Mcgraw Hill.

Grossman, P., \& Stodolsky, S. (1995). Content as context: The role of school subject in secondary school teaching. Educational Researcher, 24(8), 5-11.

Grossman, P., Wineburg, S., \& Woolworth, S. (2001). Toward a theory of teacher community. Teachers College record, 103(6), 942-1012.

Guskey, T. R. (2000). Evaluating professional development. Thousand Oaks, CA: Corwin Press.

Gustafson, K. L., \& Branch, R. M. (2002). Survey of instructional development models [4th ed.]. Syracuse: Syracuse University. (ERIC clearinghouse on Information and Technology).

Handelzalts, A. (2007). Four years of TDTs. Implementation study: Unpublished manuscript, University of Twente, Enschede, The Netherlands.

Handelzalts, A. (2009). TDTs in a diffuesed reform context. Research report: Unpublished manuscript, University of Twente, Enschede, The Netherlands.

Hargreaves, A. (1994). Changing teachers, changing times: Teachers' work and culture in the postmodern age. London: Cassell.

Hargreaves, A. (2003). Teaching in the knowledge society. Education in the age of insecurity. New York: Teachers College Press.

Hargreaves, A., Earl, L., Moore, S., \& Manning, S. (2001). Learning to change. Teaching beyond subjects and standards. San Fransisco: Jossey-Bass.

Harris, A. (2003). Behind the classroom door: The challenge of organisational and pedagogical change. Journal of Educational Change, 4(4), 369-382.

Harris, A. (2005). Leading or following educational change. School Leaderschip and Management, 25(5), 417-419.

Hendriks, M. A. (2004). Innoverende scholen voor voortgezet onderwijs: Thema's, trends en inspirerende voorbeelden [Innovative high schools: Theme's, trends and inspiring examples]. Enschede: University of Twente.

Henze-Rietveld, F. A. (2006). Science teachers' knowledge development in the context of educational innovation. Doctoral dissertation, University of Leiden, Leiden, The Netherlands.

Hopkins, D. (1998). Tensions in and prospect for school improvement. In A. Hargreaves, A. Lieberman, \& M. G. Fullan (Eds.), International handbook of educational change (pp. 10351055). Dordrecht: Kluwer Academic Publishers.

Hopkins, D. (2001). School improvement for real: Educational improvement for real. London: Routledge Falmer.

Hord, S. (2004). Learning together, leading together. Changing schools through professional learning communities. New York: Teachers College Press.

Imants, J. (2002). Restructuring schools as a context for teacher learning. International Journal of Educational Research, 37(8), 715-732. 
Inspectie van het onderwijs. (1999). Werk aan de basis: Evaluatie van de basisvorming na vijf jaar [Working on the foundation: Evaluation of the lower secondary education after five years]. Utrecht: Inspectie van het onderwijs.

Johnson, N. A. (1993). Reconsidering curriculum-development - A framework for cooperation. Interchange, 24(4), 409-433.

Kimpston, R. D., \& Rogers, K. B. (1988). Predispositions, participatory roles and perceptions of teachers, principals and community members in a collaborative curriculum planning process. Journal of Curriculum Studies, 20(4), 351-367.

Klein, F. (1991). The politics of curriculum decision making: Issues in centralizing the curriculum. Albany, NY: State University of New York Press.

Kolodner, J. L., Camp, P. J., Crismond, D., Fasse, B., Gray, J., Holbrook, J., et al. (2003). Problem-based learning meets case-based reasoning in the middle-school science classroom: Putting learning by design (TM) into practice. Journal of the Learning Sciences, 12(4), 495-547.

Kolodner, J. L., Crismond, D., Gray, J., Holbrook, J., \& Puntambekar, S. (1998). Learning by design from theory to practice. Paper presented at the International Conference of the Learning Sciences.

Kruse, S. D., \& Louis, K. S. (1997). Teacher teaming in middle schools: Dilemmas for a schoolwide community. Educational Administration Quarterly, 33(3), 261-289.

Kuiper, W., Van den Akker, J., Hooghoff, H., \& Letschert, J. (2006). Curriculum policy and school practice in a European comparative perspective. In J. Letschert (Ed.), Curriculum development re-invented. Proceedings of the invitational conference on the occasion of the 30 years SLO 1975-2005. Leiden, the Netherlands, 7-9 December 2005 (pp. 56-77). Enschede: SLO.

Kwakman, K. (2003). Factors affecting teachers' participation in professional learning activities. Teaching and Teacher Education, 19(2), 149-170.

Leat, D., \& Higgins, S. (2002). The role of powerful pedagogical strategies in curriculum development. The curriculum journal, 13(1), 71-85.

Lieberman, A., \& Miller, J. (2004). Teacher leadership. San Francisco: Jossey-Bass.

Little, J. (2002). Professional community and the problem of high school reform. International Journal of Educational Research, 37(8), 693-714.

Little, J., \& Bartlett, L. (2002). Career and commitment in the context of comprehensive school reform. Teachers and Teaching: Theory and practice, 8(3/4), 345-354.

Little, J. W. (1990). The persistence of privacy: Autonomy and initiative in teachers' professional relations. Teachers College record, 91(4), 509-536.

Little, J. W. (2002). Locating learning in teachers' communities of practice: Opening up problems of analysis in records of everyday work. Teaching and Teacher Education, 18(8), 917-946.

Little, J. W. (2003). Inside teacher community: Representations of classroom practice. Teachers College Record, 105(6), 913-945. 
Lortie, D. C. (1975). Schoolteacher : A sociological study. London: University of Chicago Press.

Loucks-Horsley, S., Hewson, P. W., Love, N., \& Stiles, K. E. (1998). Designing professional development for teachers of science and mathematics. Thousand Oaks, CA: Corwin Press.

Louis, K. S., \& Marks, H. M. (1998). Does professional community affect the classroom? Teachers' work and student experiences in restructuring schools. American Journal of Education, 106(4), 532-575.

Louis, K. S., Marks, H. M., \& Kruse, S. (1996). Teachers' professional community in restructuring schools. American Educational Research Journal, 33(4), 757-798.

Maehr, M. L., \& Midgley, C. (1996). Transforming school cultures. Boulder, Co: Westview Press.

Marsh, C., Day, C., Hannay, L., \& McCutcheon, G. (1990). Reconceptualizing school-based curriculum development. New York: The Falmer Press.

Marsh, C. J., \& Willis, G. (1999). Curriculum: Alternative approaches, ongoing issues [2nd ed.]. New Jersey: Prentice-Hall.

Marsh, D. D. (1994). Change in schools: Lessons from the literature. In S. A. Mohrman, \& P. Wohlstetter (Eds.), School-based management: Organizing for high school performance (pp. 215-251). San Francisco, California: Jossey-Bass Inc.

McCutcheon, G. (1996). Developing the curriculum: Solo and group deliberation. New York: Longman Publishing.

McLaughlin, M. W., \& Talbert, J. E. (2001). Professional communities and the work of high school teaching. Chicago: The university of Chicago press.

McLaughlin, M. W., \& Talbert, J. E. (2006). Building school-based techer learning communities. Professional strategies to improve student achievement. New York: Teachers College Press.

McLaughlin, M. W., \& Talbert, J. E. (2007). Building professional learning communities in high schools: Challenges and promising practices. In L. Stoll, \& K. Seashore Louis (Eds.), Professional learning communities: Divergence, depth dilemmas. Berkshire: Open University Press.

Meirink, J. A. (2007). Individual teacher learning in a context of collaboration in teams. Doctoral dissertation, University of Leiden, Leiden, The Netherlands.

Miles, M., \& Huberman, M. (1994). Qualitative data analysis : An expanded sourcebook. London: Sage.

Mohrman, S. A., \& Wohlstetter, P. (1994). Understanding and managing the change process. In S. A. Mohrman, \& P. Wohlstetter (Eds.), School-based management: Organizing for high school performance (pp. 253-268). San Fracisco, California: Jossey-Bass Inc.

Muijs, D., \& Harris, A. (2006). Teacher led school improvement: Teacher leadership in the UK. Teaching and Teacher Education, 22(8), 961-972.

Nieveen, N., \& Handelzalts, A. (2006). Concretisering kerndoelen onderbouw. Rapportage flankerend onderzoek [Making attainment goals concrete. Research report]. Unpublished manuscript, University of Twente, Enschede, The Netherlands. 
Nieveen, N., \& Handelzalts, A. (2008). Leergebieden in VO-onderbouw. Raportage flankerend onderzoek [Learning area in lower secodnary education. Research report]. Unpublished manuscript, University of Twente, Enschede, The Netherlands.

Nieveen, N. M. (1997). Computer support for curriculum developers: A study on the potential of computer support in the domain of formative curriculum evaluation. Doctoral dissertation, University of Twente, Enschede, The Netherlands.

Odenthal, L. E. (2003). Op zoek naar balans: Een onderzoek naar een methode ter ondersteuning van curriculum vernieuwing door docenten [Searching for balance: Researching methods for supporting curriculum renewal by teachers]. Doctoral dissertation, University of Twente, Enschede, The Netherlands.

Onderbouw-VO. (2006). Volop in beweging. Monitor onderbouw 2005 [Plenty of change. Yearly evaluation 2005]. Zwolle: Onderbouw-VO.

Onderbouw-VO. (2007). Bewegen volgens plan. Monitor onderbouw 2006 [Reforming according to plan. Yearly evaluation 2006]. Zwolle: Onderbouw-VO.

Onderbouw-VO. (2008). Bewegen met beleid. Monitor onderbouw 2007 [Controlled change. Yearly evaluation 2007]. Zwolle: Onderbouw-VO.

Onderbouw-VO. (2009). Blijvend in beweging. Vier jaar onderbouwontwikkeling. Monitor 20052008 [Staying in movement. Four years of development: Yearly evaluations 2005-2008]. Zwolle: Onderbouw-VO.

Patton, M. Q. (2002). Qualitative research and evaluation methods ( $3^{\text {rd }}$ ed.). Thousand Oaks , CA: Sage Publications.

Peterson, P. L., McCarthey, S. J., \& Elmore, R. F. (1996). Learning from school restructuring. American Educational Research Journal, 33(1), 119-153.

Pomson, A. D. M. (2005). One classroom at a time? Teacher isolation and community viewed through the prism of the particular. Teachers College Record, 107(4), 783-802.

Romme, A. G. L., \& Endenburg, G. (2006). Construction principles and design rules in the case of circular design. Organization science, 17(2), 287.

Rosenholtz, S. J. (1989). Teachers' workplace: The social organization of schools. New York: Longman.

Rousseau, C. K. (2004). Shared beliefs, conflict, and a retreat from reform: The story of a professional community of high school mathematics teachers. Teaching and Teacher Education, 20(8), 783-796.

Sackney, L., Mitchell, C., \& Walker, K. (2005). Building capacity for learning communities: A case study of fifteen successful schools. Paper presented at the American Eduational Reserach Association annual meeting.

Sandholtz, J. H., \& Scribner, S. P. (2006). The paradox of administrative control in fostering teacher professional development. Teaching and Teacher Education, 22(8), 1104-1117.

Schildkamp, K., \& Kuiper, W. (in press). Data informed curriculum reform: Which data, what purposes, and hindering and promoting factors. Teaching and Teacher Education. 
Scribner, J. P., Sawyer, R. K., Watson, S. T., \& Myers, V. L. (2007). Teacher teams and distributed leadership: A study of group discourse and collaboration. Educational Administration Quarterly, 43(1), 67-100.

Shank, M. J. (2006). Teacher storytelling: A means for creating and learning within a collaborative space. Teaching and Teacher Education, 22(6), 711-721.

Silin, J., \& Schwartz, F. (2003). Staying close to the teacher. Teachers College Record, 105(8), 1586-1605.

Skilbeck, M. (1998). School based curriculum development. In A. Hargreaves, A. Lieberman, M. G. Fullan, \& D. Hopkins (Eds.), International handbook of educational change (pp. 121144). Dordrecht: Kluwer Academic Publishers.

Stoll, L., Bolam, R., McMahon, A., Wallace, M., \& Thomas, S. (2006). Professional learning communities: A review of the literature. Journal of Educational Change, 7, 221-258.

Stoll, L., \& Seashore Louis, K. (2007). Professional learning communities; Divergence, depth and dilemmas. Berkshire: Open University Press.

Supovitz, J. A. (2002). Developing communities of instructional practice. Teachers College Record, 104(8), 1591-1626.

Taakgroep Vernieuwing Basisvorming. (2004). Beweging in de onderbouw. Voorstellen voor de eerste leerjaren van het voortgezet onderwijs [Changes in the lower secondary education. Suggestions for reform of the first school years of secondary education]. Zwolle: Taakgroep Vernieuwing Basisvorming.

Thomas, G., Wineburg, S., Grossman, P., Myhre, O., \& Woolworth, S. (1998). In the company of colleagues: An interim report on the development of a community of teacher learners. Teaching and Teacher Education, 14(1), 21-32.

Thousand, J. S., \& Villa, R. A. (1993). Collaborative teams: A powerful tool to school restructuring. In R. A. Villa, J. S. Thousand, W. Steinback, \& S. Steinback (Eds.), Restructuring for caring and effective education: An administrative guide to creating heterogeneous schools (pp. 73-108). Baltimore: Brookes Publishing.

Tripp, D. (1993). Critical incidents in teaching: Developing professional judgement. London: Routledge.

Tuckman, B. W. (1965). Developmental sequence in small-groups. Psychological Bulletin, 63(6), 384-399.

Turnbull, B. (2002). Teacher participation and buy-in: Implications for school reform initiatives. Learning Environment Research, 5(3), 235-252.

Van den Akker, J. J. H. (1990). Het gebruik van Curricula [The use of curricula]. In Onderwijskundig Lexicon II (pp. E3100/3101-E3100/3112). Alphen aan de Rijn: Samson.

Van den Akker, J. J. H. (2003). Curriculum perspectives: and introduction. In J. J. H. Van den Akker, W. Kuiper, \& U. Hameyer (Eds.), Curriculum landscapes amd trends (pp. 1-10). Dordrecht: Kluwer Academic Publishers. 
Verhagen, P., Kuiper, W., \& Plomp, T. (1999). Onderwijskundig ontwerpen in het onderwijsprogramma van Toegepaste onderwijskunder [Curriculum development in the curriculum of educational designers]. In J. M. Pieters, T. Plomp, \& L. E. Odenthal (Eds.), 20 jaar toegepaste onderwijskunde [20 years of educational design curriculum]. Enschede: Twente University Press.

Vescio, V., Ross, D., \& Adams, A. (2008). A review of research on the impact of professional learning communities on teaching practice and student learning. Teaching and Teacher Education, 24(1), 80-91.

Visscher, A. J., \& Witziers, B. (2004). Subject departments as professional communities? British Educational Research Journal, 30(6), 785-800.

Visscher-Voerman, J. I. A. (1999). Design approaches in training and education: A reconstructive study. Doctoral dissertation, University of Twente, Enschede, The Netherlands.

Voncken, E., Derriks, M., \& Ledoux, G., (with Sleegers, P., \& de Kock, J.). (2007). Een hele toer. Ervaringen van schoolleiders en docenten met de vernieuwing van de onderbouw vo [Experiences of school leaders and teachers with the reform of the lower secondary eduaction]. Amsterdam: SCO-Kohnstamm instituut.

Walker, D. F. (1990). Fundamentals of curriculum. New York: Harcourt Brace College Publishers.

Witziers, B., Sleegers, P., \& Imants, J. (1999). Departments as teams: Functioning, variations and alternatives. School Leadership \& Management, 19(3), 293 - 304.

Wohlstetter, P., \& Mohrman, S. A. (1994). Conclusion: New directions for school-based management. In S. A. Mohrman, \& P. Wohlstetter (Eds.), School-based management: Organizing for high school per formance (pp. 269-286). San Francisco, California: Jossey-Bass Inc.

Yin, R. K. (2003). Case study reseach: Design and methods (3rd ed.). Tousand Oaks, CA: Sage Publications.

Young, J. H. (1985). Participation in Curriculum-Development - an Inquiry into the Responses of Teachers. Curriculum Inquiry, 15(4), 387-414.

Zwart, R. (2007). Leren van ervaren docenten in de context van wederkerige collegiale coaching [Teacher learning in the context of reciprocal peer coaching]. Doctoral dissertation, Radboud University, Nijmegen, The Netherlands 


\section{ENGLISH SUMMARY \\ Collaborative curriculum development in teacher design teams}

\section{ORIGINS OF THE STUDY}

This study started from the premise that teacher collaboration in curriculum development is well placed in order to bridge the gap between school-level curriculum reform and classroom-level practices. As teachers are at the forefront of all educational reforms, they need not only to be involved in the implementation process, but also be active participants in the development

process of a reform. It is assumed that collaboration between teachers in these curriculum development efforts enables (1) more coherent curriculum development across teachers and subjects, (2) professional development processes of the teachers, and (3) development of the school organization as a whole. This seems to be even more the case in a context in which curriculum development takes place in a school-based and school-wide context. It is further assumed that collaborative curriculum development of teachers is best realized in teacher design teams (TDTs), defined in this study as 'a group of at least two teachers, from the same or related subjects, working together on a regular basis, with the goal to (re)design and enact a (part of) their common curriculum'.

Next to the theoretical assumptions about the potential of collaborative curriculum development, the policy trend in Dutch lower secondary education supplied a suitable context to study this phenomenon. The essence was that attainment goals have been broadened and made more general and that schools got the freedom, and in fact were encouraged, to shape their own curriculum. This freedom included both subject matter as well as pedagogy. Many schools have delegated at least some of the curriculum development tasks to teams of teachers in the school. At the same time, yearly surveys showed that schools still 
encountered many problems in this reform process in which teachers play a more active role in the curriculum reform process in their school.

Despite the evolving practice in Dutch schools and the expected benefits of collaborative curriculum development in schools, the research base of findings on how teacher teams with curriculum development tasks work or should work is yet limited. This study intended to contribute to this knowledge base by studying TDTs in their first year of development work. The main research question guiding this study was as follows:

What are conducive (or hindering) approaches and conditions for collaborative curriculum development by teacher design teams in view of school-wide reform?

This research question was further divided into three sub-questions: the first aimed at describing the work of teacher design teams, the second concerned with those activities that were specifically conducive or hindering to the teams in striving towards their goal of common curriculum, and the third aimed at exploring the school conditions that promoted or hampered these efforts.

\section{RESEARCH DESIGN}

To answer the research questions a qualitative multiple case study approach was used. Twelve teacher design teams in two different schools (seven teams in one school and five teams in another school) were followed during their first year of collaboration throughout their preparation year. During this first year, many of the TDTs' activities were documented, teachers were interviewed and observed, both at the start and at the end of the study, and (curriculum) documents produced by the TDTs were collected and analyzed. Based on the data, a rich description of the teams' work was obtained. This systematic documentation process and the perspective of the practitioners formed the basis for detecting activities and conditions that had a special (positive or negative) function for the teams. The analysis of the findings, based on the three sub-questions guiding this study, was done on three levels: (1) an analysis of the individual cases (the teams), resulting in detailed case descriptions (see sections 2 and 3 of the accompanying CD), (2) a cross-case analysis of the teams in each of the schools to find common and diverting patterns per school (see chapters 4 and 5), (3) a cross- 
study analysis, comparing the findings from the two school sites to detect commonalities and differences between the school sites (chapter 6). By choosing these schools and teams carefully and by comparing the findings with others studies some analytic generalization can be made to TDT's in other contexts.

\section{MAIN FINDINGS}

Both schools in this study applied a parallel reform strategy. Alongside the development of (part of) the school-wide reform and its organizational implications, the TDTs were working on their own plans. Results show varied work patterns of the teams in the schools. However, several commonalities and explainable differences across the teams arose (for extended discussion see chapter 6).

How TDTs addressed and carried out their development work

With regard to the work of the TDTs it became obvious that it is neither explicitly planned nor organized by any player in the process (in most cases not even by the external coaches). Teams most often proceeded from one meeting to the next tackling issues as they arose. This implied in almost all the teams that only a (small) portion of their curriculum materials was ready at the end of the preparation year. Role division in most teams was informal and not all teachers participated to the same extent in the curriculum development activities. Most of the joint work concentrated on developing general design decisions. There was little joint work on constructing concrete teaching and learning materials. In those occasions where collaboration on constructing concrete materials level did occur, this led to realizing more significant change in the curriculum of the team.

In the first phase of their work, teams were very much oriented towards the future 'time' and 'place' components of their curriculum. These issues needed to be somewhat clarified before the team was open to discussing more fundamental curricular questions such as 'content', 'teaching activities', and 'materials'. The major design decisions that teams made in their curriculum development process were done either during the first several meetings of the TDTs or even prior to the commencement of the formal process in school (teams that had already some common plans and did not yet have the chance to realize them took the opportunities given by the reform process). This underlines the importance of 
this initial phase. The overall process of the teams included only a few of the 'ideal' steps in curriculum development. While analysis activities were somewhat apparent (mainly oriented towards the organizational aspects), design and construction seemed to occur most often simultaneously. Teams conducted little to no explicit evaluation activities and judged the quality of their plans and materials mainly on the basis of their practicality.

In both schools, two work patterns developed. Teams with a clear common reform ambition and a positive disposition towards the reform started more rapidly with the design and were less dependent on the clarity of the school-wide framework. Teams with vaguer reform ambitions and often ambivalence towards the reform needed sufficient clarity of the organizational conditions of their future practice before starting to work on their concrete plans. For these latter teams, this led either to a long analysis and orientation phase followed by a short design phase or to a long period of inactivity followed by a short burst of design and construction activities. These activities then were mainly aimed at adjusting former curricula to the organization conditions of the school reform.

\section{Conducive or hindering activities and approaches}

The most conducive activities were those that assisted in creating a visualization of the future practice of the reform. The activities (such as piloting, school visits, and discussion of blue prints of design) were highly valued by the teachers and led to pattern changes in the process of the teams. On the whole it seems that teams that shared clearer initial ambitions realized more often explicit incorporation of the school-wide reform goals in their products. Teams that decided to keep their former textbooks and use these as part of their reform chose in general to continue their existing teaching approach with little change. This

might be considered a hindering approach, as it meant that they often did not even reconsider their former practice.

\section{Conducive or hindering school conditions}

Some school conditions that enabled or impeded the work of the TDTs became clear. Allocated development time for the teachers, also in the form of regular scheduled meetings, was a conditional element but not sufficient for enabling team meetings and work. The perceived effectiveness of coaching was dependent on the ability of the coach to cater to the main needs of the TDT, especially in creating or providing concrete tangible teaching materials. 
The presence of a coach also had a crucial role triggering team meetings by making concrete appointments and suggesting discussion issues.

The parallel reform strategy applied by the schools was conducive for those teams that had a clear reform ambition. Teams with vague or no common ambition showed a greater dependency on the level of clarity of the framework. These teams made, on the whole, less progress in the production of new curriculum plans and materials. When the school-wide process was more structured, this vagueness had less impact on the pace of the work of the teams. The school-wide process in both schools gave only few organized opportunities for interaction between TDTs. However, teachers often expressed a need for such opportunities and when such activities did take place, they had a strong impact on the teams. These kinds of activities gave teams an overview of the developments at the school level. It also supported the commitment of the teachers to the process as it strengthened the impression of a shared endeavor and identification with the work of other teams in the same school.

Another conducive condition was the active role of the school leaders, especially for the teams with vague reform ambitions. Even a seemingly simple act of being present in team meetings carried much weight. It supplied teams with information and had a relational function. All teams found the interest and time investment of the leader important. However, school leaders had only a vague overview of the progress of the TDTs as there was little interaction with the teams concerning their work. The importance of this issue was demonstrated when the school management did actively inquire about the development of the TDTs' work. This single incident had a positive impact leading to increased curriculum development activity and materials construction of the TDTs.

\section{OVERALL CONCLUSIONS}

Taking into account the cross-study findings (chapter 6) along with the insights from other studies (see chapter 7) several conclusions can be drawn. These conclusions are related partly to how TDTs go about the process of curriculum development and partly to those activities and conditions that seem to be conducive for their work. 
THE DESIGN PROCESS OF THE TDTS IS HEAVILY INFLUENCED BY CHARACTERISTICS OF THE TEAM ITSELF, ESPECIALLY THE CLARITY OF THE INITIAL REFORM AMBITION.

TDTs display a great variation of activities and experiences within a similar reform context. For a large part these variations can be accounted for in characteristics of the teams and their interaction with the school-wide reform. Smaller teams (two to three teachers) seem to operate more easily while cross curricular teams, although promoting coherence across the curriculum, add complexities to the development process and often need additional support in their work. Teams with a clearer common reform ambition and a more positive disposition towards the school-wide reform start more rapidly with the design and rethinking of their curriculum. They are less dependent on the school-wide framework's level of clarity. Teams that start off with a vaguer reform ambition need sufficient clarity of the organizational conditions before starting to work on their concrete plans. The issue of the school-wide framework is central in their work orientation. They either spend more time in exploring the contours of the framework or in waiting for the school leadership to provide details. In teams that operate in a diffused reform context that lacks a school-wide framework, this connection is weaker.

\section{TDTS TEND TO ORIENT THEIR DEVELOPMENT WORK TO ORGANIZATIONAL ELEMENTS OF THE CURRICULUM. THE 'TIME’ AND ‘PLACE' COMPONENTS OF THEIR FUTURE PRACTICE ARE MOST PROMINENT IN THEIR DISCUSSIONS AND WORK.}

Especially teams that start off without having an initial common ambition spend much of their time on these issues or wait until the school leadership comes up with some indication towards this end. The development activities of these teams consist mostly of fitting their former curriculum into the new organizational framework. TDTs spend little time on the issues of 'rationale' and 'goals'. Likewise, many teams have great difficulty managing vagueness at the schoolwide reform framework level. Teachers tend to focus on procedural elements of the reform at the cost of discussions on more substantive principles. This issue is also evident in the fact that teams regard practicality of the plans and materials as the main quality criteria for their products. This orientation on 'time' and 'place' is less evident in more diffused reform contexts where schools do not work toward a school-wide reform framework. 
This practicality focus has an impact on the kind of activities and conditions that are seen as conducive. Specifically, perception of effectiveness of coaching is dependent on the ability of the coach to cater to the main needs of the team. As the greatest articulated need is support in creating concrete, tangible, and thus practical teaching materials, support of this is seen as most effective in the TDTs' work.

\section{MAJOR DESIGN DECISIONS ARE MADE (IMPLICITLY OR EXPLICITLY) BEFORE OR AT THE INITIAL PHASE OF THE DEVELOPMENT PROCESS.}

In all teams the major design decision, as reflected in their curricular products, are made very early in the process. Even when teams do not make conscious, 'formal', design decisions, the ideas discussed in the first meetings become the design. In teams with an initial reform ambition these ideas had been developed in former years and are articulated in the first meetings. In teams with vague reform ambitions these design decision are seen at first as 'options'. Eventually, though, these teams return to the ideas discussed in the first meetings without critically examining them for their merit. This can be attributed to a weak development process that does not lead the team to significant insights. However, this can also be an expression of the intolerance for uncertainty in these teams. When faced with a vague context they revert to quick and obvious solutions.

\section{ANALYSIS AND EVALUATION ACTIVITIES ARE NOT AN INHERENT PART OF THE DEVELOPMENT PROCESS OF TDTS. DESIGN AND CONSTRUCTION ARE HIGHLY INTERRELATED AND ARE OFTEN EXECUTED AS AN INTEGRATED ACTIVITY.}

Analysis activities, when executed, focus on organizational conditions of the future practice. In the development process, a difference is apparent between the two kinds of teams (dissimilar mainly in having or missing a common initial ambition). Teams that start the process with little direction, and are 'held back' in exploring organizational conditions, get very little construction done during the preparation year. They combine the design and construction phases mostly at the end of the year and often recreate their former curriculum in the new school framework. Teams with clearer ambitions display somewhat more distinct design and construction phases. Construction follows the design phase, although here too much of it takes part at the end of the preparation year, under a great deal of pressure (this element varies based on the amount of school-wide pre-structuring of the process. The more structure there is, the more construction gets done). 
TDTs are not inclined to initiate evaluation activities of any sort. Piloting of part of their curriculum materials is the only activity that somewhat resembles an evaluation. However, the guiding perspective of the pilots is that of practicality. Other issues of quality (such as validity and effectiveness) are hardly discussed if at all.

There are some indications that show the potential catalytic effect of implementation. During implementation teachers come across issues they did not foresee or activities that turn out other than expected. This can be a powerful instrument to elicit more evaluation activities.

\section{THE MOST CONDUCIVE ACTIVITIES ARE THOSE THAT HELP TEACHERS CREATE CONCRETE IMAGES OF FUTURE PRACTICE WITHIN THE REFORM.}

Those activities that are either seen as conducive or have a significant impact on their work share the characteristics of helping teachers to envision their possible future practice. Activities that contribute to this are conducive to the process by helping the teams move further, making design decisions, and coming closer to creating a common curriculum. This relates to a variety of activities that also depend on the need of the specific TDT during a specific time. In this context

pilots or implementation of (part of) the materials have a positive effect on the teachers in the process. It gives teachers a concrete image of how students interact with the materials.

A second kind of conducive activities is the discussion of concrete plans or products. These design attributes make the discussion concrete and focused. Besides structuring the discussion it broadens the scope of the discussions as teachers have to consider all the implications of their decisions in the concrete attributes.

Finally, considering the vagueness that many teams seem to experience in relation to the school-wide framework, instances in which teams receive explicit information on the school-wide framework are considered conducive. Specifically schools or school section leaders that interact with the team in a direct manner during a meeting are seen as having significant potential for helping the team make progress. 


\section{COLLABORATION IN TDTS TENDS TO BE AIMED AT FORMULATING GENERAL DESIGN STATEMENTS AND NOT AT COLLABORATING ON CONCRETE MATERIALS. HOWEVER, THE LATTER HOLDS MUCH POTENTIAL FOR ATTAINING SIGNIFICANT CHANGE IN CLASSROOM PRACTICES.}

TDTs display a clear pattern in which general design discussions are conducted together in school whereas construction of materials is an individual exercise done at home with little feedback between the team members. Joint work seems limited to general issues and design statements. However, there are indications that cooperating on the concrete materials is most effective for attaining curriculum materials which are more in line with reform ambitions and represent a significant change from the former practice. The collaboration on concrete materials there takes two forms: the literal co-construction of materials, with two or more teachers working on the same set of materials (either simultaneously or in turn) or extended feedback on one another's work.

\section{Productive DEVELOPMENT BENEFITS FROM REGULARITY OF DEVELOPMENT ACTIVITIES.}

Much of the TDTs' work is realized during a short period of time in which the teams meet on a regular basis in which they make the most progress. However, this is not the dominant pattern of work as TDTs seem to meet irregularly. A centrally scheduled regular meeting roster and allocated time are conditional but not sufficient for enabling meetings. Teams require one of two kinds of triggers initiating a meeting. External trigger comes in the form of a coach or a school leader who make an appointment with the TDT or give it a concrete assignment. The internal trigger has two possible sources. In some teams when teachers conclude a meeting with concrete decisions and appointments, this leads to a following meeting based on these decisions. This was not a common practice for TDTs in this study. The other internal trigger is a sense of urgency felt by the teachers. This arises mostly at the end of the preparation year when teams need to complete some form of teaching materials. This leads to a burst of activities in TDTs. The more that team teachers own the development process the less need there is for an external trigger for the work of the teams and the more constant the internal trigger is. 
STRUCTURED, SCHOOL-WIDE MEETINGS AIMED AT SHARING TEAM'S PROGRESS AND EXPERIENCES ARE A NECESSARY INSTRUMENT FOR SECURING A CROSSOVER STRUCTURE BETWEEN TEAMS.

Considering the apparent absence of informal interaction of teachers with members of other TDTs on issues related to the reform, some structured instruments are called for. Two specific kinds of activities seem effective: presentations of teams' progress and concentrated schooling on relevant reform themes. First, the presentations of the teams' progress give other teams an overview of the development. The presentations also have a relational function. Hearing how others struggle with and solve problems shows teachers and teams that they are in a sense 'not alone' in the process. The second kind of activity, schooling days, is aimed at the school-wide reform focus. A crucial characteristic in making these school-days effective and appreciated is their practice orientation. Schooling activities are seen as relevant only when they deliver concrete products that teams can easily apply in their development work.

A coordination group, consisting of representatives of all TDTs, is an important part of the school-wide reform. Aside from giving teams access to an overview of the development and school-wide information, it supports participants of these groups in their role in their own TDT (where they often have some leadership role).

\section{APPLYING A FLEXIBLE AND EVOLVING SCHOOL-WIDE REFORM FRAMEWORK GIVES TDTS ROOM TO CREATE THEIR OWN PLANS, LEADING TO VARIATION OF INTERPRETATION AND EXPERIENCES BETWEEN THE TEAMS, CALLING FOR TAILOR MADE SUPPORT.}

Both schools in this study applied a parallel reform strategy. Alongside the development of (part of) the school-wide organizational implication of the reform, the TDTs were working on their own plans. This kind of choice has varying effects on teams. While teams with a clear reform ambition are capable of dealing with the uncertainties, teams with vague or no common ambition are more highly dependent on the clarity of the framework. When clarity is lacking, the process in these teams is slowed. These teams need more structuring and support (from a coach or the school leadership) in order to deal with this vagueness and not be hindered by it. 
SCHOOL LEADERS WHO ARE DIRECTLY RESPONSIBLE FOR THE WORK OF THE TDTS HAVE A KEY ROLE IN ASSESSING HOW TEAMS ENGAGE THE REFORM AND OFFER CUSTOM- MADE SUPPORT BASED ON THE NEED OF EACH OF THE TDTS.

Findings show little differentiation in the manner in which school leaders approached different teams, while teams showed great variation in their work. Specifically in teams with vaguer reform ambitions the activity or inactivity of the leader steered the developments (or the lack of them) in the team. Presence of these coordinators in team meetings had, for example, great impact on the teams work. They had both a relational function and an information function (see chapter 6 for more extensive discussion). It seems then advisable that the coordinators apply a differentiated approach to teams, based on the teams' characteristics and the development that they show. Certainly when a flexible and developing reform strategy is applied in the case of teams that have a vague reform ambition, a more proactive and involved role for the coordinator is called for.

\section{RECOMMENDATIONS}

\section{Recommendations for TDTs and schools leaders}

As one of the central tenets of the study is that teachers and schools are central in curriculum reform, the main recommendations are aimed at this level:

- Plan the reform process, its expected goals and the support (external and internal) on the basis of characteristics of the participating TDTs. Large, heterogeneous teams with a weak common agenda deserve extra attention.

- Undertake a baseline study in order to explore the teams' characteristics. In its course several members of the teams should be observed in practice and interviewed about their practice and ambitions. This should preferably be done by external parties.

- Facilitate team meetings by allocating teachers time for development work, and preferably making team meetings a part of the school schedule. Additionally, in some teams, if inactivity is detected, school leaders should stimulate activities and discussion by direct involvement.

- Invest much time and energy in the start of the development process in the teams as many design decisions and work patterns are set within several meetings and stay relatively stable. 
- Invest much in regular formal and informal interaction between the school leaders that are directly responsible for the TDTs' and the teams. This improves information circulation in school and serves a relational goal for some teams.

- Take into account teams' preoccupation with organizational issues in their future teaching practice. Clarify vagueness when possible and acknowledge the tension between the team and the school level. Invest in connecting the discussion on organizational issues with central curricular issues such as rationale, goals, and content.

- Invest time and energy in exploring possible forms and variations for future teaching practice based on concrete examples or pilots. Connect this exploration to several guiding questions that are related to teams' curricular goals.

- Encourage some form of collaboration on concrete curriculum materials, through either co-construction of a section of the materials or detailed feedback on individual work.

- Support teams in undertaking analysis and evaluation activities. These activities have important but untapped potential.

- Create crossover structures between teams as part of the reform strategy. This supports the coherence between teams and supports them in their development work. The crossover structures should have at least two components:

- A permanent coordination team with representatives of all TDTs.

- Organized school-wide meetings.

\section{Recommendations for policy and support}

Based on the findings several recommendations can be made on how policymakers can enable and support this process.

- Offer support to schools and teacher teams by making a variation of good examples of real practices available to schools to help teams with envisioning future practice. By supplying several variations of examples for different subjects and pedagogical choices, teams can see possible consequences of their choices.

- Support teams by supplying exemplary learning lines in different subjects. By supplying several possible options, teams can choose the learning line that fits most or be inspired to create their own learning line. The variation also diminishes possible suggestions of compulsion and top-down processes in creating learning lines. 
- Stimulate the development of curricular thinking and acting of teachers and school leaders by giving schools easy access to curriculum coaching and stimulating school networks. Stimulating curricular competencies of teachers should start already at the teachers' colleges.

\section{Recommendations for research}

Finally, some questions and issues related to this study that are worthwhile exploring in the future are raised:

- Initiate a more focused intervention study. This should start with designing interventions based on the characteristics of conducive activities and fitting them to the needs of specific TDTs that are studied.

- Explore the relation between collaborative curriculum development and teacher learning. Relating the work of the TDTs to specific learning gains of teachers and studying which activities of the teams are most beneficial for the learning process can contribute to our further understanding of the learning function of collaborative curriculum development.

- Define and explore additional indicators for conduciveness in curriculum development processes.

- Investigate further the influence of educational setting on the curriculum development activities. The manner in which TDTs work in different settings might differ (influenced by the level of teacher, national curriculum standard, organizational structure etc), Therefore, exploring TDTs at higher levels of secondary education, for example, can contribute to the understanding of how these elements influence the collaborative curriculum design process. 


\section{NEDERLANDSE SAMENVATTING Gezamenlijke curriculumontwikkeling in docent- ontwerpteams}

\section{AANLEIDING}

Dit onderzoek is gestart uit de overtuiging dat samenwerking van docenten aan curriculumontwikkeling zeer geschikt is om een brug te slaan tussen schoolbrede onderwijshervorming en de lespraktijk. Omdat docenten centraal staan in het onderwijsleerproces, dienen ze niet alleen een rol te spelen in de implementatie van een vernieuwing maar ook deel te nemen aan het tot stand komen van de vernieuwing zelf. Aangenomen wordt dat samenwerking van docenten in de curriculumontwikkeling kan leiden tot (1) samenhang in het schoolcurriculum (2) professionele ontwikkeling van de docenten (3) ontwikkeling van de schoolorganisatie. Dit wordt versterkt wanneer de curriculumontwikkeling als een schoolbreed proces aangepakt wordt. Een geschikt instrument om dit te realiseren is het Docentontwikkelteam (DOT), gedefinieerd in dit onderzoek als 'een groep van tenminste twee docenten van dezelfde of aanpalende vakken, die regelmatig samenwerken met het doel het (her)ontwerpen en realiseren van (delen van) hun gezamenlijk curriculum'.

Naast de argumenten uit de innovatie literatuur voor gezamenlijke curriculumontwikkeling, biedt onderwijsvernieuwing in de onderbouw van het Nederlandse voortgezet onderwijs een zeer geschikte context om dit fenomeen te bestuderen. De kerndoelen zijn verbreed en veralgemeniseerd en scholen hebben meer ruimte gekregen en werden zelfs aangemoedigd om hun eigen curriculum te herontwikkelen. Veel scholen hebben tenminste een deel van deze curriculumontwikkeling gedelegeerd naar teams van docenten in de school. Jaarlijkse monitorgegevens lieten echter zien dat scholen veel problemen tegenkwamen in deze vernieuwingsprocessen waarin docenten een veel actievere rol speelden. 
Ondanks de ontwikkelingen in scholen en de belofte van gezamenlijke curriculumontwikkeling is de kennisbasis over docententeams met een curriculumontwikkeltaak beperkt. Dit onderzoek is ingezet om deze kennisbasis te verbreden door DOTs in hun eerste jaar van samenwerking te bestuderen. De centrale onderzoeksvraag in dit onderzoek is:

Wat zijn bevorderende (of belemmerende) benaderingen en voorwaarden voor gezamenlijke curriculumontwikkeling door docentontwerpteams in het kader van een schoolbrede vernieuwing?

Deze onderzoeksvraag werd verder verdeeld in drie deelvragen: de eerste was gericht op het beschrijven van het werk van de teams, de tweede had betrekking op de activiteiten die bevorderend of belemmerend voor het curriculumontwikkelingswerk van de teams zijn, en de derde was gericht op schoolvoorwaarden die het werk van de teams ondersteunen of bemoeilijken.

\section{ONDERZOEKSONTWERP}

Dit onderzoek was een kwalitatieve 'multiple case study'. Twaalf docentontwerp teams in twee scholen (zeven in de ene school en vijf in de andere) zijn gevolgd in hun eerste jaar van samenwerking gedurende de voorbereidingen op de onderwijsvernieuwing. In dit eerste jaar zijn veel van de activiteiten van de teams geobserveerd, zijn docenten geïnterviewd en geobserveerd bij aanvang en aan het eind van het ontwikkelingsproces, en zijn documenten verzameld en geanalyseerd. Op basis van de data zijn rijke teambeschrijvingen verkregen. De systematische procesdocumentatie en de meningen van de deelnemers waren de basis voor het ontdekken van activiteiten en condities met een positieve of negatieve invloed op het werk van de teams. De analyse van de bevindingen, gebaseerd op de drie deelonderzoeksvragen, zijn uitgevoerd in drie fasen: (1) analyse op case (team) niveau uitmondend in gedetailleerde case beschrijvingen (zie secties 2 en 3 van de toegevoegde CD), (2) een crosscase analyse van de teams in elk van de scholen om patronen in elk van de scholen op het spoor te komen (zie hoofdstukken 4 and 5), en (3) een crosscase analyse tussen de scholen om overkoepelende patronen te ontdekken (hoofdstuk 6). Door de doelbewuste selectie van de scholen en teams en de vergelijking van de bevindingen van dit 
onderzoek met andere onderzoeken kan een analytische generalisatie gemaakt worden naar andere contexten.

\section{BEVINDINGEN}

Beide scholen in dit onderzoek gebruikten een evoluerende vernieuwingsstrategie. Parallel aan de ontwikkelingen van (delen van) het schoolbrede vernieuwingskader werkten de DOTs aan hun eigen curricula. Resultaten laten een grote variatie aan werkpatronen in de teams zien. Er zijn echter wel een aantal overeenkomsten en verklaarbare verschillen geconstateerd (zie hoofdstuk 6 voor een uitgebreide beschrijving).

\section{Hoe DOTs werkten}

Het werk van de teams was over het algemeen niet expliciet gepland noch georganiseerd (vaak ook niet door de externe ondersteuners). Teams werkten van de ene bijeenkomt naar de volgende zonder lange termijn planning. Dat betekende dat in bijna alle teams maar een (klein) deel van de curriculummaterialen klaar waren aan het einde van het jaar. De rolverdeling in de teams was informeel en niet alle docenten hebben evenredig deelgenomen aan het ontwikkelingswerk. De meeste samenwerking richtte zich op het bepalen van algemene ontwerprichtlijnen. Er was weinig samenwerking in het construeren van concrete lesmaterialen. Echter, in gevallen waar docenten wel samenwerkten aan het construeren van lesmaterialen, zijn substantiëlere veranderingen in hun curriculum gerealiseerd.

Aanvankelijk waren teams vooral gericht op de toekomstige 'tijd' en 'plaats' componenten van hun curriculum. Deze onderwerpen moesten enigszins duidelijk worden voordat teams bereid waren om andere, meer fundamentele, curriculaire vragen zoals 'inhoud', 'leeractiviteiten' en 'materialen' te bespreken. De centrale ontwerpbeslissingen van de teams zijn genomen in de eerste bijeenkomsten van de teams of zelfs voordat het formele ontwikkelproces van start ging (in teams die al gezamenlijke plannen hadden maar nog geen kans zagen om deze te verwezenlijken). Dit benadrukt het belang van de beginfase van het werk. Het curriculum ontwikkelproces in de teams volgde enkel een aantal stadia van de 'ideale' curriculumontwikkelingsmodellen. Teams ondernamen weinig analyseactiviteiten (die vooral gericht waren op organisatorische aspecten) en ontwerp en 
constructie bleken vaak simultaan plaats te vinden. Teams voerden weinig of geen expliciete evaluatieactiviteiten uit en de belangrijkste gebruikte kwaliteitscriteria voor hun producten was de bruikbaarheid ervan.

In beide scholen werden twee werkpatronen zichtbaar. Teams met een duidelijke en gezamenlijke vernieuwingsambitie en een positief beeld van de schoolbrede vernieuwing gingen sneller van start met het ontwerpen en waren minder afhankelijk van de (on)duidelijkheid van het schoolbrede vernieuwingskader. Teams met een vagere vernieuwingsambitie en gemengde gevoelens met betrekking tot de vernieuwing, hadden meer duidelijkheid nodig over de organisatorische randvoorwaarden van hun toekomstige lespraktijk voordat ze aan het bedenken van concrete plannen begonnen. Deze teams hebben hierdoor of een lange oriëntatiefase gevolgd door een korte ontwerpfase of een lange periode van weinig activiteit gevolgd door een korte inhaalslag van ontwerp en constructie. In beide gevallen waren deze activiteiten hoofdzakelijk gericht op het aanpassen van het voorafgaande curriculum aan de organisatorische randvoorwaarden van de schoolbrede vernieuwing.

\section{Bevorderende of belemmerende activiteiten en benaderingen}

De meest bevorderende activiteiten waren de activiteiten die hielpen bij het verkrijgen van een duidelijk beeld van de toekomstige lespraktijk. Deze activiteiten (zoals uitproberen van (delen van) lesmaterialen, schoolbezoeken, discussies van blauwdrukken van hun plannen) werden zeer gewaardeerd door de docenten en hebben geleid tot veranderingen in de werkpatronen van de teams. Teams met een duidelijker en gezamenlijke vernieuwingambitie, realiseerden over het algemeen meer expliciete integratie van schoolbrede vernieuwingsdoelen in hun producten. Teams die ervoor kozen om hun oude schoolboeken te behouden en te gebruiken als een deel van hun nieuwe curriculum, continueerden vaak hun lespraktijk met weinig aanpassingen. Dit kan gezien worden als een belemmerende benadering omdat het vaak betekende dat ze niet eens hun lespraktijk kritisch hebben heroverwogen.

\section{Bevorderende of belemmerende schoolvoorwaarden}

Een aantal schoolvoorwaarden dat het werk van DOTs bevorderen of belemmeren werd duidelijk. Ontwikkeltijd voor docenten, ook door het verroosteren van teambijeenkomsten, was voorwaardelijk maar niet voldoende 
voor het stimuleren van het werk van teams. Teams beschouwden het werk van de externe ondersteuners als effectief wanneer deze aan centrale behoeftes van de teams beantwoordde. Deze behoeftes waren vooral gericht op het tot stand brengen van concrete tastbare lesmaterialen. De aanwezigheid van de externe ondersteuner heeft wel geleid tot meer teambijeenkomsten door het maken van concrete afspraken en het voorstellen van discussieonderwerpen.

De evoluerende vernieuwingsstrategie waarin het schoolbrede vernieuwingskader en het teamcurriculum parallel werden ontwikkeld was bevorderend voor teams met een duidelijke vernieuwingsambitie. Teams met een vagere of gefragmenteerde ambitie waren meer afhankelijk van de mate van duidelijkheid over het schoolbrede vernieuwingskader. Deze teams maakten over het algemeen minder vooruitgang in de productie van nieuwe plannen en lesmaterialen. Wanneer het schoolbrede proces meer gestructureerd was, had de vaagheid van het vernieuwingkader minder invloed op het werk in deze teams. Het schoolbrede proces in beide scholen bood teams weinig gestructureerde gelegenheid voor interactie. Desondanks hebben docenten vaak de behoefte uitgesproken voor deze interactie en wanneer dergelijke activiteiten werden ondernomen hadden ze een groot effect op de teams. Deze interactieactiviteiten verschaften de teams een overzicht van de ontwikkelingen op schoolniveau. Ze verhoogden ook de betrokkenheid van de docenten door het versterken van het groepsgevoel en het tot stand brengen van identificatie van de docenten met het werkproces van andere teams.

De actieve betrokkenheid van de schoolleiders was een bevorderende factor, vooral in teams met vage vernieuwingsambities. Zelfs het louter aanwezig zijn bij teambijeenkomsten zonder duidelijk doel had een grote betekenis voor de teams. Het verschafte teams de nodige informatie en het had ook een relationeel doel. Teams vonden de interesse en de tijdsinvestering van de leiders belangrijk. Schoolleiders hadden over het algemeen weinig overzicht over de ontwikkelingen in de verschillende teams en er werd weinig gecommuniceerd met de teams over hun vooruitgang. Het belang van dergelijke interactie werd duidelijk toen het schoolleiderteam in een van de scholen alle teams vroeg om hun voortgang te presenteren tijdens een bijeenkomst. Dit ene incident had positieve invloed en heeft geleid tot een verhoogd tempo van curriculumontwikkeling. 


\section{CONCLUSIES}

Aan de hand van de crosscase analyse (hoofdstuk 6) en inzichten van andere onderzoeken (zie hoofdstuk 7) kunnen een aantal conclusies worden getrokken. Deze conclusies hebben betrekking op hoe DOTs omgaan met curriculumontwikkeling en de activiteiten en voorwaarden die bevorderend zijn voor hun werk.

\section{HET ONTWIKKELPROCES VAN DE DOTS IS STERK BEÏNVLOED DOOR DE TEAMKENMERKEN, IN HET BIJZONDER DOOR DE AANVANKELIJKE DUIDELIJKHEID VAN DE VERNIEUWINGSAMBITIE.}

In een en dezelfde school vertonen verschillende DOTs uiteenlopende werkpatronen. De verschillen kunnen grotendeels verklaard worden aan de hand van de teamkenmerken en hun interactie met het schoolbrede vernieuwingsproces. Kleinere teams (twee tot drie docenten) lijken gemakkelijker voortgang te boeken. Vakoverstijgende en vaak grotere teams bevorderen weliswaar samenhang tussen vakken, maar maken het ontwikkelproces complexer. Deze teams hebben hierdoor grotere behoefte aan aanvullende ondersteuning. Teams met een duidelijker en gezamenlijke vernieuwingsambitie en een positief beeld van de schoolbrede vernieuwing gaan sneller van start met het ontwerpen van hun curriculum. Deze teams zijn minder afhankelijk van de (on)duidelijkheid van het schoolbrede vernieuwingskader. Teams met een vagere vernieuwingsambitie hebben meer duidelijkheid nodig over de organisatorische randvoorwaarden van hun toekomstige lespraktijk voordat ze aan het uitzetten van concrete plannen beginnen. Het schoolbrede vernieuwingskader staat centraal in hun werkoriëntatie. Deze teams besteden veel tijd aan het verkennen van de vorm en inhoud van het vernieuwingskader of ze zijn passief totdat de schoolleiding met expliciete informatie komt. Teams die werken in een mindere schoolbrede vernieuwingscontext hebben hier minder last van.

\section{DOTS RICHTEN HUN ONTWIKKELING OP DE ORGANISATORISCHE ELEMENTEN VAN HET CURRICULUM. DE 'TIJD' EN 'PLAATS' COMPONENTEN VAN HUN TOEKOMSTIGE LESPRAKTIJK ZIJN DE MEEST PROMINENTE ONDERWERPEN IN HUN DISCUSSIE EN WERK.}

Vooral teams die beginnen zonder een duidelijke en gezamenlijke vernieuwingsambitie besteden veel tijd aan deze onderwerpen en zijn 
afwachtend totdat de schoolleiding hierover duidelijkheid verschaft. De ontwikkelactiviteiten van deze teams richten zich vaak vooral op het inpassen van hun huidige curriculum in de nieuwe organisatorische randvoorwaarden. Teams besteden weinig tijd aan componenten zoals 'basisvisie' en 'leerdoelen'. DOTs hebben ook moeite met het omgaan met de ervaren vaagheid van het schoolbrede vernieuwingskader. Docenten neigen ernaar zich te concentreren op de procedurele elementen van de vernieuwing ten koste van discussie over wezenlijke curriculaire onderwerpen. Dit wordt ook duidelijk in het feit dat teams 'bruikbaarheid' als het belangrijkste kwaliteitscriterium beschouwen voor hun producten. De 'tijd' en 'plaats' oriëntatie is minder sterk in scholen waar een schoolbreed vernieuwingskader minder centraal staat.

Het bruikbaarheidperspectief heeft ook invloed op het soort activiteiten en voorwaarden die als bevorderend worden ervaren. Dit wordt duidelijk in de perceptie van de rol van de externe ondersteuners. Deze perceptie lijkt afhankelijk te zijn van het vermogen van de ondersteuners om de centrale behoefte van de teams te dienen. Omdat teams vooral behoefte hebben aan concrete en tasbare curriculummaterialen (dus praktisch bruikbaar), wordt ondersteuning in het verkrijgen hiervan als meest effectief beschouwd.

\section{DE BELANGRIJKSTE ONTWERPBESLISSINGEN WORDEN GENOMEN (IMPLICIET OF EXPLICIET) VOOR OF GEDURENDE DE OPSTARTFASE VAN HET ONTWIKKELPROCES.}

In DOTs worden belangrijke ontwerpenbeslissingen zeer vroeg in het proces genomen. Zelfs als teams geen formele of bewuste keuzes maken, worden de ideeën die in de eerste bijeenkomsten zijn besproken uiteindelijk vastgelegd in hun producten. In teams met een duidelijke en gezamenlijke vernieuwingsambitie worden deze ideeën in de jaren voorafgaand aan de vernieuwing ontwikkeld en worden ze enkel uitgesproken in de eerste bijeenkomsten. In teams met een vagere ambitie worden deze beslissingen eerst als 'opties' beschouwd. Uiteindelijk vallen deze teams toch terug op de eerste 'opties' zonder deze kritisch te overwegen. Dat kan een resultaat zijn van een zwak ontwikkeltraject dat de teams geen nieuwe inzichten heeft verschaft. Het kan echter ook een uitdrukking zijn van de intolerantie van deze teams voor onzekerheid. In een onduidelijke context kiezen deze teams de eerste en voor de hand liggende oplossing. 


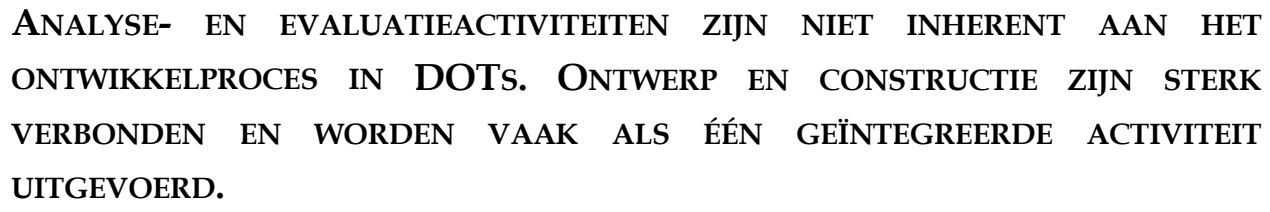

Wanneer analyseactiviteiten worden uitgevoerd richten ze zich op de organisatorische voorwaarden van de toekomstige lespraktijk. In het ontwikkelproces kunnen twee patronen worden onderscheiden. Teams die aanvankelijk geen duidelijk doel hebben worden afgeleid door het verkennen van de organisatorische randvoorwaarden. Ze komen tot weinig constructie van materialen in het eerste jaar. Ze combineren ontwerp en constructie aan het eind van het jaar en richten zich hierbij dan vooral op het inpassen van hun oorspronkelijke curriculum in het vernieuwingskader. Teams met een duidelijker vernieuwingsambitie vertonen duidelijker gescheiden ontwerp en constructie fasen. Ook in deze teams wordt de constructie grotendeels aan het eind van het jaar uitgevoerd onder grote druk (hierin speelt de mate van structuur in het schoolbrede proces een rol. Hoe meer deze gestructureerd is, hoe meer materialen worden geproduceerd).

DOTs voeren weinig evaluatieactiviteiten uit. Het uitproberen van delen van hun materialen is de enige activiteit die beschouwd kan worden als evaluatie. Deze is echter niet systematisch opgezet en is vooral gericht op de bruikbaarheid van de lesmaterialen. Andere kwaliteitscriteria (zoals validiteit en effectiviteit) worden niet of nauwelijks besproken.

Er zijn enkele aanwijzingen dat implementatie een belangrijke invloed heeft op het ontwikkelproces. Tijdens de implementatie worden docenten geconfronteerd met zaken die ze niet van te voren hebben voorzien. Lesactiviteiten lopen ook vaak anders dan verwacht. Dit kan als een effectief instrument worden gebruikt voor het op gang brengen van evaluatieactiviteiten.

\section{DE MEEST BEVORDERENDE ACTIVITEITEN ZIJN DE ACTIVITEITEN DIE DOCENTEN ONDERSTEUNEN IN HET CREËREN VAN EEN CONCREET BEELD VAN HUN TOEKOMSTIGE LESPRAKTIJK.}

Activiteiten die door de docenten worden beschouwd als bevorderend voor het werk of die een significante invloed op het werk van de teams hebben, zijn die 
activiteiten die docenten helpen een voorstelling te maken van hun mogelijke toekomstige lespraktijk. Dit soort activiteiten helpt docenten voortgang te boeken, ontwerpbeslissingen te nemen en een gezamenlijk curriculum vorm te geven. Dit zijn verschillende activiteiten die ook afhangen van de behoefte van een bepaalde DOT op een bepaald moment. In deze context heeft het uitproberen of implementeren van (delen van) de materialen van het team een positief effect op het proces. Het geeft de docenten een concreet beeld van hoe leerlingen omgaan met de lesmaterialen.

Een tweede soort bevorderende activiteiten zijn discussies van concrete plannen of producten. Deze zogenaamde ontwerpvoorwerpen maken de discussie concreet en scherp. Naast het structureren van de discussie helpt het bij de verbreding van de discussie omdat docenten verschillende implicaties van hun beslissingen in de concrete materialen moeten doorzien.

Tenslotte, omdat veel teams schoolbrede vernieuwingskaders als vaag ervaren, worden gelegenheden waarin ze expliciet daarover informatie ontvangen als bevorderend beschouwd. In het bijzonder lijken DOT-bijeenkomsten waarin school- of sectorleiders direct met het team communiceren zeer effectief om teams verder te brengen.

\section{SAMENWERKING IN DOTS IS VOORAL GERICHT OP HET FORMULEREN VAN ALGEMENE ONTWERPRICHTLIJNEN EN NIET OP HET CONSTRUEREN VAN CONCRETE LESMATERIALEN. ECHTER, JUIST DIT LAATSTE KAN SIGNIFICANTE VERANDERINGEN IN DE LESPRAKTIJK TOT STAND BRENGEN.}

In de meeste DOTs worden algemene discussies gehouden tijdens bijeenkomsten in de school terwijl constructie van materialen door de docenten afzonderlijk thuis plaatsvindt met weinig feedback. Samenwerking is gericht op het genereren van algemene ontwerpbeslissingen. Er zijn echter aanwijzingen dat samenwerken op het niveau van concrete lesmaterialen effectief is voor het creëren van lesmaterialen die in lijn zijn met de vernieuwingsambitie en ook een significante verandering van de lespraktijk betekenen. Deze samenwerking kan twee vormen aannemen: het daadwerkelijke samen construeren van lesmaterialen door twee of meer docenten (tegelijkertijd of na elkaar) of uitgebreide feedback van docenten op elkaars werk. 


\section{REGELMAAT IN DE ONTWIKKELACTIVITEITEN DRAAGT POSITIEF BIJ AAN DE PRODUCTIVITEIT VAN DE TEAMS.}

Veel van het werk van DOTs wordt gerealiseerd binnen een kort tijdbestek waarin teams regelmatig bijeenkomen en de meeste vooruitgang maken. Dit is echter niet een veel voorkomende praktijk van DOTs die meestal onregelmatig bij elkaar komen. Het vast verroosteren van de bijeenkomsten en het toekennen van ontwikkeltijd aan docenten zijn voorwaardelijk maar niet voldoende om regelmatig afspraken tot stand te brengen. Er zijn twee soorten impulsen die bijeenkomsten op gang brengen. Externe impulsen zijn een externe ondersteuner of schoolleider die een afspraak maakt met het team of ze een concrete taak geeft. Interne impulsen nemen twee vormen aan. De eerste is het afsluiten van de ene bijeenkomst met een concrete beslissingen- en takenlijst met daarin al een vooruitzicht naar de volgende bijeenkomst. Dat was echter geen veel voorkomende praktijk binnen de DOTs in dit onderzoek. De tweede interne impuls is een gevoel van urgentie in de teams. Dit komt voor vooral aan het eind van het voorbereidingsjaar wanneer teams moeten komen tot een concreet product. Dit leidde in de teams in dit onderzoek tot een inhaalslag van activiteiten. Hoe meer docenten zich eigenaar voelden van het ontwikkelproces, hoe minder er behoefte was aan een externe impuls en hoe regelmatiger het proces door het jaar verliep.

\section{GEORGANISEERDE SCHOOLBREDE BIJEENKOMSTEN DIE GERICHT ZIJN OP HET DELEN VAN ERVARINGEN VAN TEAMS ZIJN NOODZAKELIJK VOOR DE STRUCTURELE UITWISSELING TUSSEN TEAMS.}

Gezien het gebrek aan informele interactie tussen docenten van verschillende DOTs over de vernieuwing moeten hiervoor schoolbrede instrumenten worden ingezet. Twee soorten activiteiten lijken effectief te zijn: (1) presentaties van de verschillende teams over hun vooruitgang en (2) scholingsactiviteiten over onderwerpen die gerelateerd zijn aan de vernieuwing. De presentaties van de teams geven andere docenten een overzicht van de ontwikkelingen. Deze presentaties hebben echter ook een relationeel doel. Het delen van ervaringen en worstelingen vergroot de cohesie in de school omdat docenten zien dat ze niet de enigen zijn die moeilijkheden ervaren. De centrale scholingsdagen dienen praktisch georiënteerd te zijn. Ze worden pas als effectief ervaren wanneer ze uitmonden in concrete producten of instrumenten die teams direct kunnen inzetten in hun ontwikkelwerk. 
Een centrale coördinatiegroep met vertegenwoordigers van alle DOTs is een belangrijk onderdeel van het schoolbrede vernieuwingsproces. Naast de informatie over schoolbrede ontwikkelingen die deelnemers hierdoor krijgen, ondersteunt deze groep ook de deelnemers in hun rol in hun eigen DOT (waar ze vaak een vorm van leiderschaprol hebben).

\section{GEBRUIK MAKEN VAN EEN FLEXIBEL EN EVALUEREND SCHOOLBREED VERNIEUWINGSKADER GEEFT DOTS RUIMTE OM HUN EIGEN PLANNEN VORM TE GEVEN. DIT LEIDT TOT VARIATIE IN DE INTERPRETATIE EN ERVARING EN MAAKT MAATWERK IN DE ONDERSTEUNING VAN TEAMS NOODZAKELIJK.}

Beide scholen in dit onderzoek hebben een parallelle vernieuwingsstrategie toegepast. Naast het ontwikkelen van (delen van) het schoolbrede vernieuwingskader en zijn organisatorische implicaties, werkten de DOTs aan hun eigen plannen. Deze keuze had een wisselend effect op teams. Teams met een duidelijker vernieuwingsambitie zijn in staat om met de onduidelijkheden om te gaan. Teams met vagere of gefragmenteerde vernieuwingsambities zijn afhankelijk van de duidelijkheid van het vernieuwingskader. Wanneer onduidelijkheden ontstaan wordt het werk van de teams verstoord. Deze teams hebben dan behoefte aan meer structurering en ondersteuning (van externe ondersteuners of schoolleiders) om met de onduidelijkheid om te kunnen gaan.

\section{LEIDERS IN DE SCHOOL MET DIRECTE VERANTWOORDELIJKHEDEN VOOR HET WERK VAN DE DOTS HEBBEN EEN SLEUTELROL IN HET VOLGEN VAN DE VOORTGANG VAN TEAMS EN HET AANBIEDEN VAN MAATWERKONDERSTEUNING GEBASEERD OP BEHOEFTES VAN DE TEAMS.}

Leiders in scholen (schoolleiders/teamleiders/jaargroepleider) tonen weinig differentiatie in de manier waarop ze teams benaderen terwijl teams juist een grote variatie in hun werk vertonen. Vooral in teams met een vagere vernieuwingsambitie heeft de activiteit of inactiviteit van de leider een grote impact op het werk (of gebrek eraan) van het team. Het bijwonen van teambijeenkomsten had, als voorbeeld, in zichzelf al veel invloed. Dit had een relationele en informatieverstrekkende functie (zie hoofdstuk 6 voor een uitgebreide beschrijving). Het is hierdoor verstandig dat de leider die direct verantwoordelijk is voor het werk van de teams hen een maatwerk ondersteuning aanbiedt afhankelijk van de teamkenmerken en hun vooruitgang. 
In scholen waarin een flexibele en evaluerende vernieuwingsstrategie is toegepast hebben teams met een vagere vernieuwingsambitie behoefte aan een meer proactieve en betrokken houding van de schoolleider.

\section{AANBEVELINGEN}

\section{Aanbevelingen voor DOTs en schoolleiders}

- Richt het vernieuwingsproces, de doelen en de ondersteuning in op basis van de kenmerken van de deelnemende DOTs. Grote en heterogene teams met een zwakke gedeelde vernieuwingsambitie dienen meer aandacht te krijgen.

- Houd een beginsituatieonderzoek om de kenmerken van de teams te verkennen. Observeer docenten in hun praktijk en houd interviews over de huidige praktijk en hun wensen. Dit onderzoek dient bij voorkeur plaats te vinden door een externe partij.

- Geef docenten ontwikkeltijd en maak teambijeenkomsten bij voorkeur een deel van het schoolrooster. Wanneer teams weinig activiteiten of voortgang vertonen dienen schoolleiders direct betrokken te worden om het team verder te helpen.

- Investeer veel tijd en energie in de beginfase van het ontwikkelingsproces omdat veel ontwerpbeslissingen in een vroeg stadium worden genomen en niet meer veranderend worden.

- Investeer in regelmatige formele en informele interactie tussen de leiders met directe verantwoordelijkheden voor de DOTs en de teams. Dit verbeteert de informatiestroom op school en dient ook een relationeel doel voor sommige teams.

- Houd rekening met de focus van teams op de organisatorische voorwaarden van hun toekomstige lespraktijk. Verschaf duidelijkheid wanneer het kan en erken de spanning tussen het team- en schoolniveau. Verbind discussie over organisatorische onderwerpen met centrale curriculaire onderwerpen als visie, doelen en inhoud.

- Verken samen verschillende opties voor de toekomstige lespraktijk gebaseerd op concrete voorbeelden en experimenteer met werkvormen. Doe dit aan de hand van de hoofdvragen/doelen van het team.

- Bevorder samenwerking op het niveau van concrete lesmaterialen door samenwerking in de constructie of door uitgebreide feedback op individueel werk. 
- Ondersteun teams in het ondernemen van analyse- en evaluatieactiviteiten. Deze activiteiten hebben een belangrijke en nog ongerealiseerde potentie.

- Creëer verbindingsstructuren tussen DOTs als een deel van de vernieuwingstrategie. Dit verhoogt de samenhang tussen teams en ondersteunt hun werk. Deze verbindingsstructuren dienen tenminste twee elementen te hebben:

- Een vast coördinatieteam met vertegenwoordigers van alle DOTs.

- Georganiseerde schoolbrede bijeenkomsten.

\section{Aanbevelingen voor beleid en ondersteuning}

- Stel een variatie aan realistische voorbeelden van schoolpraktijken (bijvoorbeeld met videobeelden) beschikbaar zodat docenten mogelijke beelden van toekomstige lespraktijk kunnen ontwikkelen. Door meerdere variaties van voorbeelden, gerelateerd aan vakinhoud en pedagogische aanpak, beschikbaar te maken kunnen teams de consequenties van verschillende keuzes doorzien.

- Maak exemplarische leerlijnen beschikbaar voor teams. Door meerdere variaties van leerlijnen aan te bieden kunnen teams een keuze maken die geschikt is voor hun situatie of kunnen ze geïnspireerd worden om een eigen leerlijn te ontwikkelen. Variatie vermindert de mogelijke suggestie van een verplicht topdown proces.

- Stimuleer de ontwikkeling van curriculair denken van docenten en schoolleiders door externe curriculaire ondersteuning en schoolnetwerken beschikbaar te stellen. Stimuleren van curriculaire competenties begint bij voorkeur al in de lerarenopleiding.

\section{Aanbevelingen voor onderzoek}

- Verricht een interventiegericht onderzoek. Begin het ontwerp van de interventie aan de hand van de kenmerken van bevorderende en belemmerende activiteiten en voorwaarden en stem het vervolgens af op de kenmerken van de deelnemende teams.

- Verken de relatie tussen gezamenlijke curriculumontwikkeling en het leren van docenten nader. Door te begrijpen welke activiteiten van een DOT welke leeruitkomsten teweeg kunnen brengen, kan er meer inzicht verkregen worden in de potentiële leerfunctie van gezamenlijke curriculumontwikkeling. 
- Ontwikkel aanvullende indicatoren voor effecten (bevorderend of belemmerend) van gezamenlijke curriculumontwikkeling.

- Verken de relatie tussen de schoolcontext en de curriculumontwikkeling activiteiten. Hoe DOTs op verschillende schoolniveaus werken kan verschillen (beïnvloed door de vooropleiding van de docenten, kerndoelen, organisatiestructuur etc.). Het verkennen van het werk van DOTs op andere niveaus dan het huidige onderzoek kan bijdragen aan de inzichten over hoe deze elementen een rol spelen in gezamenlijke curriculumontwikkeling. 


\section{APPENDIX 1 \\ Process Scoring Sheet}


Process Scoring Sheet

\begin{tabular}{|c|c|c|c|c|c|c|c|c|c|c|c|c|c|c|c|}
\hline Date & Main content & & $\begin{array}{l}\text { gn actii } \\
\text { esent } \\
\text { scusse } \\
\text { nain }\end{array}$ & & & & $\begin{array}{l}\text { sent } \\
\text { cuss } \\
\text { in }\end{array}$ & $1 \mathrm{con}$ & ponents & & & & \begin{tabular}{|l} 
Appreciation of \\
activity
\end{tabular} & \begin{tabular}{|l|} 
Main considerations \\
-content of design \\
\end{tabular} & $\begin{array}{l}\text { Main considerations } \\
\text {-criteria voor } \\
\text { success } \\
\end{array}$ \\
\hline & & A & \begin{tabular}{|l|l|} 
D \\
\end{tabular} & \begin{tabular}{l|l}
$\mathrm{C}$ & $\mathrm{I}$ \\
\end{tabular} & E & $\mathrm{R}$ & & & \begin{tabular}{l|l|}
$\mathrm{T}$ & $\mathrm{M}$ \\
\end{tabular} & \begin{tabular}{|l|l|} 
L & G \\
\end{tabular} & $\mathrm{T}$ & \begin{tabular}{l|l} 
P & A \\
\end{tabular} & & & \\
\hline & & & & & & & & & & & & & & & \\
\hline & & & & & & & & & & & & & & & \\
\hline & & & & & & & & & & & & & & & \\
\hline & & & & & & & & & & & & & & & \\
\hline & & & & & & & & & & & & & & & \\
\hline & & & & & & & & & & & & & & & \\
\hline & & & & & & & & & & & & & & & \\
\hline & & & & & & & & & & & & & & & \\
\hline \begin{tabular}{|l|}
$\begin{array}{l}\text { Conclusions } \\
\text { considering } \\
\text { aspect }\end{array}$ \\
\end{tabular} & & & & & & & & & & & & & & & \\
\hline
\end{tabular}




\section{Process Scoring Sheet (Continued)}

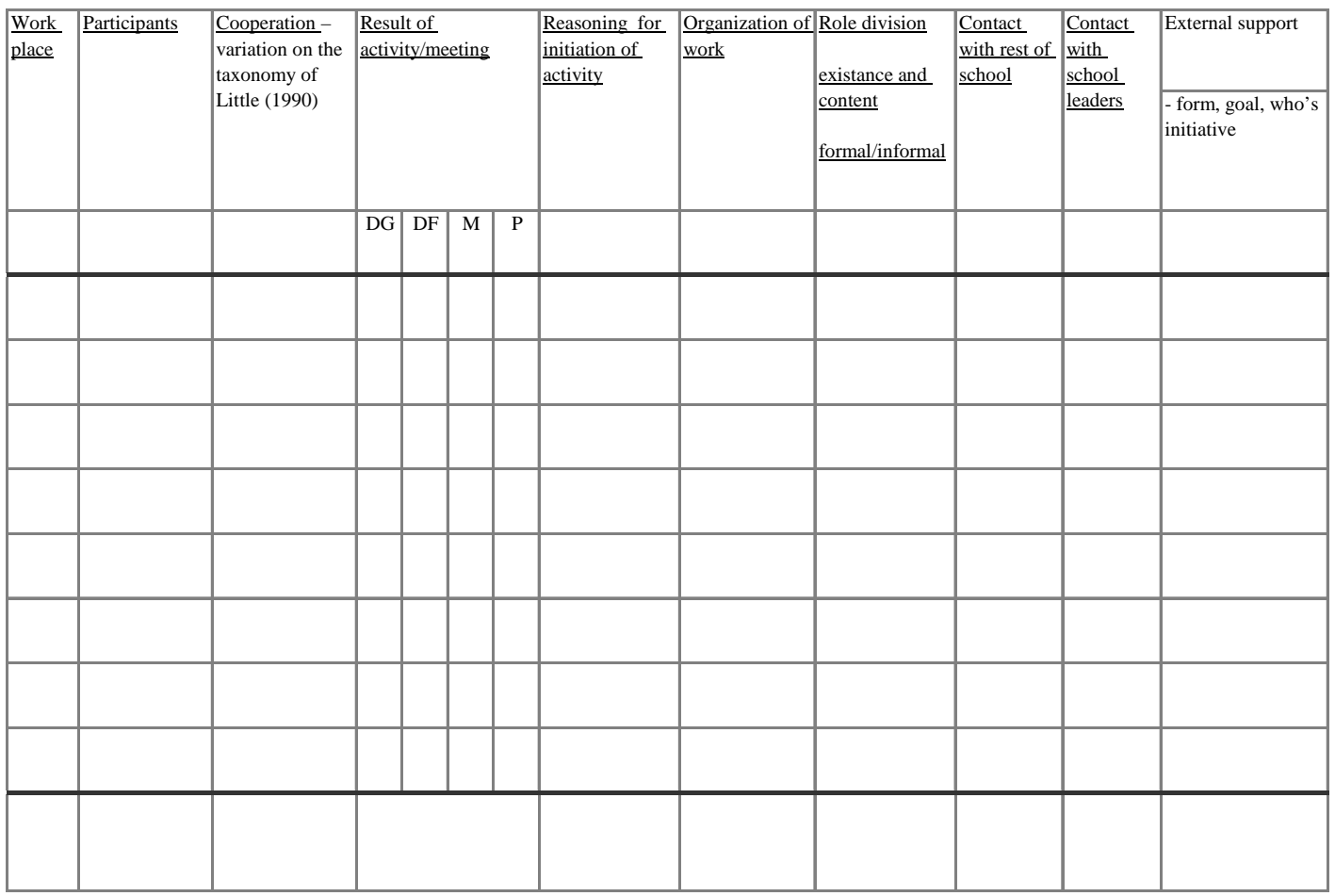




\section{ICO DISSERTATION SERIES}

In the ICO Dissertation Series dissertations are published of graduate students from faculties and institutes on educational research within the following universities: Eindhoven University of Technology, Leiden University, Maastricht University, Open University of the Netherlands, University of Amsterdam, University of Groningen, University of Twente, Utrecht University, VU University Amsterdam, and Wageningen University (and formerly Radboud University Nijmegen and Tilburg University).

166. Van der Sande, R.A.W. (04-06-2007). Competentiegerichtheid en scheikunde leren: Over metacognitieve opvattingen, leerresultaten en leeractiviteiten. Eindhoven: Eindhoven University of Technology.

167. Pijls, M. (13-06-2007). Collaborative mathematical investigations with the computer: Learning materials and teacher help. Amsterdam: University of Amsterdam.

168. Könings, K. (15-06-2007). Student perspectives on education: Implications for instructional design. Heerlen: Open University of the Netherlands.

169. Prangsma, M.E. (20-06-2007). Multimodal representations in collaborative history learning. Utrecht: Utrecht University.

170. Niemantsverdriet, S. (26-06-2007). Learning from international internships: A reconstruction in the medical domain. Maastricht: Maastricht University.

171. Van der Pol, J. (03-07-2007). Facilitating online learning conversations: Exploring tool affordances in higher education. Utrecht: Utrecht University.

172. Korobko, O.B. (07-09-2007). Comparison of examination grades using item response theory: A case study. Enschede: University of Twente.

173. Madih-Zadeh, H. (14-09-2007). Knowledge construction and participation in an asynchronous computer-supported collaborative learning environment in higher education. Wageningen: Wageningen University.

174. Budé, L.M. (05-10-2007). On the improvement of students' conceptual understanding in statistics education. Maastricht: Maastricht University.

175. Meirink, J.A. (15-11-2007). Individual teacher learning in a context of collaboration in teams. Leiden: Leiden University.

176. Niessen, T.J.H. (30-11-2007). Emerging epistemologies: Making sense of teaching practices. Maastricht: Maastricht University. 
177. Wouters, P. (07-12-2007). How to optimize cognitive load for learning from animated models. Heerlen: Open University of the Netherlands.

178. Hoekstra, A. (19-12-2007). Experienced teachers' informal learning in the workplace. Utrecht: Utrecht University.

179. Munneke-de Vries, E.L. (11-01-2008). Arguing to learn: Supporting interactive argumentation through computer-supported collaborative learning. Utrecht: Utrecht University.

180. Nijveldt, M.J. (16-01-2008). Validity in teacher assessment. An exploration of the judgement processes of assessors. Leiden: Leiden University.

181. Jonker, H.G. (14-02-2008). Concrete elaboration during knowledge acquisition. Amsterdam: VU University Amsterdam.

182. Schuitema, J.A. (14-02-2008). Talking about values. A dialogue approach to citizenship education as an integral part of history classes. Amsterdam: University of Amsterdam.

183. Janssen, J.J.H.M. (14-03-2008). Using visualizations to support collaboration and coordination during computer-supported collaborative learning. Utrecht: Utrecht University.

184. Honingh, M.E. (17-04-2008). Beroepsonderwijs tussen publiek en privaat: Een studie naar opvattingen en gedrag van docenten en middenmanagers in bekostigde en nietbekostigde onderwijsinstellingen in het middelbaar beroepsonderwijs. Amsterdam: University of Amsterdam.

185. Baartman, L.K.J. (24-04-2008). Assessing the assessment: Development and use of quality criteria for competence assessment programmes. Utrecht: Utrecht University.

186. Corbalan Perez, G. (25-04-2008). Shared control over task selection: Helping students to select their own learning tasks. Heerlen: Open University of the Netherlands.

187. Hendrikse, H.P. (22-05-2008). Wiskundig actief: Het ondersteunen van onderzoekend leren in het wiskunde onderwijs. Enschede: University of Twente.

188. Moonen, M.L.I. (26-09-2008). Testing the multi-feature hypothesis: Tasks, mental actions and second language acquisition. Utrecht: Utrecht University.

189. Hooreman, R.W. (18-11-2008). Synchronous coaching of the trainee teacher: An experimental approach. Eindhoven: Eindhoven University of Technology.

190. Bakker, M.E.J. (02-12-2008). Design and evaluation of video portfolios: Reliability, generalizability, and validity of an authentic performance assessment for teachers. Leiden: Leiden University.

191. Kicken, W. (12-12-2008). Portfolio use in vocational education: Helping students to direct their learning. Heerlen: Open University of the Netherlands.

192. Kollöffel, B.J. (18-12-2008). Getting the picture: The role of external representations in simulation-based inquiry learning. Enschede: University of Twente.

193. Walraven, A. (19-12-2008). Becoming a critical websearcher: Effects of instruction to foster transfer. Heerlen: Open University of the Netherlands. 